\title{
A cognitive model of economics
}

\author{
Lorin Friesen, mentalsymmetry.com, Abbotsford, BC, Canada
}

doi: 10.13140/RG.2.2.17044.83847

\section{Abstract}

Economics is typically regarded as a collection of partially related theories. However, if economics is analyzed from a cognitive perspective, then it becomes evident that these theories form a cognitively natural, coherent package. The theory of mental symmetry is a cognitive model based in seven interacting cognitive modules. This theory is used to analyze most of the fundamental concepts of micro- and macroeconomics, as well as behavioral economics and neuroeconomics. Economics can be explained primarily as a focus upon the interaction between the cognitive module that provides motivation and the cognitive module that emphasizes choice. Economics recognizes the existence of other cognitive modules but regards them as outside of the realm of economics. A fuller cognitive picture can be gained by including the activity of these other cognitive modules. Going further, a cognitive basis for the institutions of macroeconomics can be found by viewing these institutions from the perspective of abstract technical thought. And this cognitive basis provides a framework for applying economics to the modern world of information and technology.

\section{Introduction}

The theory of mental symmetry began as a system of cognitive styles (Friesen, 1986). Mental symmetry maps in detail onto current neurology (Friesen, 2019). It has been used to explain a number of aspects of language and culture (Friesen, 2013). It has been used to analyze theology from a cognitive perspective (Friesen, 2015) and to develop an integrated philosophy of science and theology (Friesen, 2020). And it has been applied to a number of additional topics at a less rigorous level, which can be accessed on the mentalsymmetry website.

This paper will use the theory of mental symmetry to analyze most of the basic principles of economics. Mental symmetry is a cognitive meta-theory that interprets human thought as seven interacting high-level cognitive modules. Basic economics will be defined as the content that is taught in the typical first-year university microeconomics and macroeconomics courses. This paper shows that basic economics can be interpreted primarily as one of the seven cognitive modules (Exhorter thought) interacting with one other module (Contributor thought).

Mental symmetry is a meta-theory and not a theory. A new theory typically replaces an old theory, rendering the old theory obsolete. A meta-theory acts as a general framework within which other theories can be placed. Theories that are placed within a meta-theory continue to be relevant as specialized viewpoints that provide a more detailed view of some aspect of the meta-theory.

The goal of this paper is not to introduce new economic concepts, but rather to take the existing concepts of economics, explain them from a cognitive perspective, and then discuss the larger cognitive picture that emerges. Taking an entire field and placing it within a new theory is highly unusual. 
Obviously, it is not possible to discuss an entire field within a single academic paper. But it is possible to examine the basic principles of some field within a long academic paper.

The discussion of economics in this paper will be largely limited to principles that are taught in the two introductory courses of microeconomics and macroeconomics, ensuring that the economic concepts that are being analyzed are well-known and widely accepted. Two primary references were used when researching this paper: the Khan Academy courses on AP microeconomics and AP macroeconomics, and the openstax second edition textbooks on microeconomics and macroeconomics. These textbooks were chosen because they are representative and freely available, and not because they contain any unusual information.

This paper will be quoting extensively from the two openstax textbooks. When facts from some specialization are placed within a new paradigm, then it is easy to twist these facts so that they fit better within the new paradigm. When facts have to be modified to fit a new paradigm, then this is a sign of an inadequate paradigm. Quoting extensively from an economics textbook makes it clear that existing economic facts are being used without being twisted or modified. These economic quotes also make it easier to distinguish between the facts of economics and the theory of mental symmetry, as well as assist in translating concepts between these two fields. Whenever a standard term of economics is mentioned, these this term will be put in bold. In most cases, these terms are also placed in bold in the original textbooks.

That leads to the more technical matter of referencing. Normal practice when quoting directly from some author is to mention the first author, the publishing year, and the page number from which the quote is taken. In this case, that would be either (Greenlaw, 2018, p.xx) or (Greenlaw, 2017, p.xx). But repeating this throughout the paper might give the mistaken impression that the author is the discoverer of a vast amount of original material, which is not the case. It might also give the mistaken impression that I am focusing inappropriately upon this author, or even possibly plagiarizing from this author. But that is also not the case. Instead, I am quoting from a textbook, and the only way to make it clear that one is quoting from an entire textbook is to quote many passages from many sections of the textbook. Therefore, instead of using (Greenlaw, 2018, p.xx) or (Greenlaw, 2017, p.xx), I will be using (micro, p.xx) or (macro, p.xx). This flows better as well as making it clear which concepts are being taken from a micro-economics textbook or a macro-economics textbook. Of course, authors of a textbook still need to be acknowledged as academic experts who are presenting the established concepts of a field in a coherent and comprehensible manner. Therefore, conventional references have also been included in the reference section.

Looking at this more generally, I have found over the years that the approach taken by mental symmetry does not fit into the normal methodology of academia. I have also found that attempting to understand this mismatch has proved useful for deciphering the nature of academic thought. The book that best describes my experiences is Thomas Kuhn's well-known volume on paradigms and paradigm shifts (Kuhn, 1970), and this paper will be referring several times to that book.

This paper will discuss an aspect of mental symmetry which has been largely ignored in other papers about mental symmetry. Mental symmetry began with a detailed look at personality traits. Abstract 
technical thought and its relationship to paradigms have been discussed in other papers and books. This paper will emphasize concrete technical thought as well as the interaction between Exhorter thought and Contributor thought. Placing the limited perspective of economics within a general theory of cognition will clarify how the field of economics interacts with other fields of thought as well as point out some inherent strengths and weaknesses of economic theory.

The thesis of this paper is that economics can be explained primarily as the interaction between Exhorter and Contributor thought as viewed from Contributor thought. Economics does recognize other modes of thought, but it regards them as outside of the realm of economics, and it attempts to interpret these outside effects in terms of the interaction between Exhorter and Contributor thought.

The next section introduces the theory of mental symmetry and has been copied from the paper on science and theology (Friesen, 2020). It explains terms such as 'Exhorter', 'Contributor', and 'concrete technical thought'.

\section{Mental Symmetry}

The theory of mental symmetry originated as a system of cognitive styles that divides people into seven different categories. This system of cognitive styles was first developed in the 1970s and is still being taught, primarily in religious circles. Lane Friesen (brother of Lorin Friesen) initially expanded this system of cognitive styles by analyzing approximately 200 biographies in the 1980s (Friesen, 1986). This system of cognitive styles turned into a cognitive model when it was realized that the fundamental traits of each cognitive style correspond to the general functioning of a specific brain region. Since everyone has a complete brain, this led to the conclusion that cognitive style relates in some way to consciousness: Everyone has all seven cognitive modules; cognitive style is determined by the cognitive module in which a person is conscious, consciousness being defined as awareness and control. Thus, one can speak either of cognitive styles or of cognitive modules. The explaining power of mental symmetry emerges when one thinks in terms of cognitive modules.

The theory of mental symmetry is summarized by a simple diagram known as the diagram of mental symmetry (Figure 1). The seven cognitive modules are each given a label that describes a major cognitive trait: Teacher, Exhorter, Mercy, Server, Contributor, Perceiver, and Facilitator. Studying personality has revealed details that are not explicitly shown by the diagram of mental symmetry, but this diagram still remains the best way to summarize the traits in a simple manner, and the diagram has been arranged in a manner that maps in a general way onto neurology. Thus, the seven labels (Teacher, Exhorter, Mercy, etc.) in the diagram of mental symmetry should be viewed as large-scale cognitive modules each composed of several interacting parts. The term 'Mercy thought' will be used to refer to a cognitive module, while the term 'Mercy person' refers to a cognitive style.

The diagram uses two primary axes: analytical versus associative, and emotion versus confidence. Analytical versus associative corresponds to left hemisphere versus right hemisphere. This is a crude distinction, but it remains a useful one. Many cognitive tasks involve extensive interaction between the corresponding regions in the left and right hemispheres, but the underlying principle remains that the two hemispheres are using different strategies to perform similar tasks. And it appears that these different strategies can be summarized by the terms analytical and associative. Analytical processing 
focuses upon sequences, time, order, and structure, while associative processing emphasizes objects, space, connections, and specifics. On the one hand, these two mental strategies are quite different. But on the other hand, most tasks can be handled using either—or both—of these two strategies.

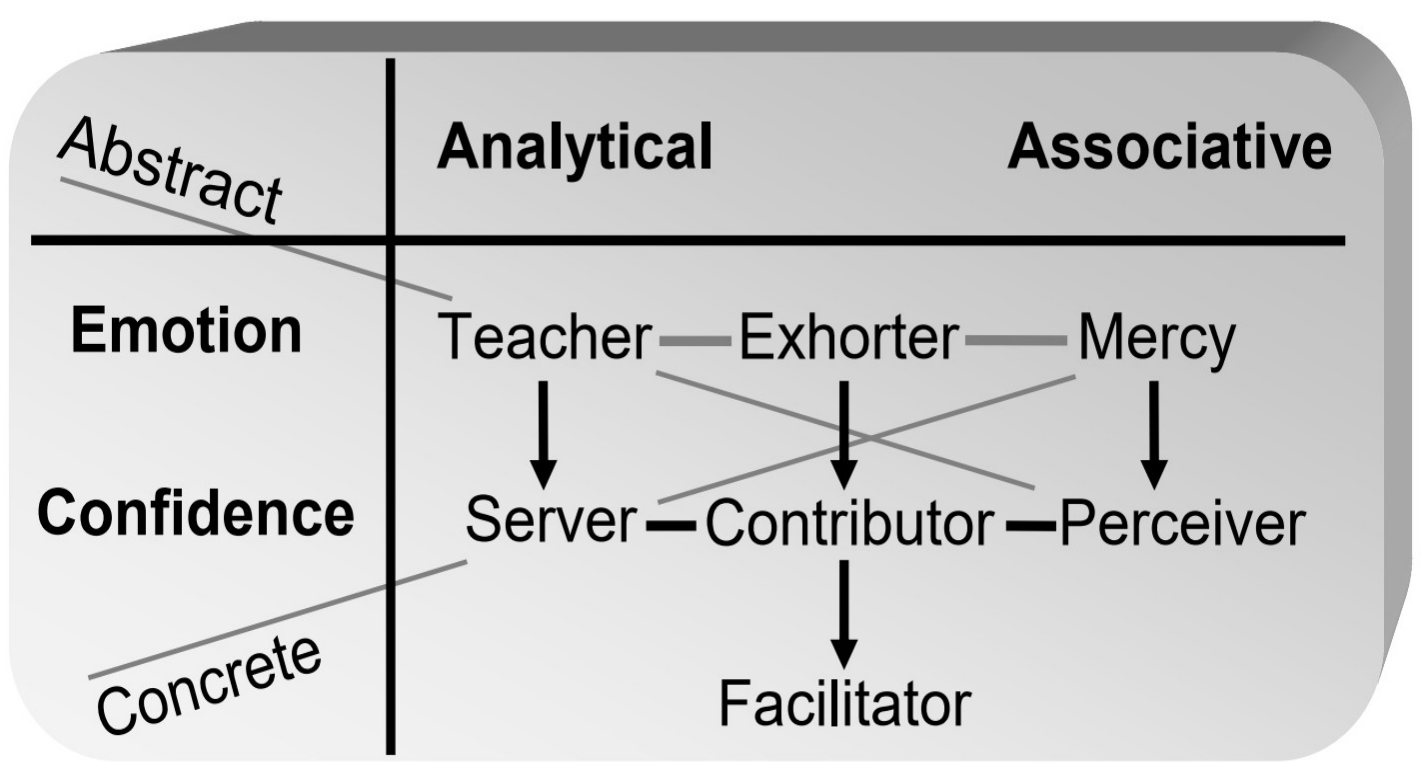

Figure 1: Diagram of Mental Symmetry

The axis of emotion versus confidence is intuitively obvious. Confidence focuses upon information, while emotion applies a label of feeling to information. When the seven cognitive styles were initially studied, it was observed that some of the cognitive styles tend to emphasize emotions, whereas other cognitive styles tend to avoid emotions.

The diagram of mental symmetry uses the two axes of analytical versus associative and emotion versus confidence to place the four 'simple styles' of Teacher, Mercy, Server, and Perceiver. In addition, the two diagonals are labeled abstract and concrete. This means that Teacher is analytical emotional abstract, Mercy is associative emotional concrete, Server is analytical confidence concrete, and Perceiver is associative confidence abstract.

Looking at this in more detail, Mercy thought applies emotional labels to concrete experiences and associates between these experiences. This makes the Mercy person naturally aware of social interaction, because each new situation will bring similar situations to mind along with their emotional labels, leading to a natural sense of emotional appropriateness. The same processing can also be used to gain a feeling for how objects and tools function.

Perceiver thought is also associative but applies labels of confidence to abstract facts. This makes the Perceiver person naturally aware of reasonableness, because each new fact will bring similar facts to mind along with their labels of confidence, leading to a natural sense of which facts are reasonable and which are not. Perceiver thought also builds connections between facts, leading to an emphasis upon objects and how they relate. 
Server thought also uses confidence but applies labels of confidence to concrete sequences. This leads to a natural focus upon physical actions, because physical action uses the body to generate concrete sequences of movement. The Server person finds it easy to learn actions and to act in a fluid manner.

Teacher thought uses emotion but Teacher emotion is quite different than Mercy emotion. Mercy thought adds emotional labels to concrete experiences. Teacher thought, in contrast, feels good when there is order-within-complexity, when many items can be summarized by a simple abstract sequence. Teacher thought feels bad when there is an exception to the general rule. Teacher emotion commonly expresses itself as an appreciation of verbal theories, because a verbal theory is a simple abstract sequence that brings order and structure to many specific items. One example of Teacher emotion is when the proverbial light bulb lights up on top of the head of a student and the student proclaims, ' $I$ understand'.

The term 'Mercy experience' will be used as shorthand for 'an experience with an emotional label that is stored within Mercy thought'. Similarly, 'Teacher theory' will refer to 'a theory that is generated by Teacher thought and stored within Teacher thought', and so on.

Confidence interacts with emotion. For instance, Perceiver thought may have sufficient confidence to know a certain set of facts when studying, while having insufficient confidence when attempting to retrieve these same facts under the emotional stress of an exam. Similarly, Server thought may have sufficient confidence to perform the sequence of actions involved in playing a musical song when practicing at home, while having insufficient confidence to perform the same piece when faced with the emotional stress of performing in a concert.

Cognitive modules do not function in isolation, but rather cooperate to generate thought and behavior. For instance, Teacher and Perceiver thought cooperate to generate abstract thought. Perceiver thought comes up with facts and Teacher thought assembles these facts into general theories. Using an analogy, this is like gathering a collection of bricks and then assembling these bricks into a building. The bricks are evaluated using Perceiver confidence, while the structure of the building leads to Teacher emotion. Similarly, Mercy and Server thought cooperate to generate concrete thought. Mercy thought focuses upon experiences and how they feel, while Server thought carries out the actions that are required to reach desirable experiences and avoid unpleasant experiences. The steps that are required to reach a goal are evaluated using Server confidence, but the goal itself involves Mercy emotions.

The 'composite styles' of Exhorter, Contributor, and Facilitator integrate corresponding regions in the two hemispheres. Exhorter combines Teacher and Mercy, and Contributor combines Server and Perceiver. Facilitator thought 'facilitates' the functioning of the entire mind, emphasizing the relationship between Perceiver and Mercy thought, as well as the relationship between Server and Teacher thought. The three composite styles also provide a chain of processing: Exhorter thought provides motivation and imagination as the first link in this chain, Contributor thought, the second link in the chain, then chooses between various options that have been suggested by Exhorter thought, while the third link of Facilitator thought maintains equilibrium by mixing and adjusting within the context of Contributor decision. 
Turning now to the relationship between simple thought and composite thought, Perceiver thought looks for connections between facts and Server thought focuses upon relating sequences, whereas Contributor thought focuses upon connecting specific Perceiver facts with specific Server sequences. This combination leads in concrete thought to a sense of cause-and-effect as Perceiver facts are connected with Server actions, and in abstract thought to precise meaning as Perceiver facts are connected with Server sequences of words.

In a similar manner, Exhorter connects Mercy with Teacher. Mercy thought applies emotional labels to experiential memories, leading among other things to a strong social awareness. Teacher thought, in contrast, comes up with general theories, which are usually communicated using words. Exhorter thought learns lessons from life, deriving general theories from personal experiences. Going the other way, Exhorter thought also applies theories to the emotional experiences of life. This relationship between experience and theory can be seen in intuition.

The integrated mind can function in one of three primary ways, which are referred to as technical thought, normal thought, and mental networks. In technical thought, the entire mind is functioning in an integrated manner under the control of Contributor thought. Concrete technical thought expresses itself through the actions of Server thought: Exhorter thought will focus upon some emotional 'bottom line' in Mercy thought and Contributor thought will then use a knowledge of cause-and-effect to reach this goal in a manner that is efficient and/or profitable. Concrete technical thought takes the normal actions of concrete behavior and optimizes them, as illustrated by the difference between normal running and competitive running.

Abstract technical thought expresses itself primarily through the words of Teacher thought: Exhorter thought will focus upon some general theory in Teacher thought and Contributor thought will then use a knowledge of precise meanings to increase the order-within-complexity of some abstract system. This type of thinking occurs when using math and logic.

Abstract and concrete technical thought can themselves be combined, and a physical illustration of this combination can be seen in machines. For instance, a truck driver operates a vehicle using concrete technical thought, attempting to reach various physical locations in an optimal manner. A mechanic will view the same vehicle using abstract technical thought, manipulating precisely-defined parts in order to maximize the order-within-complexity of the machine. Technical thought will be discussed extensively in this paper.

Normal thought is less rigorous than technical thought and emerges when the entire mind functions under the control of Perceiver and/or Server thought. Normal thought describes how the mind normally behaves in the normal experiences of life. Normal thought is guided by patterns and analogies. Perceiver and/or Server thought will compare new facts and situations with previous facts and situations and respond to the current situation based upon similarity. The cognitive model of mental symmetry uses normal thought and not technical thought. That is because mental symmetry looks for cognitive mechanisms by comparing various forms of thought and behavior in order to find similar patterns. Finding a similar pattern of human behavior in many diverse areas leads to confidence that a cognitive mechanism is being described. 
Perceiver, Server, and Contributor are all shown in the diagram as related to confidence. Perceiver and Server thought view confidence as an analog quantity-confidence grows as more evidence is gathered, while confidence shrinks as counterexamples are encountered. Contributor thought, in contrast, treats confidence as a digital value. If the confidence level of a piece of information exceeds some threshold value, then this information is treated digitally as 'true'; if it fails to pass this threshold, then it is treated digitally as 'false'. Contributor confidence can be seen in statistical analysis and peer review. If data exceeds some statistical threshold, then it becomes publishable, and if a paper passes peer-review, then the information in this paper is treated as reliable. These are both digital definitions, and digital certainty is a fundamental characteristic of technical thought. Normal thought, in contrast, works with analog certainty.

Mental networks are guided by Teacher and/or Mercy thought. A mental network is a collection of emotional memories that have formed into a network and function in an integrated manner. A strongly emotional situation will cause the memories of that situation to immediately form a mental network, while continuing to access any collection of emotional memories will eventually cause them to form into a mental network. A mental network will generate positive emotions when encountering input that is consistent with its structure, while generating negative emotions when encountering input that is inconsistent with its structure.

For instance, mental networks are the driving force behind social groups, because people naturally want to be around others who think and behave the way that they do while being emotionally repelled from those who are different. If a mental network continues to experience incompatible input, then it will generate a strong negative emotion and start to fall apart. This emotional response can be seen in culture shock. If a threatened mental network continues to receive incompatible input, then it will eventually fall apart and revert to being an isolated collection of emotional memories. This transition is illustrated by the breaking of a habit.

It was mentioned that emotion can be split into the two varieties of Mercy emotion and Teacher emotion. This means that there are two kinds of mental networks, which will be referred to as Mercy mental networks (MMN) and Teacher mental networks (TMN). The mind uses MMNs to represent people. That is because one usually encounters people as collections of associated emotional experiences. MMNs will be used to predict how people respond (which is related to 'theory of mind'). For instance, suppose that I meet my Aunt Helen. Mercy thought within my mind will be associatively reminded of the MMN that is composed of emotional experiences involving Aunt Helen, and the structure of this MMN will emotionally predict how Aunt Helen will behave. It will feel emotionally disconcerting if the real Aunt Helen behaves in a manner that is inconsistent with the MMN in my mind that represents Aunt Helen, possibly motivating me to say something like 'Are you feeling okay? You are not acting yourself today.' A TMN will form whenever some theory (verbal or nonverbal) continues to be used. A TMN will express itself as an emotional drive to use this theory to explain situations whenever that TMN is triggered. Thus, a general theory will generate positive Teacher emotions, while a theory that has turned into a TMN will also generate an emotion that motivates a person to continue using this theory. 
The emotion of a mental network is different than the emotions of the memories within that mental network. For instance, an MMN may be composed of unpleasant memories. This juxtaposition can be seen in the behavior of the abused spouse: Remaining within the situation is painful because the specific experiences have negative emotional labels. However, leaving the situation is disconcerting because MMNs will then experience inconsistent input. Saying this more simply, the abuse may be painful but it is also familiar. Similarly, if an inadequate theory continues to be used, then this theory will form a TMN which will emotionally drive Teacher thought to continue using this theory, even though it lacks order-within-complexity.

Summarizing the previous paragraphs, the mind can function in one of three primary ways, known as technical thought, normal thought, and mental networks.

That leads to the question of cognitive style itself. What exactly is cognitive style? This question first arose back in the 1980s when I was helping my brother (Lane Friesen) analyze the data that he had collected from biographies (Friesen, 1986). As was mentioned earlier, we realized that the personality traits of the seven cognitive styles could be summarized by fundamental modes of processing and that these fundamental characteristics map on to brain regions. But everyone has a complete brain. How can a person have a complete brain while also having a cognitive style that emphasizes part of the brain? Going further, I am not aware of any physical brain differences that would correspond to cognitive style. We concluded that cognitive style must reflect conscious awareness. On the one hand, every cognitive style has a similar brain which contains all seven cognitive modules. But on the other hand, several decades of observation have led to the conclusion that different cognitive styles really do view the world in different ways; each cognitive style finds certain forms of thinking blindingly obvious, while other cognitive styles appear to be mentally oblivious to these same forms of thought.

\section{Economic Utility}

The first economic concept that will be discussed is utility. As is customary in this paper, terms that are in bold will usually be defined by quoting from the openstax textbook. "People desire goods and services for the satisfaction or utility those goods and services provide. Utility... is subjective but that does not make it less real" (micro, p. 32). ${ }^{1}$ This definition refers to 'desire' and to 'satisfaction or utility'. 'Desire' is a form of 'wanting', whereas 'satisfaction or utility' refer more to 'liking'. These are not the same. This is a neurological distinction that was first clarified by Berridge (Berridge, 1996). 'Liking' involves emotional regions of the brain, whereas 'wanting' is related to dopamine. Using the language of mental symmetry, 'liking' describes Mercy emotions, whereas wanting is related to Exhorter motivation.

Economics recognizes that 'utility is subjective', which means that it is based in the Mercy emotions and MMNs of culture and personal identity, but economics moves away from subjective emotions by using the non-emotional term of utility. Going further, economics focuses upon the desire that is generated by emotional satisfaction or utility-moving beyond liking to wanting. In the same way that Exhorter thought treats emotional memories and mental networks as a source for generating

1 As explained earlier, (micro, p. 32) is shorthand for (Greenlaw, 2018, p. 32). 
motivation, so economics focuses upon the motivation that is provided by emotional objects and situations while ignoring the precise nature of these objects and situations.

Exhorter motivation differs from Mercy and Teacher emotions in two primary ways: First, Mercy and Teacher thought try to avoid painful memories while focusing upon pleasant memories. Exhorter thought, in contrast, finds both pain and pleasure equally exciting. Second, Mercy and Teacher emotion remain constant over time, while Exhorter motivation requires novelty and becomes bored whenever something continues to be repeated.

Exhorter boredom can be seen in the economic principle known as the law of diminishing utility, which states that "as a person receives more of a good, the additional (or marginal) utility from each additional unit of the good declines” (micro, p. 32). Including boredom as a fundamental factor suggests that economics is focusing upon Exhorter motivation rather than upon the underlying emotions and mental networks within Mercy and Teacher thought.

Looking at this more generally, economic theory treats MMNs of personal identity and culture as outside of the realm of economics. This is evident when calculating GDP or Gross Domestic Product. "Production of some goods_-such as home production as when you make your breakfast—is not counted because these goods are not sold in the marketplace” (macro, p. 142). ${ }^{2}$ In other words, behavior that is limited to the subjective realm of the home is not included when calculating GDP because it is not part of 'the market'. Similarly, "people who do not have a job, and for some reasonretirement, looking after children, taking a voluntary break before a new job-are not interested in having a job” are defined as out of the labor force and are not considered when calculating unemployment figures (macro, p. 191). Again, one sees that people such as children or retirees whose behavior is being guided primarily by subjective mental networks do not fall within the realm of economics.

Viewed from a different perspective, economics generally treats mental networks of culture and religion as an impediment to economic activity. "Whatever defenses may be offered for such laws in terms of social value-like the value some Christians place on not working on Sunday, or Orthodox Jews or highly observant Muslims on Saturday-these kinds of restrictions impose a barrier between some willing workers and other willing employers, and thus contribute to a higher natural rate of unemployment” (macro, p. 209). Summarizing, economics recognizes that religious beliefs may have social benefits within the subjective realm of mental networks, but states that this does not fall within the realm of economics.

Looking at this cognitively, mental networks of culture, family, and religion will emotionally drive people to behave in a manner that preserves the status quo. Economics is based upon the marketplace, and the fundamental assumption of the market is that individuals can achieve better results by letting go of the status quo. Using a simple example, mental networks may conclude that 'this farm has been in the family for generations' while economics may conclude that 'this farm can be sold for a considerable amount of money’.

2 And (macro, p. 142) is shorthand for (Greenlaw, 2017, p. 142). 
The fundamental assumption of economics is that using economic thought to pursue personal gain can improve the mental networks of society. This assumption can be seen in Adam Smith's reference to the invisible hand, and most textbooks on economics will quote from the following passage in the Wealth of Nations by Adam Smith: "Every individual...generally, indeed, neither intends to promote the public interest, nor knows how much he is promoting it... By pursuing his own interest he frequently promotes that of the society more effectually than when he really intends to promote it" (Smith, 1776, Par. IV.2.9). The microeconomics textbook explains that "The metaphor of the invisible hand suggests the remarkable possibility that broader social good can emerge from selfish individual actions” (micro, p. 40). Stated cognitively, using economic thought to question existing mental networks can actually lead to better mental networks in the end. And history indicates that there is considerable—-but not total— merit to this claim.

\section{Intuition}

The role that Exhorter thought plays in economics can also be seen in the emphasis upon intuition. Intuition plays a major role in economic theory. For instance, the Khan Academy video lectures on micro- and macroeconomics introduce almost every economic theory by saying that 'this is intuitively obvious'. On the surface level, this reflects the desire of a good teacher to communicate ideas effectively to the student. ${ }^{3} \mathrm{~A}$ student will comprehend a subject more easily if the teacher can demonstrate that the subject is intuitively obvious. However, the phrase 'it is intuitively obvious' is almost never encountered when studying physics. Instead, a teacher of physics will emphasize that physics is not intuitively obvious and will help the student to comprehend the subject by looking for partial analogies that make it possible to intuitively understand some aspects of the subject. Thus, intuitive obviousness appears to be a characteristic of the subject of economics.

Interpreting this in terms of the theory of mental symmetry, Exhorter connects Mercy and Teacher. Intuition jumps directly from Mercy emotions to Teacher emotions: Mercy thought focuses upon some emotional situation and Teacher thought then derives emotional pleasure by coming up with a general theory that explains the situation. Exhorter thought provides the motivation for intuition: Teacher thought is coming up with some simple concept that brings order to the complexity of a situation and Exhorter thought is finding excitement in this Teacher emotion. This trait of jumping directly from emotional situation to general theory was initially observed when studying the Exhorter person. And a connection has been found between dopamine and intuition (Frank, 2006).

Intuition comes up with a potentially general theory by jumping directly from specific situation to general statement. In contrast, a theory that is truly general is based upon many specific situations. Thus, intuition is useful for coming up with hypotheses, or potential general theories. Intuition often gives the impression of ignoring the facts, but intuition is being guided implicitly by Perceiver facts and Server sequences. Using an analogy, emotional memories within Mercy thought can be thought of as 'houses' and 'towns' within the 'landscape' of experiential memory. Perceiver thought comes up with facts that organize Mercy memories into different categories, leading to a mental map of Mercy

3 'Teacher' with a capital ' $\mathrm{T}$ ' refers to the cognitive style or cognitive module of Teacher, while 'teacher' in lower case refers to the profession of teaching. 
experiences. Server thought then develops sequences that lead from one location within this mental map to another, leading to a mental map with roads. Intuition then travels along this mental 'highway system' of Perceiver connections and Server roads. ${ }^{4}$ This implicit content can be seen in the Exhorter person, because intuition within the Exhorter person may stretch the facts and exaggerate the possibilities but avoids what is regarded as impossible.

Thus, intuition can be trained by developing the implicit 'highway system' of Perceiver facts and Server sequences upon which intuition travels. Trained intuition can be seen in the expert who uses intuitive thought that has been honed by knowledge and skills. The training of intuition can also be seen in the history of economics. Adam Smith's classic book on economics was published in 1776, the year in which America - the first modern constitutional liberal democracy-declared independence from Britain. The neoclassical economics of Alfred Marshall added mathematics to economics in the late $19^{\text {th }}$ century, a time when many disciplines were becoming more mathematical. The Great Depression of the 1930s led to the development of Keynesian economics, which taught that government expenditure can lead an economy out of depression. The stagflation of the 1970s led to the realization that external shocks can lead to a combination of high unemployment and high inflation. And the Great Recession of 2008 has caused many economists to recognize that economic theory does not include the financial system (Bertocco, 2019). In each of these cases, economic theory has followed reality rather than predicting reality. Economic theory was updated after the facts and sequences of reality changed. This is consistent with the idea that intuition is being guided implicitly by facts and sequences.

\section{Technical Thought}

The role that Exhorter thought plays in economics has been briefly discussed. However, economics focuses primarily upon the path from Exhorter to Contributor, viewed from the perspective of Contributor thought. The diagram of mental symmetry shows an arrow leading from Exhorter to Contributor as well as two lines connecting Contributor with Perceiver and Server. In practical terms, this means that Contributor thought places imagination within a grid of content. This combination was seen when discussing intuition, because the intuition of Exhorter thought is implicitly guided by a mental 'highway system' of Perceiver facts and Server sequences. Contributor thought makes this combination explicit by using some set of Perceiver facts and Server sequences to evaluate the stream of imagination and motivation that comes from Exhorter thought.

It was mentioned earlier that Exhorter motivation is different than either Teacher or Mercy emotion. Similarly, a distinction can be made between the way that Perceiver and Server thought treat information and how this same information is treated by Contributor thought.

First, both Perceiver and Server thought focus upon interconnections between information. Perceiver thought looks for connections between facts. Similarly, Server thought compares Server sequences with one another. Contributor thought, in contrast, will choose some specific set of Perceiver facts and Server sequences and then use this collection as a basis for Contributor thought. This can be seen, for instance, in a game. A game is played using a limited set of Perceiver objects within a restricted playing

4 This interpretation of intuition as a shortcut to careful reasoning can be seen in dual process theory (Evans, 2010). 
field. For instance, the game of chess uses a specific set of chess pieces which are moved around a chess board. Cognitively speaking, Contributor thought is limiting the realm of the game to some restricted collection of Perceiver facts, objects, and locations. A game also permits only a limited set of Server sequences. For instance, each chess piece is only permitted to move in a certain manner. Saying this more generally, Contributor thought will naturally specialize, which means restricting thought and/or activity to some specific subset of Perceiver facts and Server sequences.

Second, Perceiver thought can work with facts while ignoring sequences; similarly, Server thought can work with sequences while ignoring facts. Contributor thought, in contrast, will connect each Perceiver fact with a corresponding Server sequence, and Contributor thought requires a combination of facts and sequences to function. The physical body is capable of producing two different kinds of Server sequences: actions and sentences. In simple terms, a person can do or talk, and both doing and talking involve Server sequences. Doing performs a sequence of physical actions, while talking organizes speech into sequences of words, sentences, and paragraphs.

This means that Contributor thought can connect Perceiver facts with Server sequences in two different ways. Connecting a Perceiver fact to a Server action leads to a mental sense of cause-and-effect: Perceiver thought thinks of cause-and-effect as a fact that involves time. For instance, dropping an object is followed by the object hitting the floor. Server thought thinks of the same cause-and-effect as a sequence that occurs within some context. For instance, a released object is travelling to the ground. Notice that Perceiver thought is still thinking in terms of facts and Server thought is still thinking in terms of sequences, but Contributor connections are expanding facts to include sequences and sequences to include facts.

When Contributor thought connects Perceiver facts with Server actions, then this leads to concrete technical thought, a form of specialization that applies physical actions within some specific physical context, guided by a knowledge of cause-and-effect. For instance, a game is an example of concrete technical thought, as is a firm or a business. Cause-and-effect appears to be the basic building block for concrete technical thought.

Connecting a Perceiver fact to a verbal Server sequence leads to precise definitions. Server thought thinks of a precise definition as a verbal sequence that has a meaning. Perceiver thought thinks of the same precise definition as a carefully-defined fact that can be described verbally. When Contributor thought connects Perceiver facts with verbal Server sequences, then this leads to abstract technical thought, a form of specialization that applies verbal rules within some specific abstract context, guided by a knowledge of precise definitions. For instance, math and logic are examples of abstract technical thought. Precise definitions appear to be the basic building block for abstract technical thought. Precise definitions can go beyond words. For instance, consider the phrase ' 2.5 liters of water'. This is a precise verbal definition, but what is being defined precisely is some amount of water. ${ }^{5}$

Technical thought combines the two streams of information that have been discussed so far. The path from Exhorter to Contributor provides technical thought with a stream of imagination and motivation.

5 Evidence suggests that verbal definitions play a major but not total role in the mental ability to precisely define physical qualities (Regier, 2009). 
And the interaction between Perceiver, Contributor, and Server provides technical thought with a set of tools that can be used to manipulate the stream of imagination and motivation. Thus, technical thought is actually a combination of emotion and rigor; it is driven by emotion but responds in a rigorous manner. Concrete technical thought uses a knowledge of cause-and-effect to perform Server actions that will improve the emotions of some bottom line within Mercy thought. For instance, in the game of golf, the Server action of hitting a golf ball is being guided by a knowledge of the cause-and-effect of how a golf ball travels in order to achieve the Mercy experience of hitting the ball into a hole. The goal (in this case hitting a ball into a hole) is emotional but the actions used to achieve this goal are rational and rigorous.

Abstract technical thought uses precise definitions to manipulate Perceiver facts in a way that improves Teacher feelings of order-within-complexity. For instance, simplifying a mathematical expression turns a complicated sequence of precisely-defined mathematical terms into an equivalent form that is much simpler and shorter. Abstract technical thought also uses a combination of emotion and rigor. At the specific level, solving a technical problem brings pleasure to Teacher thought, while the steps that are used to solve the problem are both rational and rigorous. At a more general level, abstract technical thought uses rigorous logic, but this rigorous thinking occurs within the emotional context of some paradigm within Teacher thought. Thomas Kuhn pointed out the distinction between the technical puzzle-solving of abstract technical thought and the paradigm that lies behind this puzzle-solving (Kuhn, 1970). ${ }^{6}$

Summarizing, technical thought uses rigorous thinking within some limited specialization in order to improve some emotional goal. Technical thought is controlled by Contributor thought but involves the cooperation of several cognitive modules. Abstract technical thought uses precise definitions to improve general theories in Teacher thought. Concrete technical thought uses a knowledge of causeand-effect to improve the Mercy emotions of some bottom line. Both abstract and concrete technical thought focus upon Perceiver facts and Server sequences while being implicitly guided by some emotional bottom line. For instance, abstract technical thought is usually strictly rational, and the emotions that are present in a Teacher paradigm only become apparent when the paradigm is either threatened or challenged. Thus, technical thought can be described as locally rational; it is rational within some specialization as long as the goals or paradigm driving this specialization are not being threatened.

Economic thought is a form of technical thought that includes some components of concrete technical thought and abstract technical thought, but it focuses upon the interaction between Exhorter motivation and Contributor specialization.

Specialization is a core concept of economics, first explicated by Adam Smith in The Wealth of Nations. "Many authors had written on economics in the centuries before Smith, but he was the first to address the subject in a comprehensive way. In the first chapter, Smith introduces the concept of division of labor, which means that the way one produces a good or service is divided into a number of

6 Teacher thought can create many kinds of general theories. The term paradigm will be used to refer specifically to a Teacher theory that lies behind some specialization within abstract technical thought, consistent with Kuhn's discussion of scientific paradigms. 
tasks that different workers perform, instead of all the tasks being done by the same person" (micro, p. 12). We have just seen that specialization is a fundamental component of technical thought.

Specialization leads to a form of thinking that is more effective: "If people specialize in the production of what they do best, they will be more effective than if they produce a combination of things, some of which they are good at and some of which they are not" (micro, p. 13). Specialization leads to better results in Mercy thought: "Workers who specialize in certain tasks often learn to produce more quickly and with higher quality... A similar pattern often operates within businesses. In many cases, a business that focuses on one or a few products... is more successful than firms that try to make a wide range of products” (micro, p. 13). And specialization leads to greater Teacher order-within-complexity: "Specialization allows businesses to take advantage of economies of scale, which means that for many goods, as the level of production increases, the average cost of producing each individual unit declines" (micro, p. 13).

But even though economics recognizes the benefits of specialization, economics does not study or teach technical specialization. Instead, it examines the impact that the specializations taught and practiced by others have upon the interaction between Exhorter and Contributor thought.

The fundamental problem created by specialization is that a person has many desires in Mercy thought but will only meet some of these desires when pursuing some specialization. Economics solves this problem through trade. "Specialization only makes sense, though, if workers can use the pay they receive for doing their jobs to purchase the other goods and services that they need. In short, specialization requires trade” (micro, p. 14). Trade makes it possible to satisfy a wide range of Mercy desires while pursuing specialization. "Instead of trying to acquire all the knowledge and skills involved in producing all of the goods and services that you wish to consume, the market allows you to learn a specialized set of skills and then use the pay you receive to buy the goods and services you need or want. This is how our modern society has evolved into a strong economy” (micro, p. 14).

Trade can be viewed as a sort of meta-game that makes it possible to assign and transfer ownership. Using the language of economics, "There is no such thing as an absolutely free market. Economies that are primarily market-oriented have fewer regulations - ideally just enough to maintain an even playing field for participants. Regulations always define the 'rules of the game' in the economy... At a minimum, these laws govern matters like safeguarding private property against theft, protecting people from violence, enforcing legal contracts, preventing fraud, and collecting taxes” (micro, p. 20). Notice the characteristics of technical thought: A game is being played with rules. This game is being played upon the 'playing field' of ownership. Ownership can only be transferred by following the rules. Legal contracts use precise definitions to define the transfer of ownership. A market-oriented economy uses a limited set of rules to define and transfer ownership.

It was suggested earlier that Contributor thought deals with a combination of Perceiver facts and Server sequences. Ownership has both a Perceiver side and a Server side. On the one hand, ownership creates a Perceiver connection between some object and some person. On the other hand, ownership enables or disables Server actions, because gaining ownership of some object gives a person the right to perform Server actions with that object. These two facets of ownership are not the same. For instance, suppose 
that I purchase a house with a large tree on the property. From a Perceiver perspective, this property is mine, because I have the exclusive right to place my physical body within the location of this property. However, from a Server perspective, I may be forbidden from performing the Server action of cutting down the large tree. Abstract technical thought can be used to define the precise parameters of ownership. Transfer of ownership is itself a form of cause-and-effect, because the starting point of one person having ownership is followed by the ending point of another person having ownership.

Notice again that economics recognizes the existence of technical thought but performs a minimum of technical thought itself. Economics requires laws of ownership but does not itself write or enforce these laws. Economics is based upon the marketplace but does not ultimately care what is being bought or sold within the marketplace.

\section{Ownership, Money, and Piaget's Cognitive Stages}

Jean Piaget said that cognitive development goes through four stages (Huitt, 2003), and these stages can be interpreted using mental symmetry. During the first sensorimotor stage, MMNs are being formed by experiences of pain and pleasure from the physical body. This does not mean that Mercy thought is the only cognitive module that is developing, but rather that it is acting as the core cognitive module around which the rest of the mind integrates. Piaget suggested that one of the primary developments of the sensorimotor stage is a feeling of object permanence, which means that the mind is capable of knowing that an object or person continues to exist even when it cannot be seen.

Object permanence can be explained in terms of MMNs. It was mentioned earlier that related emotional experiences can combine to form mental networks that function as an integrated unit. The mind uses MMNs to predict how people, objects, and situations will behave. For instance, emotional experiences involving 'mother' will create a potent MMN and this mental network will represent mother within the mind, making it possible to 'predict' how mother will behave. Saying this another way, 'mother' acquires object permanence within the mind of the child when mother becomes represented by a MMN that continues to be present within the mind even when mother is physically absent. This leads to the feeling that 'mother is living within my head'. Other objects, such as a favorite teddy bear, can also achieve object permanence within the mind of the child through a similar mechanism.

Applying this to the field of economics, object permanence will lead to a form of ownership. Living within some location or alongside some object will create MMNs that represent this location or object. This might involve a favorite teddy bear, a farm that has 'been in the family for generations', or some ancestral homeland. Cognitively speaking, the result is not ownership but rather emotional attachment. A person feels emotionally incomplete if separated from the teddy bear, the family farm, or the ancestral homeland. That is because a mental network generates pain if it is activated and experiences input that is inconsistent with its structure. For instance, it is disconcerting if mother becomes aged and forgetful and starts to behave in a manner that is inconsistent with the mental network that represents mother. If a mental network continues to experience inconsistent input, then it will eventually start to fall apart, generating an emotional pain that is more intense than normal pain. 
Ownership that is based in MMNs cannot be sold, because transfer of ownership will threaten mental networks. For instance, selling the family farm or ancestral homeland will fundamentally alter the behavior that occurs upon that farm or homeland, causing the mental networks which represent that object or location to fall apart. This explains the passing reference made earlier to 'selling one's grandmother'.

Continuing with Piaget, the second stage is known as the preoperational stage and typically continues until a child enters school. This stage is characterized by role-playing, magical thinking, and centration. Looking at this cognitively, various mental networks are being activated within the mind of a child. For instance, a child may temporarily 'be' an airplane swooping through the air. Magical thinking reflects the idea that mental networks have the power to impose their structure upon reality, while centration means that thinking will be dominated by the mental network that is currently active. Summarizing, the mind is jumping from one mental network to another as these mental networks become triggered by the environment.

Applying this to economics, this leads to the concept of ownership as infatuation. The goal of the marketplace will be to use advertising to create a mental network that represents some product or firm within the mind of the potential consumer. This mental network will then be activated with the hope that this will lead to some expression of infatuation by the consumer. Products will be portrayed as having a magical ability to change reality in emotional ways. For instance, 'using our dish soap will make your kitchen bright and shiny'. The marketplace will tend to be characterized by impulse shopping, and packaging and presentation will be all-important, because the consumer will naturally centrate upon the existing 'ooh shiny'. Instead of owning objects, people will be owned by objects, because objects have the power to trigger and support mental networks. This describes a kind of roleplaying, because an object is being viewed as a door to a new-but temporary — persona. And the marketplace may cease to function properly because the consumer will confuse ownership with infatuation and attempt to cancel purchases if they are not accompanied by infatuation. This type of confusion can be seen in the guarantee of 'satisfaction or your money back'.

Piaget's third stage of cognitive development is known as the concrete operational stage. Logical thinking is possible at this stage, but only with concrete objects. It is also possible to view a situation from another person's perspective. Cognitively speaking, Perceiver thought, which thinks in terms of facts and connections, acquires the ability to function independently of Mercy experiences and emotions. However, the mind as a whole is still organized around MMNs of concrete experience.

Applying this to economics, this is when classic concepts of ownership emerge. The development of Perceiver thought makes it possible to think in terms of 'me and you', as well as 'mine and yours'. And ownership will no longer be equated with infatuation. However, ownership will still be defined in concrete terms, such as owning a house or a car.

Piaget's fourth and final stage is called the formal operational stage. The teenager at this stage acquires the ability to use symbols to analyze abstract concepts that have nothing to do with reality. Cognitively speaking, the mind becomes able to form and manipulate general Teacher theories. This is emotionally significant because TMNs (Teacher mental networks) of abstract theory provide an alternative 
emotional anchor to the MMNs that have held the mind together until this point. Saying this more carefully, it appears that the mind requires core mental networks. Therefore, the mind can only let go emotionally of MMNs if general theories are used long enough to turn into TMNs that can provide an emotional alternative to MMNs of culture and identity.

Applying this to economics, ownership becomes an abstract concept that is independent of physical location. For instance, I may have a piece of paper which indicates that I own certain bars of silver even though this silver is physically located in some distant vault. Going further, the concept of intellectual property can emerge, which is also an abstract form of property that has no inherent relationship with physical objects.

Summarizing, there is a cognitive parallel between Piaget's four stages of cognitive development and the concept of ownership, and the theory of mental symmetry can be used to explain this parallel. This explanation also illustrates what it means to use mental symmetry as a meta-theory of cognition. A meta-theory does not eliminate more specific theories, such as Piaget's theory of cognitive development, but rather places them within a larger context. Going the other way, more specific theories add substance to a meta-theory. For instance, merely describing the theory of mental symmetry, as was done at the beginning of this paper, is not sufficient. Instead, mental symmetry acquires substance as more specific theories are placed within this meta-theory, such as Piaget's theory of cognitive development-or the basic theories of economics.

It should be added that suggesting that there is a correspondence between the consumer society and Piaget's preoperational stage does not mean that the consumer is functioning mentally at the level of a preschool child. However, it does imply that the consumer society is appealing to a form of thinking that characterizes the mind of the preschool child, and the fact that this kind of appeal is successful indicates that this form of thinking is still present within the mind of the typical consumer.

These same four cognitive stages can be seen in the development of money. The sensorimotor stage could be described as one of subsistence, in which one is simply attempting to survive within the physical world. For instance, "Think back to pioneer days, when individuals knew how to do so much more than we do today, from building their homes, to growing their crops, to hunting for food, to repairing their equipment” (micro, p. 12). Looking at this cognitively, interaction with the physical environment is too pervasive to permit the development of trade and specialization.

The preoperational stage would correspond to a barter system. Trade is limited to direct transfer, in which one gives up what one no longer needs in order to gain what one needs. Monetarily speaking, nothing exists except objects. Barter can be made more efficient by centering trade around attractive objects such as gold, silver, cowrie shells, or beads. But all trade still involves exchanging one inherently desirable object for another.

The concrete operational stage describes money that is backed up by commodities, which is known in economics as representative money or commodity money. Concrete operational thought works with facts and uses logic, as long as thinking remains rooted in concrete objects. Similarly, representative money can use pieces of paper to represent value as long as these worthless pieces of paper can be turned into concrete objects of value such as gold or silver. 
The formal operational stage is associated with fiat money, which is money that has no intrinsic value. In the same way that the formal operational teenager can work with abstract concepts that have no connection to reality, so fiat money is ultimately based in an abstract concept that has no connection with reality. Cognitively speaking, concepts are being held together mentally by TMNs of abstract understanding rather than MMNs of personal experience. Similarly, fiat money is ultimately backed up by the Teacher order-within-complexity of some system of banking and/or government.

A distinction needs to be made between the level of cognitive thought that is required to set up some monetary system and the level of cognitive thought that is being used within a monetary system. For instance, the final shift from representative money to fiat money happened in the 1970s when Nixon decoupled the US dollar from gold in 1971 (Redish, 1993). However, even though fiat money now pervades the modern economy, many consumers within this economy are still susceptible to marketing that appeals to the mindset of the preoperational stage. Such a cognitive mismatch between the economic system and the consumer will make the system vulnerable to being abused.

Piaget's cognitive stages can also be applied to economics itself. The theory of microeconomics began with Adam Smith's Wealth of Nations. Microeconomics can be summarized as a rational analysis of the production and trade of concrete objects. This falls into the concrete operational stage, which is capable of thinking rationally within the concrete realm of physical objects. Adam Smith's view of money also appears to be consistent with a concrete operational mindset. "According to Smith, the sole purpose of holding money is to facilitate the circulation of goods and services. Thus, the inhabitants of a country demand the specific quantity of money necessary to circulate the whole of their goods, and are unwilling to hold either more or less than this amount” (Curott, 2015, p. 4). Notice how money is being discussed within an assumed mental context of physical goods.

Macroeconomics, in contrast, does not deal with the specific experiences and objects of Mercy thought but rather analyzes an entire economy from the Teacher perspective of general theory. This is an example of the formal operational stage, which is capable of using Teacher thought to deal with abstract concepts and general principles. Going further, macroeconomics assumes the existence of fiat money and a significant portion of macroeconomic theory discusses the manipulation and effect of fiat money. This is consistent with the suggestion that fiat money is an expression of formal operational thinking.

Returning to the cognitive perspective, Piaget's stages also illustrate a mental transition from emotional Mercy experiences to solid Perceiver facts. Pleasurable and painful experiences from the physical body program Mercy thought with MMNs during the first sensorimotor stage, and these MMNs dominate thinking during the second preoperational stage. In the third concrete operational stage, the mind develops the ability to determine and manipulate Perceiver facts within the context of MMNs. The development of TMNs in the fourth formal operational stage makes it possible to consider Perceiver facts within the context of abstract theory apart from concrete experience.

Saying this more carefully, mental symmetry suggests that Perceiver thought can gain certainty in facts in one of two primary ways, which could be summarized as 'who is right' versus 'what is right'. The diagram of mental symmetry shows an arrow leading from Mercy to Perceiver thought. This indicates a 
flow of information; a Perceiver fact is a way of connecting or organizing Mercy experiences. 'Who is right' occurs when the emotions associated with some experience or person overwhelm Perceiver thought into 'knowing' that some specific set of connections defines 'truth'. For instance, if Rev. Dr. Frederick Jones Smith says that the moon is made of green cheese, then the great emotional respect that Mercy thought has for this exalted and erudite expert will overwhelm Perceiver thought into 'knowing' that 'moon' and 'green cheese' belong together. Mental symmetry refers to this type of 'knowing' as emotional 'truth', because the truth of some Perceiver fact is being determined by emotional pressure from Mercy thought. Because Perceiver thought is being overwhelmed, 'knowing' and ‘truth' are both placed in quotes.

'What is right' happens when Perceiver thought looks for connections that are repeated. Whenever some connection becomes noticed again, then this repetition increases Perceiver confidence in that fact. For instance, seeing Piaget's stages being repeated in ownership, money, and economic theory increases Perceiver confidence that legitimate facts are being described. Emotional pressure from Mercy thought makes it more difficult for Perceiver thought to function. Thus, Perceiver confidence can be defined as the level of emotional pressure that a fact can handle. For instance, it may be possible to assert the fact that there is a connection between overeating and obesity in between meals, but Perceiver thought may have insufficient confidence to assert this fact when faced with a slice of double chocolate cheesecake topped with chocolate drizzle.

This transition from emotional 'truth' to factual truth can be seen when moving from Piaget's preoperational stage to the concrete operational stage, because Perceiver thought is gaining sufficient confidence to be able to function in the presence of MMNs. And Scottish society was going through this kind of transformation during the time of Adam Smith. One author points out this connection. "Understanding the relationship between church and state, for instance, both in Scotland and in the Reformed tradition, leading up to and during Smith's own time, can help us better understand the significance of Smith's teachings related to the role of religion in society and the state's role in promoting or protecting religion” (Ballor, 2020).

One of the primary concepts being promoted in Scottish society at that time was that Perceiver thought has the right to function in the midst of MMNs of personal status. "For Scottish covenanters, for instance, the monarch was bound by law and subject to divine authority in a way analogous to the kings of Israel. Just as King David was obliged to obey the strictures of Torah, rulers in the Scottish Presbyterian tradition were likewise bound by legal and covenantal obligation” (Ballor, 2020). Summarizing, it is easy for current economic theory which functions at Piaget's formal operational level to regard the thinking of Adam Smith as cognitively limited. But it is more appropriate to view Adam Smith as a step forward from the preceding political mindset of preoperational thought with its focus upon MMNs of royal personage, its magical mindset of royal privilege, and its centration upon the divine right of kings.

Applying this distinction to economics, the openstax textbook describes four kinds of product differentiation: "physical aspects of the product, location from which it sells the product, intangible aspects of the product, and perceptions of the product” (micro, p. 237). 
Looking at this more carefully, "Physical aspects of a product include all the phrases you hear in advertisements: unbreakable bottle, nonstick surface, freezer-to-microwave, non-shrink, extra spicy, newly redesigned for your comfort. A firm's location can also create a difference between producers' (micro, p. 237). Notice that all of these differences involve Perceiver facts which either refer to some attribute of an object or to the location of the object.

Going further, “Intangible aspects can differentiate a product, too. Some intangible aspects may be promises like a guarantee of satisfaction or money back, a reputation for high quality, services like free delivery, or offering a loan to purchase the product” (micro, p. 237). Quality, delivery, and loans involve primarily the Contributor realm of cause-and-effect, and their presence or absence can be tested factually, leading to Perceiver knowledge.

Summarizing, Perceiver thought organizes Mercy experiences into categories based upon similarities and differences. If a consumer has decided that 'products are distinctive in some way', then this means that Perceiver thought has mentally organized these products into distinctive categories. In this case, Perceiver thought is gaining its facts by actively looked for connections that are either repeatedly present or repeatedly absent.

However, Perceiver differences can also result from emotional 'truth'. "Product differentiation may occur in the minds of buyers. For example, many people could not tell the difference in taste between common varieties of ketchup or mayonnaise if they were blindfolded but, because of past habits and advertising, they have strong preferences for certain brands. Advertising can play a role in shaping these intangible preferences” (micro, p. 237). Notice that Perceiver thought is unable to discern any actual facts that differentiate one product from another. But Perceiver thought still 'knows' that the products are different for the emotional reason of 'having strong preferences for certain brands'. And this emotional 'truth' is being shaped by the emotional manipulation of advertising. Similarly, with 'satisfaction or your money back', the facts of the transaction are being determined by the feelings of the consumer. I am not suggesting that all advertising is emotional manipulation, but when a celebrity endorses some product or the product is being portrayed in some emotional environment, then it is clear that emotions are being manipulated.

Economics places both rational facts and emotional 'facts' within the same category of differentiated products. I suggest that there is a cognitive reason for this. One can see in the diagram of mental symmetry that Contributor is connected to Perceiver and Server. As was mentioned before, this means that Contributor thought acquires its Perceiver facts and Server sequences indirectly from Perceiver and Server thought. Perceiver thought lives within a mental 'world' of facts, while Server thought inhabits a mental 'world' of sequences. Contributor thought, in contrast, acquires a specific set of facts and sequences from Perceiver and Server thought and then works with this limited set of facts and sequences.

One of the cognitive by-products of using information that is evaluated by other cognitive strategies means that Contributor thought does not care how Perceiver thought acquires its certainty in facts. What matters when choosing to use some Perceiver fact is whether or not Perceiver thought has certainty. (This is why the word 'certainty' is being used rather than 'confidence'.) This means that 
technical thought can be based in either rational facts or in emotional 'truth'. A rational fact gains certainty as Perceiver thought continues to notice some connection being repeated. For instance, scientific experiments and statistical analysis use repetition to build Perceiver confidence in facts. Perceiver facts that are based in repetition will be referred to as universal truth, because they describe connections that can be found if not universally, at least generally.

Emotional 'truth' can also acquire sufficient certainty if words spoken by important people are written down and shared with believers. This second mechanism will be referred to as absolute truth, and absolute truth provides the certainty for belief in holy books and textbooks. ${ }^{7}$ A textbook may eventually be regarded by the student as a description of rational facts, but a student will initially approach a textbook as a form of a holy book, in which the words of exalted scholars have been recorded and are now being promulgated to disciples. The cognitive impact of a holy book is discussed further in a paper on science and theology (Friesen, 2020). The relationship between absolute truth and universal truth will be examined later in this paper when looking at the banking system and the creation of fiat money. Contributor-controlled technical thought can be based in either rational facts or in absolute truth. For instance, both the scientist and the theologian use the rigorous thinking of technical thought, even though the scientist builds primarily upon universal truth and the theologian upon absolute truth. This explains why economics does not distinguish between facts and 'facts' when discussing product differentiation. However, if one considers the larger picture, then facts are quite different than 'facts'. For instance, the Internet is very useful as a source of facts, as illustrated by sites such as Wikipedia. However, the Internet becomes socially divisive when used as a source of 'facts', because it becomes segregated into echo chambers that do not interact with one another (Cinelli, 2021).

\section{Choice}

The general thesis of this paper is that economics can be explained cognitively as the interaction between Exhorter and Contributor thought. Exhorter thought uses emotional Teacher and Mercy memories as a source of motivation. Exhorter motivation is similar to Mercy and Teacher emotion but becomes bored when there is a lack of novelty. This desire for novelty is expressed in economics by the law of diminishing returns.

Contributor thought responds to Exhorter motivation with choice. That is because Exhorter motivation is (almost?) always accompanied by a few alternatives. Therefore, Contributor thought will be faced with several options. If Contributor thought does nothing, then the option with the greatest Exhorter motivation will naturally be selected by default. However, Contributor thought can also choose to follow one of the suggested alternatives.

Using an analogy, free will appears to be like an election in which one chooses from some list of suggested candidates. If one candidate is much more popular than the other candidates, then the results can be predicted, and the election will be merely a formality. However, if two candidates from different parties are equally popular, then the election will have a major impact. Similarly, it appears that free

7 When referring to absolute truth, the word 'truth' is not placed in quotes because it is an intermediate form of knowledge that adds aspects of universal truth to emotional 'truth'. 
will becomes maximized when the mind is driven by two incompatible sets of core mental networks, while free will becomes minimized when the mind is dominated by a single set of mental networks.

This concept of choosing between a limited set of alternatives is expressed in economics as opportunity cost. "The idea behind opportunity cost is that the cost of one item is the lost opportunity to do or consume something else. In short, opportunity cost is the value of the next best alternative” (micro, p. 29). Notice that Contributor choice is being defined in terms of Exhorter motivation. First, Contributor thought is not choosing between random alternatives. Instead, Contributor thought is choosing between the alternative with the greatest Exhorter motivation and the alternative with the second-greatest motivation. Second, choosing one alternative means turning down the other; allowing one motivation from Exhorter thought to be expressed means suppressing an alternative motivation from Exhorter thought. Using economic language, "Since people must choose, they inevitably face tradeoffs in which they have to give up things they desire to obtain other things they desire more" (micro, p. 29).

Economists recognize that this is not a normal way of determining cost. The microeconomics textbook provides an example of burgers costing $\$ 2$ and then asks "What would it cost Alphonso for one more burger? It would be natural to answer $\$ 2$, but that's not the way economists think. Instead they ask, how many bus tickets would Alphonso have to give up to get one more burger, while staying within his budget? Since bus tickets cost 50 cents, Alphonso would have to give up four to afford one more burger. That is the true cost to Alphonso" (micro, p. 29). Looking at this cognitively, value is a way of representing — and comparing — the emotional significance of items within Mercy thought. Economics refers to these inherent Mercy emotions as utility. "People desire goods and services for the satisfaction or utility those goods and services provide. Utility... is subjective but that does not make it less real” (micro, p. 32). But economics focuses upon the interaction between Exhorter and Contributor thought where value is experienced as opportunity cost, which means having to choose between alternative motivations.

Economics defines rational thinking as pursuing opportunity cost. Continuing with the burger versus bus ticket example, “A rational consumer would only purchase additional units of some product as long as the marginal utility exceeds the opportunity cost... As [Alphonso] consumes more bus tickets, the marginal utility of bus tickets will diminish, while the opportunity cost, that is, the marginal utility of foregone burgers, will increase. Eventually, the opportunity cost will exceed the marginal utility of an additional bus ticket. If Alphonso is rational, he won't purchase more bus tickets once the marginal utility just equals the opportunity cost” (micro, p. 32). Translating this example into cognitive language, Exhorter thought is motivating Contributor thought with the two possible alternatives of 'burger' and 'bus ticket'. Contributor thought is choosing 'bus ticket' because Exhorter thought finds it more exciting. But as Contributor thought continues to choose 'bus ticket', Exhorter thought gradually gets bored with this alternative, making 'burgers' look more attractive. When 'burgers' become more exciting than 'bus tickets', then Contributor thought will switch from choosing 'bus tickets' to choosing 'burgers'.

This is known as marginal analysis. Economics views marginal analysis as the way of achieving an optimal result. "Most choices involve marginal analysis, which means examining the benefits and costs 
of choosing a little more or a little less of a good. People naturally compare costs and benefits, but often we look at total costs and total benefits, when the optimal choice necessitates comparing how costs and benefits change from one option to another. You might think of marginal analysis as 'change analysis.' Marginal analysis is used throughout economics” (micro, p. 32). Using the example of burgers and bus tickets, the average person places burgers and bus tickets within a larger context when determining value. Economics, in contrast, focuses upon the immediate result of choosing either one more burger or one more bus ticket. This is consistent with the thesis that economics focuses upon Exhorter-Contributor interaction. The rest of the mind provides the context for marginal analysis. For instance, the entire mind is required to design, construct, and drive the buses that make bus tickets possible. Similarly, many cognitive modules must be used to grow and prepare the various components of a burger. But economics does not recognize that as rational thought. Instead, economics defines rational thought as limiting the mind to the interaction between Exhorter and Contributor thought.

There is some truth to this claim that economic thinking defines rational thought. That is because the childish mind is initially programmed by MMNs that do not behave in a rational manner. We saw that these MMNs are acquired in Piaget's sensorimotor stage, and that they motivate the mind to think magically in the preoperational stage. Childish mental networks can be reprogrammed to be consistent with rational thought, but that is not a simple process. The term childish mental network will be used to refer to this kind of mental network that promotes magical thinking and is incompatible with rational thought. Economic thought is rational compared to the typical childish mental network.

However, the 'rational thinking' of economics is actually using Contributor thought in a semi-passive manner. It takes effort for Contributor thought to choose a secondary option that is not being emphasized by Exhorter thought. Using the example, it is hard for Contributor thought to choose burgers when bus tickets are more exciting. If Contributor thought merely chooses the option that Exhorter thought currently finds exciting, then Contributor thought is actually doing nothing but rather responding in a passive manner. The effort that Contributor thought has to exert to make some choice will be referred to as Contributor confidence. This will be discussed further when looking at neurology.

The semi-passivity of Contributor thought can be seen in the concept of indifference. "People cannot really put a numerical value on their level of satisfaction. However, they can, and do, identify what choices would give them more, or less, or the same amount of satisfaction. An indifference curve shows combinations of goods that provide an equal level of utility or satisfaction” (micro, p. 509). 'Level of satisfaction' or 'utility' refers to the emotional label given to some experience or situation within Mercy thought. Indifference indicates that two (or more) alternatives are generating the same level of motivation in Exhorter thought. One can tell that Exhorter motivation is being described and not Mercy emotions because indifference curves include the concept of Exhorter boredom, in which Exhorter thought gets bored when experiences are repeated. "Indifference curves... are steeper on the left and flatter on the right. The reason behind this shape involves diminishing marginal utility-the notion that as a person consumes more of a good, the marginal utility from each additional unit becomes lower” (micro, p. 510). However, these Exhorter urges are based upon personal feelings within Mercy thought. "Each person determines his or her own preferences and utility. Thus, while indifference curves have the same general shape-they slope down, and the slope is steeper on the left 
and flatter on the right - the specific shape of indifference curves can be different for every person” (macro, p. 510).

Optimal pleasure is reached by following marginal utility until a point of indifference is reached and there are no more funds. "We can write this argument as a general rule: If you always choose the item with the greatest marginal utility per dollar spent, when your budget is exhausted, the utility maximizing choice should occur where the marginal utility per dollar spent is the same for both goods" (micro, p. 139). Pursuing marginal utility means that the optimal result is being reaching by using a method that involves Contributor passivity, because Contributor thought is merely deferring to the strongest Exhorter motivation.

The situation with indifference is slightly different. Contributor thought is required, because a choice has to be made between alternatives. But making this choice does not necessarily require great Contributor confidence. Contributor confidence will be required if the options are deeply emotional, because choosing one alternative will mean not choosing the other. However, a state of indifference is typically reached after going through several rounds of diminishing returns, which means that Exhorter thought will probably be finding all possible options rather boring by this time, similar to one's lack of hunger at the end of a satiating meal. That is why I describe Contributor thought as being semi-passive when reaching indifference.

Before continuing, it may be helpful to describe a form of Exhorter-Contributor interaction in which Contributor thought is not playing a passive role. This form of thinking, referred to as contingency planning, became apparent when examining biographies of Contributor persons. Instead of automatically choosing the option suggested by Exhorter thought, Contributor thought will choose every option, going through them mentally one by one. Each choice will set a mental context, causing Exhorter thought to be attracted to some set of exciting possibilities. These possibilities may be good or bad, because Exhorter thought finds both pleasure and pain exciting. If the Mercy emotions of some possibility are unpleasant, then Contributor thought will come up with a sequence of cause-and-effect that makes it possible to recover from this potential disaster. For instance, 'I might get a flat tire, so I will carry a spare tire. I might get stranded, so I will bring a cell phone. My car might break down, so I will become a member of an Automobile Association.' And for those who know what a prairie winter is like, 'I might go off the road and get stuck in a snowdrift, so I will bring along some candles so I do not freeze to death.'

Contingency planning combines Exhorter-Contributor interaction with the cause-and-effect elements of concrete technical thought, and its effectiveness depends upon knowledge and skill. Exhorter thought will only be attracted to some possible disaster if Perceiver thought has learned about that cause-andeffect, and Contributor thought will only be able to come up with some possible solution if Server thought can perform the appropriate action of cause-and-effect. One concludes that economics by itself is incapable of carrying out effective contingency planning because it delegates the content of technical thought to other disciplines.

I should add that economics does make allowance for long-term thinking. For instance, "Participants in financial markets must decide when they prefer to consume goods: now or in the future. Economists 
call this intertemporal decision making because it involves decisions across time. Unlike a decision about what to buy from the grocery store, people make investment or savings decisions across a period of time, sometimes a long period” (micro, p. 95). Economics uses temporal discounting to interpret such long-term thinking, which means that a future possibility will be regarded as less valuable than the same possibility in the present. For instance, "To place a present discounted value on a future payment, think about what amount of money you would need to have in the present to equal a certain amount in the future. This calculation will require an interest rate. For example, if the interest rate is $10 \%$, then a payment of $\$ 110$ a year from now will have a present discounted value of $\$ 100$ ” (micro, p. 523). Notice that long-term thinking is still being interpreted in terms of Exhorter-Contributor interaction. Contributor thought is choosing between alternatives suggested by Exhorter thought. But Exhorter thought finds a future possibility less exciting than a present possibility.

However, neurological evidence suggests that there is more to the story. "Numerous imaging studies have examined temporal discounting using a variety of intertemporal choice tasks. Although the discounting tasks used across experiments have differed on various important aspects, the findings have converged on a common set of subcortical and cortical regions that are involved in temporal discounting. Commonly, these regions are divided into two networks: a valuation network that is involved in estimating the incentive value of the different options, and a control network that is involved in action selection, considering and maintaining future goals, exerting top-down modulation over the valuation network, and inhibiting prepotent responses” (van den Bos, 2013, p. 7). In other words, a 'control network' involving other cognitive modules is modifying the 'valuation network' of Exhorter-Contributor interaction to include 'future goals'.

A more recent paper describes many different methods that are used to help people pursue long-term goals rather than impulsively choosing short-term gratification. These include mindfulness-based approaches, contingency management, episodic future thinking, framing, perspective taking, priming, cueing, context, learning-based approaches, and environmental enrichment/deprivation (Rung, 2018). This multiplicity of possible approaches indicates that there is quite a bit more to the story than the Exhorter-Contributor interaction being described by economics.

Looking at one facet of this, Exhorter motivation will be affected by the mental context. For instance, it takes effort to choose to study when it is sunny outside, because lazing in the sun brings more marginal utility than studying a textbook. In this case, if the mind focuses upon the larger picture, then this will result in motivation to study the textbook. But if the mind focuses upon the immediate context, then the motivation to enjoy the sun will tend to be stronger.

The microeconomics textbook mentions a similar example, looking at the economic choices made by consumers during the 2008 Great Recession. "In what category did consumers worldwide increase their spending during the Great Recession? Higher education... Why were consumers willing to spend on education during lean times? Both individuals and countries view higher education as the way to prosperity. Many feel that increased earnings are a significant benefit of attending college” (micro, p. 148). In other words, many people looked at the immediate financial problems and chose to pursue the long-term solution of developing rational thought through higher education. But economics interprets this choice using marginal analysis: "Why spend the money to go to college during recession? Because 
if you are unemployed... the opportunity cost of your time is low. If you're unemployed, you don't have to give up work hours and income by going to college" (micro, p. 148). In other words, lazing in the sun eventually becomes boring, making the alternative of going to college more exciting. But this does not explain why 'going to college' is being regarded as the alternative to 'being unemployed', or why 'going to college' is being viewed as a prerequisite for 'getting a higher paying job'.

Looking at this from a computing perspective, marginal analysis is capable of reaching a local optimal if the various parameters and constraints are carefully defined. Using a common analogy, marginal analysis is like rolling a ball down a slope. Marginal analysis ignores the landscape and simply asks which direction leads down from the current location. This strategy will eventually reach some minimum, but this may be a local minimum, a depression that is still part way up the slope. Marginal analysis will not necessarily reach the global minimum - the valley at the bottom of the mountain. Going further, marginal analysis assumes the existence of some landscape. It is a form of intuitive thinking which moves along some implicit 'road system' or 'landscape' of content that is being provided by the rest of the mind. This is another aspect of being locally rational, because a local minimum is being achieved and not necessarily the global minimum. Applying this to economics, the typical investor finds it difficult to look around the corner and is often willing to pay considerable sums to financial experts who appear to have the ability to look around the corner.

Local optimization also shows up in the analysis of trade. Economics distinguishes between comparative advantage and absolute advantage. "When a country can produce a good at a lower opportunity cost than another country, we say that this country has a comparative advantage in that good. Comparative advantage is not the same as absolute advantage, which is when a country can produce more of a good" (micro, p. 37). Absolute advantage compares the abilities of one person or country with another. For instance, saying that Brazil can grow more sugarcane than the United States is an example of absolute advantage. With comparative advantage, each partner does its own calculations without considering the other partner. And the calculations of each partner will be limited to the Exhorter-Contributor interaction of opportunity cost. For instance, the United States might compare growing sugarcane with growing corn. Potential trading partners then use the single quantity of price to determine what will be traded with whom. The result of this trade is also a local improvement. For instance, Brazil will discover that trading sugar cane for corn improves the situation within Brazil. The key principle is that "When countries engage in trade, they specialize in the production of the goods in which they have comparative advantage, and trade part of that production for goods in which they do not have comparative advantage. With trade, manufacturers produce goods where the opportunity cost is lowest, so total production increases, benefiting both trading parties" (micro, p. 38).

This concept of relative advantage is politically significant, because it means that a central plan enforced by some central planner is not required to create a wealth-generating market economy. Stated cognitively, each individual person or country can use concrete technical thought to pursue personal goals in Mercy thought and then interact through the simple mechanism of price. But one sees again that economic analysis is being limited to the interaction between Exhorter and Contributor thought. 


\section{Elasticity}

Elasticity quantifies the idea of Contributor thought choosing between alternate suggestions given by Exhorter thought. "Elasticity is an economics concept that measures responsiveness of one variable to changes in another variable" (micro, p. 108). Elasticity can be used to compare any two variables but is commonly used with price. "Price elasticity is the ratio between the percentage change in the quantity demanded or supplied and the corresponding percent change in price. The price elasticity of demand is the percentage change in the quantity demanded of a good or service divided by the percentage change in the price. The price elasticity of supply is the percentage change in quantity supplied divided by the percentage change in price" (micro, p. 108).

We saw earlier that price is an external quantity that is used by potential trading partners to evaluate whether or not to make a trade. Price elasticity transforms the external quantity of price into the language of Exhorter-Contributor interaction. In most markets, the price is not set by individual suppliers or consumers. Instead, it is a number that is common knowledge to both sellers and buyers. Price elasticity treats this externally provided number as a form of opportunity cost: If the price changes from its current value, then what effect will this have upon Exhorter motivation? ${ }^{8}$

Elasticity is a dimensionless quantity. "As with the elasticity of demand, the elasticity of supply is not followed by any units. Elasticity is a ratio of one percentage change to another percentage changenothing more-and we read it as an absolute value” (micro, p. 112). A dimensionless quantity is a simple number that lacks any units such as 'dollars' or 'bushels of corn'. Cognitively speaking, a dimensionless number eliminates all content. This is consistent with the suggestion that economics focuses upon Exhorter-Contributor interaction while ignoring any content associated with this interaction.

Price elasticity also reduces the process of optimizing to a single number. Looking at the example of a band selling concert tickets, "The key concept in thinking about collecting the most revenue is the price elasticity of demand... If demand is elastic at that price level, then the band should cut the price, because the percentage drop in price will result in an even larger percentage increase in the quantity sold - thus raising total revenue. However, if demand is inelastic at that original quantity level, then the band should raise the ticket price, because a certain percentage increase in price will result in a smaller percentage decrease in the quantity sold—and total revenue will rise" (micro, p. 117). Notice how the process of optimizing revenue has been reduced to the effect that Contributor choice has upon Exhorter motivation. And this effect is being expressed as a simple numerical calculation that ignores any of the technical expertise involved in either playing in a band or setting up a concert.

Elasticity also makes it possible to reduce the problem of attempting to read the content of other people's minds (known as theory of mind) to a single number. For instance, "The demand for cigarettes is relatively inelastic among regular smokers who are somewhat addicted... If society increases taxes on companies that produce cigarettes... these higher taxes on cigarettes will raise tax revenue for the government, but they will not much affect the quantity of smoking” (micro, p. 119). Thus, knowing the

8 Cognitively speaking, a number is a simple way of connecting concrete technical thought with abstract technical thought. This is discussed in a paper on science and theology (Friesen, 2020). 
single number of elasticity makes it possible to predict how some choice in Contributor thought will affect Exhorter motivation within the minds of other people.

This focus upon local optimization can be seen in the Latin phrase ceteris paribus, which means 'all other things being equal'. The Investopedia website points out that this “acts as a shorthand indication of the effect one economic variable has on another, provided all other variables remain the same. Many economists rely on ceteris paribus to describe relative tendencies in markets and to build and test economic models. In reality, one can never assume 'all other things being equal'” (Liberto, 2021). Cognitively speaking, ceteris paribus assumes that the rest of the mind will not function while economic thought is doing its local optimization. If the rest of the mind remains motionless, then economic thought can compare the relative benefits of the various options within the current market. But, as this website points out, the rest of the mind does function when dealing with reality.

When the rest of the mind interferes, then this causes the curves of relative benefit to shift. Economics distinguishes between movement along some curve and the shift of that curve. Movement along a curve can be analyzed using Exhorter-Contributor interaction. The curve itself shifts when the rest of the mind interferes, causing the assumption of ceteris paribus to fail. For instance, the average person probably is not comparing lazing in the sun with studying a textbook. Instead, a more typical comparison would be lazing in the sun versus having a nap. Textbooks tend to become motivating options when the rest of the mind intervenes.

\section{Locally Rational Thought}

The statements that have been made so far raise the distinction between positive statements and normative statements. "Economists make the careful distinction between positive statements, which describe the world as it is, and normative statements, which describe how the world should be. Even when economics analyzes the gains and losses from various events or policies, and thus draws normative conclusions about how the world should be, the analysis of economics is rooted in a positive analysis of how people, firms, and governments actually behave, not how they should behave" (micro, p. 43). Notice that economics is making positive and not normative statements but it is coming up with normative conclusions. Similarly, stating that economics focuses upon Exhorter-Contributor interaction is a positive statement, because it describes the cognitive modules that are being used by economics. But it leads to a normative conclusion, because the implication is that economics should be using more of the mind.

The previous quote says that economics avoids starting with normative statements. But if economics emphasizes Exhorter-Contributor interaction while ignoring other cognitive modules, then economics is actually starting with a normative statement when it defines economic thinking as rational, because this implies that other cognitive modules are sub-rational. Notice that the problem does not lie with emphasizing Exhorter-Contributor interaction while relegating other aspects of rational thought to other disciplines. That is a matter of specialization. And defining rational thought as going beyond the emotional processing of mental networks starts with positive statements and makes a normative conclusion. However, focusing upon Exhorter-Contributor interaction and then defining this to be rational thought starts with a normative statement that is not supported by any positive statements. 
This dismissive attitude can be explained cognitively as a natural characteristic of technical thought. It was mentioned earlier that abstract technical thought is guided by some emotional paradigm within Teacher thought. Abstract technical thought is naturally rational when functioning within this paradigm. This is reflected by Thomas Kuhn's statement that the typical scientist spends most of his time solving puzzles within some paradigm. "The scientific enterprise as a whole does from time to time prove useful, open up new territory, display order, and test long-accepted belief. Nevertheless, the individual engaged on a normal research problem is almost never doing any one of these things. Once engaged, his motivation is of a rather different sort. What then challenges him is the conviction that, if only he is skilful enough, he will succeed in solving a puzzle that no one before has solved or solved so well” (Kuhn, 1970, p. 38). However, when the paradigm is threatened, then technical thought will naturally switch from rational thought to some form of emotional belittling-because the technical thought is now facing an emotional threat. The belittling happens because Teacher emotion comes from generality. A rival general theory will generate strong Teacher emotions; belittling this competing theory will make it feel less general and thus less threatening.

Summarizing, technical thought can be described as locally rational for three primary reasons: First, technical thought involves expertise within some field of technical content. For instance, a car mechanic has technical knowledge and skill about the functioning of a car. Second, technical thought uses rigorous logic and rational thinking within this field of specialization. Third, technical thought tends to respond emotionally when the paradigm behind the field is challenged - usually by external forces.

Economics is not just locally rational, but it is locally rational at the level of numbers. This is because economics delegates the content of technical thought to other specializations, and then reduces this technical content to numbers that represent the interaction between Exhorter and Contributor thought.

It is important to clarify the relationship between logic and emotion that occurs in technical thought because of the course of current society. Abstract technical thought became honored during Enlightenment because it was so successful at deciphering the laws of the universe. Technical thought became preeminent after the Industrial Revolution because the combination of abstract and concrete technical thought succeeded in transforming the physical world through science and technology. On the positive side, this led to the development of many technical specializations, each exhibiting brilliant, locally rational thought. On the negative side, this also expressed itself emotionally as a form of universal belittling, in which all technical specializations looked down their trained noses at the unwashed, uneducated masses who lacked the ability to 'think rationally'.

It should be pointed out that describing technical thought as locally rational is a different conclusion than that reached by postmodern questioning, which typically rejects the thinking of the Enlightenment as invalid. Mental symmetry, in contrast, suggests that technical thought is the best form of thinking to use when attempting to optimize within some limited specialization, and that technical thought is the appropriate mental strategy to choose when studying the physical laws of nature. But mental symmetry also suggests that a study of human behavior, of which economics is one example, must also include normal thought and mental networks as well as technical thought. 
Saying this more generally, the locally rational nature of technical thought means that scientific research can usually be trusted, because researchers go to great lengths to ensure the accuracy of their research. But science cannot necessarily be trusted when it comes to applying this research or fitting this research into the larger picture.

Some economists recognize that economics provides a rather low standard for the definition of 'rational'. For instance, a webpage from the University of Toronto explains that "It is important to understand that economists' definition of rationality means simply that individuals behave consistently, however stupid and irrational that consistent behaviour might appear to others” (Floyd, 2021). Stated cognitively, economic 'rationality' is ignoring mental content and limiting its definition to the premise that Contributor thought is choosing between Exhorter urges in a consistent manner.

However, no such recognition can be found in the openstax textbook on microeconomics. On the contrary, economic rationality is described as more rational than the average person, and the textbook adds that economists have a tendency to tell students in an emotionally belittling manner that their thinking is less rational than economic rationality. "In fact, economics professors often delight in pointing out so-called 'irrational behavior' each semester to their new students, and present economics as a way to become more rational” (micro, p. 147).

This emotional belittling can also be seen implicitly in the typical examples found in many microeconomics textbooks. The openstax textbooks being quoted in this paper do not contain trivial examples, but many examples given in many courses (including those in Khan Academy) use extensive nonsense words for products, companies, towns, and countries. Such imaginary terms make the subject more interesting, they avoid offending people, and they emphasize that economics goes beyond specific companies to general principles. But encountering a continual stream of imaginary entities, nonsense terms, and trivial objects (some examples from Khan Academy are fidgit spinners, meeps, robotic sandwich stuffers, Burginville, Nadyaland, and Xela) also has the cumulative emotional impact of belittling the content that lies behind economic thought. This implicitly conveys the idea that economic analysis is a beacon of rational thinking within a landscape of triviality, when in fact the opposite is closer to the truth. Economics only exists to the extent that real people and companies are capable of designing and building real objects within real countries, while the 'rational thinking' of economics could be summarized as responding in a consistent manner to the current excitement. I am not suggesting that this describes all of economics. Economic analysis can involve advanced mathematics. And I have found that economic papers often provide enlightening rational analyses of social issues. But this does describe the definition that economics gives to rational thought.

It should be added that a cognitive analysis of microeconomics — as this paper is doing — also leads to a form of emotional belittling. That is because the Teacher emotion that is associated with a general theory depends upon the generality of that theory. A Teacher theory that explains more specific items will generate stronger Teacher emotions, while a theory that explains fewer items will generate weaker Teacher emotions. Therefore, showing that a general theory is less general is a form of emotional belittling. 
Economics appears to be a general theory when viewed from a physical perspective because economic trade based in money is associated with most of the wealth of the world. And a market economy is rational compared to the non-specialized mental-network-driven societies that existed before market economies. However, a different picture emerges if one thinks in terms of cognition. Economic thought is doubly limited when it comes to using the entire mind. It is locally rational because it uses technical thought, which by its very nature limits rational thinking to some specialization. And it is locally, locally rational because it limits its technical analysis to a small subset of the content of technical thought. Thus, viewing microeconomics from a cognitive perspective leads to the conclusion that economic thought only describes one aspect of the general theory of what it means to think and act rationally. And such a conclusion will be regarded by Teacher thought as emotionally belittling.

This section began by looking at the distinction between positive statements and normative statements. Economics makes normative conclusions, but it attempts to base these upon positive statements. Similarly, the theory of mental symmetry makes it possible reach normative conclusions while making positive statements. Mental symmetry suggests that people fall into seven different cognitive styles, and that each cognitive style is conscious in a different cognitive module of the mind. Thus, by observing how each cognitive style does think, it is possible to assemble a composite picture of how the entire mind could think. Similarly, by placing a cognitive analysis of how economics does think within the larger picture of the entire mind, one gains an understanding of which cognitive modules are being used and which cognitive modules are being ignored, leading to a normative conclusion about how economics should think. This does not imply that economics is wrong, because it appears that economics accurately describes the functioning of part of the mind. And it also does not imply that economics should be rejected. However, it does imply that economic thought should be placed within the larger picture of the functioning of the entire mind. This is what it means in practical terms for mental symmetry to act as a meta-theory.

\section{Behavioral Economics}

Microeconomics focuses upon the Exhorter-Contributor interaction that occurs within concrete technical thought. But Exhorter thought generates this motivation by being attracted to emotional memories within Mercy thought. The underlying assumption is that Mercy thought is not processing the emotions of utility but rather passing them on unfiltered to Exhorter thought, which then modifies these emotions through the diminishing returns of Exhorter boredom. However, behavioral economics has discovered that the mind does process emotions before they reach economic motivation and choice.

Economics has actually known for several decades that Mercy feelings of utility are being preprocessed in some manner but has largely ignored these findings because they do not fit into the paradigm of economic activity. In the words of a 2013 review paper, Kahneman and Tversky showed in 1979 that "people systematically violate the predictions of expected utility theory, economists' workhorse model of decision making under risk... More than 30 years later, prospect theory is still widely viewed as the best available description of how people evaluate risk in experimental settings. Kahneman and Tversky's papers on prospect theory have been cited tens of thousands of times and were decisive in awarding Kahneman the Nobel Prize in economic sciences in 2002... It is curious, 
then, that so many years after the publication of the 1979 paper, there are relatively few well-known and broadly accepted applications of prospect theory in economics... While prospect theory contains many remarkable insights, it is not ready-made for economic applications” (Barberis, 2013).

Kahneman and Tversky as well as behavioral economics are mentioned in the openstax textbook on microeconomics. However, this is presented primarily as a way of explaining irrational human behavior. "There is much human behavior that mainstream economists have tended to call 'irrational' since it is consistently at odds with economists' utility maximizing models. The typical response is for economists to brush these behaviors aside and call them 'anomalies' or unexplained quirks. 'If only you knew more economics, you would not be so irrational,' is what many mainstream economists seem to be saying. A group known as behavioral economists has challenged this notion, because so much of this so-called 'quirky' behavior is extremely common among us” (micro, p. 385).

This quote is cognitively revealing, because two kinds of emotional response are being described. On the one hand, the typical consumer is being driven by Mercy emotions to behave in a manner 'that mainstream economists have tended to call irrational'. And economics is being presented as a cure for this irrational thought. But on the other hand, the typical economist is being driven by Teacher emotions to 'brush behaviors aside' that do not fit into the Teacher paradigm of 'economists' utility maximizing models'. Notice the characteristics of Teacher emotion: Facts that are 'at odds with' the Teacher theory are being emotionally belittled as 'anomalies or unexplained quirks'.

It was suggested earlier when looking at Piaget's fourth cognitive stage that the TMN of a general theory can provide an alternate emotional anchor to the MMNs of the childish mind. The previous paragraph illustrates this principle, because the TMN of economic theory is making it emotionally possible for the typical economist to go beyond the 'irrational' MMNs that drive the typical consumer. In the words of the economist, 'If only you knew more economics, you would not be so irrational'.

This quote also illustrates another characteristic of a TMN, which is that it acts like a mental prison, driving a person to emotionally belittle information that is inconsistent with its structure. Thomas Kuhn describes this imprisoning effect and suggests that it is an integral part of scientific technical thought. "The transfer of allegiance from paradigm to paradigm is a conversion experience that cannot be forced. Lifelong resistance, particularly from those whose productive careers have committed them to an older tradition of normal science, is not a violation of scientific standards but an index to the nature of scientific research itself” (Kuhn, 1970, p. 151).

This imprisoning effect of a paradigm appears to be inevitable. That is because any theory that continues to be used will turn into a TMN and this mental network will emotionally impose the theory upon the mind. This provides a strong incentive for discovering and using a meta-theory such as mental symmetry, because the TMN of a meta-theory will 'imprison' the mind within a theoretical 'mansion' that is capable of housing many general theories under its roof.

Returning now to behavioral economics, Tversky and Kahneman mention "five major phenomena of choice, which violate the standard model and set a minimal challenge that must be met by any adequate descriptive theory of choice. All these findings have been confirmed in a number of experiments, with both real and hypothetical payoffs" (Tversky, 1992, p. 298). These five phenomena are framing effects, 
nonlinear preferences, source dependence, loss aversion, and risk seeking. Mental symmetry suggests that these phenomena can be explained as the influence that various cognitive modules are having upon Exhorter-Contributor interaction.

The first phenomena are framing effects. "The rational theory of choice assumes description invariance: equivalent formulations of a choice problem should give rise to the same preference order. Contrary to this assumption, there is much evidence that variations in the framing of options (e.g., in terms of gains or losses) yield systematically different preferences” (Tversky, 1992, p. 298). This describes the effect of Mercy mental networks. Triggering some element of a mental network will activate the whole mental network, which will impose an emotional context upon Mercy feelings. For instance, a single knowing glance from a mother will bring to awareness a collection of emotional expectations within the mind of her child. Thus, emotional utility can be altered by triggering a different mental network. In contrast, the 'rational theory of choice' taught by economics focuses upon Exhorter-Contributor attraction while ignoring mental content.

Saying this more carefully, Mercy emotions are generated in three ways: First, physical sensations of pain and pleasure suggest emotional labels to Mercy thought. Mercy thought acquires its initial set of emotional memories in this matter during Piaget's sensorimotor stage. (And these emotional memories also coalesce to form Mercy mental networks.) Second, each new Mercy experience brings to mind related experiences and the emotional label given to the new experience will be determined by the emotional labels of these related experiences. This is a form of associative processing, and economics recognizes this second method of generating emotions. "In the classical theory, the utility of an uncertain prospect is the sum of the utilities of the outcomes, each weighted by its probability" (Tversky, 1992, p. 299). Third, if an experience triggers a mental network, then the mental network will generate an emotion based upon how consistent the situation is with the structure of that mental network. The framing effect appears to be describing this third method.

This means that a mental network generates an emotion based upon compatibility while the memories contained within a mental network also generate emotions based upon associative emotional labeling. As was mentioned before, these two are not the same, because a person may choose an unpleasant situation because it feels familiar, or reject a pleasant situation because it is too unfamiliar.

The second phenomena are nonlinear preferences. "According to the expectation principle, the utility of a risky prospect is linear in outcome probabilities... [but] more recent studies observed nonlinear preferences in choices that do not involve sure things” (Tversky, 1992, p. 298). Linearity means that a relationship can be graphed as a straight line. It appears that linearity is a characteristic of technical thought, and an emphasis upon linearity pervades scientific thought and education. For instance, a book entitled The Illusion of Linearity opens by observing that "Linear or direct proportional relationships receive a lot of attention in contemporary mathematics education, both at the elementary and secondary level. The reason lies in the fact that linear relationships are the underlying model for approaching numerous practical and theoretical problem situations within mathematics and science... linearity passes through the entire mathematical building” (de Bock, 2007, p. 1). In a similar vein, the fundamental assumption of calculus is that a complicated problem can be treated as linear if one focuses upon the details. Applying this to economics, I suggest that classic economic theory assumes 
that Mercy emotions are being generated linearly not because this is the case, but rather because technical thought thinks in terms of linear relationships.

What really happens is that "For both positive and negative prospects, people overweight low probabilities and underweight moderate and high probabilities. As a consequence, people are relatively insensitive to probability difference in the middle of the range.” (Tversky, 1992, p. 312). This can be explained cognitively as a by-product of Exhorter thought, which finds extreme events exciting while finding the expected boring and uninteresting. This expresses itself in the Exhorter person as a tendency to exaggerate, which means focusing upon the extreme aspects of a situation while downplaying the more mundane components.

The third phenomenon is source dependence. The question here is "Does the manner in which people obtain objects affect their valuation of those objects? Specifically, do people value objects differently depending on whether they were obtained by skill or luck, 'legitimately', or 'illegitimately'? From an economic perspective this issue is significant because economic analyses of labor supply and consumption generally assume 'source independence' - that the valuation of an object does not depend on how it was obtained” (Loewenstein, 1994, p. 157). The author found that items acquired through skill are valued more highly than those obtained by chance. This relates to the concept of cognitive ownership, which will be discussed later in the paper. The general principle is that officially owning something is different than actually feeling that one owns something. An internal sense of ownership comes from using a skill to acquire some item. This internal sense is missing when an object is received as a gift or by luck, leading to the feeling that 'this object is not really mine'.

The fourth phenomenon is loss aversion. "One of the basic phenomena of choice under both risk and uncertainty is that losses loom larger than gains” (Tversky, 1992, p. 298). This results from the difference between Exhorter thought and Mercy thought. Exhorter thought finds both pain and pleasure equally motivating because they are both exciting. Mercy thought, in contrast, tries to focus upon what is good while avoiding what is bad. Saying this another way, personal identity can be defined as the set of emotional experiences in Mercy thought that keep coming to mind. As far as Exhorter-Contributor interaction is concerned, a loss is merely an emotional setback in the game of life. But Mercy thought feels this as personal pain-an emotional attack upon personal identity.

The final phenomenon is risk seeking. This effect depends upon relative probability and can be explained as a combination of Exhorter exaggeration and Mercy identity. On the one hand, "People tend to be risk averse over moderate probability gains: they typically prefer a certain gain of $\$ 500$ to a 50 percent chance of $\$ 1,000$. However, people also tend to be risk seeking over losses: they prefer a 50 percent chance of losing $\$ 1,000$ to losing $\$ 500$ for sure” (Barberis, 2013, p. 175). In this case, the two possibilities are fairly similar in magnitude, which means that Mercy feelings will predominate over Exhorter exaggeration. In the positive situation, the certainty means that Mercy thought can treat the potential gain of $\$ 500$ as part of personal identity without having to fear that it might be taken away. In the negative situation, the uncertainty means that Mercy thought does not have to regard the loss as part of personal identity but rather can focus instead upon the possibility of losing nothing rather than being forced to face the pain of certain loss. 
On the other hand, "People like both lotteries and insurance - they prefer a 0.001 chance of $\$ 5,000$ to a certain gain of $\$ 5$, but also prefer a certain loss of $\$ 5$ to a 0.001 chance of losing $\$ 5,000$ ” (Barberis, 2013, p. 177). Exhorter exaggeration will predominate in this case because $\$ 5000$ is so much greater than \$5. In addition, neither gaining \$5 nor losing \$5 will have any significant impact upon personal identity in Mercy thought. In the positive situation, Exhorter thought will be attracted to the excitement of winning $\$ 5000$ while finding the alternative of winning $\$ 5$ to be boring. In the negative situation, Exhorter thought will again find the extreme situation of losing $\$ 5000$ to be exciting. However, in this case the Exhorter attraction will face Mercy thought with a potentially painful situation, motivating concrete technical thought to come up with a solution to this potential problem-hence the tendency to buy insurance in order to protect against potential disaster. This type of behavior was described earlier as contingency planning.

More detailed research into risk aversion provides evidence that response is modified by cognitive style. A study that made 18,000 observations of 448 Swiss and Chinese subjects found that there are "two distinct types of individuals: In all three data sets, the choices of roughly $80 \%$ of the subjects exhibit significant deviations from linear probability weighting, consistent with prospect theory. $20 \%$ of the subjects weight probabilities near linearly and behave essentially as expected value maximizers. Moreover, individuals are cleanly assigned to one type with probabilities close to unity" (Bruhin, 2010, p. 1375). Looking at this cognitively, economic theory describes the way that the typical Contributor (or possibly Facilitator) person calculates value, and one would expect that the majority of economists are Contributor persons. Thus, it makes sense that about $1 / 5$ of the subjects would use typical Contributor thinking. (Study of personality indicates that the cognitive style of Contributor is one of the more common styles.) The fact that individuals can be cleanly assigned to one type or the other indicates that their approach is being determined primarily by thinking style and not by the situation.

Going further, the non-linear group could be subdivided into two categories. "In all three data sets a proportion of approximately $30 \%$ of the subjects display pronounced departures from linear probability weighting, whereas the relative majority of $50 \%$ differ less radically from linear probability weighting” (Bruhin, 2010, p. 1378). The typical Exhorter or Mercy person would tend to be part of the 30\% who 'display pronounced departures from linear probability weighting', while the other cognitive styles would tend to fall into the 'less radical' category.

Cognitive style leads to a tendency rather than a certainty because cognitive style describes consciousness rather than programming. The strategy that is being used depends upon the programming of the mind. This would be heavily influenced by cognitive style but is also affected by environment and upbringing. This cultural effect also showed up in the study, which found that "there are substantial cultural differences in CPT [non-linear] type behavior, the most prominent being the existence of a pronouncedly optimistic group of Chinese subjects who distort small probabilities much more strongly than do the Swiss” (Bruhin, 2010, p. 1411).

Summarizing, the core phenomena of behavioral economics involve an interaction between Mercy processing and the motivational Exhorter side of Exhorter-Contributor interaction. And economic theory agrees. "Kahneman and Tversky emphasize that the transformed probabilities do not represent erroneous beliefs; rather, they are decision weights. In the framework of prospect theory, someone who 
is offered a 0.001 chance of winning $\$ 5,000$ knows exactly what it means for something to have a 0.001 probability of occurring; however, when evaluating the gamble, this person weights the $\$ 5,000$ by more than 0.001" (Barberis, 2013, p. 178). The logical processing in Contributor thought remains unchanged, but the Exhorter motivation is altered.

\section{Supply and Demand}

The supply and demand curve is fundamental to microeconomics. The supply curve slopes up, indicating that suppliers are willing to supply more of a good when the price goes up. The demand curve slopes down, indicating that the demand for some good goes down when the price goes up. Where these two curves meet is the equilibrium point where supply equals demand. This graph was popularized by Alfred Marshall in the textbook Principles of Economics, first published in 1890.

The supply-versus-demand graph is deceptively simple because it is comparing two curves which are cognitively different. The demand curve is an expression of emotions and mental networks. Using economic language, "Demand is fundamentally based on needs and wants-if you have no need or want for something, you won't buy it. While a consumer may be able to differentiate between a need and a want, but from an economist's perspective they are the same thing” (micro, p. 47). Need and want relate to emotions. Supply, in contrast, is determined by the Server skills and Perceiver knowledge of technical thought. "A firm produces goods and services using combinations of labor, materials, and machinery, or what we call inputs or factors of production." Factors of production cannot be emotionally manipulated. One cannot encourage machinery to perform new functions, market material into existence, or exhort labor to perform unlearned skills. In contrast, consumer demand can be emotionally manipulated through marketing and advertising.

One might think that this dichotomy does not apply to entertainment, but I suggest that this preconception reflects the viewpoint of the audience. An audience who is being entertained demands fun, enjoyment, meaning, and excitement, all related to the emotional realm of mental networks. But what is being supplied is technical skill. A performer uses technical thought to perfect some routine before performing 'spontaneously' before an audience. A similar statement can be made about tourism. The typical tourist demands fun, adventure, and exotic experiences. But what is being supplied is technical expertise in the form of transportation, guides, and accommodation.

Thus, plotting supply and demand on the same graph is cognitively like comparing apples and oranges. But these two entities do come together cognitively in the interaction between Exhorter and Contributor thought: Exhorter thought derives its motivation from the emotional needs and wants of Mercy (and Teacher) thought. Contributor thought uses technical thought to satisfy the motivations generated by Exhorter thought. One sees again the fundamental relationship between economics and ExhorterContributor interaction.

Looking at this historically, Alfred Marshall was a British professor who popularized the supplyversus-demand graph during a period of British history that was characterized by an extreme juxtaposition of technical supply and emotional demand. Wikipedia summarizes that "Ideologically, the Victorian era witnessed resistance to the rationalism that defined the Georgian period and an increasing 
turn towards romanticism and even mysticism with regard to religion, social values, and arts. Technologically, this era saw a staggering amount of innovations that proved key to Britain's power and prosperity" ("Victorian Era”, 2021). Thus, it makes cognitive sense that Marshall would place the 'apples and oranges’ of technical supply and emotional demand on a single graph, because Marshall lived in a society in which these two were being juxtaposed. This admixture came into being during the Industrial Revolution, became prominent during the Victorian era, and continues to characterize Western society.

This distinction between technical thought and mental networks is also expressed by the circular flow diagram. "It pictures the economy as consisting of two groups-households and firms - that interact in two markets: the goods and services market in which firms sell and households buy and the labor market in which households sell labor to business firms or other employees” (micro, p. 17). 'Household' refers to the subjective realm occupied by people, which the mind represents as mental networks. 'Firm', in contrast, refers to a corporation that is applying technical thought within some specialization. In the normal supply-and-demand graph, the firm uses technical thought to supply goods and services while the demand of the consumer is determined by mental networks. In the labor supplyand-demand graph, the laborer provides technical knowledge and skill, while the firm responds with the emotional approval of a salary. In both cases, the focus is upon Exhorter-Contributor interaction.

Obviously, a salary is more than just emotional approval. However, I suggest that the final goal of an employee is still ultimately emotional. This can be seen in the concept of job satisfaction. One author summarizes that "The most-used definition of job satisfaction in organizational research is that of Locke (1976), who described job satisfaction as 'a pleasurable or positive emotional state resulting from the appraisal of one’s job or job experiences'... social attitudes are generally weak predictors of specific behaviors, yet job attitudes are generally reliably and moderately strongly related to relevant job behaviors" (Judge, 2008, p. 394). Notice that job satisfaction is described as a 'positive emotional state resulting from appraisal', which is a form of 'emotional approval'. And this emotional approval does have an effect upon job performance. Going further, the concept of a 'dream job' indicates that people want jobs that provide an emotional satisfaction. And even if a job is being done purely for the money, the purpose of earning this money is to be able to use it to avoid personal pain and achieve personal happiness.

A similar intermediate stage can be seen in the goods and services market. A firm may sell its products directly to the consumer or else may produce intermediate goods or services that are used by other firms. For instance, a firm may make electric switches which are then used in electric and electronic products made by other firms. This intermediate interaction remains primarily at the level of technical thought, but the final product is still being sold to consumers who are being driven by emotional demands. This is similar to an employee working at a non-satisfying job in order to make money in order to satisfy emotional demands. The employee is regarding the job primarily as 'a job' in which technical skills are being used as an intermediate step to gaining emotional utility. However, even when intermediate steps remain within the realm of technical thought, research on job satisfaction indicates that some emotional satisfaction is still required. 
Looking more closely at technical factors involved in production, a firm is defined as "an organization that combines inputs of labor, capital, land, and raw or finished component materials to produce outputs" (micro, p. 181). These various inputs are known as the factors of production, and entrepreneurship is often included as one of the factors of production. It was mentioned earlier that Contributor thought controls technical thought and works with a combination of Perceiver facts and Server sequences.

Each of these factors of production involves a combination of facts and sequences. The factor of land includes land and raw materials. The mind normally treats places and objects as Mercy experiences that are organized into different categories by Perceiver thought. But a firm views a plot of land as a location for performing the Server actions of 'combining raw materials to produce outputs'. Similarly, a raw material is being treated as a Perceiver object upon which Server actions will be performed. Labor also requires people who have the skill to perform the required Server actions as well as a knowledge of the appropriate Perceiver facts. Looking, for instance, at pizza making, "Labor means human effort, both physical and mental. The pizzaiolo was the primary example of labor here. He or she needs to be strong enough to roll out the dough and to insert and retrieve the pizza from the oven, but he or she also needs to know how to make the pizza, how long it cooks in the oven and a myriad of other aspects of pizza-making” (micro, p. 159).

Capital means "physical capital, the machines, equipment, and buildings that one uses to produce the product” (micro, p. 159). Related to capital is technology, which "refers to the process or processes for producing the product” (micro, p. 159). Deciphering this cognitively requires looking at machines, which were briefly mentioned at the beginning of this paper. A distinction was made earlier between abstract technical thought and concrete technical thought. The typical Contributor person tends to develop one of these two but not the other. For instance, the 'absent-minded professor' uses abstract technical thought to logically manipulate verbal systems but is impaired when it comes to using concrete technical thought to act within the physical world. Going the other way, the practical expert is skilled at using concrete technical thought while abstract technical thought may be limited to slogans and vague theories.

A machine is an object that can be analyzed using both concrete and abstract technical thought. Concrete technical thought views a machine as an object that generates cause-and-effect. Some raw material goes into the machine and the output is some finished product. Labor can also be treated as a form of machine that transforms input into output. Abstract technical thought views the same machine as an example of Teacher order-within-complexity because many parts are working together in an integrated manner. For instance, the consumer views a car as a tool that can be used to reach some desired location in Mercy thought. A firm also treats a car as a tool but does so in a more rigorous manner guided by concrete technical thought. A mechanic, in contrast, treats the same car as a combination of parts functioning in a harmonious manner. The goal of the mechanic is not to reach some destination in Mercy thought but rather to achieve the Teacher goal of getting all the parts of a car to run together smoothly.

It was mentioned earlier that abstract technical thought uses precise definitions of verbal sequences to manipulate general theories. A machine involves a form of abstract technical thought. But what is being 
precisely defined is not the meaning of some word but rather the shape and material of some part. And instead of placing precisely-defined words within sequences of sentences and paragraphs, preciselydefined parts are being assembled to carry out sequences of actions. For instance, the crankshaft of a car engine performs the action of spinning around, the crankshaft is made out of a well-defined form of metal with well-defined properties, and the shape of a crankshaft is determined to within a fraction of a millimeter.

Precise definitions can also be seen in the use of interchangeable parts, which became widespread in the $19^{\text {th }}$ century. Looking at this in more detail, "The American System of Manufactures was the name given to the novel method of production in the United States that used interchangeable parts as a way to economize on the craft skill necessary to 'fit' components into final goods. To assist this 'assembling' that replaced the more time-consuming and skill-intensive 'fitting' also required the invention and diffusion of specialized machines" (Goodfriend, 2021). Notice how the order-within-complexity of the assembly process is being improved by using interchangeable parts — parts that can all be defined by the same technical meaning. This is also an example of using the precise definitions of abstract technical thought to improve Teacher emotions.

Abstract and concrete technical thought are also combined in science and technology. Science uses the precisely-defined language of mathematics to analyze the laws of nature. Technology translates these precisely-defined verbal theories into machines that move with precision. Going the other way, science uses experiments to perform carefully defined Server actions upon the physical world and then translates these actions into the precisely-defined language of mathematics in order to gain a better understanding of the laws of nature. And the word 'precisely' has been deliberately repeated in order to emphasize that these all involve the precise definitions of abstract technical thought. ${ }^{9}$

Economics recognizes that machines and technology are 'factors of production', but economics itself has no knowledge of either science or technology. Using cognitive language, it was mentioned earlier that technical thought involves an emotional, motivational component coming from Exhorter thought to Contributor thought as well as a rational component involving the interaction between Perceiver facts and Server sequences. This rational component involves machines, science, experiments, and technology. Economics ignores the rational component of technical thought while focusing upon the motivational component. This is again consistent with the thesis that economics describes ExhorterContributor interaction.

Entrepreneurship is often included as one of the factors of production. "Production involves many decisions and much knowledge, even for something as simple as pizza. Who makes those decisions? Ultimately, it is the entrepreneur, the person who creates the business, whose idea it is to combine the inputs to produce the outputs" (micro, p. 160). Summarizing, an entrepreneur turns an idea into a real business by deciding how to combine the factors of production. Using cognitive language, an entrepreneur is driven by some motivation from Exhorter thought, and then uses Contributor choice to combine various aspects of abstract and concrete technical thought that have been developed by other people. In other words, entrepreneurship describes Exhorter-Contributor interaction.

9 Science equates the verbal abstract technical thought of mathematics with the physical abstract technical thought of experimental theory. This paper will be performing a similar equating when looking at macroeconomics. 
A successful entrepreneur will also expand technical thought by acquiring skills and knowledge, but that lies outside of the realm of economics. Instead, economics describes these various technical factors as an outsider while limiting its analysis to Exhorter-Contributor interaction. It should be added that advanced economics uses extensive mathematical analysis, but as far as I can tell, the purpose of this math is not to design machines, understand natural law, or create technology but rather to describe more precisely the interaction between Exhorter and Contributor thought.

The supply-versus-demand graph glosses over another complication, which is that the people who are doing the demanding are not the same as the people who are doing the supplying. This relates to the fundamental principle of a market economy, which is that social well-being can be increased through specialization. Stated cognitively, technical thought can improve Mercy experiences by narrowing down to some specialization and then improving skills, knowledge, and machines within this specialization. However, Mercy thought within each person has a wide variety of needs and desires. The supply-versus-demand graph is adding up total supply and total demand, but these are each coming from different directions. With supply, each worker or firm is producing many copies of a single item. If workers and firms specialize in different areas, then all the workers and firms together can produce many copies of many items. With demand, each consumer requires a few copies of many different items. The combined demand of many consumers leads to a desire for many copies of many items.

This means that delivering products from firms to consumers requires an infrastructure. A physical infrastructure is composed of roads and intersections. Roads enable Server actions while intersections provide Perceiver connections. A mental 'infrastructure' is provided by a mesh of Server sequences and Perceiver facts. This mental 'road system' was mentioned earlier when looking at intuition. The quality of an infrastructure is determined by technical thought. When Adam Smith was writing his seminal work, the only infrastructure that existed was that of physical roads and physical intersections, expanded by canals, shipping routes, and marketplaces. Marshall developed the supply-versus-demand graph during the period of time when British infrastructure was becoming transformed by a web of railroads. Thanks to technology, today's infrastructure includes railroads, air travel, telecommunications, and the Internet. All these infrastructures contain the same essential elements of Server roads combined with Perceiver intersections, or saying this another way, Perceiver hubs connected by Server routes.

This is cognitively significant, because mental symmetry suggests that the mind can function in three basic ways, each controlled by different cognitive modules: mental networks, which involve Mercy and Teacher thought, technical thought, which centers upon Contributor thought, and normal thought, which uses Perceiver facts and Server sequences. Normal thought is less rigorous than technical thought, because it uses analogies and metaphors rather than rigorous logic. But the analogies of normal thought can function like a mental infrastructure that bridges and interconnects the various mental networks and technical specializations within the mind.

Putting this together, the integrated mind is composed of mental networks and technical specializations interconnected by normal thought. Similarly, a market economy is composed of consumers with their mental networks and firms with their technical specializations interconnected by a common infrastructure. A physical infrastructure will only be effective if the technical requirements for using the 
infrastructure are not too high and if mental networks of culture, religion, politics, and personal status do not override the infrastructure. For instance, driving a car requires a driver's license. Getting a driver's license requires some technical skills, but it is much easier than getting a commercial license to drive a truck. Looking at mental networks, a highway system cannot function if some cultural group driven by its mental networks decides to block the highway. Similarly, 'travelling' along the ‘information highway’ of the Internet requires some technical skills, but using a web browser is much easier than writing a computer program. However, the Internet cannot function as an infrastructure of knowledge if cultural groups driven by their mental networks step in to 'cancel' people and viewpoints.

If Perceiver thought is overwhelmed by Mercy emotions, then the infrastructure that connects producer to consumer will break down. That is because an infrastructure requires Perceiver thought, and emotional 'truth' prevents Perceiver thought from functioning. This can be seen, for instance, on the Internet. Instead of exchanging Perceiver facts, people search for others who share similar mental networks of lifestyle, religion, or culture and then interact with these people in a way that reinforces emotional 'truth' (Cinelli, 2021).

\section{Social Surplus}

Economics derives two quantities from a supply-versus-demand graph which are known collectively as social surplus. "The demand curve traces consumers' willingness to pay for different quantities. The amount that individuals would have been willing to pay, minus the amount that they actually paid, is called consumer surplus... The supply curve shows the quantity that firms are willing to supply at each price... The amount that a seller is paid for a good minus the seller's actual cost is called producer surplus... The sum of consumer surplus and producer surplus is social surplus, also referred to as economic surplus or total surplus” (micro, pp. 71 - 72). Notice that producer surplus and consumer surplus are being defined in slightly different ways. Producer surplus is a precise definition involving cost: It is the price paid for a product minus the cost of that product. Both price and cost are monetary values to which numbers can be assigned. Consumer surplus, in contrast, combines money and emotion, because the price that was paid is being subtracted from the emotional term 'willing to pay'. ${ }^{10}$

And we saw earlier when looking at marginal utility that "People cannot really put a numerical value on their level of satisfaction. However, they can, and do, identify what choices would give them more, or less, or the same amount of satisfaction. An indifference curve shows combinations of goods that provide an equal level of utility or satisfaction” (micro, p. 509). Looking at this cognitively, the level of feelings in Mercy thought is not being measured. Instead, the Exhorter motivation of some option is being changed until it leads to a different choice in Contributor thought: 'Would you choose given this alternative? No. Would you choose now? Yes.'

10 A similar ambiguity appears to be present in Marshall's textbook on economics. Consumer surplus is defined using emotions. "The excess of the price which he would be willing to pay rather than go without the thing, over that which he actually does pay, is the economic measure of this surplus satisfaction. It may be called consumer's surplus” (Marshall, 2009, p. 103). Notice the phrase 'willing to pay'. Producer surplus, in contrast, is defined by comparing cost with remuneration. Marshall uses the example of a farmer cultivating land. "Since the return to the dose on the margin of cultivation just remunerates the cultivator, it follows that he will be just remunerated for the whole of his capital and labour by as many times the marginal return as he has applied doses in all. Whatever he gets in excess of this is the surplus produce of the land” (Marshall, 2009, p. 129). 
A similar methodology can be seen in papers on behavioral economics, such as the research of Tversky. "The subject indicated a preference between each of the seven sure outcomes and the risky prospect... We wish to emphasize that although the analysis is based on certainty equivalents, the data consisted of a series of choices between a given prospect and several sure outcomes. Thus, the cash equivalent of a prospect was derived from observed choices, rather than assessed by the subject” (Tversky, 1992, p. 305-6). And a similar methodology was used in the paper on behavioral economics that we related to cognitive style. "The screen displayed a decision sheet containing the specifics of the lottery under consideration and a list of 20 equally spaced certain outcomes, ranging from the lottery's maximum payoff to the lottery's minimum payoff... The subjects had to indicate whether they preferred the lottery or the certain payoff for each row of the decision sheet” (Bruhin, 2010, p. 1383).

Cognitively speaking, an extrapolation is being made from Exhorter-Contributor interaction back to Mercy thought. This can be seen in both the 1979 Kahneman and Tversky paper as well as the Tversky and Kahneman 1992 paper because both attempt to come up with a mathematical representation of utility. In other words, technical thought is attempting to come up with a more precise method of using technical thought to ignore mental networks.

What does it feel like when economics succeeds in using technical thought to model emotional networks? It was mentioned earlier that the mind uses MMNs (Mercy mental networks) to represent people. Personal identity also exists within the mind as a collection of MMNs. Therefore, if people think that the numbers of technical thought are being used to model their MMNs of personal identity, then they will feel as if they are being treated as numbers. Reducing a person to a number is, by definition, dehumanizing.

There is a cognitive reason for this normative statement. Study of personality strongly indicates that humans require a set of core MMNs to exist. The mind does not just uses MMNs to represent humans. MMNs also define the essence of what it means to be human. ${ }^{11}$ The validity of this statement is easy to demonstrate: Those who reduce others to numbers invariably treat themselves as people whose personal feelings must not be reduced to numbers. For instance, the centrally planned economies of communist countries were an extreme example of economically reducing people to numbers. However, party officials who created these central plans shopped in special stores, known as beriozka, that were not subject to the economic constraints of their central plans (Ivanova, 2013).

Saying this another way, it has been suggested that economic supply emphasizes technical thought while economic demand comes from mental networks. Recognizing that demand comes from mental networks can be viewed as an affirmation of humanity - a declaration that people should not be reduced to numbers.

However, personal feelings are increasingly being reduced to numbers in order to shape economic (and political) choices. For instance, the introduction to one book on Marketing Metrics observes that "Marketing may once have been regarded as more an art than a science... Those days, however, are

11 It was suggested earlier that the mind can build around TMNs of general understanding. It is being suggested here that MMNs of personal identity are needed to define humanity. Reconciling these two emotional needs is not trivial, and it appears that many of the fundamental topics of philosophy and religion can be summarized as an attempt to grapple with the relationship between universal understanding in Teacher thought and personal identity in Mercy thought. 
gone. Today, marketers must understand their addressable markets quantitatively. They must measure new opportunities in the investment needed to realize them. Marketers must quantify the value of products, customers, and distribution channels" (Farris, 2010, p. 2).

There are times when human life has to be reduced to a number. For instance, how much money should be spent on treating cancer? This moral predicament is typically addressed by rephrasing the question. "Economic evaluation rephrases the question of how much the life of a cancer patient is worth into the question of how much society is willing to pay per quality-adjusted life year (QALY) of the cancer patient... Such thresholds are used to inform pricing and reimbursement decisions in countries including Australia, Canada, the Netherlands, New-Zealand, Sweden, the United Kingdom and the United States” (Simoens, 2011). It was suggested previously that the economic concept of opportunity cost avoids dealing directly with Mercy feelings of utility. Such emotional avoidance can be emotionally helpful when being forced to apply economic analysis to MMNs of human existence. Looking at this cognitively, asking 'how much of life is worth' attempts to place a monetary value on the existence of some mental network, and a mental network will generate strong negative emotions when its existence is questioned. In contrast, opportunity cost places a monetary volume on the extension of some mental network, which does not feel as threatening.

The previous paragraphs suggest that economic calculations should not replace mental networks of demand. An alternate approach can be seen in the phrase 'the customer is always right'. This recognizes that demand is driven by mental networks, but it also accepts these mental networks without questioning. However, the customer is not always right. Instead, customers are often motivated by childish MMNs. For instance, one study of call centers found that employees experience customer verbal aggression about ten times a day (Grandey, 2004).

A more cynical alternative is to recognize that humans are motivated by childish MMNs and then attempt to manipulate these mental networks in order to achieve some economic (or political) goal. This type of emotional manipulation is also becoming more common, especially on the Internet. "Socalled astroturfing, fake grassroots campaigns and organizations that are created and backed by political actors or businesses, have a long tradition. Astroturfing on the Internet is more problematic than the traditional kind: Digital astroturfing is cheaper, has a greater scope, and is potentially much more effective than regular astroturfing” (Kovic, 2018, p. 70). A 'fake grassroots campaign' creates the illusion of being motivated by mental networks of demand, replacing humanity with a manipulated imitation of humanity.

A more positive alternative has also emerged, known as nudging. Nudging attempts to guide human mental networks, but does so in an open manner. "A principal advantage of nudges, as opposed to mandates and bans, is that they avoid coercion. Even so, they should never take the form of manipulation or trickery. The public should be able to review and scrutinize nudges no less than government actions of any other kind. All over the world, nations have become keenly interested in nudges” (Sunstein, 2014).

Summarizing, the concept of consumer surplus implicitly reduces mental networks of demand to the numbers of technical thought, even though economics explicitly states that this cannot be done. 
Replacing mental networks of humanity with numbers is inherently dehumanizing. But accepting the mental networks of humanity without question can threaten the functioning of a market economy. The remaining option is to recognize human mental networks while also attempting to guide them. This can be done in a secretive and manipulative manner through methods such as astroturfing, or in an open and positive manner through methods such as nudging.

Mental symmetry suggests that the underlying challenge is to reprogram childish MMNs with a more adequate set of core MMNs. That describes the topic of personal transformation, which goes beyond the scope of this paper. ${ }^{12}$ One of the main projects of mental symmetry has been to analyze the path of personal transformation from a cognitive perspective (Friesen, 2015).

When supply and demand do not function efficiently, then economics regards this as deadweight loss, defined more precisely as "The loss in social surplus that occurs when a market produces an inefficient quantity" (micro, p. 75). Mental symmetry suggests an alternate viewpoint. Some market inefficiency can be regarded as deadweight loss, but a substantial portion of what is regarded as deadweight loss can also be viewed as an emotional buffer zone that leaves room for mental networks of humanity.

Mental networks tend to function silently when experiencing compatible input while protesting vigorously when incompatible input is experienced. For instance, those who have never traveled to other cultures tend to assume that they are behaving rationally and not being driven emotionally by MMNs of culture. Cultural mental networks become apparent when one travels to a different culture and realizes at an emotional level that other people do things differently. Applying this principle to the practice of economics, the assumption is that economic principles can be pursued without threatening mental networks of culture and meaning. Thus, each application of economic optimization will be viewed as a benefit to society. But the sum result of applying many steps which are each motivated by the technical thinking of economics will be a society devoid of cultural and personal mental networks. People will wake up and realize that the society that they knew and loved is now gone. Using an analogy, it may be economically profitable for someone to 'sell their grandmother'. But if everyone 'sells their grandmothers' then no one will be able to visit grandmother anymore or eat grandmother's delicious home cooking.

Summarizing, economic thought that optimizes utility can improve societal well-being at a detailed level, but the cumulative impact may be to create an inhuman society. That is because Mercy thought does not just generate emotions of utility. It also forms mental networks and humans need mental networks to exist.

Economic theory does recognize this to some extent. "Some people may choose high-pressure, highpaying jobs so that they can earn and spend considerable amounts of money on themselves. Others may allocate large portions of their earnings to charity or spend it on their friends and family. Others may devote themselves to a career that can require much time, energy, and expertise but does not offer high financial rewards, like being an elementary school teacher or a social worker. Still others may choose a job that does consume much of their time or provide a high level of income, but still leaves time for

12 The idea of cognitive reprogramming has become suspect in today's social climate. However, the basic premise of school is that children are motivated by childish thinking that requires reprogramming. 
family, friends, and contemplation” (micro, p. 39). 'Friends and family', 'school teacher', 'social worker’, and ‘contemplation’ all involve the subjective and personal realm of Mercy mental networks.

And this realization can be seen more practically in nonprofit organizations and charities. Nonprofit organization are included in calculations of GDP. A nonprofit organization attempts to follow principles of economic and managerial efficiency but, by definition, is not supposed to be driven by a profit motive. A report from the John Hopkins Center summarizes that "The 12.3 million paid workers employed by U.S. nonprofit establishments as of 2016 accounted for a substantial 10.2\% of the total U.S. private workforce” (Salaman, 2019, p.3). This is about the same size as the manufacturing industry. Nonprofit organizations in the United States include primarily health care, educational services, and social assistance. Health care assists people physically, education benefits people mentally, while social assistance provides more generic personal help. These share the general trait of treating people as whole beings with personal needs and emotions.

\section{Neuroeconomics}

Mental symmetry analyzes human thought as seven interacting cognitive modules, and these seven cognitive modules can be mapped in detail onto brain regions (Friesen, 2019). This neurological mapping covers all brain regions of higher thought, leading to the conclusion that mental symmetry is a general theory of human intelligence. In addition, the function of these brain regions can be discussed in some detail when mapping mental symmetry onto neurology, implying that mental symmetry is an accurate model of human intelligence and not just a vague overview. ${ }^{13}$

Neuroeconomics looks at the brain regions that are involved in economic activity. A recent review paper entitled Over a Decade of Neuroeconomics: What Have We Learned? observes that most neuroeconomic papers focus upon a specific region of the brain. "Open up an article on neuroeconomics, and you are most likely to see mention of the ventromedial prefrontal cortex (vmPFC) or the striatum (or the encompassing basal ganglia or subregions: caudate, putamen, and nucleus accumbens). Activity in these regions is present in nearly every study of economic choice and thus certainly plays a key role in decision making” (Konovalov, 2019, p. 150). This focus upon a limited region of the brain is consistent with the suggestion made earlier that economics provides a narrow definition of 'rational thought'.

The nomenclature in neurology can be confusing, especially when dealing with this region of the brain. This section will be discussing four regions of the brain: 1) the orbitofrontal cortex (OFC), which is part of the ventromedial prefrontal cortex (vmPFC); 2) the anterior cingulate cortex (ACC), which lies just above the vmPFC; 3) the ventral striatum (VS), which contains primarily the nucleus accumbens (NAcc or NAc); and 4) the striatum, which includes caudate and putamen. We will also be referring to dopamine (DA).

13 Mental symmetry sidesteps the question of mind versus brain. Neurology obviously studies the brain, while searching for cognitive mechanisms focuses upon the mind. If the mind maps in detail onto the brain, then it is possible to combine cognitive and psychological research on the mind with neurological research on the brain without having to define precisely what is mind and what is brain. 
Going further, it has been suggested several times that economics ignores the content of thought while focusing upon Exhorter-Contributor interaction. The review paper makes a similar statement. "Neuroeconomists have perhaps struggled to have an impact on mainstream economics because they have wrongly assumed that economists care to open the black box of the brain when in reality, economists are only interested in predicting behavior from observable features of the environment. From that viewpoint, the only use for psychological and neuroscience data is to provide inspiration for additions (sometimes called rationalizations) to choice models” (Konovalov, 2019, p. 149). Stated bluntly, economists are not interested in exploring what it really means to be rational (while at the same time referring to economic thought as 'rational'). Instead, they are only interested in finding intuitive 'inspiration' for 'choice models' that focus upon how Contributor thought chooses between Exhorter motivations. This is consistent with the suggestion made earlier regarding the imprisoning effect of a paradigm.

We saw when looking at behavioral economics that prospect theory is still regarded as "the best available description of how people evaluate risk in experimental setting” even though it was developed back in the 1970s (Barberis, 2013, p. 173). This is not the case with neurological research, because knowledge of brain functioning has exploded in recent years. Our analysis will begin with a 2019 paper by Rolls that provides a good summary of how the brain calculates value.

The orbitofrontal cortex involves Mercy thought with its emotional experiences and its mental networks. "The orbitofrontal cortex represents the reward value of stimuli. It is in a sense an output region for all the sensory systems, including taste, olfaction, visual, auditory, and somatosensory, that represents 'what' a stimulus is, and uses that information to build what are frequently multimodal representations but in value space rather than in 'what' or stimulus identity space. Orbitofrontal cortex neurons focus on reward value representations for stimuli and know little about actions” (Rolls, 2019, p. 4). Summarizing, the orbitofrontal region is a 'multimodal' area that adds an emotional label to all kinds of experiences, regardless of how these experiences were acquired. This describes Mercy thought. This region focuses upon the emotional labels of experiences and 'knows little about actions', also consistent with Mercy thought.

\section{Anterior Cingulate Cortex}

The anterior cingulate cortex (ACC) translates Mercy emotions into the Contributor language of cost and benefit. "The orbitofrontal cortex sends inputs to the ACC about the value of stimuli, that is, about goals including the value of outcomes (the reward received) and the expected value. The ACC in combination with the midcingulate motor area, which contains representations of actions, interfaces actions to outcomes (rewards or punishers received) using action-outcome learning, and also takes into account the cost of actions to obtain the goal when selecting actions” (Rolls, 2019, p. 4). Summarizing, the orbitofrontal cortex attaches emotional labels to both memories and goals. This value information is sent to the anterior cingulate cortex, which interprets it in terms of cause-and-effect.

What the anterior cingulate precisely does is still somewhat uncertain, but the various interpretations all describe aspects of Contributor thought as well as distinguishing between Contributor and Mercy thought. One paper talks about choice - a fundamental trait of Contributor thought. The "vmPFC 
weighs attribute evidence by the reward it predicts and dACC weighs it by its attentional priority (i.e., the degree to which that attribute drives choice)” (Shenhav, 2018, p. 2). (dACC refers to dorsal anterior cingulate cortex.)

Another paper refers to 'choice difficulty', which relates to the concept of Contributor confidence that was discussed earlier. "We found that activity in vmPFC was related to the subjective valuation of prospective effort, while ACC activity was best described by choice difficulty. These results suggest that vmPFC encodes the subjective costs that underlie choices involving physical effort, and ACC activity is related to the cognitive control required at the time of choice.” (Hogan, 2019, p. 4287).

A more comprehensive viewpoint looks more generally at the Contributor choices and Contributor confidence required to carry out some plan. "The dorsal anterior cingulate cortex (dACC)... has been implicated in a diversity of functions, from reward processing and performance monitoring to the execution of control and action selection... We present a normative model of EVC [expected value of control] that integrates three critical factors: the expected payoff from a controlled process, the amount of control that must be invested to achieve that payoff, and the cost in terms of cognitive effort. We propose that dACC integrates this information, using it to determine whether, where and how much control to allocate” (Shenhav, 2013, p. 217).

Interpreting this cognitively, concrete technical thought thinks in terms of cause-and-effect, and a plan can be viewed as a series of steps involving cause-and-effect. Carrying out a plan usually includes using Contributor thought to choose steps that Exhorter does not regard as the most exciting. For instance, the plan of eating a meal may include the step of eating vegetables as well as enjoying dessert. 'Expected value of control' describes the level of Contributor choice and effort that is required to implement some plan.

The concept of Contributor confidence is backed up by a study that electrically stimulated the cingulate cortex of two humans undergoing surgery for epilepsy. "Electrical charge delivery in the anterior midcingulate cortex (aMCC) elicits autonomic changes and the expectation of an imminent challenge coupled with a determined attitude to overcome it" (Parvizi, 2013, p. 1). One patient said that "It was more of a positive thing like ... push harder, push harder, push harder to try and get through this”, While the others patient "recounted feeling worried and anxious about something negative that was going to happen, but simultaneously knowing that he had to fight to make it through and not give up" (p. 3). This precisely describes Contributor confidence.

A high level of Contributor confidence is required when dealing with significant issues. But Contributor confidence also appears to be required when handling trivial matters. A study that looked at activity in the anterior cingulate cortex found "that anxiety and its neural correlates demonstrate a Ushaped function of choice set value, greatest when choosing between both the highest value and lowest value sets. Intermediate (moderate-value) choice sets provoke the least anxiety, even when they are just as difficult to select between as the choice sets at the two extremes. We show that these counterintuitive findings are accounted for by decision makers perceiving low-value items as aversive... rather than simply unrewarding. Importantly, though, neural signatures of these anxious reactions only appear when participants are required to choose one item from a set and not when simply appraising that set's 
overall value” (Shenhav, 2018a, p. 1892). Notice that this response only happened when making choices, indicating that one is dealing with Contributor thought. Consistent with this, our study of personality found that the Contributor person dislikes 'small talk' and may go to extensive length to avoid trivial conversations. However, the typical Contributor person also finds it difficult to discuss deeply emotional topics. Looking at this more generally, economics itself can be viewed as a study of 'intermediate choice sets'. On the one hand, economics deals with the important topic of money and economic choice. But on the other hand, choices of deep emotional significance are avoided.

Economic marginal analysis emphasizes that the optimal result is reached at a point of indifferencewhen the various Exhorter urges from competing options balance out. Looking at this neurologically, "Information about both costs and benefits are represented in the ACC proper during offer valuation. Moreover, the EVC account also predicts increased dACC involvement when decisions are more difficult. Our data confirm this prediction by showing that there is higher dACC activity when participants decide between offers that were close in value versus when offers were far apart" (Westbrook, 2019, p. 3945). This quote appears to be equating two effects which mental symmetry suggests may be distinct. When competing alternatives from Exhorter are close in value, then Contributor calculations of cause-and-effect become active, as shown by increased anterior cingulate activity. However, the assumption is that this equates to 'a more difficult decision' requiring greater Contributor confidence. In contrast, the previous paragraph suggests that Contributor confidence is related to anxiety, which is highest when dealing with either significant or trivial matters.

Summarizing, I suggest that having to use Contributor thought to choose between similar options is distinct from the Contributor confidence that is required to make such a choice.

Economics uses the common currency of price to compare many different items. "In neuroeconomics, the 'common currency' account suggests diverse incentives are represented in a common neural representation that enables incentives to be compared, combined, and selected under decision-making contexts" (Yee, 2021, p. 4). Yee "found evidence of an incentive integration neural mechanism present in the dACC, but not in other brain regions classically associated with representing the neural common currency of subjective value” (p. 30). The author explains why Mercy thought in the vmPFC was not activated. "Because our task paradigm is optimized for motivated cognitive control, it is unsurprising that only dACC appeared to encode the incentive condition effects on reward rate. These results are consistent with prior work demonstrating that cost-benefit valuation in physical effort tasks elicit activation in dACC, but not vmPFC" (p. 31). Summarizing, Mercy thought compares the emotional labels of various experiences and situations. Contributor thought, in contrast, compares the cost-benefit of various Perceiver-Server cause-and-effects.

\section{Ventral Striatum}

The anterior cingulate cortex moves from Mercy emotions to Contributor cost/benefit. The ventral striatum moves from Mercy emotions to Exhorter motivation. A recent human imaging study looked at the connections of the orbitofrontal cortex (OFC). As expected, "The medial OFC has direct connections with the anterior cingulate cortex... consistent with the hypotheses that the OFC computes reward value and thereby is related to emotion and that the anterior cingulate cortex provides a route to 
goal-related actions” (Hsu, 2020, p. 5838-9). But, in addition, the "ventromedial prefrontal cortex shares with the medial OFC especially strong outputs to the nucleus accumbens and olfactory tubercle, which comprise the ventral striatum” (p. 5839).

Turning now to the function of the ventral striatum, "A main function of the NAc is to bias the direction and/or intensity of behavior, thereby increasing the likelihood that certain actions are committed. This function is likely mediated through output pathways from the NAc that ultimately feed into motor systems and nudge behavior in certain directions” (Floresco, 2015, p. 34 - 35). This is consistent with the suggestion that Exhorter thought pushes Contributor thought to go in a certain direction.

The neurological distinction between 'liking' and 'wanting' was first described by Berridge, who discovered that dopamine is related to 'wanting' and not 'liking'. Using cognitive language, dopamine is related to Exhorter motivation and not Mercy emotions. "What dopamine loss actually seemed to do was to selectively abolish 'wanting' for the reward while leaving its liking intact. Subsequent brain studies confirmed that increasing dopamine also did not enhance pleasure 'liking', though extra dopamine boosted wanting” (Berridge, 2019, p. 186).

It has been suggested that Exhorter thought finds motivation in both pleasant and unpleasant experiences. Berridge associates this dual response with dopamine and the nucleus accumbens. "The nucleus accumbens, with its dopamine input projections, is famously identified with appetitive functions of 'wanting', 'liking', and learning about rewards. Yet... nucleus accumbens neurons and their dopamine inputs can also reversibly generate negative valence in the form of actively coping 'fear' reactions, in which perceived threatening stimuli are defended against with antipredator reactions, frantic escape attempts, or reactive aggression” (Berridge, 2019, p. 192).

We saw earlier that the anterior cingulate uses a 'common currency' based in cause-and-effect. The ventral striatum also appears to use a 'common currency', but that currency is described as being related to emotion and motivation. "Hedonic goods are goods that people buy to obtain emotional experiences, such as joy or excitement, while utilitarian goods are bought to meet functional or instrumental needs... the value of both hedonic and utilitarian goods is commonly represented in the ventral striatum, and indicate that the value construct underlying consumer purchases is unidimensional” (Motoki, 2019, p. 1).

Looking at this cognitively, it was suggested earlier that a supply-and-demand graph is comparing two dissimilar items, because demand is being guided by mental networks whereas supply involves technical thought. Consistent with this juxtaposition, two types of common currency can be seen in the brain. The demand of a consumer is being motivated by a 'common currency' related to need and excitement generated within the ventral striatum. In contrast, the supply of a firm is being motivated by a 'common currency' of cause-and-effect being calculated within the anterior cingulate cortex.

Contributor confidence is related to the control that is required to keep some plan or process on-track. 'Flow' describes a similar channeling of attention happening from the perspective of Exhorter motivation, which one paper defines as the "the subjective experience of engaging just-manageable challenges by tackling a series of goals, continuously processing feedback about progress, and 
adjusting action based on this feedback” (Di Domenico, 2017, p. 5). This relates to the concept mentioned earlier that a minimum of Contributor confidence is required when dealing with intermediate-level goals. Flow follows a plan at the intermediate level of moderate challenge where the minimum level of Contributor confidence is required. Speaking from personal experience, I find that my feeling of flow is typically broken when a challenge is encountered that exceeds my threshold of difficulty.

Flow also optimizes the balance between Contributor confidence and Exhorter novelty. "Intrinsic motivation researchers have long noted that whereas too much novelty relative to a person's skill and knowledge produces anxiety, too little novelty produces boredom. During intrinsic motivation, feelings of interest and positive excitement predominate over both anxiety and boredom” (Di Domenico, 2017, p. 3).

This paper continues by saying that flow has been described by other researchers as a "seeking system [which] is a spontaneous, unconditioned behavior generator that takes animals to places, actively and inquisitively, where associated learning mechanisms allow them to develop knowledge structures" and "The core structures that comprise the seeking system in the rat are the ventral tegmental area (VTA), the nucleus accumbens (NAcc), the ventromedial prefrontal cortex (VMPFC), and the dopaminergic projections originating from the VTA that innervate these areas” (Di Domenico, 2017, p. 4). Thus, flow is related neurologically to the brain regions involved in the interaction between Mercy thought and Exhorter motivation. ${ }^{14}$

Summarizing, a plan can be implemented either by ensuring that Contributor thought has sufficient confidence to be able to make the required choices or by ensuring that Exhorter thought has sufficient motivation to maintain attention. Carrying out the typical plan probably involves some combination of these two cognitive mechanisms. The method that is described by economic theory appears to correspond more to Exhorter flow than to Contributor confidence. That is why I referred to economic optimization earlier as a form of semi-passive Contributor thought. Contributor thought is functioning and is making choices, but it is also functioning in a manner that requires a minimum of Contributor confidence. However, investor confidence is also mentioned frequently in the context of the economy.

\section{Basal Ganglia}

Exhorter-Contributor interaction comes together in the basal ganglia. The basal ganglia are quite complicated and their relationship with Exhorter thought and Contributor thought is discussed in another paper (Friesen, 2019). This paper will focus on some highlights.

The anterior cingulate projects strongly to the striatum (the striatum include the caudate and putamen and are part of the basal ganglia). "Projections from the dACC to the striatum are extensive and stretch from its rostral pole to the anterior commissure. Terminals are located in both the central caudate nucleus and putamen” (Haber, 2016, p. 13). Looking at this in more detail, "There is a region within the rostral, anterior striatum that receives projections from across the prefrontal cortical regions, including

14 It is possible that the 'seeking system' is also being driven by Teacher emotions, because exploring some region leads to Teacher emotions of order-within-complexity. However, one is still dealing with a flow that involves emotions and motivation, and we will see later that Teacher emotion is also generated within the orbitofrontal cortex. 
the vmPFC, OFC, dACC, and dorsal and lateral PFC... This rostral striatal region may serve as a hub for vmPFC, OFC, and dACC to connect with dorsal and lateral PFC regions that integrate motivational, reward, and cognitive control information” (p. 15). ${ }^{15}$ Summarizing, neurological connections strongly suggest that Mercy feelings of value are combining with a Contributor sense of cause-and-effect within the striatum.

The ventral striatum (VS) influences this striatal processing largely through dopamine. "The VS influences a wide range of DA neurons, but is itself influenced by a relatively limited group of DA cells... Through this spiral of inputs and outputs between the striatum and midbrain DA neurons, information can flow from limbic to cognitive to motor circuits, providing a mechanism by which motivation and cognition can influence motor decision-making processes and appropriate responses to environmental cues" (Haber, 2016, p. 17). Notice again the flow of information from limbic (shorthand for emotional memories) through the cognition of economic thought to the actions of motor circuits. This summarizes the goal-oriented behavior that is carried out by concrete technical thought.

The goal-oriented thinking of the basal ganglia can be disrupted in two primary ways: First, normal cost-benefit thinking may be overturned by stress and strong emotions. "Chronic stress exposure in rodents produces abnormal evaluation of costs and benefits resembling non-optimal decision-making in which choices of high-cost/high-reward options are sharply increased. Concomitantly, alterations in the task-related spike activity of medial prefrontal neurons correspond with increased activity of their striosome-predominant striatal projection neuron targets (Friedman, 2017, p. 1191). In other words, the normal rational thinking of economic evaluation can break down under stress causing extreme alternatives to be pursued. The striosomes are subregions within the striatum that, among other things, maintain the balance of dopamine in the basal ganglia. (Shumilov, 2018).

Second, repetition can cause the goal-oriented behavior of the basal ganglia to degrade into habitual actions. "Although instrumental behavior, in which voluntary actions are performed to cause a particular outcome, may start out goal directed, with repeated practice behavioral control can shift to the more automatic, habitual system to perform the exact same behavior” (Malvaez, 2020, p. 2).

Maintaining goal-oriented behavior requires emotional input from Mercy thought. "OFC projections specifically to the DMS are vital for goal-directed control. Inhibiting the activity of OFC terminals in the DMS prevents goal-directed learning and forces reliance on the habit strategy, even in the training context where the goal-directed strategy should dominate" (Malvaez, 2020, p. 3). (DMS is dorsomedial striatum and is the rodent equivalent to the human caudate, which is part of the striatum.) Notice that the absence of Mercy emotions from the orbitofrontal cortex is causing habitual behavior to emerge.

Applying these two points to economics, neurological evidence is suggesting that the goal-oriented behavior of economic thought functions best at intermediate emotional levels. If emotions are too high, then the resulting stress will cause cost-benefit calculations to be replaced by a focus upon extreme solutions. Cognitively speaking, this suggests that Contributor confidence is being overwhelmed and

15 The dorsal and lateral prefrontal cortex have not been discussed in this paper, but evidence suggests that they relate to Perceiver and Server thought. Projections from this cortical region would allow Perceiver and Server content to affect Exhorter-Contributor interaction. 
being replaced by an Exhorter fixation upon extreme emotions. ${ }^{16}$ Going the other way, if emotions are too low, then goal-oriented behavior will be replaced by habits that continue regardless of economic utility. This implies that Contributor cause-and-effect finds 'low value items as aversive' not because they are physically or mentally threatening, but rather because they threaten Contributor thought by eliminating the need for goal-oriented behavior.

These two disruptions to goal-oriented behavior combine in addiction. Becoming addicted involves the 'wanting' of Exhorter thought, expressed through dopamine and the ventral striatum. "All addictive drugs are positively reinforcing. Acquisition of this instrumental behaviour requires DA signalling in the mesolimbic pathway, particularly by neurons of the ventral tegmental area (VTA) that project to the medial shell of the nucleus accumbens (NAc; part of the ventral striatum)” (Lüscher, 2020, p. 247). Addiction eventually turns habitual. "Burgeoning evidence suggests that addiction to drugs is associated with a general bias to a habitual mode of behaviour, as distinct from goal-directed behaviour" (p. 247). And addiction promotes extreme behavior. "In severe addiction, individuals spend much time and effort in procuring drugs for subsequent use that may not be in rich supply or immediately available, despite considerable risk of personal, physical and social harm. Such compulsive drug seeking, despite adverse or negative consequences, occurs in the absence of the drug” (p. 247).

This surface look at addiction is glossing over many details, but the primary point is that economic goal-oriented behavior is being threatened from the two directions of emotional stress and habitual behavior. Using economic language, a 'demand' is coming from irresistible Exhorter urges that Contributor thought is powerless to suppress, while the 'supply' is being provided by unchangeable habits that Contributor thought lacks the power to alter.

\section{Teacher Emotion}

We have looked at microeconomics and have interpreted it in terms of concrete technical thought being driven primarily by Mercy emotions of utility. The focus of this paper will now shift to macroeconomics and abstract technical thought and its relationship to Teacher emotion. Before discussing Teacher emotion, a more basic question needs to be addressed: Does Teacher emotion exist? Evidence indicates that the answer is yes, but not automatically.

Historically speaking, Teacher emotion has been recognized in the form of beauty. The Stanford Encyclopedia of Philosophy summarizes that "The classical conception is that beauty consists of an arrangement of integral parts into a coherent whole, according to proportion, harmony, symmetry, and similar notions. This is a primordial Western conception of beauty, and is embodied in classical and neo-classical architecture, sculpture, literature, and music wherever they appear” (Sartwell, 2017). The 'arrangement of integral parts into a coherent whole' refers to order-within-complexity, which we have described as Teacher emotion.

Quoting further from this encyclopedia article, “Aquinas, in a typically Aristotelian pluralist formulation, says that 'There are three requirements for beauty. Firstly, integrity or perfection—for if

16 This also suggests that the stress aspect of Contributor confidence may be happening within the striatum rather than the anterior cingulate. However, that is a detail which does not affect the general concept of Contributor confidence. 
something is impaired it is ugly. Then there is due proportion or consonance. And also clarity: whence things that are brightly coloured are called beautiful'” (Sartwell, 2017). 'Perfection' describes the natural tendency for Teacher thought to come up with a theory that defines the simplified essence of some entity and then eliminate anything that is an exception to the general rule. 'Proportion' refers to order-within-complexity. And 'clarity' relates to the precise definitions of abstract technical thought, which are guided by the Teacher emotions of various paradigms.

A clear reference to order-within-complexity can also be seen in Hutcheson's definition of beauty. "Francis Hutcheson in the eighteenth century gives what may well be the clearest expression of the view: 'What we call Beautiful in Objects, to speak in the Mathematical Style, seems to be in a compound Ratio of Uniformity and Variety; so that where the Uniformity of Bodys is equal, the Beauty is as the Variety; and where the Variety is equal, the Beauty is as the Uniformity”' (Sartwell, 2017). Hutcheson's language makes it clear that an emotion is being described, because he "rapturously praises nature, with its massive complexity underlain by universal physical laws as revealed, for example, by Newton. There is beauty, he says, 'In the Knowledge of some great Principles, or universal Forces, from which innumerable Effects do flow. Such is Gravitation, in Sir Isaac Newton's Scheme”, (Sartwell, 2017).

This final quote relates beauty to mathematics and the general laws of nature. This supports the idea that the mental strategy-Teacher thought—-that comes up with general theories is using emotions to evaluate these theories. The reference to mathematics also emphasizes the relationship between words, Teacher thought, and abstract technical thought. That is because mathematics constructs its general theories out of precisely-defined words and written symbols.

I have quoted the Stanford Encyclopedia entry on beauty rather than the original authors because I want to make it clear that scholars today are still aware of the idea that there is an emotion based in orderwithin-complexity.

Turning now to neurology, we saw earlier that the orbitofrontal cortex generates Mercy emotions of value. ${ }^{17}$ The orbitofrontal cortex also generates Teacher emotions of beauty. "Brain imaging studies exploring the neurobiology of beauty have shown that the experience of visual, musical, and moral beauty all correlate with activity in a specific part of the emotional brain, field A1 of the medial orbitofrontal cortex" (Zeki, 2014, p. 1). Notice that several kinds of beauty are all activating the same emotional region, consistent with the suggestion that Teacher thought comes up with general theories that apply to many kinds of specific experiences.

Going further, mathematical beauty also activates this region. "The experience of mathematical beauty correlates parametrically with activity in the same part of the emotional brain, namely field A1 of the medial orbito-frontal cortex (mOFC), as the experience of beauty derived from other sources” (Zeki, 2014, p. 1). Thus, there is solid evidence connecting Teacher emotion with the orbitofrontal cortex.

However, as Zeki points out in another paper, mathematical beauty has unusual properties. It triggers the same part of the brain as other forms of beauty even though it is an artificial emotion that has to be

17 Technically speaking, the amygdala is the emotional processor, while longer-term emotional labels are being stored within the orbitofrontal cortex. 
taught to be appreciated. "Unlike visual or musical beauty, only those versed in mathematics can experience the beauty of mathematical formulations. And yet the experience of mathematical beauty correlates with activity in the same part of the emotional brain as the experience of beauty derived from sensory sources, such as the visual or the musical” (Zeki, 2018, p. 1).

And even though mathematical beauty is an artificial emotion that has to be learned, all mathematicians share similar concepts of mathematical beauty. "Those not versed in the language of mathematics cannot experience the beauty of a mathematical formulation. And yet, once the language of mathematics is mastered, the same formulae can be experienced as beautiful by mathematicians belonging to different races and cultures” (Zeki, 2018, p. 7). This is consistent with statements made earlier when looking at Piaget's four cognitive stages. Physical experiences of pain and pleasure teach the infant mind about Mercy emotions during the first sensorimotor stage. But the developing mind only becomes capable of fully appreciating Teacher emotion in the fourth formal operational stage.

This neurological finding provides an alternative to postmodern questioning. Postmodernism insists that all apparent general theories are merely propaganda posing as general understanding; in other words, all Teacher theories are merely verbal statements backed up by Mercy emotions of personal status. Or in the words of Wikipedia, "Postmodernism is generally defined by an attitude of skepticism, irony, or rejection toward what it describes as the grand narratives and ideologies associated with modernism, often criticizing Enlightenment rationality and focusing on the role of ideology in maintaining political or economic power” (“Postmodernism”, 2021).

Mental symmetry, in contrast, suggests that Teacher emotion is an acquired taste. Teacher emotions are cognitively natural; the brain does generate feelings of beauty. But Teacher emotions have to be taught; a person has to learn the order-within-complexity of some subject before the brain will generate feelings of beauty.

It should be clarified in passing why the definition of postmodernism was taken from Wikipedia and not from a more rigorous source. Postmodernism rejects precise definitions as well as Teacher theories. Therefore, it is difficult to find a precise definition of postmodernism in an academic source. Cognitively speaking, this is a contradiction in terms, because a mode of thinking that requires precise definitions is being prevented from using precise definitions. For instance, the Stanford Encyclopedia of Philosophy article begins with the sentence "That postmodernism is indefinable is a truism" (Aylesworth, 2015). Therefore, one has to turn to a semi-rigorous source such as Wikipedia to find a precise definition of postmodernism. Looking at this cognitively, if postmodernism is consistently using cognitive modules in a certain manner, then it is possible to give a precise cognitive definition of postmodernism, which is what Wikipedia is essentially doing.

\section{Four Kinds of Economy}

Our examination of macroeconomics will be introduced by discussing a topic within microeconomics that requires an understanding of Teacher emotion in order to be analyzed adequately. 
Economics refers to four different kinds of economies: perfect competition, monopolistic competition, oligopoly, and monopoly. This spectrum can be explained cognitively as a shift from Mercy emotions to Teacher emotions.

Looking at this in more detail, "Firms are in perfect competition when the following conditions occur: (1) many firms produce identical products; (2) many buyers are available to buy the product, and many sellers are available to sell the product; (3) sellers and buyers have all relevant information to make rational decisions about the product that they are buying and selling; and (4) firms can enter and leave the market without any restrictions" (micro, p. 188). Identical products mean that there is no product differentiation. This means cognitively that Perceiver facts and Server sequences can be ignored, because the items look the same and behave the same. Many buyers and sellers mean that an adequate physical infrastructure of Server roads and Perceiver intersections can be assumed. Relevant information means that an adequate internal network of Perceiver facts and Server sequences can be assumed. Finally, entering and leaving without restriction means that Contributor thought can make choices without having to worry about inadequate Contributor confidence. What is left is pure Exhorter-Contributor interaction.

In addition, "A perfectly competitive firm is known as a price taker, because the pressure of competing firms forces it to accept the prevailing equilibrium price in the market” (micro, p. 188). Basic economic theory says that prices are set by the intersection between supply and demand. Supply is determined by the content of the technical thought that is required to produce a good or service, while demand is an expression of the mental networks that motivate purchases. Being a price taker means that other entities are determining both the content of technical thought and the nature of mental networks. Cognitively speaking, economics is recognizing that pure Exhorter-Contributor interaction is actually driven by other cognitive strategies.

Perfect competition leads to a kind of interaction between Exhorter and Contributor thought that was described earlier as 'flow'. "When profit-maximizing firms in perfectly competitive markets combine with utility-maximizing consumers, something remarkable happens: the resulting quantities of outputs of goods and services demonstrate both productive and allocative efficiency” (micro, p. 206). Notice how this is being described in emotional terms as 'something remarkable'.

The economic flow of a perfectly competitive market optimizes Contributor cause-and-effect. "Productive efficiency means producing without waste... firms produce and sell goods at the lowest possible average cost” (micro, p. 206). 'Producing without waste' suggests that economic plans are being fully channeled using Contributor confidence (within the anterior cingulate cortex). 'Producing and selling at the lowest average cost' implies that Contributor thought is achieving optimal costbenefit results (also within the anterior cingulate cortex).

In addition, Exhorter motivation (within the ventral striatum) is also being optimized. "Allocative efficiency is defined as "when the mix of goods produced represents the mix that society most desires" (micro, p. 42). 'Desire' relates to 'wanting', and we saw earlier that 'wanting' is a basic function of dopamine and Exhorter thought. 
This optimal point is reached when marginal revenue equals marginal cost. We saw earlier that both of these quantities are local changes that can be calculated within the current context. Stated neurologically, marginal revenue and marginal cost can be calculated within the anterior cingulate cortex without having to defer to other regions of the brain. This does not mean that the rest of the brain is not functioning, but rather that Contributor cause-and-effect can remain the dominant strategy.

However, economic theory recognizes that "Perfect competition, in the long run, is a hypothetical benchmark... Real-world markets include many issues that are assumed away in the model of perfect competition... However, the theoretical efficiency of perfect competition does provide a useful benchmark for comparing the issues that arise from these real-world problems” (micro, p. 207). Summarizing, perfect competition is a 'hypothetical benchmark' that 'assumes away' most of the content of human thought and behavior. But it provides a 'useful benchmark' because it describes the ideal form of Exhorter-Contributor interaction-which is 'flow'.

Perfect competition is a hypothetical ideal. In contrast, "Most of the markets that consumers encounter at the retail level are monopolistically competitive" (micro, p. 236). And "Monopolistic competition is probably the single most common market structure in the U.S. economy” (micro, p. 249). In summary, "Monopolistic competition refers to an industry that has more than a few firms, each offering a product which, from the consumer's perspective, is different from its competitors” (micro, p. 238). Notice the key phrase 'from the consumer's perspective'. This means that a product does not really have to be different. Instead, it is sufficient for consumers to believe that the product is different.

This distinction was examined earlier when looking at product differentiation. It was mentioned there that Perceiver thought can acquire certainty in two ways: Perceiver thought can gain confidence by noticing that connections are repeated. And Perceiver thought can also be overwhelmed by emotional pressure (primarily from Mercy thought) into 'knowing' that some fact is 'true'.

Looking at an example of the second option of emotional 'knowing', it was mentioned earlier that "Many people could not tell the difference in taste between common varieties of ketchup or mayonnaise if they were blindfolded but, because of past habits and advertising, they have strong preferences for certain brands. Advertising can play a role in shaping these intangible preferences” (micro, p. 237). Notice that Perceiver thought is unable to distinguish the competing products in any factual manner. Instead, factual differentiation is being driven emotionally by 'strong preferences', which are being shaped by advertising. This describes 'knowing' that comes from emotional pressure. Notice that habit is also mentioned in this quote.

These two factors relate to the discussion on the basal ganglia, because we saw that goal-oriented behavior can be emotionally hijacked or it can degrade into habit. This implies that there is often a cognitive contrast between the supplier and the consumer. The supplier is using goal-oriented behavior to optimize sales, but the supplier is increasing sales by using marketing strategies that mentally hijack goal-oriented behavior in the consumer through emotional pressure and habit.

Turning now to the first option of factual knowing, it is also possible for Perceiver facts to be modified by Teacher emotions. This is described using the example of golf balls. "Balls do differ in various ways, such as the pattern of dimples on the ball, the types of plastic on the cover and in the cores, and 
other factors... large companies have a powerful incentive to persuade players that golf balls are highly differentiated and that it makes a huge difference which one you choose... [but] most golf balls are pretty much indistinguishable” (micro, p. 239). In this case, actual physical differences exist that can be determined by Perceiver thought, such as 'patterns of dimples' or 'types of plastic'.

The emotional manipulation here is happening at the level of relative importance. Teacher emotion comes from generality, and Teacher thought comes up with a general theory by taking some general statement or concept and regarding it as more general than other statements. In this example, Teacher generality is showing up in the size of the verbal source, because 'large companies' are making verbal claims. A claim is being regarded as emotionally significant because it comes from a company that has great Teacher order-within-complexity. Teacher generality is also showing up in the significance of the statement, because the impression is being conveyed that 'it makes a huge difference which one you choose'. Thus, a Perceiver distinction such as 'dimples on the ball' is being emotionally inflated to the level of a general theory; instead of being merely a characteristic of a golf ball, it is being treated as a fundamental statement that defines the essence of the golf ball.

Summarizing, emotional manipulation can function at a blatant level by using Mercy status to overwhelm Perceiver thought. For instance, 'Our shampoo is excellent because this famous sports star endorses it'. But emotional manipulation can function at a more subtle level by using Teacher thought to emotionally inflate Perceiver facts. For instance, 'The dimples on our golf balls will make a huge difference'. The first method ignores the facts and prevents Perceiver thought from functioning, while the second method acknowledges the facts but presents them in a biased manner.

It appears that emotional bias is impossible to avoid. Finite minds are incapable of evaluating all the facts and must cope by emphasizing certain facts while downplaying other facts. If emotional bias cannot be avoided, then the best alternative is to be emotionally biased by a general Teacher theory that is consistent with 'how things work', because the mind will then be emotionally biased in the direction of the facts of reality. For instance, this paper is attempting to place economics within a general metatheory of how the mind works.

Returning to monopolistic competition, when products are differentiated, then one has gone beyond pure Exhorter-Contributor interaction to include Perceiver facts and Server sequences. This describes normal thought, which uses analogies to notice similarities between one item or situation and another. Looking at this more closely, "If a monopolist raises its price, some consumers will choose not to purchase its product-but they will then need to buy a completely different product. However, when a monopolistic competitor raises its price, some consumers will choose not to purchase the product at all, but others will choose to buy a similar product from another firm. If a monopolistic competitor raises its price, it will not lose as many customers as would a perfectly competitive firm, but it will lose more customers than would a monopoly that raised its prices” (micro, p. 238). Notice that one is no longer dealing with 'completely different products' but rather with 'similar products', and raising prices is only leading to the loss of some customers rather than causing all customers to turn elsewhere.

Technical thought naturally treats facts in a digital manner: A fact is either sufficiently certain to be assumed as true, or else is treated as false because it lacks sufficient certainty. This mindset can be seen 
in statistical analysis which treats facts as ‘certain’ if they pass some threshold of statistical significance. This can also be seen in peer-review, which treats a scientific fact as meaningful if it passes the threshold of being published in an academic journal and as insignificant if it is not published in a journal. Similarity introduces a range of options. People are still choosing as individuals to purchase or reject some product, but these individual choices are occurring over a range of possibilities. An economist may regard this as suboptimal, but it actually expands the realm over which Contributor thought can make choices.

Monopolistic competition also leads to greater potential excitement for Exhorter thought. "Even though monopolistic competition does not provide productive efficiency or allocative efficiency, it does have benefits of its own. Product differentiation is based on variety and innovation. Most people would prefer to live in an economy with many kinds of clothes, foods, and car styles; not in a world of perfect competition where everyone will always wear blue jeans and white shirts, eat only spaghetti with plain red sauce, and drive an identical model of car" (micro, p. 243). Exhorter thought finds it boring when everything is exactly the same. Similarity provides a combination of variety and stability. There is enough variety to keep Exhorter thought motivated and enough stability to preserve Contributor planning.

Looking at this more generally, the basic premise of economics is that the well-being of a society is improved when specialization is used within a market economy. But the previous paragraph just stated that the well-being of a society is greatest when the economic ideal of perfect competition is not reached. This is a significant statement that needs to be repeated. Technical specialization does improve the well-being of society. But this well-being is only achieved if society follows economic thought incompletely. This reinforces the statement made earlier when looking at consumer surplus and mental networks.

And economists are aware of this inherent self-contradiction. "Economists have struggled, with only partial success, to address the question of whether a market-oriented economy produces the optimal amount of variety. Critics of market-oriented economies argue that society does not really need dozens of different athletic shoes or breakfast cereals or automobiles. They argue that much of the cost of creating such a high degree of product differentiation, and then of advertising and marketing this differentiation, is socially wasteful — that is, most people would be just as happy with a smaller range of differentiated products produced and sold at a lower price. Defenders of a market-oriented economy respond that if people do not want to buy differentiated products or highly advertised brand names, no one is forcing them to do so" (micro, p. 243).

Mental symmetry suggests that the underlying problem lies in an inadequate concept of ownership. Notice the focus upon buying and selling in the previous paragraph. Potential consumers are being presented with 'dozens of different athletic shoes or breakfast cereals or automobiles'. Advertising and marketing are then being used to encourage potential consumers to 'buy differentiated products or highly advertised brand names'. What is being ignored is the entire process of developing and producing a product that occurs before the purchase, as well as the process of education and training that is required to use a product. Stated more clearly, a product does not magically appear on the market 
but rather requires extensive technical knowledge and skill to produce; a producer has to mentally 'own' a product before being truly capable of selling it.

We saw earlier that items acquired through skill are valued more highly than those obtained by luck. Unfortunately, the requirement for skill is no longer present in much of the Western economy. If a Western company gets some factory in China to produce a product, then as far as the Western company is concerned, no skill was used to produce the product. Even less skill is used when a Western company slaps some brand name on a product both made and designed in China. This leads to products being sold by companies that have a limited sense of mental ownership of the products that they sell. The online economy extends this mindset to the consumer. The customer goes to a webpage, makes a few clicks of the mouse, and the desired object appears on the doorstep within a day or two. Very little skill is involved in clicking and waiting. Instead of mentally owning a product, the typical consumer tends to be driven by ownership-as-infatuation, which means either returning it because it generated insufficient Exhorter excitement, or else throwing it away and buying something new-and-improved when it stops providing sufficient Exhorter excitement.

An article in Bloomberg describes the growing waste of returning items bought over the Internet. "In December, American consumers will return more than 1 million packages to e-commerce retailers each day... By one recent estimate, they accounted for 5 billion pounds of landfilled waste in the U.S. alone... The problem is that consumers are returning more and more every year. In 2018, Americans sent back 10\% of their purchases, valued at \$369 billion, up from 8\% two years earlier” (Minter, 2019). Thus, in addition to demonstrating an inadequate mental sense of ownership, the motto of 'satisfaction or your money back' is actually physically wasteful—to the extent of billions of pounds of waste a year. ${ }^{18}$

Summarizing, I suggest that consumer variety is not inherently wasteful but adds to the utility of human existence. But consumer variety that is enabled by an inadequate sense of ownership and driven by ownership-as-infatuation is inherently wasteful.

The fear is that moving away from a consumer society might lead to a massive depression. However, mental symmetry suggests that a deeper concept of ownership would shift a significant part of the economy away from producing an endless stream of new-and-improved trinkets to learning how to produce better products as well as how to use existing products in a better fashion.

This is not just wishful thinking because the American economy, for instance, has experienced a significant shift away from goods to services. "In thinking about what is produced in the economy, many non-economists immediately focus on solid, long-lasting goods, like cars and computers. By far the largest part of GDP, however, is services. Moreover, services have been a growing share of GDP over time... It has been decades since most of the U.S. economy involved making solid objects. Instead, the most common jobs in a modern economy involve a worker looking at pieces of paper or a computer screen; meeting with co-workers, customers, or suppliers; or making phone calls” (macro, p. 141). I am not suggesting that the United States has shifted to the optimal kind of service economy, but rather

18 'Satisfaction or your money back' is different than a guarantee that the product will function as advertised. The former is an emotional statement, whereas the latter involves technical thought. 
pointing out that it is possible to move away from goods to services while maintaining a market economy.

The third kind of economy is an oligopoly. “Oligopoly arises when a small number of large firms have all or most of the sales in an industry. Examples of oligopoly abound and include the auto industry, cable television, and commercial air travel” (micro, p. 244). Cognitively speaking, an oligopoly involves a juxtaposition of Mercy and Teacher emotions. That is because large companies that possess Teacher generality are being controlled by a few individuals who are driven by personal MMNs.

The result is that interaction can be driven either by Mercy emotions or by Teacher emotions. “Oligopolistic firms are like cats in a bag. They can either scratch each other to pieces or cuddle up and get comfortable with one another. If oligopolists compete hard, they may end up acting very much like perfect competitors, driving down costs and leading to zero profits for all. If oligopolists collude with each other, they may effectively act like a monopoly and succeed in pushing up prices and earning consistently” (micro, p. 244). ${ }^{19}$ An MMN will generate negative feelings when encountering experiences that are inconsistent with its structure. This leads naturally to feelings of tribalism and xenophobia. When Teacher feelings are added, then this can magnify Mercy feelings of mutual antagonism, resulting in 'scratching each other to pieces'. That is because the competitor is not just viewed as different in Mercy thought but becomes seen as the essence of difference in Teacher thought, the major exception to the universal rule of Teacher thought, not just 'bad' but 'the epitome of badness'.

The cognitive problem is that Teacher emotions are being added to Mercy feelings in an intuitive manner, jumping directly from specific Mercy experience to general Teacher theory; 'me' versus 'you' in Mercy thought becomes magnified by Teacher thought to become 'my kingdom' versus 'your kingdom'. In a competitive economy, Teacher thought and Mercy thought are not directly connected in an intuitive manner. Instead, there are many players within a field, which means that the Teacher order of the entire field is interacting with the Mercy experiences of individual players within an infrastructure of Perceiver facts and Server sequences.

It is also possible for oligopolists 'to collude with each other'. This type of interaction is being driven by Teacher thought, because Teacher emotion comes from order-within-complexity, and cooperation leads to greater order-within-complexity.

But this Teacher order is not the order-within-complexity of a market economy, but rather the collusion of a personal agreement. A few leaders with individual Mercy feelings are agreeing personally to create Teacher order. This is also an intuitive leap from Mercy specific to Teacher generality. This type of Teacher order is unstable and can easily revert back to Mercy-driven tribalism. "Even when oligopolists recognize that they would benefit as a group by acting like a monopoly, each individual oligopoly faces a private temptation to produce just a slightly higher quantity and earn slightly higher profit - while still counting on the other oligopolists to hold down their production and keep prices high. If at least some oligopolists give in to this temptation and start producing more, then the market

19 Most countries have laws against collusion, but a law is an external force applied by society. We are looking here at the underlying cognitive motivations. 
price will fall. A small handful of oligopoly firms may end up competing so fiercely that they all find themselves earning zero economic profits” (micro, p. 245).

Notice the emotional tension between Teacher order and Mercy individuality, because each individual partner experiences the best results by personally pursuing Mercy thought while the others continue to follow Teacher order. This leads naturally to the duplicity of pretending to follow an agreement while secretly violating it. Going further, if secret violations become publicly known, then this will emotionally reinforce the idea that the other group is the 'epitome of badness'.

Economics has no general Teacher theory for an oligopoly but rather explains it as a struggle between Teacher and Mercy thought. "Because of the complexity of oligopoly, which is the result of mutual interdependence among firms, there is no single, generally-accepted theory of how oligopolies behave... The prisoner's dilemma is a scenario in which the gains from cooperation are larger than the rewards from pursuing self-interest. It applies well to oligopoly” (micro, p. 245). Summarizing, no general theory exists because of the emotional struggle between Teacher feelings of 'cooperation' and Mercy feelings of 'pursuing self-interest'.

The textbook points out that "Oligopoly is probably the second most common market structure" (micro, p. 249). This is an interesting statement because the previous paragraph stated that economics has 'no single, generally accepted theory of how oligopolies behave'. Looking at the larger picture, one observes that these four models of the economy are not doing very well as general theories. A good theory can explain the facts. However, the ideal economy of perfect competition exists primarily within the minds of economists and not within reality. And economics has no generally accepted theoretical explanation for the second most common economy of oligopoly. As for the most common alternative of monopolistic competition, economic theory recognizes that social well-being becomes maximized when economic theory is only partially applied. I am not suggesting that economic theory is worthless, but these statements demonstrate that the economic focus upon Exhorter-Contributor interaction provides an incomplete picture that needs to be filled out.

The final type of economy is a monopoly, which is "a situation in which one firm produces all of the output in a market” (micro, p. 231). Two types of monopoly are explicitly mentioned. "One is natural monopoly, where the barriers to entry are something other than legal prohibition. The other is legal monopoly, where laws prohibit (or severely limit) competition” (micro, p. 217). A third type of monopoly, which could be called a marketing monopoly, is also described but not explicitly mentioned. The dominant emotional force in a monopoly is Teacher order-within-complexity.

“A natural monopoly arises when average costs are declining over the range of production that satisfies market demand. This typically happens when fixed costs are large relative to variable costs. As a result, one firm is able to supply the total quantity demanded in the market at lower cost than two or more firms - so splitting up the natural monopoly would raise the average cost of production and force customers to pay more. Public utilities, the companies that have traditionally provided water and electrical service across much of the United States, are leading examples of natural monopoly" (micro, p. 265). 
Physical infrastructure such as 'water and electrical service', highways, or telecommunication systems are all physical examples of Teacher order-within-complexity because a network of Server 'roads' and Perceiver 'intersections' is bringing order to a vast complexity of specific locations. With an oligopoly, Mercy emotion was fighting Teacher emotion, and each partner typically experienced the best results when it secretly followed Mercy thought while the other partners submitted to Teacher thought. In a natural monopoly, greater Teacher order leads also to better personal results in Mercy thought. For instance, an integrated transportation network contains great Teacher order-within-complexity, but it also makes it easier for individuals to move from one location in Mercy thought to another.

Looking at this more carefully, infrastructure can be viewed either from a Mercy perspective or from a Teacher perspective. The Mercy perspective views infrastructure as a more effective way of connecting products with consumers. The Teacher perspective views the same infrastructure as a network to expand and maintain. A similar distinction was seen when looking at machines, because the same machine can be viewed from a Mercy perspective as a tool or from a Teacher perspective as an integrated system. Teacher thought feels bad when infrastructure breaks down while feeling good when more complexity can be placed within the order of the infrastructure. Both Teacher and Mercy perspectives are essential. A Teacher perspective is required to build and maintain an infrastructure, while a Mercy perspective provides the primary motivation for using an infrastructure.

An infrastructure has large fixed costs because its usefulness depends upon its size. For instance, a rail system that interconnects a dozen cities is far more useful than one which only connects two cities. When competing firms construct rival infrastructures, then each has to pay its own massive fixed costs while having access to fewer customers.

The fundamental characteristic of a natural monopoly is that Teacher order-within-complexity is being created within physical reality. And because the laws of nature are immutable, there is no way of avoiding the associated fixed costs. However, it may be possible to change these fixed costs by using a different form of technology. For instance, Africa has been able to avoid the huge fixed cost of constructing a telephone network by jumping directly to mobile phones. A 2015 Pew Research article summarizes that "In a few short years, the proliferation of mobile phone networks has transformed communications in sub-Saharan Africa. It has also allowed Africans to skip the landline stage of development and jump right to the digital age... In 2002, only 8\% of Ghanaians said they owned a mobile phone, while that figure stands at 83\% today, a more than tenfold increase. Similar growth in mobile penetration is seen in all African countries where survey data are available" ("Cell phones", 2015).

A legal monopoly occurs when there are "legal prohibitions against competition, such as regulated monopolies and intellectual property protections created by government” (micro, p. 231). Government is an artificial system of Teacher order that is created by a group of people. A government passes laws that (theoretically) apply universally within the domain of that government. I say 'theoretically' because, unlike the laws of nature which automatically apply, the laws of a government have to be artificially imposed through some sort of legal system. 
With a 'regulated monopoly', government law is reinforcing the inherent Teacher order-withincomplexity of a natural monopoly. For instance, "Under U.S. law, no organization but the U.S. Postal Service is legally allowed to deliver first-class mail. Many states or cities have laws or regulations that allow households a choice of only one electric company, one water company, and one company to pick up the garbage. Most legal monopolies are utilities — products necessary for everyday life - that are socially beneficial. As a consequence, the government allows producers to become regulated monopolies, to insure that customers have access to an appropriate amount of these products or services” (micro, p. 218). Notice that all of these examples involve physical infrastructure. Notice also that this infrastructure provides 'products necessary for everyday life'. This is an example of Teacher thought and Mercy thought functioning in a symbiotic manner. Teacher thought appreciates the orderwithin-complexity of a utility, while personal existence within Mercy thought requires the product that is being delivered by the utility.

If government regulation of a utility is to be effective, then this regulation must be motivated by Teacher emotions and not Mercy feelings. First, there is the Teacher feeling of universality. Teacher thought feels bad when there is an exception to the general rule. For instance, an exception to the general rule occurs if some rural customers do not have access to electricity. A natural monopoly will naturally build an electrical infrastructure that supplies electricity to most customers while avoiding those that are hardest to reach. Government regulation can ensure that (almost) everyone has access to a utility. The proviso of 'almost' needs to be added because government regulation can encourage a natural monopoly to do something that is physically difficult but not something that is physically impossible.

Second, there is the Teacher feeling of exclusivity. In simple terms, there is only room for one universal theory. When there are two potential universal theories, then this can lead to the 'cats in a bag' competition that was seen in oligopoly, because each will see the other as an exception to the universal rule. General theories can coexist if one is a translation of the other, and this will be examined further when looking at exchange. For instance, this paper is translating between the general theories of economics and the general theory of mental symmetry. Legislated exclusivity prevents competing firms from entering some market. This enhances Teacher order-within-complexity by ensuring that all of the complexity is held together by a single system of Teacher order.

Companies like government-legislated exclusivity because it keeps out competitors, but they do not like government-legislated universality because it raises costs. Thus, there will be a natural tendency for companies to claim universality while practicing exclusivity. This is actually a contradiction in terms, because pursuing exclusivity will mean that outlying customers are not serviced, while universality only exists if all potential customers are serviced. This contradiction can be seen, for instance, in stories of Internet Service Providers claiming to provide service to some location and then saying that it cannot be done when it comes to actually hooking up, or else charging several thousand dollars for the privilege of getting connected (Hollister, 2020).

Third, there is the Teacher feeling of standards. The idea here is that government is forcing a monopoly to function 'like other companies'. "Regulators of public utilities for many decades... calculated the average cost of production for the water or electricity companies, added in an amount for the normal 
rate of profit the firm should expect to earn, and set the price for consumers accordingly. This method was known as cost-plus regulation” (micro, p. 266). Saying this cognitively, the behavior of the typical firm is being treated as a general Teacher theory and this standard is being imposed upon a monopoly by the government. The underlying assumption, of course, is that the typical firm is behaving in a desirable fashion.

One problem with this method is that it replaces Mercy emotions with Teacher emotions. Using economic language, "If producers receive reimbursement for their costs, plus a bit more, then at a minimum, producers have less reason to be concerned with high costs-because they can just pass them along in higher prices. Worse, firms under cost-plus regulation even have an incentive to generate high costs by building huge factories or employing many staff” (micro, p. 266). By allowing a monopoly to pass on its costs to the consumer, Mercy-generated emotions of cost and benefit have been effectively eliminated from economic calculations. These will be replaced by Teacher feelings of orderwithin-complexity. Teacher thought feels good building and maintaining an infrastructure that effectively services a large group of people. But good Teacher feelings can also be generated by 'building huge factories or employing many staff', because these are also examples of Teacher orderwithin-complexity.

The challenge is to add Teacher feelings of universality without disabling Mercy-driven goal-oriented behavior. For instance, "In the 1980s and 1990s, some public utility regulators began to use price cap regulation, where the regulator sets a price that the firm can charge over the next few years. A common pattern was to require a price that declined slightly over time. If the firm can find ways of reducing its costs more quickly than the price caps, it can make a high level of profits” (micro, p. 266).

The third kind of monopoly could be referred to as a marketing monopoly. This is related to the idea of a brand name. "Firms may need to reach a certain minimum size before they are able to spend enough on advertising and marketing to create a recognizable brand name. The problem in competing with, say, Coca-Cola or Pepsi is not that producing fizzy drinks is technologically difficult, but rather that creating a brand name and marketing effort to equal Coke or Pepsi is an enormous task" (micro, p. 244). Teacher thought naturally thinks in terms of words, and a general theory is usually described using words. A brand name is a form of general theory because it uses some word to bring order to a complexity of products and behaviors.

Looking at this more generally, it has been mentioned several times that the mind uses mental networks within Mercy thought to represent people. The mental networks that represent some person can be summarized by the Teacher theory of a name. Personal names are usually acquired intuitively by jumping from Mercy experience to Teacher label. For instance, parents may look at the new bundle of joy sleeping within mother's arms and proclaim, 'We call you Tom'. But a name can also be acquired in a more rigorous manner through technical thought, similar to the matter in which a machine can be viewed from either a Mercy or a Teacher perspective. For instance, suppose that Tom grows up and decides to specialize in fixing automobiles. He will become known as 'Tom the car mechanic'; Tom's name has become modified by a set of technical skills. Now suppose that the demand for car mechanics increases, causing Tom to hire some employees and other auto mechanic shops to be established.

Eventually, people will stop calling for Tom and start asking for 'a mechanic'. Tom will now be viewed 
as a specific example of the general category of mechanic. Tom's technical skills have not changed. What has changed is people's view of Tom. Instead of being viewed from Mercy thought as a specific person with technical skills, he is now being viewed from Teacher thought as one expression of the order-within-complexity of the generic name of car mechanic. A similar cognitive transition happens whenever some technical specialization turns into a recognized profession.

A brand name can also turn into a generic label through a process known as genericization. For instance, 'escalator' began as a trademark of Otis, 'thermos' was declared generic in 1963, 'laundromat' began as a term used by Westinghouse, 'zipper' was introduced by the universal fastener company in 1917, and Bayer was forced to give up its trademark on ‘Aspirin’ after Germany lost the First World War (Abadi, 2018). Using the example of 'Tom the car mechanic', Tom would lose his personal identity and become genericized if people started asking for 'a Tom' to fix their cars.

Cognitively speaking, I suggest that genericization involves a distinction between Teacher thought and abstract technical thought. A theory within Teacher thought will turn into a Teacher mental network (TMN) if it continues to be used. Thus, enough advertising will turn a brand name into a TMN. Creating a successful brand name that exists as a TMN within the minds of consumers takes considerable resources. "If the only way to launch a successful new national cola drink is to spend more than the promotional budgets of Coca-Cola and Pepsi Cola, not too many companies will try. A firmly established brand name can be difficult to dislodge" (micro, p. 220). A TMN is very effective for creating demand. That is because a mental network will use emotional pressure to impose its structure upon the mind when it is triggered. Therefore, anything that brings to mind the mental network that represents some product will create a desire to purchase that product. Going further, a Teacher mental network comes from a general theory, and a general theory is, by definition, activated in many different specific situations. Therefore, a well-known brand name can create a desire to purchase some product in many situations.

Abstract technical thought, in contrast, deals with precise definitions. A TMN can be defined precisely. This happens, for instance, with a certified profession, such as a medical doctor. The term 'medical doctor' is represented by a TMN within most people's minds, because the average person who gets sick or injured will be reminded of the TMN of 'medical doctor' and 'medical treatment'. But the term 'medical doctor' is also a technical term that is precisely defined by the medical profession; in order to be permitted to be called a medical doctor, a person must go through a technical program of acquiring technical knowledge and skill.

The goal for a trademark or brand name is to remain at the level of TMN without crossing the boundary into precise definition. For instance, “Adobe is fighting tooth and nail to keep 'Photoshop’ from becoming a generic term for any photo-manipulation software. On its website, it discourages users from using 'Photoshop' as a verb and from referring to an edited image as 'a photoshop.' The company offers some alternative, albeit clunky ways to get around the problem: 'The image was enhanced using Adobe Photoshop software,' reads one example” (Abadi, 2018). In other words, ‘photoshop’ is supposed to remain a mental network that brings to mind some company rather than a technical term that describes some set of technical procedures. However, this is difficult because other words such as 'enhance' do not have the correct precise meaning. 


\section{Ownership and Teacher Thought}

Two terms were mentioned when looking at a legal monopoly. These terms were regulated monopoly and intellectual property. The previous paragraphs have discussed a regulated monopoly. The concept of intellectual property will now be analyzed. This will be an extended discussion that involves looking more closely at the concepts of ownership and property.

Microeconomics deals with the realm of concrete technical thought, in which people exchange goods and services guided by Mercy feelings of utility. Concrete thought is concrete because it interacts with a physical world composed of physical objects. A good is some fragment of physical reality that has been formed into a Perceiver object while a service describes some Server action that is performed within physical reality. Concrete technical thought finds it easy to think in terms of goods and services because Contributor thought connects Perceiver facts with Server actions. Going further, economics is based upon the assumption that Perceiver thought can be used to subdivide physical reality into fragments and that these fragments can be connected with people through ownership: For instance, 'This plot of land is mine. That car is yours. I want to buy your car.' Using the language of economics, physical goods are excludable and rival.

Cognitively speaking, excludable means that Perceiver thought can place some sort of wall around the good which prevents non-owners from accessing the good. Rival means that the good can be defined by Perceiver thought as an object that occupies some specific location. Because every object is limited to some specific location, only one person can use an object at a time. For instance, my car is a physical object that exists in some place. If someone else drives my car then this prevents me from driving my car. Excludable and rival are both attributes of normal, solid, concrete reality.

The fundamental economic principle of private property breaks down when these two traits are not present. For instance, fish in the ocean are rival but not excludable. A fish is a physical object and can be defined by Perceiver thought as an object. But fish reside in the sea, and water is a liquid which cannot be subdivided into different regions by Perceiver thought. Hence, the reference to solid reality in the previous paragraph. This combination of rival but not excludable leads to common goods, and the typical economics textbook will give the example of fish in international waters.

Attempting to apply economic thinking to common goods typically leads to the tragedy of the commons. Looking at the example of the conch mollusk, "Economists view this as a problem of property rights. Since nobody owns the ocean, or the conch that crawl on the sand beneath it, no one individual has an incentive to protect that resource and responsibly harvest it” (micro, p. 312). But behind these 'property rights' lie two other more fundamental problems. The physical problem is that a liquid such as water cannot be subdivided into distinct parcels by Perceiver thought. The cognitive problem is that the Mercy emotions (or utility) associated with the desirable object (in this case the conch) is overwhelming the ability of Perceiver thought to impose facts of ownership. These two problems are related because Perceiver thought acquires confidence through repetition; a solid object maintains the same shape over time-leading to a mental sense of repetition, while a liquid does not.

One partial solution is to come up with a form of ownership that relies upon Server thought rather than Perceiver thought. It was mentioned earlier that ownership can be defined from a Perceiver perspective 
as some object that is connected to me. But ownership can also be defined from a Server perspective as the actions which I am permitted to perform. For instance, a fishing license gives a person the permission to perform the Server action of fishing. Perceiver ownership is usually associated with spatial location, because objects exist within space. Server ownership normally exists within time, because a sequence of actions takes time and is performed at a specific time. For instance, a fishing season limits the action of fishing to some specific period of time.

It is also possible to deal with the problem of ownership by focusing explicitly upon Teacher thought. Common goods exist within some Teacher system of order-within-complexity such as the ecosystem of marine life within the ocean. A Teacher perspective might pay people to maintain the Teacher order of some system. We saw earlier that the mind has to learn about the order-within-complexity of some subject in order to feel Teacher emotion about that subject. Therefore, a Teacher perspective will only be effective if people are hired who have a Teacher understanding of this system and are emotionally driven by Teacher emotion to maintain this Teacher order.

It should be added that acquiring such Teacher emotions does not require a formal, 'scientific' education. Instead, what is needed is a sufficiently detailed understanding of how the various elements of some system interact in order to generate order. In fact, we saw earlier that Teacher feelings of beauty existed before the development of modern scientific thought. And we saw when looking at the concept of 'emotional imprisonment' that the specialized thinking of modern technical thought tends to ignore the Teacher emotions of larger systems while focusing upon the Teacher emotions of some specialized paradigm. Going further, a Teacher perspective will be reinforced if trained individuals are hired by some institution that focuses upon Teacher thought, such as government or university. For instance, a government may hire marine biologists to monitor the health of the conch in local waters.

Private ownership can also lead to the preservation of some resource. For instance, a logging firm that harvests trees on private land will be motivated to maintain these trees (if cost-benefit calculations within the anterior cingulate include long-term implications). But a method of private ownership assumes that it is possible to define ownership. When ownership cannot be defined, then it is possible to approach the situation from a Teacher perspective. But the average person does not have a Teacher perspective. Therefore, people and institutions need to be used which have been trained to adopt a Teacher perspective.

This also provides a way of addressing the problem of 'the revolving door', in which those who regulate firms are chosen from those who work for firms (i Vidal, 2010). This is not a trivial problem. On the one hand, choosing regulators from within firms can lead to the political corruption of government passing general rules in Teacher thought that favor specific firms in Mercy thought, which is known in economics as a non-level playing field. On the other hand, choosing regulators from outside an industry leads to the problem of regulations being passed by people who are incapable of being driving by Teacher emotion because they lack the knowledge that is required to enable Teacher emotion.

A regulator is typically chosen who does not have a conflict of interest. Quoting from the Investopedia website, "A conflict of interest occurs when an entity or individual becomes unreliable because of a 
clash between personal (or self-serving) interests and professional duties or responsibilities” (Segal, 2020). Looking at this cognitively, 'personal or self-serving interests' refer to MMNs of personal identity. Conflict of interest happens when the technical thinking of 'professional duties' becomes warped by MMNs of personal identity. Eliminating conflict of interest is important, but this is only the negative side of the story. What matters more than ensuring that a regulator will not be motivated by personal MMNs is that a regulator will be motivated by TMNs of professional understanding.

A common good is rival but non-excludable. A public good is both non-rival and non-excludable. Some examples are fresh air, knowledge, water, radio, and national defense. It is obvious that these all involve some form of Teacher generality: Water and air are universal substances that pervade the earth. Radio is a form of electromagnetic radiation that spreads universally from some source. National defense protects an entire nation. And knowledge (hopefully) describes Perceiver facts that are universally true.

However, these examples are cognitively distinct. Natural biological systems are responsible for the universality of fresh air and drinkable water. What typically happens in such a situation is that people assume that human activity will have no impact upon the continued universal existence of these resources. However, as human activity increases, then the supposedly universal resource gradually becomes scarce or polluted. At some point people will be forced to explicitly adopt a Teacher perspective in order to preserve the universality of what was supposedly a limitless resource. That is because the disruption of a universal resource will have a universal impact. For instance, air pollution may be generated by a few firms, but it affects everyone.

Radio and national defense are examples of human activity that naturally have a universal impact. A radio or television signal is being broadcast by people, but the laws of physics ensure that anyone with a radio or television can receive the signal without paying for it. Similarly, national defense is also performed by people but has a universal impact because of the nature of physical location; everyone residing within the physical location of some country will receive the benefits of the national defense of that country.

In both of these situations, explicit steps will need to be taken at a Teacher level in areas where universality is lacking. For instance, radio waves are rival in the sense that two local stations cannot broadcast simultaneously on the same frequency without generating interference. Therefore, universal steps will need to be taken to allocate the frequency spectrum to various users, and the radio spectrum is highly regulated by government authorities. This is an example of Server ownership, because what a radio or television station does is being regulated and not the physical property or goods of that station.

The requirement for explicit Teacher structure is even more apparent in the case of national defense. The natural tendency is for someone with weapons to use physical force to impose MMNs of personal desire or status upon others. But an army can be prevented from turning into a gang of armed thugs by emphasizing Teacher thought. These traits can be seen in a modern professional army. A professional army is based in rank, and a system of rank is an example of Teacher order-within-complexity. Professional soldiers are taught professions, and a profession is a set of Server skills and Perceiver knowledge held together by the Teacher paradigm of some technical specialization. Professional 
soldiers are forbidden from using their skills and weapons to pursue personal goals in Mercy thought, but rather are guided by verbal instructions that come from the Teacher structure of a chain-ofcommand. And professional soldiers function as an integrated group, in which individuals cooperate in a manner that expresses Teacher order-within-complexity. Notice also the extensive use of Server ownership, because the rank and profession of a soldier determine which Server actions a soldier is permitted to perform.

\section{Intellectual Property}

Knowledge is unlike other forms of public goods because it resides within people's minds. It was mentioned earlier that Perceiver facts can be acquired in two basic ways: First, the emotional status of some expert can overwhelm Perceiver thought into 'knowing' that certain 'facts' are 'true'. ${ }^{20}$ Second, Perceiver thought can observe that certain connections occur repeatedly within the physical environment. (Similarly, Perceiver thought can also notice certain cognitive mechanisms being repeated within people's minds.) A fact that is repeated is by definition non-rival, and teaching knowledge is inherently non-excludable, because learning a fact 'opens one's eyes' to seeing this fact in the environment.

This has major implications when attempting to define intellectual property. A concept of private property makes sense when applied to the concrete realm of physical objects, because physical objects are inherently rival and excludable. A physical object is a specific collection of physical matter that occupies a specific physical location. A book is a physical object. Therefore, writing knowledge down in books will create the impression that knowledge can be treated as physical objects, because knowledge can only be accessed through the physical object of some book. But knowledge is not composed of physical matter and does not occupy a specific location. This becomes apparent when knowledge is stored electronically on digital recordings or computer programs, because it is easy to transfer the knowledge from one electronic device to another. Electronically stored information is not rival, because the information can be copied from one device to another, and it is not excludable because making a copy of the information is trivial.

This has been pointed out by others. “Texts on paper, skin, clay, or stone are rivalrous material objects... All texts were rivalrous before the digital age. But digital texts are non-rivalrous. With the right equipment we can all have copies of the same digital text without having to take turns, block one another, multiply our costs, or deplete our resources. This may be the deepest transformation wrought by the digital revolution. For the first time in the history of writing, we can record our non-rivalrous knowledge without turning it into a rivalrous material object” (Suber, 2009).

The microeconomics textbook ignores these problems, viewing intellectual property as simply another form of property. "Taken together, we call this combination of patents, trademarks, copyrights, and trade secret law intellectual property, because it implies ownership over an idea, concept, or image, not a physical piece of property like a house or a car” (micro, p. 219). Notice that ownership is being 'implied'. However, ownership assumes that an item is rival and excludable, and knowledge by its very

20 Similarly, the emotions of some traumatic event can overwhelm Perceiver thought into 'knowing' that the 'facts' of that event define 'truth'. This is an alternative way of creating emotional 'truth' which is not being discussed in this paper. 
nature is non-rival and non-excludable. Therefore, intellectual property will have to be imposed artificially by government law, and this law will continually have to fight the inherent nature of knowledge.

This imposition of government law is apparent in the definition of intellectual property, which is defined as "the body of law including patents, trademarks, copyrights, and trade secret law that protect the right of inventors to produce and sell their inventions" (micro, p. 314). Notice the reference to a 'body of law', which implies that imposing property upon knowledge requires extensive government effort, because attributes are being artificially imposed upon knowledge that violate the inherent nature of knowledge. Notice also that this definition does not make any reference to knowledge, even though the ownership of knowledge is supposedly being defined. Instead, what is being protected is the producing and selling of inventions within concrete technical thought. Protecting the producer is a reasonable goal because a fundamental principle of the market economy is that a supplier who produces some good should be paid for producing this good. However, it is a category mistake to connect buying and selling within concrete technical thought to the technical knowledge of abstract technical thought.

This paper is quoting from the openstax textbooks on economics. Openstax has just released a textbook entitled Introduction to Intellectual Property (Kline, 2021). It is cognitively revealing to note how patents and knowledge are discussed. The statement is repeatedly made in this textbook that patents lead to the spread of knowledge. Patents are called "the greatest vehicle for knowledge-sharing and technology transfer ever devised by human beings” (p. 10). "Patents have served as a powerful stimulant to technological knowledge sharing” (p. 14). "Even the word 'patent' signifies its social purpose of disclosure. It is derived from the Latin patent meaning 'open"” (p. 14). "Intellectual property rights tend to stimulate invention, economic growth, and the diffusion of new technological knowledge in every country where they exist” (p. 15). And "This lack of regularity limited the technological knowledge sharing that is one of the great benefits of a patent system” (p. 17).

Spreading knowledge is an aspect of the American patent system, because a "unique feature of the U.S. patent system was its systematic effort to spread new technological knowledge throughout society" (Kline, 2021, p. 23). But if patents are 'the greatest vehicle for knowledge-sharing ever devised', then why does the textbook take an entire chapter to describe in detail the legal process of patent litigation? Two chapters are devoted to patents. And one of these chapters talks only about the process by which a patent owner enforces intellectual property by taking another person to court. If the primary goal of a patent is to share knowledge, then why devote a whole chapter to legally preventing knowledge from being shared? Going further, if patents are so wonderful for society, then why do they have to be imposed so strenuously through legal means?

About half of the other chapter on patents is an emotional promotion that appeals to American patriotism, the American Founding Fathers and the American Dream. "The Founders viewed intellectual property rights as vital to the new nation's economic survival. As George Washington himself stated...” (Kline, 2021, p. 11). “This, then, is the story of one of the most admired of all American inventions - the modern democratized patent system, now used widely throughout the world” (p. 18). "Men such as George Washington, Thomas Jefferson, and James Madison knew they 
had to find a way to unleash the creative and productive potential of these independent citizens if the country was to industrialize and survive” (p. 20). "The real genius of the Founders, however, lay in the way they consciously integrated democratic principles into the design of the world's first modern patent system” (p. 21). “Only two months after America’s first patent law was signed in 1790, in fact, Thomas Jefferson himself noted that it had 'given a spring to invention beyond my conception'” (p. 31). “The secret of America's success was a uniquely democratic patent system that 'added the fuel of interest to the fire of genius' in generations of ordinary citizens - and in so doing, helped in a very real way to give birth to the American Dream itself” (p. 35).

Summarizing, it is a basic cognitive principle that people should be rewarded for their work. Saying this cognitively, Exhorter thought provides motivation for the mind, and the Exhorter motivation for concrete thought comes from emotional goals in Mercy thought. A potential reward provides a motivation for work. It also makes sense that intellectual labor should be rewarded. This is a "commonsense premise that most of us instinctively hold to be true: that the product of mental labor is by all rights the property of its creator, no less than the product of physical labor is the property of its creator" (Kline, 2021, p. 12).

The cognitive flaw lies in thinking that it is possible to treat intellectual labor as an extension of physical labor. "Indeed, the entire history of economic progress on our planet may be described as one long climb by humanity up the ladder of abstraction — from brute force to the subtle use of energy, from wealth derived from tangible resources and industrial machinery to wealth derived from ever-more ingenious ways to deploy that energy and those resources. It seems only logical, therefore, to expect that invention itself should follow a similar trajectory-from the realm of the tangible to the realm of the intangible” (Kline, 2021, p. 41). But the 'entire history of economic progress' cannot 'be described as one long climb' of evolutionary change. Instead, modern humanity moved 'up the ladder of the abstraction' through a revolution, known as the Scientific Revolution. Similarly, the widespread introduction of industrial machinery occurred in an Industrial Revolution. As Kuhn stated in his ground-breaking book, the evolutionary growth of normal science is interspersed by episodes of revolutionary science, and the introduction of science itself was a revolution (Kuhn, 1970). Thus, if one truly understand history and cognition, then it will 'seem only logical, therefore, to expect that invention itself should follow a similar trajectory' - a trajectory of evolutionary changes interspersed by revolutionary transformations. And a revolutionary change in the storage of knowledge will have to be accompanied by a revolutionary change in the legal and economic view of knowledge.

Kuhn also mentions that it is normal for a technical specialization to redefine history as an evolutionary progression guided by the current paradigm. "Partly by selection and partly by distortion, the scientists of earlier ages are implicitly represented as having worked upon the same set of fixed problems and in accordance with the same set of fixed canons that the most recent revolution in scientific theory and method has made seem scientific. No wonder that textbooks and the historical tradition they imply have to be rewritten after each scientific revolution” (Kuhn, 1970, p. 138). Cognitively speaking, this 
rewriting of history demonstrates the emotional power of a paradigm, because a theory that is turned into a mental network will impose its structure upon all thinking-including thinking about the past. ${ }^{21}$

When thinking is followed that is cognitively flawed, then this thinking will have to be imposed upon people through government legislation. Hence, a chapter on patent litigation. And MMNs of culture and patriotism will have to substitute for TMNs of rational understanding. Hence, the repeated references to the icons of American culture. Again, it needs to be emphasized that the laws of intellectual property function reasonably well as long as inventions are reasonably concrete and physical and knowledge is stored in ways that are difficult to copy. The problem arises when intellectual property becomes disconnected from physical property, because then the category mistake between property and knowledge becomes manifest.

I suggest that this category mistake involving intellectual property will naturally accompany absolute truth. Absolute truth comes from some source of truth, such as an expert, a textbook, or a holy book. A person who blindly accepts the opinions of some source of truth will view other sources of truth as rivals that are competing for acceptance. For instance, a believer in one holy book will view other holy books as rival sources of religious truth. Going further, a person who follows one source of truth will try to exclude other potential sources of truth, viewing them as sources of error rather than truth.

This category mistake will usually be expressed as an implicit attitude rather than stated explicitly. The believer in absolute truth will usually claim to believe that truth applies everywhere and excludes no one. That is because absolute truth is being evaluated within abstract thought, which is guided by Teacher feelings of generality. But a believer in absolute truth will be emotionally driven to treat other sources of truth as rivals and try to exclude them. That is because absolute truth is ultimately based in Mercy feelings of respect for some source.

This combination is most obvious when dealing with the absolute truth of a holy book. However, we will see later that most—if not all_education begins as some form of absolute truth. Saying this more simply, absolute truth is, by definition, a category mistake, because universal facts are being based in specific sources. Saying this another way, absolute truth can be viewed as a form of intellectual property, because a believer in absolute truth will feel that those who respect the 'right source of truth' have exclusive ownership over truth. I am not suggesting that all concepts of intellectual property can be traced back to absolute truth. Instead, I am suggesting that resolving the dilemma of intellectual property requires having an adequate understanding of the nature-and prevalence_-of absolute truth.

Absolute truth will be examined in more detail later when looking at borrowing. This section will attempt to explore more carefully the concept of intellectual property and how a person or group can be paid for coming up with new knowledge.

As was mentioned previously, Perceiver ownership is a fundamental characteristic of physical property. This is because the physical world is composed primarily of objects residing within spatial locations. This can be expanded to include Server ownership, leading to a market in goods and services. Server

21 Notice that this rewriting of history is happening primarily at the Teacher level of importance rather than the Perceiver level of facts. Thus, the facts of historians — or textbooks — can usually be trusted, but not necessarily the relative emphasis placed upon these facts. This is another facet of locally rational thought. 
ownership becomes increasingly important as skills become more involved. For instance, automobiles used to be simple enough for the average person to be able to do an oil change or tune-up. However, performing these actions now requires specialized tools and skills. Using cognitive language, the Server path from cause to effect is now more involved.

Server ownership appears to be a fundamental characteristic of knowledge. This can be seen in computer programs. For instance, it is not possible to insert a 'backdoor' into some computer program that allows only some individuals, such as government or police, to have access (Masnick, 2014). In other words, if some electronic device is capable of performing some Server action, then it will perform this Server action for everyone. This is also a characteristic of machines in general. A machine performs the Server sequence of some function and a machine will perform its Server function for any person who uses this machine. For instance, a car will not stop working when a thief gets into the driver's seat; a gun will shoot bullets for both the police and criminals. This leads to the general characteristic that technology is morally ambiguous, because the same technology can be used either to benefit or harm society.

It is possible to add an artificial component of Perceiver ownership to knowledge by requiring extraprecise definitions. It was mentioned earlier that abstract technical thought is based in precise definitions, and a definition is made more precise by adding details to the Perceiver meaning that is attached to some Server sequence. This can be seen, for instance, in passwords. Instead of pressing a button to enable some function, one typically has to enter some precise combination of 'upper and lowercase characters, symbols, and numbers that is at least eight characters long'. Cognitively speaking, a password adds Perceiver details to the Server skill that is required to perform some task. This will create an approximation of the Perceiver ownership that is inherent with physical objects because presumably only the 'owner' is capable of performing the complicated Server skill of entering the password. However, this is really a form of Server ownership and not a true form of Perceiver ownership, because anyone else who learns the password becomes capable of operating the device while an 'owner' who forgets the password loses the ability to operate the device.

Server ownership also appears to be a fundamental property of scientific knowledge. Thomas Kuhn pointed this out with his concept of exemplars (Kuhn, 1970). An exemplar is a characteristic example that epitomizes a number of related examples. For instance, if one learns how to solve one problem involving the path of a projectile through the air, then many similar problems can be solved by using the same technique. Science is learned by performing the Server sequences of solving exemplars. Going further, science is studied through the Server sequences of performing experiments, and science describes the Server sequences that are inherent in the structure of the universe.

We have seen that knowledge does not fit within a normal market economy because it is inherently non-rival and non-excludable. There is a further problem related to intellectual complexity. For instance, anyone can look at a physical computer and recognize it as an object that is distinct from surrounding objects. This ability to distinguish one item from another is a prerequisite for ownership. In order to know if some item belongs to me, I must first be able to recognize this item as an item. But technical knowledge has become so complicated that the average person is no longer capable of recognizing intellectual items or distinguishing one intellectual item from another. 
For instance, consider the following two patents retrieved at random. One is entitled Systems and methods for initializing dynamic model states using a Kalman filter (Healey, 2010), while the other has the title Target trajectory generator for predictive control of nonlinear systems using extended Kalman filter (Baramov, 2011). The average person has no knowledge of Kalman filters and would be unable to recognize these two pieces of intellectual property or distinguish one from the other. (A Kalman filter is a way of gaining a more accurate estimate of some measurement over time.) In the words of one IT association website, “One of the biggest problems with patent law is that you can 'violate' a patent without even knowing it exists, as it can be very difficult to search and differentiate between similar patents” (Pirzada, 2008).

This brings us back to a variation of common goods. With fish in the sea, ownership cannot be assigned because the location of water cannot be subdivided into specific locations. With sufficiently technical intellectual property, ownership cannot be assigned because the objects themselves are too vague within the minds of most people. A lot more could be said — and has been written — about intellectual property and patents, but I do not see any way around the fundamental cognitive problem of object recognition. Any attempt to assign ownership to items that are difficult to recognize and/or distinguish from one another will run into problems. Laws of private property may be fundamental to economics, but what is cognitively even more fundamental is the mental ability to distinguish between one piece of property and another.

The openstax textbook mentions this problem when discussing software patents. "To be patentable nowadays, software has to take a genuinely-inventive step and either trigger an action, employ a device, or in some other way produce a tangible transformative result” (Kline, 2021, p. 39). (This is known as the 'Alice ruling'.) But a computer that is running one piece of software looks exactly like a computer that is running another piece of software. It takes a computer expert to be able to determine if some software is 'taking a genuinely-inventive step', and even the experts are having problems. “The highest-value products and services today... involve cloud computing, Big Data, machine learning, connectivity, mobility and location-based services, and on-demand and anything-as-a-service software applications and business processes. But ironically, these high-value innovations are also the most difficult to patent nowadays as a result of the Supreme Court's Alice decision. Cronin calls this the ‘Alice Paradox,' and it has left many in-house patent groups struggling for a solution” (p. 39). Posed simply, how can laws of private property be applied to items that even experts are having problems identifying?

\section{Transcending Intellectual Property}

Government law recognizes — to a certain extent — that knowledge is fundamentally different than physical objects because inventions, which are concrete expressions of ideas, can be patented while ideas cannot be patented (Quinn, 2018). This is described in more detail in the openstax textbook. "The most important reason why one thing is patentable and another is not lies in the difference between ideas and applications... You cannot patent a mathematical formula. You cannot patent a law of nature, such as Einstein's E=MC². And you cannot patent natural phenomena like electricity” (Kline, 2021, p. 36). 
Going further, patenting inventions will work to some extent as long as inventions are physical objects that can be recognized and identified by the average person. But the two inventions mentioned in the previous section are not physical objects that can be recognized and identified by the average person. Similarly, copyright — the 'right' to 'copy'—worked to some extent as long as copying involved physical processes that were sufficiently costly and laborious. But this is no longer the case.

Trademark is cognitively different, because a name or symbol is being assigned to some firm. Teacher thought works with names and symbols. We saw earlier that Teacher emotion has to be taught in order to be appreciated. Thus, a name or symbol has no meaning or generality unless it acquires this by being associated with some firm or else becoming part of some language. For instance, the word 'Sony' was invented in 1958 to replace the company name 'Totsuko' (Hall, 2020). This meaningless word acquired Teacher generality as a result of Sony's success at selling transistor radios, transistor calculators, and Trinitron color televisions. Thus, a firm itself and its products provide the mental content that add substance to the TMN of a brand name. This suggests that the idea of trademark is cognitively natural, as long as trademarks are allowed to become part of the language if they acquire an established meaning that goes beyond the firm. That transition was discussed earlier when looking at genericization.

Academia deals with the problem of intellectual ownership by acknowledging the person who first came up with an idea, as expressed by the references and citations that are found in academic papers. Citations do not lead to financial utility, but they do result in a form of emotional utility which can often be turned into some form of financial reward. Cognitively speaking, this is similar to a trademark. Looking at this in more detail, personal status is usually represented by MMNs within Mercy thought composed of various experiences and situations associated with that person. Academic status, in contrast, focuses upon the name of a person, and a name is a verbal label within Teacher thought that refers to some person. If a theory that is developed by some person becomes generally known and applied, then this will increase the order-within-complexity of that theory, causing the name of the associated scholar to acquire Teacher status. For instance, Isaac Newton is associated with his three laws of motion. Because Mercy emotions feel like Teacher emotions, Teacher respect for the theory of some scholar may spill over to generate Mercy feelings of status, but the primary source of this emotion is coming from Teacher thought and Teacher generality.

One problem with the academic approach is that names are too rival and too excludable. If one scholar is given credit for discovering a theory, then another scholar will not receive the credit. Going further, the first scholar to make some discovery will receive all the credit. For instance, Newton and Leibniz fought vigorously over who should receive the academic credit for having invented calculus. In addition, there are far fewer general theories than specific goods, and discovering a new general theory is far more difficult than developing some new product. The end result is that a few scholars become fabulously wealthy in terms of Teacher utility while other scholars are merely footnotes in the book of history.

Notice that this extent of personal inequality does not happen when trademarks are applied to firms, because firms can grow to be large entities that include many employees; thus, many individuals can share in the Teacher status of some firm by being employees of that firm. For instance, 'I work for 
NASA' conveys feelings of Teacher status, whereas 'I use Newtonian physics' does not. That is because my work is helping NASA to develop exciting new products, whereas my use of Newtonian physics does not add anything to the theory of Newton.

A similar Teacher-based method is used with computer programs. Computer programs are expensive to develop but cost almost nothing to copy and distribute. Intellectual property views this inherent nonrival and non-excludable nature as a problem that should be fought through government legislation. However, the development of the Internet leads to an alternative strategy which regards the non-rival and non-excludable nature of software as a feature to exploit rather than a bug to eliminate. This can be seen in social media programs such as Facebook, Twitter, or any other program that includes some aspect of social interaction. The value of such a program depends upon its Teacher generality, because more users means more people with which one can potentially interact. For instance, a 2021 survey revealed that 23\% of American adults use Twitter while 69\% use Facebook (“Social media”, 2021).

This leads to the same kind of inequality that exists with academic credit, because human attention is a finite resource. If people are using one program to interact, then they will not be using another program. Academia assigns credit to the scholar who first publishes some concept. The computer industry is not driven by any such intellectual code of ethics. Instead, what matters is gaining and maintaining Teacher generality. Thus, new programs will typically be given away for free, or bundled for free with other programs that are already widely used. And even when programs are sold, some software piracy will be tolerated in order to increase market share. "While piracy on large-scale is clearly detrimental to profits, a strategic tolerance toward some piracy may actually increase profits. Specifically, piracy may help in diffusing the software to its target market because it increases the size of the user base, resulting in benefits to legal buyers due to network externalities” (Haruvy, 2004). Often, the program that ultimately becomes the most dominant is not the original program but rather some later program which takes the fundamental ideas of the original program and packages and markets them more successfully. For instance, Visicalc was the first spreadsheet program, and it drove the sale of the Apple II computer as a 'killer app'. But when the IBM PC was introduced, then Visicalc was replaced by Lotus 1-2-3, which became the best-selling PC software in the world. However, Lotus 1-2-3 itself has been replaced by Excel, a part of the Office suite sold by the juggernaut Microsoft (Cornell, 2021).

That leads to the problem of monetization. How can market share be turned into financial gain? One method is through education. This takes advantage of the fact that intellectual objects are harder to define than concrete objects. For instance, I have found when helping people to use computers that the typical beginning user has no concept of where information is being stored: 'What is a folder? What does it mean to copy information from one folder to another?' Saying this another way, education recognizes that ownership requires a knowledge of Perceiver facts and Server sequences. The more complicated a device or concept, the greater the need for mental ownership. Money can be made teaching users how to mentally own devices that they have purchased and supposedly own. And the more widely that some gadget or program is used, the greater the opportunity for making money from having the technical skill and knowledge that are required to use this device or app. For instance, Linux is given away for free as an operating system. But Red Hat has succeeded in making so much money 
from Linux through technical support and education that it was acquired by IBM in 2018 for \$34 billion (Baker, 2018).

Two other methods of monetization have emerged which both relate to Teacher generality. The first method is advertising. The primary goal of advertising is to form mental networks within the mind of potential consumers. This is known as brand awareness, and brands were discussed earlier when looking at oligopolies (and trademarks). One paper explains that "Brand awareness refers to whether consumers can recall or recognize a brand, or simply whether or not consumers know about a brand... The brand name provides the memory nodes in consumers' minds, and consumers may link the brand knowledge to the brand name, which culminates in brand equity. Hence, brand awareness provides learning advantage for the brand and influences consumer decision making. Brands that consumers know are more likely to be included in the consumers' consideration set” (Huang, 2014). Notice the various characteristics of a mental network. A 'memory node' is being formed 'in consumers' minds'. This provides a 'learning advantage for the brand' and 'influences consumer decision-making'. Using cognitive language, thinking about some product triggers the mental network of a firm that produces this product, and this mental network then imposes its structure upon the mind, motivating the consumer to purchase that firm's version of the product.

This type of emotional pressure normally comes from MMNs, but Teacher thought is being added in three ways. First, brand names and symbols are being emphasized, and both are elements within Teacher thought that are used to represent many specific items. The second aspect of Teacher thought involves Platonic forms. A Platonic form is an idealized and simplified image that forms within Mercy thought as a result of some Teacher theory. For instance, if Teacher thought comes up with a general theory of 'round things', then this will lead to the Platonic form of the ideal circle which is based in real circles but is also more perfect and ideal than any real circle. Similarly, advertising can emphasize Teacher thought by portraying a form of alternate reality that is simpler and more ideal than real life. For instance, when the firm's cleaning product is being used, then the sun will shine, the birds will sing, and the countertops will glisten. Third, Teacher thought can be added implicitly by replicating a mental network within the minds of more people. For instance, there is no Teacher generality when one person drinks a cup of coffee. But if millions of viewers watch this person drinking coffee on television, then the specific experience has acquired Teacher generality.

Any mental network that acquires Teacher generality will, by definition, be activated in more situations, and thus influence a greater range of purchasing decisions. If the goal is to achieve Teacher generality, then it makes sense to do this using a method that involves Teacher generality. Thus, advertising will attempt to piggyback upon methods that embrace Teacher generality, such as radio, television, the Internet, or social networking. This provides a way of monetizing Teacher generality: advertisers pay money to advertise and advertising acquires Teacher generality by being added to messages and media that possess Teacher generality.

Another way of monetizing Teacher generality is through data mining. In the words of one author, "Digital data represents the newest key asset organizations should use to gain a competitive edge. Data can be sold, matched with other data, mined, and used to make inferences about anything, from people's behavior to weather conditions... An entire business ecosystem has emerged around the digital 
data asset, and new types of companies, such as analytical competitors and analytical deputies, are proliferating as a result of the analysis of digital data. However, virtually absent from the big data debate is any mention of one of its constitutive mechanisms - that is, dataveillance. Dataveillancewhich refers to the systematic monitoring of people or groups, by means of personal data systems in order to regulate or govern their behavior” (Degli Eposti, 2014).

Dataveillance involves the convergence of several elements which all emphasize Teacher thought and Teacher generality. The first requirement is access to many customers, which requires a firm or organization that has achieved Teacher generality. The second requirement is data, which means gathering knowledge about the behavior of people. We have seen that knowledge and data involve the abstract realm of Teacher thought. Analyzing this data requires powerful computers. Computers function within the Teacher realm of verbal instructions, and a modern computer contains incredible Teacher order-within-complexity. Analyzing big data leads to general conclusions-general statements that summarize the behavior of many people. And big data is most useful for large firms and governments - social organizations that exhibit Teacher order-within-complexity. When various Teacher structures become combined, then the end result is even greater Teacher order-withincomplexity. Big data increases Teacher order-within-complexity in both directions. In the one direction, it becomes possible to make general statements about millions of individuals. In the other direction, it becomes possible to make statements about human thought, an aspect of humanity which has neveruntil now-been accessible. The ultimate result is Teacher generality that applies to all aspects of all human thought and behavior. Obviously, firms and governments will be willing to pay for big data in order to 'to gain a competitive edge', and 'the analysis of digital data' will lead to 'an entire business ecosystem'.

Going further, in the same way that Teacher emotion causes a bureaucracy to grow for its own sake, so the process of gathering big data will itself become driven by Teacher emotion. For instance, the CIA's chief technology officer infamously stated in a 2013 speech that "The value of any piece of information is only known when you can connect it with something else that arrives at a future point in time. Since you can't connect dots you don't have, it drives us into a mode of, we fundamentally try to collect everything and hang on to it forever” (Konkel, 2013). This goes beyond Teacher generality to the holy grail of Teacher thought, which is Teacher universality.

Saying this more simply, 'if you're not paying for it, you become the product'. A Forbes article provides Google as an example. "Google will track what you search for in its search engine facility and then use that intelligence to its advantage. It may suggest YouTube videos you might like or simply present you with advertisements it thinks are relevant to you. It's obvious why Google is doing this. Advertising is its main source of income, boasting \$38 billion every year. And it makes complete sense to offer advertisers 'targeted ads' to the right audience because in most cases Google only gets paid if someone 'clicks' on an ad link. Naturally, the more relevant and successful the advertising program, the more money Google will make” (Goodson, 2012). That article describes what focused advertising was like back in 2012. Moving forward to the current situation in 2021, the Forbes webpage that contains this article includes five visual ads (mostly targeted), a video ad that automatically plays, a popup asking to fill out a survey—so that the ads can be more targeted, and a complaint that I am using a 
popup blocker to limit the use of ads. The actual text of the article occupies less than half of the screen. And Forbes magazine is regarded as a reputable website.

Cognitive theory suggests that attempting to turn back the clock and eliminate data mining is futile. Thomas Kuhn claimed that a scientist who acquires a paradigm is incapable of letting go of this paradigm. "What scientists never do when confronted by even severe and prolonged anomalies. Though they may begin to lose faith and then to consider alternatives, they do not renounce the paradigm that has led them into crisis” (Kuhn, 1970, p. 77). Instead, a scientist will only let go of an existing paradigm if given a superior paradigm as an alternative. "Once it has achieved the status of paradigm, a scientific theory is declared invalid only if an alternate candidate is available to take its place” (Kuhn, 1970, p. 77). Using cognitive language, once behavior becomes driven by the TMN of some general theory, it is essentially impossible to return to the previous state of not being driven by a general theory. That is because Teacher emotions will provide a strong motivation to continue expanding this behavior and to eliminate all exceptions to this general behavior. The only alternative is to replace the existing Teacher theory with a more general Teacher theory.

Thus, mental symmetry suggests that only viable solution to the increasingly intrusive use of Teacherdriven technology lies in formulating personal well-being as a meta-theory that is more general than all other theories. Saying this another way, science and industry will only let go of Teacher-driven behavior that exploits human individuals if preserving the humanity of individuals is presented as a more general Teacher theory.

The theory of mental symmetry is a viable candidate. From a general perspective, mental symmetry is a meta-theory that can explain many aspects of human thought and behavior that are currently regarded as unrelated. From a personal perspective, mental symmetry defines personal well-being in terms of mental wholeness: Whatever causes cognitive modules to function together in harmony is morally good, while anything that shuts down cognitive modules or leads to conflict between cognitive modules is morally bad. The end result is a convergence of personal MMNs and universal TMNs; mental wholeness is both the ultimate goal in Mercy thought as well as the most general theory in Teacher thought.

The Encyclopaedia Britannica defines religion as "human beings' relation to that which they regard as holy, sacred, absolute, spiritual, divine, or worthy of especial reverence. It is also commonly regarded as consisting of the way people deal with ultimate concerns about their lives and their fate after death. In many traditions, this relation and these concerns are expressed in terms of one's relationship with or attitude toward gods or spirits" ("Religion”, 2020). Translating this into cognitive language, religion can be defined as an attempt to address the most general concepts in Teacher thought and how they interact with the deepest personal needs and desires in Mercy thought. In contrast, it was noted earlier that economics tends to focus upon the realm of intermediate emotional significance. Thus, a metatheory that deals with personal transformation enters the realm of religion. And mental symmetry has been used to analyze religious thought in considerable detail (Friesen, 2012, 2015).

This paper makes some references to religion. I suggest that these should not be viewed as extraneous intrusions into the discussion of economics. Instead, they should be interpreted as extending a cognitive 
model beyond the intermediately emotional realm of economics to include the strongly emotional realm. When economic thought is extended into this emotional realm, then one major religious concept that emerges is the concept of incarnation. Incarnation is not discussed in this paper, but it is analyzed from a cognitive perspective in the paper on science and theology (Friesen, 2020).

\section{Macroeconomics}

The previous section used the four kinds of economy described in microeconomics as a starting point for examining the relationship between Mercy and Teacher thought. The rest of this paper will look at macroeconomics. Economic theory emphasizes that macroeconomics is built upon microeconomics. "Macroeconomics looks at the economy as a whole. It focuses on broad issues such as growth of production, the number of unemployed people, the inflationary increase in prices, government deficits, and levels of exports and imports. Microeconomics and macroeconomics are not separate subjects, but rather complementary perspectives on the overall subject of the economy” (macro, p. 14). Using cognitive language, macroeconomics studies Teacher generality by coming up with general theories that explain the general state of the economy. Our discussion of macroeconomics will include growth, unemployment, inflation, deficits, and international trade, as well as looking more generally at money.

The macroeconomics textbook summarizes questions that are addressed by macroeconomics: "What determines the level of economic activity in a society? In other words, what determines how many goods and services a nation actually produces? What determines how many jobs are available in an economy? What determines a nation's standard of living? What causes the economy to speed up or slow down? What causes firms to hire more workers or to lay them off? Finally, what causes the economy to grow over the long term?” (macro, p. 15). Notice that these questions all involve the extent and change of Teacher generality: 'the level of economic activity', 'how many goods and services', 'how many jobs', 'standard of living', 'the economy speed up or slow down', 'hire more workers or lay them off'.

We saw when looking at microeconomics that Exhorter thought is attracted to strong emotions, especially when there is novelty. Strong Teacher emotions come from generality, which means that Exhorter novelty is provided by changes in generality, either up or down. The questions in the previous paragraph all deal with Teacher generality and how it changes. This means that Exhorter thought is not focusing upon the paradigm of some technical specialization, but rather is focusing upon the general theory of the entire economy. And what is attracting the attention of Exhorter thought is primarily the changes — or novelty — in the entire economy. ${ }^{22}$

We saw earlier that microeconomics focuses upon Exhorter-Contributor interaction. Therefore, when macroeconomics develops theories about microeconomics, then it is coming up with general theories about Exhorter-Contributor interaction. This theoretical pursuit will itself lead to Exhorter-Contributor interaction - now at a theoretical level, motivated in this case by TMNs of general theory about the economy rather than MMNs of consumer utility. And when macroeconomics focuses upon the effect

22 Notice that these are the most emotional topics for which Contributor thought has sufficient confidence and can use technical thinking. 
that various choices have upon the motivation of an entire economy, then what is being emphasized in abstract thought is again Exhorter-Contributor interaction.

Looking at this in more detail, the primary purpose of economic examination is to study how Contributor thought chooses. Microeconomics studies individual decisions, and personal decisions both affect and are affected by the general state of the economy. "The micro decisions of individual businesses are influenced by whether the macroeconomy is healthy. For example, firms will be more likely to hire workers if the overall economy is growing. In turn, macroeconomy's performance ultimately depends on the microeconomic decisions that individual households and businesses make" (macro, p. 15). The state of the economy is guided by the choices made by the institutions of government and central banks. "A nation's central bank conducts monetary policy, which involves policies that affect bank lending, interest rates, and financial capital markets... A nation's legislative body determines fiscal policy, which involves government spending and taxes” (macro, p. 15). Summarizing, both micro- and macroeconomics focus upon Exhorter-Contributor interaction. Misstating a well-known saying, this is not a matter of 'turtles all the way down' but rather one of Exhorter-Contributor interaction all the way up.

And economists recognize that economics is using a form of mental processing that ignores the content that is studied by other fields. The openstax textbook points out that "Keynes famously wrote in the introduction to a fellow economist's book: '[Economics] is a method rather than a doctrine, an apparatus of the mind, a technique of thinking, which helps its possessor to draw correct conclusions.' In other words, economics teaches you how to think, not what to think. Economists see the world through a different lens than anthropologists, biologists, classicists, or practitioners of any other discipline. They analyze issues and problems using economic theories that are based on particular assumptions about human behavior" (macro, p. 16). Notice that in both micro- and macroeconomics, economics recognizes that technical content is being gathered by other specializations but then chooses not to focus upon that technical content.

\section{Abstract Technical Thought}

When a transition is made from concrete technical thought to abstract technical thought, then this involves both a change in the approach being used and the information being studied. Applying this to economics, a market economy can be approached either from the Mercy perspective of attempting to make a profit or gain additional utility, or from the Teacher perspective of coming up with general theories about a market economy. This indicates a change in approach. But the same information is still being studied; Teacher thought is coming up with general theories about the concrete elements of a market economy. In order to make a full transition to abstract technical thought, the information has to be changed as well, which means that the concrete technical elements of cause-and-effect need to be replaced with the abstract technical elements of precise definitions. This will require translating the various elements of economics into the form of precisely-defined words.

A similar kind of duality exists in science. In the words of Paul Dirac, "The physicist, in his study of natural phenomena, has two methods of making progress: (1) the method of experiment and observation, and (2) the method of mathematical reasoning. The former is just the collection of selected 
data; the latter enables one to infer results about experiments that have not been performed. There is no logical reason why the second method should be possible at all, but one has found in practice that it does work and meets with reasonable success. This must be ascribed to some mathematical quality in Nature" (Dirac, 1940).

Looking at this cognitively, the first 'method of experiment and observation' uses abstract technical thought to build theories based upon the observations of concrete technical thought. This is a change in approach, and describes the method used by macroeconomics, which collects data about microeconomics in order to come up with general theories about the economy. "Whether you are scrutinizing lakes or economics, the micro and the macro insights should blend with each other. In studying a lake, the micro insights about particular plants and animals help to understand the overall food chain, while the macro insights about the overall food chain help to explain the environment in which individual plants and animals live” (macro, p. 15).

The second 'method of mathematical reasoning' uses verbal abstract technical thought based in precise definitions. This is a change in information. Advanced economics uses a science-like version of this second method when it comes up with mathematical models of the economy. This paper will be using the second method at a cognitive level by taking basic concepts used in macroeconomics and translating these concepts into the verbal language of precise definitions. Dirac pointed out that there is no logical reason why this second method should work in science, but it does so because of some inherent 'quality in Nature'. Similarly, it may initially appear that there is no logical reason to follow the approach that we will be using in our examination of macroeconomics. However, I suggest that this approach is valid because of the inherent quality of human cognition; the abstract structures of macroeconomics are not random but rather an expression of the structure of abstract technical thought.

Looking at this more carefully, science has discovered that replacing the information of experiments with the information of mathematics works, because mathematics can be used to predict the behavior of the physical universe. Science concludes that mathematical equations describe the behavior of the physical universe. Theoretical economics assumes that this same approach can be taken with the economy, and attempts to replace the information of economic data with the information of mathematical equations. But this only works to some extent, because the mathematical equations of economics are only partially able to predict the behavior of the economy, which is why I referred to this as science-like rather than scientific. This partial success leads to the conclusion that mathematical equations do not describe the fundamental behavior of the economy. That is because the economy is based in the interaction of people rather than the interaction of physical particles. This suggests that it is more appropriate to replace the information of economic data with the information of cognitive structure, which is the approach that will be taken in the rest of this paper.

The first economic element that will be re-examined is money. Money is viewed by the typical consumer as a sort of emotional label that is applied to various items — as expressed neurologically by labels of value within orbitofrontal cortex. Technically speaking, money is actually a generic form of cause-and-effect-as calculated by the anterior cingulate cortex. Saying this more carefully (because abstract technical thought requires careful speech), in an economic exchange the 'cause' of giving up one item is followed by the 'effect' of receiving another item in trade. Money transforms this into a 
generic cause-and-effect, because the 'cause' of giving up some good or service can be followed by the 'effect' of receiving some arbitrary item at some future time or in some other place. But abstract technical thought thinks in terms of precise definitions and not in terms of cause-and-effect. Therefore, analyzing macroeconomics adequately from a theoretical perspective must include viewing money as a form of precise definition.

Reinterpreting money as a precise definition can be made more precise by examining the role that Perceiver thought plays in the various functions of money, because Perceiver thought plays a major role in making definitions more precise. Economics defines money as having three primary functions: "First, money serves as a medium of exchange, which means that money acts as an intermediary between the buyer and the seller... Second, money must serve as a store of value... Holding money is a much easier way of storing value. You know that you do not need to spend it immediately because it will still hold its value the next day, or the next year... Third, money serves as a unit of account, which means that it is the ruler by which we measure values” (macro, p. 337).

Perceiver thought connects Mercy experiences. At the most basic level, this leads to object recognition. For instance, Perceiver thought recognizes a combination of four wheels, a metal body, and some windows as the object of a car. Object recognition is also basic to economics, because we saw when looking at intellectual property that economics breaks down when object recognition fails. Going further, it has been mentioned several times that the mind represents people as MMNs within Mercy thought. Perceiver thought observes these MMNs from 'next door' and comes up with facts about people, leading to self-image. Perceiver thought can also connect objects with people, leading to the concept of ownership. Concrete Contributor thought uses a sense of cause-and-effect to change ownership, but ownership itself is defined by Perceiver thought. (Server ownership is a secondary concept that gets added to the original concept of Perceiver ownership.) We also saw that Perceiver thought can be overwhelmed by Mercy emotions. Thus, ownership requires the rule of law, which protects Perceiver facts of ownership from being overwhelmed by MMNs of personal identity.

Looking first at the function of money as a unit of account, in the same way that Perceiver thought can build connections between facts about objects and facts about people, Perceiver thought can also use facts to connect various items, leading to the use of money as a ruler to measure value. Measuring value requires both a Perceiver and a Mercy component. On the one hand, Perceiver thought is comparing the various features of similar objects. On the other hand, Mercy thought is comparing the emotions associated with the similar objects. Whenever Perceiver facts are combined with Mercy emotions, then Perceiver facts have to be protected from being overwhelmed by Mercy emotions. Saying this more concretely, the Perceiver 'ruler' that is being used to compare one item with another must not stretch, shrink, or fall apart when being used to measure or compare emotional items.

Using money as a medium of exchange extends the use of Perceiver thought as a 'ruler'. Instead of going directly from one item in Mercy thought to another through barter, money is pausing at the intermediate stage of Perceiver facts. Looking at this in more detail, Contributor thought combines Server actions with Perceiver facts, leading to a sense of cause-and-effect. Exchange connects the 'cause' of 'this was mine' with the 'effect' of 'that is now mine'. Money is basically a potential Contributor exchange viewed as a Perceiver fact-an IOU. Using the language of economics, "Another 
function of money is that it must serve as a standard of deferred payment. This means that if money is usable today to make purchases, it must also be acceptable to make purchases today that the purchaser will pay in the future” (macro, p. 337). Saying this more concretely, the Perceiver ruler that is being used as a 'standard of deferred payment' must not stretch, shrink, or fall apart when being used to exchange items over time.

Because money is a potential exchange that can be performed in the future, money is only valuable to the extent that it can be used to carry out some future exchange. "Money for the sake of money is not an end in itself. You cannot eat dollar bills or wear your bank account. Ultimately, the usefulness of money rests in exchanging it for goods or services” (macro, p. 336). For instance, written on American money is the phrase 'This note is legal tender for all debts, public and private.' In other words, the government guarantees that this money can be used to perform some exchange in the future.

That leads to the function of being a store of value. Perceiver facts of ownership can be overwhelmed by Mercy emotions. Similarly, using Perceiver thought to represent a future exchange through the use of money can also be overwhelmed by Mercy emotions. Thus, the Perceiver facts of money need to be protected from being overwhelmed by MMNs of personal identity. Saying this more concretely, the Perceiver ruler is being treated as a legitimate entity in its own right. Therefore, it must not stretch, shrink, or fall apart.

When one is dealing with a ruler that must not stretch, shrink, or fall apart, then one is dealing with a form of precise definition. A ruler that stretches, shrinks, and falls apart cannot be defined precisely. Instead, the length of a ruler can only be defined precisely to the extent that it does not stretch, shrink, or fall apart. Summarizing, abstract technical thought will view money as Perceiver facts that retain their precise definitions.

\section{Two Kinds of Monetary Stability}

This paper has discussed two methods of maintaining the stability of Perceiver facts: absolute truth and universal truth. An additional point needs to be added, which is that Perceiver thought by itself can only resist emotional pressure for a while. For instance, 'just saying no' to some delicious chocolate cake may work for a while, but eventually Perceiver confidence will cave in to the emotional pressure. Similarly, using money as a store of value requires Perceiver confidence, but this confidence ultimately has to be emotionally backed up by some form of mental network.

We will look first at the alternative of absolute truth. Absolute truth is ultimately a contradiction in terms - a category mistake. It starts off with Perceiver thought being overwhelmed by some emotional source in Mercy thought. For instance, some monarch makes an edict, some professor makes a statement, or some prophet makes a declaration. This emotional 'truth' then acquires Perceiver stability by going through some sort of universalizing and stabilizing process. For instance, the words of the monarch will be written down on official parchment, copies will be spread throughout the realm, and the royal edict will become the official law of the land. Something similar happens when the words of a professor are recorded in an academic paper or textbook, or the words of a prophet are written down in some holy book. This leads to a mental juxtaposition in which emotional status overwhelms Perceiver 
thought into 'believing' core 'truths', while Perceiver thought has sufficient confidence to manipulate peripheral facts. These two mental regions will be separated by some sort of cognitive 'no man's land', in which the transformation from 'truth' to truth occurs. Saying this another way, absolute truth can be viewed cognitively as an intermediate form of knowing that makes it possible to move from emotional ‘truth' to universal truth.

The Great Depression of the 1930s illustrates what happens when absolute truth fails. The precise cause of the Great Depression is still being debated, but the Encyclopaedia Britannica mentions four commonly accepted factors: "(1) The stock market crash of 1929 shattered confidence in the American economy, resulting in sharp reductions in spending and investment. (2) Banking panics in the early 1930s caused many banks to fail, decreasing the pool of money available for loans. (3) The gold standard required foreign central banks to raise interest rates to counteract trade imbalances with the United States, depressing spending and investment in those countries. (4) The Smoot-Hawley Tariff Act (1930) imposed steep tariffs on many industrial and agricultural goods, inviting retaliatory measures that ultimately reduced output and caused global trade to contract” (Romer, 2020).

Absolute truth assumes Perceiver stability. Saying this in more detail, absolute truth has sufficient stability to enable technical thought, and Perceiver thought gains sufficient confidence to think about the peripheral aspects of absolute truth. But the fundamental principles of absolute truth are based in emotional respect for some source of truth. Thus, both Perceiver thought and Contributor thought are building upon an assumed foundation. This assumption of Perceiver stability can be seen in the financial trading that preceded the crash of 1929, because trading continued despite all solid connections between stocks and reality being lost. Quoting further from the Encyclopaedia Britannica, "The prices of stocks soared to fantastic heights in the great 'Hoover bull market,' and the public, from banking and industrial magnates to chauffeurs and cooks, rushed to brokers to invest their liquid assets or their savings in securities, which they could sell at a profit. Billions of dollars were drawn from the banks into Wall Street for brokers' loans to carry margin accounts” (“Stock Market”, 2021). Looking at this cognitively, Contributor thought was performing economic exchanges based upon a foundation of Perceiver facts that was assumed to be solid. This is a characteristic of Contributor thought, which treats Perceiver facts and Server sequences in a digital manner as certain if some threshold of sufficient certainty is crossed. Thus, investors in the 1920s were assuming within Contributor thought that the stock market had a solid factual foundation while within Perceiver thought the stock market was becoming totally disconnected from economic facts.

Perceiver thought eventually 'woke up’ and realized that it was building its economic facts upon an assumed foundation. 'Waking up' is an accurate term because emotional 'truth' overwhelms Perceiver thought. When Perceiver thought 'wakes up', then it will re-examine existing beliefs to determine what really is connected in a solid manner and what is not. In this case, Perceiver thought realized that there was no solid connection between the stock market and the facts of reality.

This loss of Perceiver confidence led to a loss of Contributor confidence. These two are not quite the same. Perceiver and Server confidence are analog levels that grow as a result of repetition. Contributor confidence is a certainty that the current plan (or paradigm) can continue to be followed. Contributor 
confidence is built upon an assumed foundation of Perceiver and Server confidence. In this case, the current plan involved trading within the stock market.

This interplay between Perceiver and Server confidence and Contributor confidence provides a possible explanation for business cycles. Economic growth does not happen as a smooth line but rather goes through peaks of economic expansion interspersed by troughs of economic recession. The underlying cognitive problem is that Contributor thought is based upon an assumed foundation and finds it difficult to 'see around the corner'. Saying this another way, Contributor thought performs local optimization within the context of some set of assumed Perceiver facts and Server sequences. This local optimization will continue to be followed until the underlying foundation of facts and sequences begins to be questioned. Using economic language, Contributor thought will pursue some goal based upon an assumption of ceteris paribus, which in practical terms means assuming that the underlying Perceiver facts and Server sequences will not change. Eventually, the facts and sequences will change to an extent that it becomes obvious to Contributor thought that the current plan cannot be maintained. This will be followed by a loss of Contributor confidence, which will eventually be replaced by Contributor confidence in a new plan as Perceiver thought and Server thought gain sufficient confidence in some new set of facts and sequences.

Returning to the Great Depression, Contributor thought lost confidence in a major way in the stock market crash of 1929. This was followed by the second factor of Contributor thought losing confidence in many banks, leading to numerous runs on the bank.

The third factor indicates the fundamental basis for absolute truth. When absolute truth fails, then the instinctive reaction will be to use emotional experiences to attempt to re-establish belief in the fundamental principles of absolute truth. But the imposition of emotional experiences actually leads to emotional 'truth' and not to absolute truth. That is because emotional 'truth' has to go through some sort of stabilizing process to turn into absolute truth. A gold standard is a form of absolute truth, because money ultimately acquires its value by being backed up by some physical item—such as gold - to which Mercy thought assigns emotional worth. But re-imposing a gold standard will have the immediate effect of limiting Perceiver thought, because emotional experiences are being imposed upon Perceiver thought. This explains why re-focusing upon gold as the standard reduced the amount of money that was available.

The final factor indicates the power of social MMNs. A market economy leads to increased wealth because it allows firms and countries to specialize by using technical thought. But matching up supply with demand requires trade. The Great Depression began by questioning confidence. This questioning continued to the point of threatening fundamental mental networks of society. Stated simply, the struggle turned from making money in the stock market to finding enough food to stay alive. When core mental networks of identity and culture are threatened, then this will drive people-and nationsto respond in a tribalistic manner. This was expressed economically during the Great Depression as the raising of tariffs in order to protect local economies, and it was expressed politically as the rise of Fascism with its inherent tribalism. ${ }^{23}$

23 This will be examined in more detail later. 
Absolute truth uses MMNs of personal status to 'back up' Perceiver facts. The Great Depression showed the inherent limitations of this approach. The other emotional alternative is to back up money with the TMN of some system. This happens with fiat money. On the one hand, fiat money is not supported by any physical objects or experiences within Mercy thought. "Fiat money has no intrinsic value, but is declared by a government to be a country's legal tender... The only backing of our money is universal faith and trust that the currency has value, and nothing more” (macro, p. 338). But on the other hand, fiat money facilitates the order-within-complexity of a modern economy. "The global economy has come a long way since it started using cowrie shells as currency. We have moved away from commodity and commodity-backed paper money to fiat currency... As technology increases and the need to reduce transactions costs associated with using traditional forms of money increases, Bitcoins or some sort of digital currency may replace our dollar bill, just as man replaced the cowrie shell” (macro, p. 349).

Looking at this quote from a cognitive perspective, Teacher order-within-complexity is being viewed in two different ways: First, fiat currency is being described as a way of making the global economy more efficient. Sending paper bills from one location to another is more efficient than shipping cowrie shells, while transferring numbers from one computer to another is more efficient than sending paper bills. Increasing efficiency uses abstract technical thought to improve the order-within-complexity of some system. A global economy is a physical example of Teacher order-within-complexity. Second, fiat currency is being viewed from an emotional perspective as something new-and-improved. In the same way that pen and paper have been replaced by the computer, and computers are now globally interconnected, so the cowrie shell led to paper money, which was followed by electronic money transfers, which itself may possibly be replaced by bitcoin. The average consumer has no technical understanding of bitcoin but instead regards it as the-latest-and-greatest new-and-improved. ${ }^{24}$

Summarizing, fiat currency is emotionally backed up by the TMN of the growing global economy. Saying this more carefully, whenever some Teacher theory continues to be used, then it will eventually turn into a TMN and this TMN will become represented within Mercy thought by Platonic forms that provide an internal idealized image of the essence of this Teacher understanding. For instance, someone who works within a system of financial trade will acquire a Platonic form of money. Economics may state that money has no inherent emotional value, but the Platonic form of money can acquire significant emotional intensity (often represented visually as '\$' signs in someone's eyes). Similarly, living within the consumer society with its continual stream of new-and-improved gadgets will cause a Platonic form of 'progress' to form within the mind. These TMNs and their associated Platonic forms provide the emotional backing for fiat money.

One consequence of this is that people may lose confidence in the fiat currency of a small country if the technological infrastructure of that country falls apart. The small size of the country means that it does not possess inherent Teacher generality, while the failure of the infrastructure means that the TMN of modern technology is no longer present. Two recent examples are Zimbabwe and Venezuela. In

24 'Mining' bitcoin means using computers to solve a difficult mathematical problem, and bitcoin mining now (in 2021) uses about $16 \mathrm{GW}$ of electrical power ("Cambridge", 2021), which is about the total electrical consumption of the country of Sweden. 
contrast, a small country such as Switzerland can maintain a strong currency because its infrastructure and technology are epitomes of Teacher order-within-complexity, as expressed by the phrase 'running like a Swiss watch’. ${ }^{25}$

We saw earlier that commodity-backed currency is ultimately a contradiction in terms because Mercy emotion is fighting Perceiver confidence. Similarly, Teacher overgeneralization leads to an adversarial relationship between Teacher emotions and Perceiver facts. Overgeneralization makes sweeping statements while facts limit the extent of sweeping statements. (Teacher overgeneralization is an example of intuition.) For instance, Teacher thought may make the sweeping statement that 'It always rains on the weekends', to which Perceiver thought will respond with the fact that 'It did not rain last weekend'. Sweeping statements generate positive Teacher emotions while Perceiver facts limit Teacher emotions by providing exceptions to the general rule.

Generalization, in contrast, requires the cooperation of Perceiver and Teacher thought. Perceiver thought comes up with the 'bricks' of some structure, while Teacher thought assembles these bricks into the 'structure' of a general theory. Thus, universal truth is related to generalization. That is because universal truth looks for Perceiver connections that are repeated, and any Perceiver connection that is frequently repeated will be viewed by Teacher thought as a general theory.

The infrastructure of a modern economy is an example of Teacher generality. And Teacher generality supports Perceiver stability. The end result is that fiat money is cognitively more stable than commodity money—as long as the order-within-complexity of modern society is maintained.

\section{Printing Money}

Fiat money is created in three primary ways. The most direct option is for a government to print money. This can lead to hyperinflation. "Extreme cases of governments recklessly printing money lead to hyperinflation... Only national governments have the power to cause hyperinflation. Hyperinflation typically happens when government faces extraordinary demands for spending, which it cannot finance by taxes or borrowing. The only option is to print money—more and more of it” (macro, p. 239). Government was defined earlier as a social system of Teacher order artificially constructed by a group of people. When a government behaves 'recklessly', then this is an indication that the artificial orderwithin-complexity of government is breaking down. (And the 'extraordinary demands for spending' imply that the Teacher structure of the economy is also faltering.) When a government loses its Teacher structure, then it becomes merely an ideology enforced by thugs-a group of people using their Mercy status to impose the illusion of Teacher structure upon the rest of the population. The fiat money of such a regime will naturally lose its value: It is no longer emotionally backed up by the TMN of societal structure and it is not backed up by the MMNs of some valuable commodity. The only emotional backing that remains are the MMNs of emotional status of those in power, and this emotional status will be lost as leaders become viewed as dictators who have no legitimate claim to political power.

25 We are looking here at the cognitive and emotional basis for fiat currency, because fiat money is ultimately supported by belief. Swiss technology and infrastructure also make it possible for Switzerland to build technical products that are demanded in other countries, leading to a strong currency. 
The previous section related preserving the stability of money to maintaining precise definitions. Using this parallel, one concludes that postmodern questioning is a form of hyperinflation. Wikipedia explains that "Postmodernism is an intellectual stance or mode of discourse defined by an attitude of skepticism toward what it describes as the grand narratives and ideologies of modernism, as well as opposition to epistemic certainty and the stability of meaning... Postmodernism is associated with relativism and a focus on ideology in the maintenance of economic and political power... It can be described as a reaction against attempts to explain reality in an objective manner by claiming that reality is a mental construct" ("Postmodernism", 2021). Several parallels between hyperinflation and postmodernism are mentioned: 1) An attitude of skepticism toward grand narratives. Similarly, in hyperinflation there is an attitude of skepticism toward the Teacher order of the government and the economy. 2) Opposition to 'stability of meaning'. Stability of meaning was interpreted earlier as maintaining the value of money. In hyperinflation, money loses all stability of meaning. 3) A focus upon 'ideology in the maintenance of economic power'. An ideology is a fake Teacher theory promoted to maintain power. Similarly in hyperinflation, the monetary system becomes regarded as an ideology being promoted to maintain economic power. 4) Reaction against 'explaining reality in an objective manner'. In hyperinflation, the connection between money and reality is lost. Money no longer corresponds in any objective manner to economic reality.

Hyperinflation of meaning can also be seen in 'fake news'. Fake news can be defined as "fabricated information that mimics news media content in form but not in organizational process or intent. Fakenews outlets, in turn, lack the news media's editorial norms and processes for ensuring the accuracy and credibility of information" (David, 2018, p. 1094). In other words, in the same way that money is being printed by government regimes that present the illusion of the Teacher structure of modern technical society, so fake news is being propagated by sources that present the illusion of the Teacher structure of a legitimate media organization with its technical analysis.

Looking at further parallels, hyperinflation starts when traditional means of generating funds no longer work. Similarly, "General trust in the mass media collapsed to historic lows in 2016, especially on the political right, with $51 \%$ of Democrats and $14 \%$ of Republicans expressing 'a fair amount” or 'a great deal' of trust in mass media as a news source" (David, 2018, p. 1094). When TMNs of societal structure fade, then what remains are MMNs of power and tribalism. Similarly, "Polarization of partisan preferences has dramatically increased over the past 40 years, reducing opportunities for crosscutting political interaction. Homogeneous social networks, in turn, reduce tolerance for alternative views, amplify attitudinal polarization, boost the likelihood of accepting ideologically compatible news, and increase closure to new information. Dislike of the 'other side' (affective polarization) has also risen” (p. 1095). The regime then attempts to solve its economic problems by printing money. Similarly, "By liking, sharing, and searching for information, social bots (automated accounts impersonating humans) can magnify the spread of fake news by orders of magnitude. Facebook estimated that as many as 60 million bots may be infesting its platform. They were responsible for a substantial portion of political content posted during the 2016 U.S. campaign” (p. 1095). 'Liking' and 'sharing' - whether done by humans or by bots—are a form of 'printing' intellectual currency, because in both cases quantity is making up for a loss of precision. 
Summarizing, both postmodernism and fake news involve hyperinflation of meaning. This cognitive equivalence is interesting because postmodernism is considered to be 'liberal' or left-wing while fake news has become associated with 'conservative' or right-wing. This implies that the same end state of cognitive hyperinflation can be reached through a left-wing path or through a right-wing path.

The second method of generating money involves a central bank. In most modern countries, the government does not directly print money. Instead, money is printed by a central bank that functions independently of the government. For instance, in the United States the Federal Reserve acts as the central bank, and printed money has the label 'Federal Reserve Note'. A central bank has three primary functions: "1. To conduct monetary policy. 2. To promote stability of the financial system. 3 . To provide banking services to commercial banks and other depository institutions, and to provide banking services to the federal government” (macro, p. 358).

In the same way that a central bank promotes the stability of the financial system, so academia promotes the stability of knowledge and information. The average individual does not interact directly with the central bank. Similarly, the average individual does not interact directly with academia. Instead, a central bank provides banking services to regular banks which do interact with consumers. Likewise, academic interaction occurs primarily at the 'inter-banking' level of academic papers, and academic papers are written and read primarily by professors at institutions of higher learning. The average person encounters academic thought by interacting with professors and instructors at these institutions of higher learning.

Looking at this cognitively, we saw when looking at microeconomics that a market economy connects the various specializations of concrete technical thought with the MMNs of consumer need and desire. This system is being maintained economically by a central bank that functions at the level of abstract technical thought, guided by the Teacher goal of 'promoting the stability of the financial system'. And this system is being maintained educationally by an academic system that also functions at the level of abstract technical thought, guided by the Teacher goal of ensuring that academia continues to function at a level of sufficiently technical abstract thought. Anyone who has acquired a $\mathrm{PhD}$, or has attempted to publish an academic paper, knows from personal experience what it means for academia to maintain a sufficient level of abstract technical thought. Economics acknowledges the educational aspect as human capital, but the educational aspect is actually more fundamental than the economic side, because the system of technical education teaches the knowledge and skills that are required to design and produce the goods and services of a modern economy.

However, what is most fundamental is the cognitive development that makes it possible for people to function at the level of abstract technical thought with its Teacher paradigms. This can be illustrated by the number of foreign students in the typical Western university. The university system maintains a high level of abstract technical thought, but many of the students now come from outside North America and Europe, indicating that Western culture is having difficulty generating the level of cognitive development that is required to take advantage of Western academia. And the proportion of international students is highest in the STEM fields that emphasize abstract technical thought (Ruiz, 2014). Looking specifically at Canada, if one looks at the twenty most popular universities, between a quarter and a half of those pursuing graduate degrees are international students (Dwyer, 2017). 
If money is printed by a central bank and not by the government, then the government has to borrow money just like any other institution. "Each year, the government borrows funds from U.S. citizens and foreigners to cover its budget deficits. It does this by selling securities (Treasury bonds, notes, and bills) - in essence borrowing from the public and promising to repay with interest in the future” (macro, p. 411). In the United States, the right 'to coin money' was delegated to the Federal Reserve when it was created in 1913.

A similar transition has happened in the realm of knowledge. Government used to be regarded as the ultimate arbiter of truth and knowledge. Whatever the government decreed became the absolute truth of the land. But modern government has delegated this function to academia. When some scientific discovery is made by academia, then government is expected to pass laws that are consistent with this scientific discovery. For instance, this relationship between academia and government temporarily changed under the presidency of Donald Trump. In contrast, the White House website currently says the Biden administration will be "restoring scientific integrity and evidence-based policymaking across the federal government, and re-establishing the President's Council of Advisors on Science and Technology” (“Fact Sheet”, 2021).

\section{Expanding Money}

The third way of generating money is by banks through the method of fractional reserve. This reserve ratio is set by the central bank. For instance, suppose that $\$ 1$ million is deposited in a bank and the reserve ratio is $10 \%$. Based upon this $\$ 1$ million deposit, the bank can then make $\$ 10$ million of loans. Going further, if these loans are then deposited in other banks, then the $\$ 1$ million dollar deposit could potentially end up expanding the money supply by $\$ 90$ million. "All the money in the economy, except for the original reserves, is a result of bank loans that institutions repeatedly re-deposit and loan” (macro, p. 348).

It was mentioned earlier that emotional 'truth' has to go through some sort of stabilizing process in order to turn into absolute truth. A bank provides this kind of stabilizing process when it expands the supply of money. Simply printing money would base that money in MMNs of personal status. But when money goes through the institution of a bank, then the TMN of respect for that institution adds emotional backing to the money that is being created by the bank. Notice also that a bank is multiplying money rather than creating it out of thin air the way a central bank does.

A similar cognitive process happens with universities and other institutions of higher learning. If my neighbor insists that some fact is 'true', then I will probably view this as a form of emotional 'truth', and feel that my neighbor is using emotional manipulation to try to impose some 'fact' upon me. But if a professor at a university states the same fact, then this will probably be viewed as absolute truth. That is because the words of the professor are emotionally backed up by TMNs of respect for the institution of the university. This assumes, of course, that words have not lost their meanings through the 'hyperinflation' of either postmodernism or fake news.

The stabilizing process carried out by banks and universities is typically reinforced by the physical stability of bank and university buildings. For instance, many university buildings have been 
constructed in a form of architecture known as Gothic Collegiate. The supervising architect at Princeton University, for example, "hoped that as a well-planned, collegiate Gothic university, Princeton would, like Oxford and Cambridge universities, evoke a tradition that transcended the limits of time and place, a tradition that was infused with the standards of scholarship and character" (Lanford, 1982, p. 184). 'Tradition infused with standards of scholarship' describes the nature of absolute truth, which acts as the timeless reference point for factual analysis. Similarly, "Between 1870 and 1914 there was an unprecedented expansion of the ancient universities in England and an entirely new sector of higher education, the Redbrick's universities, appeared in some provincial cities... Architects attempted to establish a new style of collegiate architecture which would suggest the antiquity and prestige of the universities, yet be appropriate for the demands of the late nineteenth century” (Lowe, 1982). ‘Antiquity and prestige’ are characteristics of absolute truth, while modern research and development began in the late $19^{\text {th }}$ century.

A similar distinction between source of truth and multiplier of truth can be seen in religious systems. A holy book takes on the role of a central bank because it is the ultimate source of absolute truth. However, a book only contains a finite amount of words. Therefore, the absolute truth of a holy book has to be expanded by some sort of religious priesthood, which plays the role of banks. These priests will be viewed as custodians of the holy book and this emotional status will allow them to extend the absolute truth of the holy book by interpreting its message of absolute truth.

A bank does not give away money but rather expands the supply of money through loans. A loan allows a borrower to use money that belongs to someone else, and interest has to be paid on borrowed money. Cognitively speaking, a loan separates Perceiver ownership from Server ownership. Money was defined earlier as Perceiver confidence that some Contributor exchange can be performed in the future. A loan allows someone else to use the money, and using implies the actions of Server thought. Lending money retains Perceiver ownership because the money still belongs to the lender, but it temporarily transfers Server ownership, because the borrower can use the money.

A similar relationship can be found in institutions of higher learning. This relationship becomes apparent if one understands the cognitive equivalent of ownership. A person 'owns' a fact when Perceiver thought is able to hold on to this fact in the midst of emotional pressure. For instance, if a person knows that 'smoking causes cancer' but lacks the mental confidence to assert this fact when craving a cigarette, then that person does not 'own' this fact. Truth is mentally 'purchased' by acquiring the Perceiver confidence that is needed to hold on to this truth. Perceiver facts describe connections. Perceiver confidence in some connection will naturally grow whenever Perceiver thought notices that this connection is repeated. Perceiver confidence gives a fact the ability to survive emotional pressure. Thus, building Perceiver confidence usually includes going through some sort of testing process. This may involve the pragmatic testing of some personal struggle or the formal test of passing some school examination. In both cases, the ability to use Perceiver thought under stress is being tested.

Absolute truth is borrowed in the sense that Perceiver thought is acquiring facts that are owned by other people. Absolute truth is unavoidable because of the nature of technical specialization. It is impossible today to have an adequate technical knowledge of all specializations. For instance, mental symmetry uses Perceiver thought to look for cognitive similarities between various technical specializations. 
Doing this sort of massively interdisciplinary research adequately requires gaining a knowledge of many technical specializations. It has taken me decades to become competent in half a dozen different fields. Thus, one of the inevitable by-products of a market economy is that most facts will have to be accepted as absolute truth from the experts of various specializations.

It was suggested earlier that academia has convinced modern society into believing that technical thought is the only valid form of knowledge. (Postmodern thought questions this belief but does not provide an alternative.) It was also mentioned that technical thought can be based either in a foundation of absolute truth or universal truth. This means that technical thought can be expanded through the use of absolute truth. Describing this in more detail, a student goes to an institution of higher learning and is taught technical thought within some specialization. The typical student will be able to use Perceiver thought to analyze some of this information but will accept most of the facts as absolute truth based in TMNs of respect for the institution of higher learning, combined with MMNs of respect for personal authorities within this institution. After graduation, the student will then use this technical knowledge within some job that requires technical skills. Using the technical knowledge will build Server ownership. That is because Server confidence can be acquired by repeating some action, which is done when practicing or rehearsing. But most of the technical knowledge will still be borrowed at a Perceiver level because it will be viewed as absolute truth acquired in an institution of higher learning. This borrowing of technical thought works because technical thought can function with either absolute truth or with universal truth.

When absolute truth is 'borrowed', then a form of 'interest' has to be paid. Interest is money that one person has to pay for the privilege of borrowing money from another. Similarly, a student of absolute truth has to 'pay' for the expertise that is required to apply this absolute truth in an intelligent manner. For instance, a technician may be guided by instructions in a handbook that are not fully understood, but a technician has learned how to follow the instructions of the handbook in a competent manner. This is related to the concept mentioned earlier that absolute truth uses Perceiver thought when dealing with peripheral aspects. This development of Perceiver thought at the periphery is the mental 'interest' that is being paid on the 'loan' of absolute truth.

When money is borrowed, then some of the principal will usually be paid back in addition to the interest. Similarly, applying the instructions of absolute truth in an intelligent manner will gradually help Perceiver thought to gain confidence in this information. Over time, this will 'pay back' the initial intellectual debt of 'borrowed knowledge', until eventually all of the absolute truth has been replaced by universal truth. The student that originally believed the information because 'it is written in the textbook' now knows the information because of repeatedly experiencing that 'this is how things work'. Thus, absolute truth was described earlier as a transitional form of learning that leads from emotional 'truth' to universal truth.

A central bank can regulate the economy through monetary policies. "A central bank has three traditional tools to implement monetary policy in the economy: open market operations; changing reserve requirements; changing the discount rate” (macro, p. 362). It is possible to come up with a cognitive explanation for these policies by examining the corresponding interactions that exist in the relationship between academia and institutes of higher learning. 
The most common monetary policy in the United States is open market operations. A central bank will either expand the money supply by using money that it has printed to buy bonds, or it will reduce the money supply by selling bonds at some interest rate. In a similar manner, academia has the power to add or remove the 'currency' of knowledge from the 'marketplace' of ideas. When some new concept is published in a peer-reviewed journal, then this expands the supply of ideas. Similarly, when an academic paper is withdrawn or previous knowledge is shown to be inadequate, then this reduces the supply of ideas.

This is a valid comparison because both the economy and academia use technical thought. Looking at this in more detail, money was defined earlier as a guarantee of a future transfer of ownership. Instead of bartering one good for another, money is received for the first good and this money is then exchanged at some later date for the second good. An economic exchange is an example of cause-andeffect, and concrete technical thought is based upon such 'bricks' of cause-and-effect. Saying this another way, money adds an internal, intermediate step to the physical cause-and-effect of barter. Similarly, learning a practical skill adds an internal, intermediate step to the cause-and-effect of physical action. Instead of responding to some physical need in a simple Pavlovian manner of stimulusand-response, concrete technical thought acquires some skill through learning and practice and then applies this skill at some later date.

Macroeconomics uses abstract technical thought to formalize the system of money. Similarly, academia uses abstract technical thought to formalize the system of education. Abstract technical thought develops processes based upon precise definitions. Money is created by a central bank by going through a precisely-defined process carried out by an official institution. Similarly, knowledge is created by academia by going through a precisely-defined process of publishing carried out by official journals.

Going further, open market operations affect the supply of money by interacting with the existing banking structure. Printed money is not just dumped on the street or taken out of peoples' wallets. Instead, existing institutional debts (bonds) are bought or sold. Similarly, academia usually adds to the currency of technical thought by providing technical explanations for existing technical problems. Whenever academia comes up with a rational explanation for previously unexplained data, then this effectively cancels an intellectual debt, because information that previously had to be regarded as a form of absolute truth can now be explained using Teacher understanding and Perceiver facts. This understanding expands the supply of intellectual 'currency' because general theories can be applied to new situations. Going the other way, when some theory or fact is officially withdrawn, then this will also have a ripple effect upon the 'economy' of ideas.

A central bank can also affect the supply of money by changing reserve requirements, which "is the percentage of each bank's deposits that it is legally required to hold either as cash in their vault or on deposit with the central bank. If banks are required to hold a greater amount in reserves, they have less money available to lend out. If banks are allowed to hold a smaller amount in reserves, they will have a greater amount of money available to lend out” (macro, p. 364). Academia carries out a similar function by regulating the ratio of empirical evidence to theoretical extrapolation. Science is based in empirical evidence-real principles of cause-and-effect gathered from observing the physical world. 
But science also extrapolates from empirical evidence by using Teacher thought to come up with general hypotheses. This leads to a tension between specific Perceiver facts and general Teacher theories. Academia can regulate this tension by deciding how far one is permitted to generalize before requiring more specific facts. If too little generalization is permitted, then this will stifle the 'economy' of academic interaction. But if too much generalization is used, then this may lead to a loss of confidence in academic institutions. A similar tension exists within the economy. Banks can expand the supply of money by 'extrapolating' from existing deposits. A central bank regulates the extent of this extrapolation. If too little expansion is permitted, then this will stifle the economy by restricting the supply of money. But if too much expansion is used, then this may lead to a loss of confidence in banking institutions_-expressed as a bank run.

Finally, a central bank changes the discount rate, which is the interest rate that the central bank charges to other banks. Explaining this in more detail, the initial problem was that consumers could lose confidence in banks. "Even a rumor that a bank might experience negative net worth could trigger a bank run and, in a bank run, even healthy banks could be destroyed. Because a bank loans out most of the money it receives, and because it keeps only limited reserves on hand, a bank run of any size would quickly drain any of the bank's available cash” (macro, p. 361). The solution was to set up a central banking system. "The Federal Reserve was founded to be the 'lender of last resort.' In the event of a bank run, sound banks, (banks that were not bankrupt) could borrow as much cash as they needed from the Fed's discount 'window' to quell the bank run. We call the interest rate banks pay for such loans the discount rate" (macro, p. 365). Summarizing, the method of fractional reserve banking means that no bank has sufficient cash on hand to allow everyone to withdraw their money. Therefore, this method will only survive as long as there is sufficient confidence in the system. A central bank helps to preserve confidence in the system.

Similarly, institutions of higher learning did not always have the respect of the population. That is because they use Teacher generalization to 'expand' the existing supply of empirical facts. No academic institution can survive if concrete factual evidence is demanded for every concept being taught. The system of academia with its peer-reviewed journals was initially established in order to be a 'lender of last resort'. If people lose confidence in some institution of higher education, then it is always possible to appeal to the system of academia for help. For instance, 'This is a respectable university because the professors all have higher degrees acquired at legitimate academic institutions and they have all published papers in respected journals.' Systems of academic accreditation now exist to ensure that individual universities meet accepted standards of academic rigor, because the public may lose confidence in universities that are not accredited.

Accreditation also ensures that academic credits gained in one university are transferable to other universities. Similarly, the deposits of individual investors are protected through deposit insurance. In the United States, "Even if a bank fails, the government guarantees that depositors will receive up to $\$ 250,000$ of their money in each account” (macro, p. 361). Even if an accredited university ceases to exist, the academic credits that were acquired at that university will continue to be honored within the system of academia. Banks have to pay an insurance premium in order to have access to deposit insurance. Similarly, becoming and staying accredited as an institution requires meeting various 
technical standards that go beyond normal academic technical thought. A similar technical overhead is incurred whenever a firm or organization becomes officially accredited in some manner.

Putting this all together, both banking and higher learning are supported by numerous systems of abstract technical thought, each enhanced emotionally by TMNs. Each entity within the system performs technical operations, guided by TMNs of 'official procedure'. Each entity is housed physically within buildings that exhibit solid Teacher order. The entities are themselves organized within a general system of Teacher order-within-complexity. And the output of both systems is a form of 'currency' that can be used to enable technical thought. Mental symmetry suggests that these similarities are neither random, nor the result of one of these systems copying the other, but rather because people are being driven by the structure of the mind to solve similar cognitive problems in similar cognitive ways.

Comparing these two, I suggest that higher learning is more fundamental than banking because higher learning deals with the actual content of abstract technical thought while banking uses money, which merely represents the content of technical thought. An original item is more fundamental than anything that represents this item. Historically speaking, both banking systems and universities began in Renaissance Italy, but the university may go back a little further than the banking system. In the words of Wikipedia, "the University of Bologna [was] founded in 1088 by an organised guild of students (hence studiorum), it is the oldest university in continuous operation in the world, and the first university in the sense of a higher-learning and degree-awarding institute, as the word universitas was coined at its foundation" ("University”, 2021). Similarily, "Many histories position the crucial historical development of a banking system to medieval and Renaissance Italy and particularly the affluent cities of Florence, Venice and Genoa. The Bardi and Peruzzi Families dominated banking in 14th century Florence” (“History”, 2021).

\section{Inflation}

Hyperinflation was discussed earlier as the breakdown of an economic system. Inflation occurs within an economic system. The primary mandate of most central banks is to reduce inflation. "Many countries have rewritten their central banking laws since in the 1990s to have their bank practice inflation targeting, which means that the central bank is legally required to focus primarily on keeping inflation low. By 2014, central banks in 28 countries, including Austria, Brazil, Canada, Israel, Korea, Mexico, New Zealand, Spain, Sweden, Thailand, and the United Kingdom faced a legal requirement to target the inflation rate” (macro, p. 374).

Inflation looks at prices from a perspective of Teacher generality. "Inflation is a sustained increase in the overall level of prices, and is measured by the consumer price index" (macro, p. 135). Inflation involves Teacher generality because it is a 'sustained increase in the overall level', which means that all money is purchasing less technical products or services as time passes.

Inflation tends to be associated with several characteristics. "In a number of middle- and low-income economies around the world, inflation is far from a solved problem... In these countries, the problem of very high inflation generally arises from huge budget deficits, which the government finances by 
printing its domestic currency. This is a case of "too much money chasing too few goods"' (macro, p. 465).

Looking at the situation of 'low-income economies', we have examined the relationship between the banking system and higher learning. We also saw that both the fiat money of a central bank and the 'fiat money' of academia are emotionally based in various institutional TMNs. A middle- or lowincome economy will not have such institutional and educational structures. In such an environment, it is easy for money to lose its value. Looking at this more carefully, fiat money acquires its stability by passing through institutions and processes that are driven by abstract technical thought. (Abstract technical thought uses precise definitions and carefully-defined processes within some specialization, but it is emotionally driven by the TMN of some paradigm.) When this money is used to purchase some technical good or service, then this will be viewed as a technical exchange. However, if a government tries to pay for its debts by printing money, then this will feel like exchanging 'funny money' for real technical services. This may sound like a weak argument, but we saw earlier that those who use technical thought have a natural tendency to emotionally belittle thinking or behavior that is regarded as insufficiently rigorous. Most goods and services in a modern economy require technical thought. 'Funny money' will be regarded as insufficiently rigorous to be used in such an economy. For instance, I have often experienced Americans looking at my colorful Canadian money and declaring it to be 'funny money'.

This can be clarified by looking at the educational equivalent. Non-accredited schools are typically viewed intellectually as sources of educational 'funny money'. This can often be seen, for instance, in a Bible School or Christian University. The intellectual content of such an institution tends to be based in the absolute truth of the Bible and Christian experts. Intellectual content that comes from a holy book will naturally be emotionally belittled by the technical thinking of academia as lacking in empirical evidence.

We saw earlier that all education uses absolute truth. That is because it is impossible for a finite person to gain a rational understanding of all technical understanding. Therefore, most knowledge has to be accepted initially because 'it is written in the textbook' or 'it was taught by a professor'. Thus, the problem does not lie with the use of absolute truth but rather with paying off the intellectual debt that is incurred by the use of absolute truth. An intellectual debt can be 'paid off' by gradually turning Perceiver 'truth' based in respect for some authority with Perceiver facts that are supported by repeated experience. This transforms 'who is right' into 'what is right'. This was mentioned earlier when looking at interest.

Turning now to the matter of 'huge budget deficits', the temptation is for a government to to finance this by 'printing its domestic currency'. Government was defined earlier as a Teacher structure based in social interaction. The educational equivalent of a government 'printing its domestic money' is when a group of people uses social structure to proclaim more absolute truth. For instance, a Bible school may become fundamentalist and emphasize that all of its beliefs are based in the Bible and that all of its professors are Bible-believing fundamentalist Christians. For those who are in such a system-for whom this 'money' is 'domestic', the intensified emphasis upon the Mercy status of the source of 'truth' may lead to a 'revival' in which Perceiver thought again becomes sufficiently overwhelmed into 
'knowing' what is 'true'. But the end result will be a 'huge budget deficit' by 'the government', because the social system itself is incurring an intellectual debt by basing its beliefs in absolute truth.

In addition, there will be 'too much money chasing too few goods'. This happens educationally when there is too much educational content and not enough real application. For instance, a fundamentalist mindset tends to generate a lot of preaching that is forgotten and not applied. An emotional sermon on Sunday may temporarily reinforce Perceiver certainty in 'truth', but these words will tend to be forgotten during the rest of the week. In contrast, a seminal academic paper may be remembered-and cited - for decades and has the power to change the course of an entire specialization. Saying this more succinctly, the general expectation within religious circles is that one listens to a sermon, feels emotionally warmed, and then forgets what was said. In contrast, the expectation within academia is that one reads a paper, uses Perceiver thought to compare the content of this paper with existing knowledge, and then adds the content of this paper to the body of knowledge.

The forgetful behavior within religious circles is not because 'all fundamentalists are hypocrites' but rather is a byproduct of absolute truth. Absolute truth is ultimately based in some source of truth, and absolute truth will only be recognized as truth by those who respect this source. Going further, belief in absolute truth will only survive as long as there is sufficient emotional respect for the source of truth. Therefore, when a fundamentalist leaves his social group to interact with the 'secular' world, then he is entering a realm where his absolute truth does not apply and where the lack of respect for his source of truth will cause him to doubt his belief in absolute truth. Thus, fundamentalism requires regular emotional 'topping up' and belief in absolute truth will naturally tend to falter in between these sessions of emotional 'refuelling'.

Turning now to academia, the academic requirement of 'publish or perish' is leading to 'inflation' because there is 'too much money chasing too few goods'. One paper complains that "The emphasis on publishing has decreased the value of the resulting scholarship as scholar must spend time scrambling to publish whatever they can manage, rather than spend time developing significant research agenda. The pressure to publish-or-perish also detracts from the time and effort professors can devote to teaching undergraduate and post-graduates” (Rawat, 2014). The phrase 'decreased the value' uses economic language to describe a cheapening of academic knowledge. 'Scrambling to publish' implies that abstract technical thought is losing its technical rigor. And the increase in 'publishing whatever they can manage' combined with the decrease in 'developing significant research agenda' indicates that 'too much money chasing too few goods'.

The situation that this paper describes sounds more like 'hearing a sermon and then forgetting about it the next day' than adding academic findings to the body of knowledge. The "Majority of the publications still goes uncited. This means that neither they are appreciated by the peers nor they are of any importance to the industry or patient. Research is essential to carry science forward... Most of the published research works are done just to improve the curriculum vitae (CV) of the researcher and they do not find any merit in practical terms" (Rawat, 2014). ${ }^{26}$

26 One can tell that English is not the first language of the authors. However, google scholar reports that this paper has been cited 190 times. 
A country that is experiencing hyperinflation may eventually adopt a foreign currency. For instance, "In the case of Zimbabwe, the government covered its widening deficits by printing ever higher currency notes, including a \$100 trillion bill. By late 2008, the money was nearly worthless, which led Zimbabwe to adopt the U.S. dollar, immediately halting their hyperinflation” (macro, p. 465). Similarly, it is possible for an institution of higher learning to regain academic respectability by adopting a ‘foreign' technical methodology of academic respectability. For instance, the Bible or some other holy book may be analyzed using the methodology of academia with its precise definitions and peer-reviewed papers. Similarly, studying myth or literature becomes academically acceptable when performed in a sufficiently rigorous manner.

This may work, but it also introduces a 'foreign currency'. The original content is still being treated intellectually as 'funny money', but this worthless content is now being studied in a rigorous manner. For instance, the words of the Bible will be viewed as myth and poetry, but the rigorous thinking of abstract technical thought will be used to compare this myth with other myths, and to quote and compare the opinions of the various scholars who have used academic thought to study myth and poetry. Similarly, a Bible school can get academically accredited by teaching its classes in a sufficiently rigorous manner. What is being accredited is not the content of absolute truth being taught, but rather the technical manner in which this content is being taught and the technical structure of the educational institution. This also is an example of 'adopting a foreign currency'. One sees again the general principle that money is acquiring a feeling of legitimacy by passing through a sufficiently technical process.

But the underlying problem that 'too much money is chasing too few goods' cannot be addressed if money lacks the ability to be turned into goods. Saying this more carefully, the 'money' of scientific understanding can be turned into the 'goods' of technological gadgets because science describes how the natural world functions. This correspondence between theory and reality is missing with a holy book. That is because the absolute truth of a holy book is based in emotional respect for authorities who are regarded as special and different from normal people. ${ }^{27}$ When absolute truth is based in emotional Mercy experiences that are regarded as different than normal experiences, then it is not possible to turn knowledge about absolute truth into the goods of normal experiences. A similar problem happens whenever academic knowledge loses connections with reality.

This disconnection between academic thought and reality may be the fault of the content that is being taught or it may be the result of the mindset of a holy book. A holy book can be defined more carefully as the absolute truth of a book combined with the 'apartness' of 'holiness'. If the content is faulty, then there will always be too much money and not enough goods, because the intellectual money has no relationship with the real realm of goods. For instance, ancient myths do not accurately describe how the natural world functions. However, it is also possible that the content itself is accurate and that the flaw lies in the mindset of absolute truth combined with the attitude of holiness. For instance, modern scholarship is realizing that ancient myths are not totally meaningless but have some intellectual value as descriptions of timeless social and cognitive principles.

27 The Greek word ö $ү 10 \varsigma$ that is translated as 'holy' in the Bible means 'different'. Similarly, the Hebrew word שדֶק that is translated as 'holy' in the Bible also has the sense of 'apartness'. 
Saying this in more detail, a holy book describes absolute truth that is emotionally supported by MMNs of religious fervor and religious experience. A textbook describes absolute truth that is emotionally supported by TMNs of respect for some institution or general theory. However, a textbook will probably be viewed by the beginning student as a kind of holy book emotionally based in MMNs of respect for teachers and professors - who will be regarded as 'special and different'. Going the other way, a holy book can become emotionally supported by the TMN of some institution. And if the content of the holy book describes a rational integrated understanding, then a holy book may become emotionally supported by the TMN of a general theory, expressed as some system of theology. Finally, if this general theory describes 'how things work', then it will be possible to descend mentally from the theories of abstract technical thought to the application of concrete technical thought. The result will be a legitimate mental currency without inflation, because goods will exist that the intellectual money can chase.

For instance, one of my projects has been to analyze the Bible from a cognitive perspective to see if the content goes beyond ancient myth. I have found that Biblical content makes sense if the theory of mental symmetry is used to analyze the original Greek text of the New Testament. A synopsis can be found in a paper on science and theology (Friesen, 2020). Going further, the resulting rational understanding appears to correspond in considerable detail to 'how the mind works'.

I recognize that some might regard such a statement as being similar to the claim that Zimbabwean currency actually has some real value. However, in the same way that Zimbabwe exports a significant amount of mineral wealth despite having a collapsed economy, so it appears that the Bible contains significant intellectual wealth despite being preached by the 'collapsed economy' of fundamentalism. But like mineral wealth which does not appear on the surface but rather has to be mined, the intellectual wealth of the Bible also requires some 'mining'. This clarification is necessary in light of the multiple disparaging remarks that are made about Evangelical and fundamentalist Christianity in this paper. ${ }^{28}$

High inflation will often be seen in a converging economy. "It is clearly possible—and perhaps sometimes necessary - for a converging economy (the economy of a country that demonstrates the ability to catch up to the technology leaders) to live with a degree of uncertainty over inflation that would be politically unacceptable in the high-income economies” (macro, p. 465). The physical reason why a converging economy can catch up is because technology can be purchased from the technology leaders. Therefore, "It can make economic sense for a national economy to borrow from abroad, as long as it wisely invests the money in ways that will tend to raise the nation's economic growth over time. Then, it will be possible for the national economy to repay the borrowed money over time and still end up better off than before” (macro, p. 259). This 'wise investment' will include using borrowed money to buy technological equipment which can then be used to produce items that can be sold. The educational equivalent is to acquire technical thought from foreign institutions of higher learning and

28 And the theory of mental symmetry itself began as a list of seven 'spiritual gifts' given in the $12^{\text {th }}$ chapter of the Biblical book of Romans. As far as I can tell, this list was first interpreted as a system of cognitive styles in the 1970s (Harvey, 1976). One might think that 'Bible-believing Christians' would appreciate a cognitive model that respects the original Greek text of the New Testament, but that is not the case. That is because mental symmetry violates a mindset of absolute truth. 
then use this this 'borrowed' knowledge to develop local technical understanding and infrastructure. The first leads to physical capital and the second to human capital. For instance, both of these factors can be seen in the development of South Korea. On the one hand, South Korea built up physical capital in order to export manufactured products. On the other hand, South Korea places a great emphasis upon education and training, especially from foreign universities (Lee, 2007).

There is an additional cognitive factor that economic theory tends to overlook, but which is described in the previous quote about a converging economy. The uncertainty is coming from questioning the existing Perceiver facts, Server sequences, and mental networks of society; new knowledge is being acquired, new ways of doing things are being learned, and cultural MMNs are being overturned. Learning to function within such uncertainty will build Perceiver and Server confidence in the process of transformation - as well as build Contributor confidence in following such a plan. Such Perceiver, Server, and Contributor confidence make it possible to 'live with a degree of uncertainty that would be politically unacceptable in the high-income economies'. Saying this more bluntly, the typical modern consumer lacks the mental confidence that would be required to construct a modern consumer society. Thus, a converging economy is capable of catching up to a high-income economy partially because many individuals within a converging economy have had to develop levels of mental confidence that are no longer possessed by most of the younger generation within a high-income economy because economic success has made life too easy.

This 'living with a degree of uncertainty' can be seen in the informal entrepreneurship that is prevalent in many developing countries. "For much of the twentieth century, the informal sector in developing countries was largely deemed unimportant and unworthy of scholarly attention... Over the past few decades however, the informal sector has been recognized as an extensive and persistent feature of the developing world, equivalent to some $40-60 \%$ of GDP, with $60 \%$ of the workforce having their main employment in the informal economy, of which 70\% are self-employed" (Williams, 2016, p. 3). This paper defines 'the informal sector' as unregistered businesses that function unofficially. Cognitively speaking, this means functioning outside the technical thinking of a 'registered business'. We saw earlier that technical thought tends to emotionally belittle activity that fails to meet accepted technical standards, which explains why the informal sector has tended to be 'deemed unimportant and unworthy of scholarly attention'.

When a technical framework is inadequate, then normal thought and mental networks can provide an alternative standard to the official rules of technical thought. "All societies have both formal institutions (i.e., codified laws and regulations) that set out the legal rules of the game, as well as informal institutions which are the 'socially shared rules, usually unwritten, that are created, communicated and enforced outside of officially sanctioned channels'. Informal entrepreneurship is viewed as an endeavor occurring outside of formal institutional prescriptions but within the norms, values, and beliefs of informal institutions" (Williams, 2016, p. 3). Carrying out business in such an informal and uncertain manner requires the development of Perceiver and Server confidence. And developing this confidence has long-term economic benefits. "Enterprises that started up unregistered and spent longer operating unregistered are revealed to have significantly higher subsequent annual sales, employment, and productivity growth rates compared with those that registered from the outset" 
(p. 1). Thus, in the same way that 'living with a degree of uncertainty' helps a converging economy to catch up, functioning informally can help a developing business - in a developing economy — to grow faster. $^{29}$

Inflation has several side effects which also have educational analogs. "People who are hurt by inflation include those who are holding considerable cash, whether it is in a safe deposit box or in a cardboard box under the bed. When inflation happens, the buying power of cash diminishes” (macro, p. 233). Similarly, when ideas become inflated, then the purchasing power of all knowledge becomes reduced. That is because the average student initially acquires most technical knowledge as absolute truth. This absolute truth may come from the words of some respected holy book, but it also results from the 'multiplying' of knowledge that happens in the 'banking system' of higher education, supported by emotional respect for these institutions. Therefore, if respected sources start peddling knowledge that is unreliable, then this will cause all knowledge to be doubted. For instance, a recent American survey "found that $87 \%$ of respondents said they ignore phone calls from unknown numbers often or very often" (Sterling, 2019). The article adds that "This is undoubtedly driven by the increase in robo calls and mobile-phone spam, which... will represent about $45 \%$ of mobile calls in the U.S. this year." The technical structure of the telephone system used to give telephone calls an implicit air of legitimacy. Thus, all phone calls were regarded as important, and an unexpected long-distance call often indicated a family emergency. But the unreliable nature of some unknown phone calls is now causing all unknown phone calls to be instinctively rejected.

Inflation also makes it difficult to do comparison shopping. "Prices are the messengers in a market economy, conveying information about conditions of demand and supply. Inflation blurs those price messages... does a higher price of a good mean that inflation has risen, or that supply of that good has decreased, or that demand for that good has increased?” (macro, p. 235). Similarly, it becomes difficult to compare facts when the meanings of words become uncertain. If some fact becomes discredited, does this means that all factual knowledge is becoming discredited, that this fact is based upon inadequate data, or that the demand for evidence has changed? For instance, one paper examined abstracts for linguistic conferences that used vague language and "found that half the authors had not completed the analysis and some had not finished collecting their data” (Cutting, 2012). In this case, words with uncertain meanings were being used to cover up inadequate data and/or analysis. But if all language becomes less precise, then how can normal imprecision be distinguished from imprecision that is being used to cover up inadequate analysis?

Inflation may motivate firms to seek wealth by manipulating the system. “An economy with high inflation rewards businesses that have found clever ways of profiting from inflation, which are not necessarily the businesses that excel at productivity, innovation, or quality of service” (macro, p. 236). Similarly, when the meaning of words becomes uncertain, then some sources will stop using rational thought to evaluate information and start manipulating the system by presenting information that gives the appearance of being factual. This was discussed earlier when looking at fake news.

29 It should be emphasized that this paper is examining the underground economy within a developing nation where official regulations are incomplete, inconsistent, and often corrupt. 
An economy can adjust to inflation through indexing. "An indexed payment increases according to the index number that measures inflation. Those in private markets and government programs observe a wide range of indexing arrangements. Since the negative effects of inflation depend in large part on having inflation unexpectedly affect one part of the economy but not another... indexing will take some of the sting out of inflation” (macro, p. 237). Similarly, if words continue to lose their meanings, then this consistent loss of meaning will itself become a solid fact, causing new information to be automatically 'adjusted for inflation'. For instance, it is now expected that the typical website will be cluttered with numerous annoying and intrusive ads, causing most of these ads to be mentally ignored. Combining this with the previous point, those who are attempting to manipulate the system will continually have to develop new-and-improved methods of manipulation in order to remain effective.

Looking at this point more generally, inflation benefits those who borrow. "When interest rates are fixed, rises in the rate of inflation tend to penalize suppliers of financial capital, who receive repayment in dollars that are worth less because of inflation, while demanders of financial capital end up better off, because they can repay their loans in dollars that are worth less than originally expected" (macro, p. 235). Borrowing money was interpreted cognitively as learning absolute truth that is based in knowledge acquired by other people. Borrowed intellectual wealth is 'paid back' by gaining the Perceiver (and Server) confidence that is required to 'own' this information. When words lose their meanings, then it is easier to turn borrowed knowledge back into legitimate facts, because using factual analysis will cause much of the information to be 'explained away'.

For instance, postmodern thought was interpreted previously as an extreme form of intellectual inflation, because postmodern thinking questions the very existence of solid factual information. Normally, each generation borrows knowledge from the previous generation through education and then pays back this intellectual debt by gaining the mental confidence that comes from applying this information. The 'inflation' of postmodernism makes it possible to 'pay back' this debt using language that has lost its meaning. For instance, 'We can explain away that author because he is just another traditional authority figure who is using paternal privilege to impose his views upon the population.' This is a corollary of inflation causing carefully gathered intellectual wealth to lose its purchasing power.

Looking at this even more generally, inflation benefits governments that borrow. "Traditionally, government bonds have paid a fixed rate of interest. This policy gave a government that had borrowed an incentive to encourage inflation, because it could then repay its past borrowing in inflated dollars at a lower real interest rate” (macro, p. 238). Government was defined earlier as the social Teacher structure that is constructed by a group of people. A government can print its own money, corresponding cognitively to absolute truth being based in the TMN of some social institution. But a government can acquire money by borrowing from the market. Similarly, a government can acquire facts from other sources that are regarded as reliable sources of information. Inflation makes it easier for a government to pay back such 'borrowed money'.

Looking at this process in more detail, the government will borrow information by acquiring facts from legitimate sources. This is borrowed information because the typical legislator does not understand this information but rather accepts it as absolute truth. The government will then use this information to 
make policies and pass laws. The payback comes when these policies and laws are eventually compared with the facts and sequences of reality. Inflation of information makes it easier to pay back the debt, because it will be expected that words lose their meanings. Therefore, a government will not be held accountable if it promises much and delivers little.

Economists think that some inflation can be helpful for dealing with the problem of sticky wages. Sticky wages means that "even though wage increases may occur with relative ease, wage decreases are few and far between” (macro, p. 201). Inflation causes wages to decrease automatically. "Economists sometimes argue that moderate inflation may help the economy by making wages in labor markets more flexible... A little inflation could nibble away at real wages, and thus help real wages to decline if necessary. In this way, even if a moderate or high rate of inflation may act as sand in the gears of the economy, perhaps a low rate of inflation serves as oil for the gears of the labor market” (macro, p. 237).

Mental symmetry suggests that sticky wages can be explained in terms of mental networks. A mental network tends to function silently under the surface when encountering consistent input, while complaining emotionally when input becomes inconsistent. Thus, sticky wages can be viewed as a form of cultural preservation, in which employees are being emotionally driven by their mental networks to preserve the status quo. This desire to maintain the status quo can be seen in the first explanation mentioned in the openstax textbook. Workers "often work under an implicit contract, which is that the employer will try to keep wages from falling when the economy is weak or the business is having trouble, and the employee will not expect huge salary increases when the economy or the business is strong... this sort of implicit contract means that firms will be hesitant to cut wages, lest workers feel betrayed” (macro, p. 202). Notice that a desire to maintain the status quo is functioning in both directions. Employees are willing to maintain the status quo when the economy is strong but also expect the status quo to be maintained when the economy is weak. Notice also that this is functioning at an implicit level, consistent with the idea of mental networks.

Looking at the educational analog, wages gradually falling through inflation corresponds to technical knowledge gradually losing its precise meaning. This happens naturally when there is continual technical innovation because technical knowledge will gradually become out of date. For instance, the general principles that are taught in engineering seldom change, but the technical details that were taught in an engineering program twenty years ago are considerably different than the technical details taught in a current program. This means that engineers gradually lose their ability to deal with current technology in a precise manner.

This 'oils the gears of the labor market' in two ways. First, continual on-the-job training is required to keep up with technical developments. That is because maintaining the status quo actually results in falling behind. Thus, mental networks have to be continually challenged in order to keep up with new technology. Second, if existing employees require continual training, then this lowers the relative cost of hiring new employees that have to be trained. Saying this another way, all employees are implicitly subject to a form of structural unemployment, in which existing skills are becoming inadequate. 
The connections that we have examined between money, factual certainty, and government may seem somewhat contrived, but history suggests that there is a valid cognitive relationship. For instance, the openstax textbook quotes from a 1997 paper by Shiller, “A fact that is probably little known to young people today, even in Germany, is that the final collapse of the mark in 1923... came in the same month as Hitler's Beer Hall Putsch, his Nazi Party’s armed attempt to overthrow the German government... the Kapp Putsch, which resulted in Berlin’s temporary capture in March 1919 by the Freikorps, occurred immediately after a sudden, temporary burst of inflation” (Shiller, 1997, p. 53 - 54). In other words, monetary uncertainty was accompanied by political instability. We saw earlier that absolute truth begins as emotional 'truth' and must go through some sort of stabilizing process. If this stabilizing process itself becomes uncertain, then any attempt to restore absolute truth will actually turn into the imposition of emotional 'truth' through personal status. The Beer Hall Putsch and the Kapp Putsch can be interpreted cognitively as unsuccessful attempts to impose emotional 'truth' upon society, while the rise of Nazism can be viewed as a successful attempt to impose emotional ‘truth' upon German society.

Summarizing, this section has treated knowledge as an analog to money, equating inflation with words losing their meanings. This equating was done because integrating concrete technical thought with abstract technical thought requires connecting the basic elements of the one with the basic elements of the other, which means that cause-and-effect has to be connected with precise definitions. For instance, inflation can be viewed by concrete technical thought as a weakening of the monetary link of causeand-effect. But it can also be viewed by abstract technical thought as a weakening of precise definitions. Thus, when inflation is compared with words losing their meanings, then this goes beyond an analogy to a mapping between concrete technical thought and abstract technical thought.

It should be emphasized that normal speech does not correspond to money, because normal speech involves either the partial definitions of normal thought or the emotional connotations of mental networks. ${ }^{30}$ Thus, inflation does not correspond necessarily to a loss of meaning in normal conversation. Instead, inflation corresponds to the loss of meaning of technical words with precise definitions that are being generated by various institutions, such as government, media, religion, and academia. This also explains why fiat money needs to be generated by some institution. What gives fiat money its value is that it is being produced in a precisely-defined manner by institutions that have been defined using precise language. Monetary inflation happens when money that was defined in a precise manner loses some of this meaning. Similarly, educational inflation happens when concepts that were defined in a precise manner become vague and lose some of their meaning.

\section{Unemployment}

It was pointed out earlier that economics defines unemployment in terms of the labor force. The labor force does not include the realm of household activity with its personal MMNs nor does it include personal work for which no pay is received. Unemployment is defined as those who are capable of using technical thought but are not being employed in some technical capacity. This means that unemployment needs to be regarded cognitively as a disruption of technical thought. Technical thought

30 We saw when looking at the informal economy that economic activity can still function when technical thought is inadequate if normal thought and mental networks provide an alternative source of stability. But anyone who has visited a third-world market will know that an informal economy tends to be messy and unstable. 
is always limited to some specialization. Being hired to do some job means using technical thought within some specialization in return for receiving money that can be converted into receiving specialized technical goods or services from other people. This summarizes the essence of the market economy.

This means that unemployment is the concrete equivalent of a paradigm shift. A paradigm shift happens when the TMN driving some system of abstract technical thought falls apart and is replaced by a new TMN. Thomas Kuhn came up with the term 'paradigm shift' and his classic book interprets a paradigm shift as a revolutionary gap that intersperses one episode of abstract technical thought from another (Kuhn, 1970). Similarly, unemployment interprets the loss of a job as a gap in employment that intersperses one episode of concrete technical thought from another. In both cases, using technical thought within some specialization is being regarded as normality and the shift from one specialization to another is being viewed as abnormal. (Kuhn defined the period between paradigm shifts as 'normal science'.)

Economics divides unemployment into the two categories of frictional unemployment and structural unemployment. "In the real world, even if the number of job seekers is equal to the number of job vacancies, it takes time to find out about new jobs, to interview and figure out if the new job is a good match, or perhaps to sell a house and buy another in proximity to a new job. Economists call the unemployment that occurs in the meantime, as workers move between jobs, frictional unemployment" (macro, p. 205). Looking at this cognitively, technical thought always occurs within some context of Perceiver facts and Server sequences. And each person is emotionally motivated by some combination of core MMNs and TMNs. Frictional unemployment uses normal thought to see if a 'new job is a good match'. First, there is the technical match. Do Perceiver and Server thought have knowledge, skill, and confidence in the Perceiver facts and Server sequences required by a potential job? Second, there is also an emotional fit. Do personal TMNs and MMNs resonate with the mission statements and goals of the new company? This is cognitively similar to the bridging role that normal thought plays in connecting technical supply with mental networks of demand. When there is a good match both technically and emotionally, then employment will involve the kind of flow that characterizes a dream job. In reality, one typically has to settle for having most of the prerequisite skills and knowledge and sharing some of the emotional goals.

Structural employment specifically addresses technical training. “The structurally unemployed are individuals who have no jobs because they lack skills valued by the labor market, either because demand has shifted away from the skills they do have, or because they never learned any skills” (macro, p. 205). Previous sections examined the parallel between the banking system and higher education. Structural employment is affected by education. "Education seems to be the key in minimizing the amount of structural unemployment. Individuals who have degrees can be retrained if they become structurally unemployed. For people with no skills and little education, that option is more limited” (macro, p. 206).

Looking at this cognitively, structural unemployment goes beyond being the concrete equivalent of a paradigm shift to involving an actual paradigm shift, because retraining for a new job often involves the learning of a new technical paradigm. And because getting a job in the modern economy requires 
technical thought, those who lack technical skills are typically taught a limited set of Perceiver facts and Server actions on the job and are then expected to perform this limited repertoire in a repetitiveand typically monotonous - manner.

A skilled laborer is capable of using concrete technical thought, usually acquired through some form of vocational training. Concrete technical thought is capable but inflexible. It is capable because it is able to use Server actions to manipulate real objects in the real world. But it is inflexible because it performs specific Server actions guided by specific Perceiver facts. Thus, it is susceptible to structural unemployment when demand shifts away from existing skills.

A professional is capable of using abstract technical thought, typically acquired through some program of higher education. Abstract technical thought is flexible but can be impractical. It is flexible because specific Server actions are being replaced by exemplars and specific Perceiver facts by Platonic forms. Exemplars and Platonic forms were discussed earlier in the paper. Looking at this in more detail, the first step in using abstract technical thought to solve some problem is to replace specific situations with their Platonic forms. For instance, in basic physics, objects are treated as point masses, gravity is viewed as a constant force, friction is either ignored or else treated as a constant ratio, and so on. In each case, each real item is being represented by a Platonic form, which is an idealized and simplified version of this real element. This idealized version of the problem is then solved by following some Server sequence of computational steps. Learning how to solve one physics problem makes it possible to solve many related problems, which means that specific sequences can be treated as exemplars, or characteristic solutions, that apply to many related situations (Friesen, 2015). Because abstract technical thought deals with an idealized and simplified version of reality, it is easy for thinking to become too simple, idealized, and unrealistic to apply to the real world with its messy details.

Platonic forms and exemplars can also be seen in the theories of economics. "A theory is a simplified representation of how two or more variables interact with each other. The purpose of a theory is to take a complex, real-world issue and simplify it down to its essentials. If done well, this enables the analyst to understand the issue and any problems around it. A good theory is simple enough to understand, while complex enough to capture the key features of the object or situation you are studying” (macro, p. 16). A Platonic form 'takes a complex real-world issue and simplifies it down to its essentials'. An exemplar makes it possible to 'understand the issue and any problems around it'. The ideal theory contains order-within-complexity; it is simple enough to be ordered but has enough details to handle complexity.

Notice in passing that we are seeing yet another version of the second, third, and fourth levels of Piaget's stages of cognitive development, with non-technical thought being followed by concrete technical thought and then being superseded by abstract technical thought.

\section{Deflation and the Great Depression}

The opposite of inflation is deflation. "Deflation occurs when the rate of inflation is negative; that is, instead of money having less purchasing power over time, as occurs with inflation, money is worth more" (macro, p. 372). Inflation was interpreted as words losing their precise meanings. This means 
that deflation corresponds to words acquiring more precise meanings. If one item goes up in price, that is not inflation. Instead, inflation describes everything becoming more expensive, and inflation of speech reflects a general loss of technical meaning. When a situation is explained in a more scientific manner, then some words become defined more precisely. For instance, words that are in bold in this paper, such as inflation, are defined precisely in an economics textbook. But most of the words of this paper have normal meanings and can be replaced by synonyms with similar meanings. Deflation of speech happens when all speech becomes more careful and precise.

A connection was made earlier between German hyperinflation and the unsuccessful Beer Hall and Kapp Putsches. However, those putsches failed. German hyperinflation produced political and economic instability, but Hitler did not come to power during this period of German hyperinflation. Instead, Hitler successfully gained power during a later period of deflation. "How did the Nazis go from being a tiny party in 1929, to the largest single party in 1932? The answer is simple-deflation (or more precisely falling NGDP.) The severe deflation of the early 1930s pushed Germany into a very deep depression with massive unemployment, and a desperate German electorate turned to the Nazis” (Sumner, 2015).

A number of threads connect deflation, depression, authoritarianism, and a general imposition of precise meanings, and these connections will now be explored.

Looking first at the Great Depression, the neoclassical perspective on macroeconomics holds that, in the long run, the economy will fluctuate around its potential GDP and its natural rate of unemployment” (macro, p. 317). Using cognitive language, neoclassical economics views the economy as a system in Teacher thought and feels that this system should be allowed to function undisturbed. Keynesian economics, in contrast, argued that the system is broken. Therefore, people should use government to intervene in the economy at the general level of Teacher thought. "Keynesian economists argue that if the adjustment from recession to potential GDP takes a very long time, then neoclassical theory may be more hypothetical than practical. In response to John Maynard Keynes' immortal words, 'In the long run we are all dead,' neoclassical economists respond that even if the adjustment takes as long as, say, ten years the neoclassical perspective remains of central importance in understanding the economy” (macro, p. 321).

A similar breakdown at the level of general Teacher theory can be seen in clinical depression, which is described as the 'hopelessness theory of depression'. A review paper summarizes that "When confronted with a negative life event, the child attempts to come to an understanding about the cause of the maltreatment event, so as to prevent its potential recurrence. Initially, the child may be likely to form relatively benign causal attributions that are external, unstable, and specific in nature (e.g., one's parent was having a bad day). If these events become chronic or pervasive, however, such attributions are repeatedly disconfirmed, increasing the likelihood that the child will instead turn to more depressogenic causal attributions that are internal, stable, and global in nature (e.g., concluding that there is something inherent in oneself that makes one the target of repeated abuse from others). The hopelessness that results regarding the prospect of addressing the cause of these events, and thus thwarting their future recurrence, places the child at eventual risk for depression” (Liu, 2015, p. 3). 
Looking at this cognitively, the starting point is unpleasant Mercy experiences. Teacher thought then comes up with specific Teacher theories to explain these Mercy experiences, such as 'one's parent was having a bad day'. But the unpleasant Mercy experiences are continuing; they are 'chronic or pervasive'. This repetition is causing Perceiver thought to come up with facts that 'disconfirm' these specific Teacher theories. Teacher thought then tries to explain the repeated pain by coming up with general theories about personal identity, leading to the conclusion that 'there is something inherent in oneself that makes one the target of repeated abuse'. This is a case of the system becoming broken, because Teacher generality has turned upon Mercy identity; Teacher thought feels good when Mercy thought feels bad, while feeling bad when Mercy thought feels good. This is a vicious circle that has to be broken at the level of Teacher generality, because any specific pleasant Mercy experiences will be disregarded as exceptions to the general theory.

Applying this to the Great Depression, the experiences of economic hardship lasted for years, spread to the entire world, and were reinforced in North America by the extended drought of the 'dirty thirties'. This eventually led to a general Teacher theory of hopelessness, expressed by Keynes as 'In the long run we are all dead'. When the mindset of society is affected at this level of Teacher generality, then the normal business cycles of neoclassical theory become more hypothetical than practical.

Summarizing, the Great Depression went beyond a severe loss of economic confidence to the acquisition of a general Teacher theory of hopelessness. A general Teacher theory of hopelessness will affect the economy at the emotional level of demand. In the words of the Encyclopaedia Britannica, "The fundamental cause of the Great Depression in the United States was a decline in spending, which led to a decline in production as manufacturers and merchandisers noticed an unintended rise in inventories. The sources of the contraction in spending in the United States varied over the course of the depression, but they cumulated in a monumental decline in aggregate demand” (“Causes”, 2021).

Turning to the next factor, there was significant deflation during the Great Depression. "In the U.S. economy during the early 1930s, deflation was 6.7\% per year from 1930-1933, which caused many borrowers to default on their loans and many banks to end up bankrupt, which in turn contributed substantially to the Great Depression” (macro, p. 372). Looking at this from an economic perspective, inflation was described earlier as 'too much money chasing too few goods'. If there is 'a monumental decline in aggregate demand', then there will be too little money chasing goods, because no one wants to spend their money. Going further, one or two bank failures can be attributed to specific causes. But if 'many banks end up bankrupt', then this repeated failure will cause Teacher thought to come up with a general theory of economic failure and hopelessness.

Looking at this cognitively, loans have been interpreted as the borrowed knowledge of absolute truth. Defaulting on a loan would mean no longer attempting to 'purchase' knowledge but rather allowing knowledge to remain at the borrowed level of absolute truth. A bankrupt bank corresponds to an academic institution that is no longer able to generate the wealth of technical knowledge. Saying this in more detail, if enough scholars default on their intellectual loans and remain at the level of absolute truth, then technical knowledge becomes reduced to the level of repeating and quoting absolute truth. If enough educational 'banks' of higher learning go bankrupt, then academic growth itself will come to an end, resulting in a 'Great Depression'. 
Looking further at the relationship between defaulting on economic loans and retreating to absolute truth, the 1930s were characterized politically by a retreat to absolute truth. This expressed itself as a rise in authoritarianism. "Between 1920 and 1945 the liberal democratic nation-state retreated, battered by authoritarians. By 1938, fifteen of Europe’s twenty-seven parliamentary regimes were rightist dictatorships, most claiming to embody a single organic nation, curtailing minority rights" (Mann, 2004, p. 38). The basic premise of absolute truth is that some special group in Mercy thought is the source of truth in Perceiver thought. A dictatorship that 'embodies a single organic nation' views that 'single organic nation' as the source of truth to impose upon other groups. Relating this to a general theory of hopelessness, a basic premise of absolute truth is that I have no emotional status compared to my source of truth. The idea that I have no emotional status is quite compatible with a general theory of hopelessness.

An intellectual 'defaulting on loans' could also be seen in the rise of religious fundamentalism. An article in Christianity Today summarizes this intellectual transition. "What happened to fundamentalism after the 1930s? After losing a number of public battles, like the Scopes trial, the fundamentalists regrouped; they formed independent denominations, Bible churches, and parachurch and revivalist organizations. They mobilized the radio-Charles Fuller and his Old Fashioned Revival Hour is a good example. The watchers of mainstream culture were writing off fundamentalism, assuming that as people became more educated they would become more liberal. In fact, fundamentalism was moving on the popular front and was still quite effective” (Marsden, 1997).

Looking at this cognitively, an intellectual debt is 'paid' by turning absolute truth into rational understanding. Biblically-based Christianity had attempted to transform the absolute truth of the Bible into rational understanding, but failed 'after losing a number of public battles'. This failure to pay off the intellectual debt expressed itself as the general assumption that becoming more educated implied abandoning belief in the Bible. Fundamentalism responded by 'defaulting' on its loan, which meant abandoning any attempt to move beyond the 'borrowed money' of absolute truth. This changed fundamentalism into a theoretical belief system that no longer had any connection with the physical world.

Notice also the characteristics of a theory of hopelessness. Fundamentalism went beyond experiencing occasional experiences of rejection to 'losing a number of public battles'. This was followed by the general Teacher theory writing off fundamentalism, spread by the 'watchers of mainstream culture'. In other words, society turned on the fundamentalists and told them the general theory that 'You are intellectually and culturally hopeless'.

Returning to the cognitive interpretation of deflation as a general tightening of technical definitions, one of the basic characteristics of fundamentalism is literalism. In the words of Wikipedia, Christian "Fundamentalists are almost always described as having a literal interpretation of the Bible...

Fundamentalists usually believe in a core of Christian beliefs which include the historical accuracy of the Bible and all of the events which are recorded in it" (“Christian fundamentalism”, 2021). Literalism is, by definition, a general tightening of technical definitions, because every word of a holy book is being regarded as technically true. 
Looking at a related parallel, deflation increases the real interest rate. "If the nominal interest rate is 7\% and there is deflation of $2 \%$, then the real interest rate is actually $9 \%$. In this way, an unexpected deflation raises the real interest payments for borrowers” (macro, p. 372). Absolute truth is being interpreted as a form of intellectual borrowing, and interest is being interpreted as the mental confidence required to apply this borrowed knowledge in an intelligent manner. The mental cost of borrowing knowledge increases in an environment of fundamentalism. That is because there is the nominal 'interest' of being able to apply borrowed knowledge in the real world and then the additional 'interest' of being able to apply borrowed knowledge within a fundamentalist environment.

Going further, there is a statistical connection between authoritarianism and religious fundamentalism because "about two-thirds of persons who score highly on the measure of right-wing authoritarianism also score highly on the measure of religious fundamentalism” (Altemeyer, 2005, p. 389). Altemeyer makes a distinction between 'dominators' who lead and those who follow. "The dominators do not, as you might guess, have many religious inclinations. But authoritarian followers tend to be religious, and religious fundamentalists in particular” (p. 386). An 'authoritarian follower' feels that 'I am nobody compared to my source of truth'. A dominator does not feel this way but rather acts as a source of truth. In the words of the saying attributed to the Roman philosopher Seneca, "Religion is regarded by the common people as true, by the wise as false, and by rulers as useful.”

Altemeyer describes some of the traits of the religious fundamentalist. "Their beliefs bring them great comfort and joy in life, which they do not particularly get from logic and science. They are given to intensive proselytizing... Scientific evidence that shows they are wrong would simply be ignored. They cannot conceive of anything that would lead them to change their belief in God. They admit to virtually no doubts about their religious beliefs” (Altemeyer, 2005, p. 385). This describes several attributes of emotional 'truth'. First, emotional 'truth' uses an emotional source to overwhelm Perceiver thought. This causes opposing facts to be ignored, because the cognitive module that evaluates facts is not functioning. Second, emotional 'truth' leads to a sense of total certainty. This characteristic has not been mentioned before. When Perceiver thought is functioning, then Perceiver thought gains confidence gradually as connections are repeated. However, when Perceiver thought is overwhelmed, then this leads to a total sense of certainty in Perceiver thought. Not only does Mercy thought have great emotional respect for the source of 'truth', but Perceiver thought also has total certainty in the facts that come from the source of 'truth'. Third, emotional 'truth' believes that it follows the correct source of 'truth' while others do not. Thus, spreading 'truth' means proselytizing - getting others to become emotionally overwhelmed by the same emotional source of 'truth'.

The previous paragraph referred to emotional ‘truth' rather than absolute truth. That is because emotional 'truth' turns into absolute truth by going through some sort of stabilizing process. The overall stability of absolute truth will be preserved if only some emotional 'truth' is being 'stabilized'. However, an attempt to reimpose absolute truth in a more general manner will end up overwhelming the stabilizing institutions, leading to a more blatant focus upon emotional 'truth'. This emphasis upon the general restoration of absolute truth can be seen in the twenty questions of Altemeyer's 'right wing authoritarianism scale'. For instance, "8. Our country will be destroyed someday if we do not smash the perversions eating away at our moral fibre and traditional beliefs. 12 . What our country really needs 
is a strong, determined leader who will crush evil, and take us back to our true path” (Altemeyer, 2005, p. 387). And the underlying assumption will be that absolute truth needs to be restored by some source of truth. "5. The only way our country can get through the crisis ahead is to get back to our traditional values, put some tough leaders in power, and silence the troublemakers spreading bad ideas” (p. 387).

Notice that the 'restoration' of absolute truth is leading to positive Teacher feelings. "Their beliefs bring them great comfort and joy in life, which they do not particularly get from logic and science" (Altemeyer, 2005, p. 385). It was suggested earlier that a general theory of hopelessness has to be addressed at the level of Teacher thought. A restoration of absolute truth will create Teacher feelings of societal order that provide an emotional alternative to the general theory of hopelessness, typically expressed as the feeling that some charismatic leader is making the nation great again. Notice that this method of generating positive Teacher feelings is not coming from logic and science. This alternate form of Teacher joy in the face of a general fear of hopelessness can also be seen in 1930s religious fundamentalism. "The watchers of mainstream culture were writing off fundamentalism, assuming that as people became more educated they would become more liberal. In fact, fundamentalism was moving on the popular front and was still quite effective” (Marsden, 1997). Notice how fundamentalism is shrugging off the rejection of society by 'moving on the popular front'. Both of these cases involve Teacher emotion because the general welfare of some country or system is being restored.

Looking further at these Teacher emotions, the Teacher pleasure of a scientific theory that describes how the natural world functions can be increased by using this theory to explain more real situations. That option is not open to a theory which is not based in logic and science. But a system of absolute truth can still gain in Teacher generality by having more people submit to this absolute truth. This provides a strong emotional drive for proselytization.

Looking more closely at Germany, in the same way that mainstream thinking rejected fundamentalism in the 1930s, so Germany felt rejected by the rest of the world in the Treaty of Versailles after the First World War. "The Germans had hoped until the very end for a moderate treaty based on negotiation with the idealistic principles of Woodrow Wilson... Germany therefore reacted with fury and anger to the final terms of the treaty. The allies searched for German officials who would affix their names to such a lopsided treaty, then summarily called them into the majestic Hall of Mirrors at Versailles for a short and anticlimactic signing ceremony” (Neiberg, 2017, preface).

And a triumph of absolute truth could be seen in the rise of eugenics and racial law. This type of thinking was not limited to Nazi Germany. An article in The Atlantic discusses the influence that American racial laws had upon Nazi racism. For instance, in 1934, a "conference of leading German lawyers gathered to exchange ideas about how best to operationalize a racist regime. The record reflects how the most extreme among them... were especially drawn to American legal codes based on white supremacy. The main conceptual idea was Freisler's. Race, he argued, is a political construction. In both America and Germany, the importance and meaning of race for the most part had been determined less by scientific realities or social conventions than by political decisions enshrined in law” (Katznelson, 2017). Notice the core element of absolute truth, because the special group of some race is imposing itself upon society through the absolute truth of 'political decisions enshrined in law'. 
Examining the intellectual climate of that era in more detail, eugenics can be viewed cognitively as a form of absolute truth. In the words of one author, "The achievements of a society, in this view, were considered to be a simple outgrowth of the constitutional endowments of its people. In other words, history (past or future) was bound in some basic way to genetics” (Marks, 1993, p. 650). Notice how truth is being 'revealed' to racial groups who possess superior genetics; truth is ultimately written upon the book of human genetics, because those who have superior genetics will naturally discover truth. "It readily followed that cultural progress was driven principally by the birthrate of geniuses, regardless of any other social processes" (p. 650). Notice also the feeling that 'I am nothing compared to my source of truth', because social processes are being regarded as having only a minimal impact upon cultural progress. Instead, the 'revealed truth' of genetics is being regarded as playing the overwhelming role.

This eugenic viewpoint was the accepted scientific norm. "To be against eugenics in the 1920s was to be perceived as being against modernity, progress, and science. The ideas were inaccurate and insensitive - but they were modern science as it was constituted in that decade” (Marks, 1993, p. 651). Thus, feelings of racial superiority became transformed into absolute truth by passing through the institution of academia (and academia was insufficiently advanced to be able to reject these feelings as unscientific). The absolute truth of eugenics was then 'borrowed' by government. "The Nazis, after all, did not have to invent the idea of sterilizing or exterminating undesirables - they merely appropriated it from the science of eugenics” (p. 651). This suggests that the primary difference between the Nazis and the rest of the world was not that the Nazis believed in eugenics and the rest of the world did not, but rather that the Nazis practiced a policy of eugenics with greater technical precision and thoroughness than the rest of the world. This genocidal behavior can be viewed as a form of fundamentalism, because the Nazis applied their words about racism more literally than the rest of the world.

While there are definite parallels between the political climate today (in 2021) and the situation in the 1930s, there are also significant differences. The institutions of government, academia, and religion were still viewed with considerable respect in the 1930s. This institutional respect made it possible to emphasize absolute truth, because institutions existed that were capable of transforming emotional 'truth' into absolute truth. This can be seen in the academic institutions that gave academic respectability to racism, as well as the various institutions used by Christian fundamentalists to spread their message. ${ }^{31}$ The postmodern questioning which began in the 1970s has attacked the emotional status of these institutions. As a result, current attempts to restore absolute truth have tended to remain at the level of emotional 'truth' and have not succeeded in re-establishing absolute truth. Going the other way, the technical structure of the academic thought is far more developed today than it was back in the 1930s, which means that academia is less susceptible to crude theories of racism or eugenics.

Summarizing, it appears that there are cognitive connections between deflation, depression, authoritarianism, and a general imposition of precise meanings, and that these factors became dominant during the 1930s. Going further, these connections suggest that it makes cognitive and historical sense to interpret deflation as a tightening of the precision of language.

31 German hyperinflation caused many German institutions to be questioned at a deeper level, removing much of the institutional structure required for absolute truth. 
I have suggested that the Great Depression was characterized by a general theory of hopelessness that had to be counteracted at the level of Teacher thought. It has been suggested government is a social system of Teacher order constructed by a group of people. Therefore, when government intervenes, then people are behaving collectively at the level of general Teacher thought. The extensive official racism and tribalism of the 1930s demonstrated the danger of using the institutions of society, such as government, to impose absolute truth based in the MMN of some race, ethnicity, or religious book.

Another primary response of that era was to use government spending to get out of the Great Depression. This was the policy advocated by Keynes in the 1930s. "Keynes recognized that the government budget offered a powerful tool for influencing aggregate demand. Not only could more government spending stimulate $\mathrm{AD}$ (or less government spending reduce it), but lowering or raising tax rates could influence consumption and investment spending. Keynes concluded that during extreme times like deep recessions, only the government had the power and resources to move aggregate demand” (macro, p. 301). (AD is Aggregate Demand.)

The government programs in the 1930s showed that government intervention at the level of Teacher thought can generate beneficial results for society. This intervention also involved extensive borrowing at a governmental level, leading to the conclusion that a governmental deficit is not necessarily a bad thing. "There is also no particular reason to expect a government budget to be balanced in the medium term of a few years. For example, a government may decide that by running large budget deficits, it can make crucial long-term investments in human capital and physical infrastructure that will build the country's long-term productivity. These decisions may work out well or poorly, but they are not always irrational” (macro, p. 427). This strategy was discussed earlier when looking at a converging economy.

Looking at this more carefully, government programs of the 1930s built many dams, bridges, and highways. This construction required significant technical skill and expertise, and the massive scale of this construction meant that this technical expertise had to extend to the abstract level of Teacher order. So many workers acquired so many technical skills that this 'paid off' the intellectual debt that was incurred by the absolute truth of government programs. Saying this more simply, the workers who built dams, bridges, and highways started by submitting to the massive artificial Teacher structure of government programs, but they ended having acquired the real technical skills-both concrete and abstract - that were needed to perform massive physical projects.

Summarizing, physical infrastructure is a physical system of Teacher order-within-complexity. Investing in human capital increases the ability of people to use abstract technical thought with its Teacher theories. Cognitively speaking, the Teacher debt of national borrowing is being repaid at the Teacher level with greater physical and intellectual order. Notice that the two interpretations of economics and education are functioning together.

Putting this all together, it was suggested that the Great Depression was characterized by a general theory of hopelessness that had to be addressed at a Teacher level. Religious fundamentalism generated positive Teacher feelings by restoring belief in the absolute truth of a holy book. Authoritarianism generated positive Teacher feelings by restoring belief in the absolute truth of some country or race. And government-funded public works generated positive Teacher feelings by teaching groups of people 
the skill of cooperating to build massive systems of Teacher order. A restoration of absolute truth will generate Teacher feelings of order, but it will not actually eliminate the basic premise of a general theory of hopelessness, which is that I as an individual have no value. In contrast, cooperation based in technical skills will generate Teacher feelings of order and also lead to the feeling that I am an individual with valuable skills. The next section will examine more closely what it means to be an individual with valuable skills within some technical system.

\section{Aggregate Supply and Demand}

The Phillips Curve was proposed in the 1950s and is based on the observation that "when the level of output is at or even pushing beyond potential GDP, the economy is at greater risk for inflation. Phillips analyzed 60 years of British data and did find that tradeoff between unemployment and inflation, which became known as the Phillips curve” (macro, p. 306). Looking at this in more detail, potential GDP is defined as "the maximum quantity that an economy can produce given full employment of its existing levels of labor, physical capital, technology, and institutions” (macro, p. 289). Using cognitive language, potential GDP is what a country can produce if all the workers who are capable of using technical thought use their technical training (human capital) to invent, innovate, or run machines (physical capital).

Economics describes potential GDP as a 'maximum quantity' that can only be exceeded by a small amount for a short time with exceptional effort. This may seem like an obvious statement, but it points out a significant principle, which is that technical thought cannot use magic. The science fiction writer Arthur C. Clarke observed in his third 'law' that "any sufficiently advanced technology is indistinguishable from magic” (Clarke, 1968).

We saw earlier that magical thinking is a natural expression of Piaget's preoperational stage with its dominant MMNs. Modern gadgets are developed and produced using technical thought. This was mentioned earlier when looking at supply. But the typical consumer approaches these same gadgets from the viewpoint of mental networks, which was mentioned earlier when looking at demand.

Clarke was pointing out that if a consumer lacks the technical thinking to comprehend technology, then that technology will be approached using the magical thinking of childish mental networks. Clark used the phrase 'sufficiently advanced'. This implies that a detailed technical understanding is not required to avoid magical thinking. Instead, magical thinking becomes predominant when a technology cannot be mentally placed within the TMN of any rational paradigm. We saw earlier that marketing and advertising typically try to sell products by implanting mental networks within the minds of potential consumers, and this process of implanting mental networks often encourages magical thinking, emotionally reinforcing the misconception that advanced technology is magic. However, potential GDP really is a solid barrier that is limited by the current human and physical capital.

Suppose that "the level of output in the economy is far below potential GDP... At these relatively low levels of output, levels of unemployment are high, and many factories are running only part-time, or have closed their doors. In this situation, a relatively small increase in the prices of the outputs that businesses sell—while assuming no rise in input prices—can encourage a considerable surge in the 
quantity of aggregate supply because so many workers and factories are ready to swing into production" (macro, p. 273). In other words, spare technical processes that are required to generate supply exist, but they are not being used. The situation is different when an economy is functioning near its potential GDP. "At this quantity, higher prices for outputs cannot encourage additional output, because even if firms want to expand output, the inputs of labor and machinery in the economy are fully employed... When an economy is operating at its potential GDP, machines and factories are running at capacity, and the unemployment rate is relatively low" (macro, p. 274). In other words, all of the machines that exhibit technical thought are being used and all of the people that have technical skills are working. At this point it is not possible for the mental networks of demand to magically increase production.

Looking at this from the viewpoint of education, when production is significantly below potential GDP, then there will be many potential workers with technical training who are capable of being hired. But when there is full employment, then any new employees will require significant technical training in a short period of time. When this happens, then the quality of education will tend to suffer. Those who received their training in such an environment will find that their 'currency' of knowledge is not 'worth' as much. This is a corollary of the suggestion made earlier that technology is not magic. Technical training is also not magic. Thus, the Phillips curve could also be viewed as a trade-off between quality of education and speed of education. Decreasing the unemployment rate implies that workers have less time to gain new technical skills. The end result of this hurried education will be a form of inflation, experienced as a drop in the ability to transform the 'money' of technical knowledge into the 'goods' of real technical application.

For instance, the technical economy is currently experiencing (in 2021) a sort of hybrid version of these two effects. A loosening of the technical definitions of electronic parts is happening as a result of attempting to go beyond potential GDP. "Since the start of the COVID-19 crisis, in effect, electronic device makers have come under the pressure of unprecedented demand from consumers... This has led to global shortages that have now trickled down to most industries that depend on electronic components... The risks of using counterfeit chips, even unknowingly, should not be underestimated... the final product might meet basic quality standards, but it will not have gone through any of the testing processes or reliability criteria that authentic chip manufacturers invest time and money into" (Leprince-Ringuet, 2021). Notice how the shortage is allowing counterfeit chips to enter the market which do not meet the normal technical standards. This is a form of abstract inflation expressed as a loosening of technical definitions, which is accompanying the normal inflation that happens when parts are in short supply.

The supply-versus-demand graph was discussed earlier when looking at microeconomics, and this was interpreted cognitively as the interaction between Exhorter thought and Contributor thought. Supply depends upon technical thought with its machines and technical skills. Demand, in contrast, is expression of the Exhorter motivation that comes from Mercy feelings of utility. ${ }^{32} \mathrm{~A}$ similar graph exists within macroeconomics. "To build a useful macroeconomic model, we need a model that shows

32 These Mercy feelings may be colored by Teacher feelings such as elegance, beauty, and efficiency, but Mercy experiences and emotions are still playing the primary role. 
what determines total supply or total demand for the economy, and how total demand and total supply interact at the macroeconomic level. We call this the aggregate demand/aggregate supply model” (macro, p. 272).

The two axes of the AD/AS curve are real GDP and price level. "The diagram's horizontal axis shows real GDP — that is, the level of GDP adjusted for inflation. The vertical axis shows the price level, which measures the average price of all goods and services produced in the economy... the price level is different from the inflation rate. Visualize the price level as an index number, like the Consumer Price Index, while the inflation rate is the percentage change in the price level over time” (macro, p. 273). Summarizing, the horizontal axis describes total amount that is being supplied within some economy. The vertical axis describes the cumulative impact of inflation. Educationally speaking, this describes the societal impact of either insisting that words have precise meanings or else allowing the language of technical knowledge to lose its precise meaning.

The aggregate supply side of this graph has already been discussed. Increasing the total supply is easy when the economy is far below potential GDP and there are many trained workers willing to work as well as machines waiting to be used. However, increasing the total supply is difficult when workers have to be trained and machines have to be built. Stated cognitively, total supply depends upon the solid facts and sequences of technical thought. For this reason, the potential GDP is also referred to as the long-range aggregate supply and is represented on the AD/AS curve as a straight line that acts as a hard barrier. As was mentioned earlier, neither technical thinking nor technology is magic. One cannot snap one's fingers and wish supply into existence.

Aggregate demand slopes downward like demand in a supply-versus-demand graph. It is reasonably constant but economists say that it is affected to some extent by three factors. "The wealth effect holds that as the price level increases, the buying power of savings that people have stored up in bank accounts and other assets will diminish, eaten away to some extent by inflation. Because a rise in the price level reduces people's wealth, consumption spending will fall as the price level rises” (macro, p. 275). Looking at this cognitively, stored-up wealth represents accumulated technical knowledge. This knowledge provides a general level of confidence when encountering new situations.

One could think of this as a mental toolkit. The bigger my toolkit of technical knowledge, the more confident I will be that I have the appropriate tool for the job. In contrast, if my technical skills become 'rusty', then my demand for new situations will go down. Looking at this from another perspective, if knowledge is realistic - if the level of intellectual inflation is low-then Exhorter thought will not be frustrated when knowledge is turned into reality. But if knowledge has become inflated, then thinking will be unrealistic, leading to frustration for Exhorter thought when ideas encounter the real world.

"The interest rate effect is that as prices for outputs rise, the same purchases will take more money or credit to accomplish. This additional demand for money and credit will push interest rates higher. In turn, higher interest rates will reduce borrowing by businesses for investment purposes and reduce borrowing by households for homes and cars - thus reducing consumption and investment spending” (macro, p. 275). Interest was defined cognitively as the cost of borrowed knowledge; if technical knowledge is acquired as absolute truth, then Perceiver thought has to gain the confidence that is 
required to apply this knowledge. Interest does not refer to the mental cost of understanding technical knowledge, but rather the lesser cost of being capable of applying knowledge that is not understood.

If there is intellectual inflation, then the 'interest rate' of applying knowledge will go up. For instance, if schooling becomes less technical and focuses upon personal feelings and social causes, then it will become more difficult to train students how to use technical thought. Stated simply, the aggregate demand for products will go down if consumers lose the ability to use technical thought; products will be too complicated to use, leading again to frustration for Exhorter thought.

"The foreign price effect points out that if prices rise in the United States while remaining fixed in other countries, then goods in the United States will be relatively more expensive compared to goods in the rest of the world... Thus, a higher domestic price level, relative to price levels in other countries, will reduce net export expenditures” (macro, p. 275). Cognitively speaking, this describes how a 'foreign country' that assigns precise meanings to words views some 'domestic economy' that has allowed words to lose their precise meanings. The result will again be frustration for Exhorter thought, as illustrated by the Western company that attempts to do business in a Third World country where technical rules do not mean what they say but rather have to 'oiled' through personal connections and bribes. This type of 'high price level' makes goods 'more expensive’ compared to other countries.

Aggregate supply is determined by the solid facts of technical training and machinery. "In the long run, the most important factor shifting the AS curve is productivity growth. Productivity means how much output can be produced with a given quantity of labor” (macro, p. 278). Notice that productivity growth is described as a shift in the AS curve rather than a movement along the curve. In other words, economics recognizes the impact that the content of technical thought has upon aggregate supply, but treats this technical content as an outside force that is affecting the curves of economics.

Aggregate demand, in contrast, is affected by emotion and confidence. "When consumers feel more confident about the future of the economy, they tend to consume more. If business confidence is high, then firms tend to spend more on investment, believing that the future payoff from that investment will be substantial” (macro, p. 281). The opinions of some important person cannot affect aggregate supply, but they can impact aggregate demand. "U.S. presidents, for example, must be careful in their public pronouncements about the economy. If they offer economic pessimism, they risk provoking a decline in confidence that reduces consumption and investment and shifts AD to the left” (macro, p. 281).

Summarizing, one again sees a focus upon Exhorter-Contributor interaction. Aggregate supply is determined by the technical thinking of Contributor thought, but economics does not focus upon the content of this technical thinking. Aggregate demand, in contrast, describes Exhorter motivation. The three effects of wealth, interest rate, and foreign price that were just discussed were leading to frustration for Exhorter thought. In contrast, Contributor confidence implies that Exhorter thought is not getting frustrated. (Remember that Contributor confidence reflects an ability to continue operating within the current plan or system.)

The openstax textbook introduces the AD/AS curve by referring to two different economists with two different approaches. "Those economists who emphasize the role of supply in the macroeconomy often refer to the work of a famous early nineteenth century French economist named Jean-Baptiste Say 
(1767-1832). Say's law is: 'Supply creates its own demand'”' (macro, p. 271). Say lived during the early Industrial Revolution when new machines were being invented that possessed a Teacher orderwithin-complexity that exceeded anything seen before. For instance, imagine the excitement of first encountering a massive, noisy, belching, powerful steam engine. In such an environment, the supply of never-seen-before machines will create its own emotional demand.

"The alternative to Say's law, with its emphasis on supply, is Keynes' law: 'Demand creates its own supply'... Keynes argued that the Great Depression—and many ordinary recessions as well—were not caused by a drop in the ability of the economy to supply goods as measured by labor, physical capital, or technology. He argued the economy often produced less than its full potential, not because it was technically impossible to produce more with the existing workers and machines, but because a lack of demand in the economy as a whole led to inadequate incentives for firms to produce" (macro, p. 272). We saw in the previous section that the Great Depression was accompanied by a major drop in aggregate demand. Technology was no longer exciting in the 1930s. That is because the optimism of the Victorian Era had just been crushed by the trauma of the First World War, which had used modern technology to slaughter millions of humans.

Summarizing, I suggest that Say and Keynes came up with different economic focuses because they lived in different eras with different emotional focuses.

The economic conclusion is that "We need to take into account both supply and demand... Keynes' law applies more accurately in the short run and Say's law applies more accurately in the long run" (macro, p. 272). In other words, aggregate supply depends upon facts and sequences that can only be changed over time. Machines take time to construct and technical understanding takes time to develop. Aggregate demand, in contrast, is affected by emotions and emotions can change in an instant, as illustrated by the president triggering a drop in aggregate demand by making the wrong public pronouncement.

\section{Human Capital and Productivity}

Economics defines labor productivity as "value that each employed person creates per unit of his or her input" (macro, p. 167). In other words, how efficient is a person? Three factors affect labor productivity. These three factors will be discussed in a different order than they are presented in the textbook.

Starting with number two, "The second factor that determines labor productivity is technological change. Technological change is a combination of invention —advances in knowledge — and innovation, which is putting those advances to use in a new product or service” (macro, p. 167). In other words, a new product or process is an invention, while an improvement on some existing product or process is an innovation. Looking at this cognitively, an invention requires using abstract technical thought to create something new within concrete technical thought, while an innovation happens when abstract technical thought improves something within concrete technical thought. Viewed from this perspective, abstract technical thought is a multiplier of concrete technical thought. Using concrete technical thought enables the specialization that makes a market economy possible. Invention is a 
supercharging of concrete technical thought that happens as a result of taking a detour into the theoretical realm of abstract technical thought.

The openstax textbook gives the example of the transistor. "The transistor was invented in 1947. It allowed us to miniaturize the footprint of electronic devices and use less power than the tube technology that came before it. Innovations since then have produced smaller and better transistors that are ubiquitous in products as varied as smart-phones, computers, and escalators. Developing the transistor has allowed workers to be anywhere with smaller devices” (macro, p. 167). The transistor was invented as a result of extensive abstract technical thought within the realm of quantum physics. This theoretical detour into abstract technical thought multiplied the effectiveness of concrete technical thought through innovations such as smartphones and computers. (And looking at this physically, one of the primary uses of transistors is to amplify—or multiply—electrical signals.)

"The third factor that determines labor productivity is economies of scale. Recall that economies of scale are the cost advantages that industries obtain due to size" (macro, p. 167). Economy of scale can be viewed cognitively as an extension of innovation and invention. We saw earlier that abstract technical thought views a machine as a collection of precisely-defined objects that work together to perform some function. Abstract technical thought will be driven by Teacher emotions to make a machine run faster, more reliably, and more efficiently. This describes an innovation. Such optimization also involves a detour through abstract technical thought. Innovation generally involves a small detour into abstract technical thought, in which abstract technical thought is used to modify and improve existing tools within concrete technical thought. Invention, in contrast, usually requires a larger detour into abstract technical thought, to the extent of allowing abstract technical thought to transform some aspect of concrete technical thought. The end result is not just a better tool, but rather a totally new kind of tool.

Looking in more detail at this detour into abstract technical thought, concrete technical thought uses machines as tools to produce products. Abstract technical thought rebuilds machines to run more efficiently. There is a cost to this optimization because concrete technical thought cannot use a machine while abstract technical thought is rebuilding the machine. Saying this another way, hiring engineers to rebuild a machine adds to the cost of hiring technicians to run a machine, and engineers usually cost more than technicians because engineers have more training than technicians. What this means in practice is that the cost of using abstract technical thought to optimize some machine will only be economically viable if many of these machines will be used to construct a large quantity of products. Economics observes that such optimization only happens in large firms and describes it as economies of scale. Going further, microeconomics recognizes that production costs can be changed over the longterm through the appropriate use of technology. "No costs are fixed in the long run. A firm can build new factories and purchase new machinery, or it can close existing facilities. In planning for the long run, the firm will compare alternative production technologies (or processes)" (micro, p. 172).

Notice that this is a different kind of economy of scale than that found in infrastructure, but both are examples of Teacher order-within-complexity. A large interacting system, such as the infrastructure of the global economy, exhibits Teacher order-within-complexity. But an intricate device, such as an optimized machine, also exhibits Teacher order-within-complexity. Generally speaking, infrastructure 
describes the view from the inside looking out, whereas intricacy describes the view from the outside looking in. For instance, the Internet is an infrastructure because it connects many people together in a structured manner; each person is one element in a vast structure of order-within-complexity. In contrast, a computer chip feels intricate because one is looking at the chip from the outside and noticing that it contains many complex elements that function together in an ordered manner. These two viewpoints can overlap. For instance, the dense road, railroad, canal, and bicycle-path network of the Netherlands feels like an infrastructure when one is in the country, while feeling more like an intricate web when one compares the Netherlands to other, much larger countries.

These two forms of Teacher order-within-complexity are politically and economically significant, because it means that a country—or economy—does not have to be huge to generate Teacher feelings of order-within-complexity. A small country with a dense infrastructure filled with optimized machines will also generate Teacher feelings of order-within-complexity. For instance, both the United States and the Netherlands are examples of Teacher order-within-complexity, even though the US has twenty times the population, is 250 times as big, and has an economy that is twenty times larger.

Finally, "The first determinant of labor productivity is human capital. Human capital is the accumulated knowledge (from education and experience), skills, and expertise that the average worker in an economy possesses" (macro, p. 167). Human capital refers to the technical thought that is being used by people, and we have seen that it is composed of the skilled labor of concrete technical thought and the professional knowledge of abstract technical thought. I am not suggesting that a skilled laborer uses only concrete technical thought and that a professional uses only abstract technical thought. But it is possible to make a distinction between the technician, artisan, or tradesman who emphasizes concrete technical thought and the professional, researcher, or manager who emphasizes abstract technical thought. This distinction can be seen in the terms 'blue-collar work' and 'white-collar work'.

\section{Physical Capital and Productivity}

The previous three points looked at the labor productivity of people. "The category of physical capital includes the plant and equipment that firms use as well as things like roads (also called infrastructure)" (macro, p. 174). Here too a distinction can be made between concrete technical thought and abstract technical thought. Equipment refers to the use of machines - which are physical examples of technical thought—as tools to generate cause-and-effect within concrete technical thought. Material goes into a machine and what comes out is some finished product.

Infrastructure, in contrast, is a physical example of abstract technical thought, because many individual elements are being interconnected in a way that generates Teacher order-within-complexity. We saw earlier when looking at natural monopolies that economy of scale is related to infrastructure (and we just saw that economy of scale also relates to optimized machines). That is because building an infrastructure can be viewed as taking a detour into abstract technical thought, because considerable order-within-complexity has to be constructed before infrastructure becomes a useful tool for concrete technical thought. Constructing an infrastructure can be quite expensive, which means that the cost of using abstract technical thought to build an infrastructure will only be economically viable if this 
infrastructure becomes widely used within concrete thought. (Similarly, it was noted that optimizing a machine can be quite expensive.)

An effective infrastructure requires the precise definitions of abstract technical thought. For instance, using a standard gauge in the railway system made the infrastructure of railways more useful.

Similarly, shipping became far more efficient by shipping goods in standard-sized shipping containers.

A distinction needs to be made between the level of technical thought involved in designing and building an infrastructure and the level of technical thought required to use an infrastructure. Generally speaking, if precise definitions are followed when constructing an infrastructure, then they can be assumed when using an infrastructure. For instance, if all railroads are constructed using the same gauge - the same precise definition of track width, then it can be assumed that a train will be able to travel on any track. Looking at a more modern example, the electrical and mechanical specifications for computer interfaces are defined very carefully. This makes it possible, for instance, for USB devices made by different manufacturers to function together. A similar principle can be seen with the interchangeable part, because precisely defining each part makes it much easier to assemble these parts.

We have seen that abstract technical thought is capable of multiplying the effectiveness of concrete technical thought. The assumption has been that the abstract technical thinking is being done by humans. However, machines have now become capable of performing abstract technical thought. Economists recognize this to some extent: "When most people think of new technology, the invention of new products like the laser, the smartphone, or some new wonder drug come to mind... Technology, as economists use the term, however, includes still more. It includes new ways of organizing work, like the invention of the assembly line, new methods for ensuring better quality of output in factories, and innovative institutions that facilitate the process of converting inputs into output” (macro, p. 174). In other words, the average person thinks in terms of the innovations of new-and-improved tools and gadgets. But there are also the inventions that have resulted from new ways of organizing production in Teacher thought.

What is missing from this description is the introduction of machines that function at the level of verbal Teacher theories within abstract technical thought. This describes a computer, which carries out instructions that are written using the precisely-defined instructions of some computer language. Cory Doctorow, an expert in technology, explains what this implies. "The world we live in today is made of computers. We don't have cars anymore, we have computers we ride in... Think of radio for a minute. The entire basis for radio regulation up until today was based on the idea that the properties of a radio are fixed at the time of manufacture and can't be easily altered. You can't just flip a switch on your baby monitor and turn it into something that interferes with air traffic control signals. But powerful software-defined radios can change from baby monitor to emergency services dispatcher to air traffic controller, just by loading and executing different software” (Doctorow, 2011).

Looking at this cognitively, a machine like a radio is a physical example of technical thought. But a traditional machine carries out a single Server function. For instance, a radio carries out the single function of transforming electromagnetic radio waves into the audio of music and voice. A radio cannot 
be reprogrammed to perform another function. Such a machine is the physical equivalent of the technician or skilled laborer, because it uses technical components to perform some set of Server actions. In contrast, a software-defined radio combines the hardware that is required to detect and demodulate a radio signal with a computer. The result is an inexpensive radio that can be reprogrammed to access any frequency and signal-including those that are not supposed to be accessed. This is the physical equivalent of the professional who functions at the level of abstract technical thought. This abstraction and generalization of function is even more obvious with smartphones. For instance, when I was young, I would look admiringly at the wide range of technical gadgets illustrated in a RadioShack catalog. The typical smartphone of today can be programmed to replace about half of the gadgets in that catalog. (RadioShack itself went bankrupt in 2015.) And this reprogramming happens at the level of knowledge, which is non-rival, non-excludable, and costs almost nothing to reproduce.

Going further, most devices are now run by one or more single-chip computers. Many of these are faster, miniaturized versions of a typical desktop computer of the 1980s. For instance, the Z80 was a popular computer processor that ran at a speed of $4 \mathrm{MHz}$. The ez80 (“eZ80190", 2008) is a single-chip version that runs at $50 \mathrm{MHz}$. The most recent paper I could find was a report from 2009 which summarized that "Less than two percent (2\%) of today's computers even looks like PCs. In fact the most common form of computer in use today is the embedded computer... These new types of computers have become such a normal part of everyday life that we barely even notice them. The average family has more than 40 embedded computers at home... The average new car has a dozen small embedded computers inside it... In short, nearly anything that takes batteries or plugs into a power outlet probably has a computer inside" (Turley, 2009, p.4).

It was suggested earlier that intellectual property is a category mistake. Concepts of physical property make sense when applied to real objects, because physical objects are both rival and excludable. In contrast, intellectual property does not make sense because knowledge is by its very nature non-rival and non-excludable.

The inherent contradiction of intellectual property is manageable as long as machines have specific Server functions (such as a radio) and knowledge is stored in physical means that are difficult to copy (such as a book). In both cases, the Server functions and Perceiver facts are implicitly limited by the physical objects that carry out these functions and store these facts. The inherent non-rival and nonexcludable nature of knowledge becomes apparent as the cost of storing and duplicating the knowledge becomes trivial compared to the cost of generating this knowledge.

Embedded computing brings the non-rival and non-excludable nature of knowledge into the realm of physical objects. A computer-controlled tool is no longer rival because it can be reprogrammed to perform the function of other physical objects. We saw this when looking at a smartphone. Not only is a smartphone capable of performing many functions, but the functions that it performs can be changed by downloading new apps. Such a computer-controlled tool is no longer excludable because computer programs can be copied easily from one device to another. Thus, if one person uses a smartphone as a video recorder, then it is trivial for many people to copy the computer program that allows a smartphone to function as a video recorder. 
This invasion by abstract technical thought into concrete technical thought is not a trivial problem, because the average home has 40 embedded computers—and that was the estimated number back in 2009.

Firms have responded to this transformation by getting government to pass laws that attempt to apply traditional concepts of ownership to both information and information-driven devices, such as the 1996 "WIPO Copyright Treaty, passed by the United Nations World Intellectual Property Organization, which created laws that made it illegal to extract secrets from unlocking programs. And it created laws that made it illegal to extract media cleartexts from the unlocking programs while they were running. And it created laws that made it illegal to tell people how to extract secrets from unlocking programs. And it created laws that made it illegal to host copyrighted works" (Doctorow, 2011).

The openstax textbook on intellectual property asserts that no fundamental difference exists between smartphones and past technology. “Today's smartphone wars, then, are simply 'back to the future' when it comes to the ways in which disruptive new industries are developed. Historians have noted that every major industrial breakthrough of the last 150 years - from the development of the sewing machine, telephone, automobile, radio, aircraft, medical stent, and even disposable diaper industries, to the birth of the semiconductor and Internet e-commerce industries - witnessed exactly the same surge in patenting and patent litigation that we see in today's smartphone field” (Kline, 2021, p. 30).

And yet a few pages later, it is recognized that smartphones (and computers in general) have created a conflict between knowledge and property that did not exist before. "The boundary between ideas and applications might seem clear, but it has become blurred since the advent of computer technology 40 years ago, especially regarding the patentability of software” (Kline, 2021, p. 37). In other words, today's 'smartphone wars' are not just a case of 'back to the future'.

This paper has broadened the concept of ownership to include understanding; a person mentally owns a device by gaining the Perceiver knowledge and Server skills that are required to intelligently use such a device. The laws being described in the previous paragraph make it illegal to gain mental ownership. This needs to be restated. Education starts off with the borrowed knowledge of absolute truth. This intellectual debt is paid off by turning the blind faith of absolute truth into the intelligent understanding of universal truth. Laws that prevent consumers - and service technicians-from understanding devices prevent them from paying off this intellectual debt.

What is happening is that two different methods of defining intellectual property are colliding. The first method starts with personal ownership and extends this to the intellectual. Originally, the market economy trades physical objects. As what is being traded becomes more abstract, government laws are enacted that treat information and knowledge as if they are physical objects. The second method starts with the intellectual and adds personal ownership. This method has been discussed in our examination of education. Knowledge is universal. But knowledge only helps me if I acquire ownership of that knowledge, which means gaining the Perceiver confidence and Server confidence that are required to comprehend and apply this knowledge.

This conflict between laws of intellectual property and mental ownership can be seen in the current struggle over the right to repair. Looking at the current situation in the United States, "Twenty states 
have pending legislation that would require product manufacturers to make available replacement parts and repair manuals... Manufacturers have been lobbying the legislatures to stop the enactment of these repair laws based on different concerns, including how these laws may impinge on their intellectual property rights. Indeed, a right to repair may not be easily reconcilable with the United States' farreaching intellectual property rights regime. For example, requiring manufacturers to release repair manuals could implicate a whole host of intellectual property laws” (Grinvald, 2019, p. 63). Repair manuals are required to learn the Perceiver facts of mental ownership, and replacement parts are required to apply the Server actions of mental ownership. But these requirements for mental ownership appear to be incompatible with 'a whole host of intellectual property laws'.

And embedded computers make this problem worse. "Gone are the days when an at-home do-ityourselfer could unscrew the back of the coffee maker and fix it with a few tools. With embedded computer chips, software, and other technology, specialized knowledge and tools are now needed to make simple repairs” (Grinvald, 2019, p. 66).

Summarizing, suggesting that intellectual property is a category mistake is not just a theoretical statement. Instead, it means that contradictions will arise whenever 'intellectual' comes into contact with 'property'. We have now seen three levels of conflict between these two. One level happens when objects store intellectual content. For instance, this describes a book or a DVD. The contradiction becomes prominent as it becomes easier to copy intellectual content from one object to another. In this case, limiting the copying makes it harder for individuals to gain mental ownership. A second level happens when objects require intellectual content. This happens, for instance, when attempting to use or repair technical gadgets. At this level, mental ownership is required. The contradiction becomes prominent as gadgets become more complicated. A third level happens when objects use intellectual content. This happens, for instance, with embedded computers. At this level a different question of mental ownership emerges. Will the person own the gadget, or will the gadget own the person? Gaining mental ownership at this point becomes a requirement for maintaining humanity.

This third level is not just referring to some hypothetical future singularity in which artificial intelligence takes over from humans. Many humans are already experiencing what it means to be owned by intelligent machines. An article from The Verge summarizes that "In warehouses, call centers, and other sectors, intelligent machines are managing humans, and they're making work more stressful, grueling, and dangerous... In few sectors are the perils of automated management more apparent than at Amazon. Almost every aspect of management at the company's warehouses is directed by software... Any slack is perpetually being optimized out of the system, and with it any opportunity to rest or recover” (Dzieza, 2020).

\section{China versus the West}

The United States was described a few paragraphs earlier as a "far-reaching intellectual property rights regime” (Grinvald, 2019). What would happen if one followed the other extreme and eliminated intellectual property rights from society? That option can be explored by looking at China. One paper on the subject opens by stating that "China is not meeting its international obligations to protect intellectual property rights” (Brander, 2017, p. 908). 
Looking at this in more detail, in 2011, "The market for illegal software in China was \$9 billion, while the market for legal software was only \$3 billion” (Brander, 2017, p. 910). Going further, “China is the world's primary source of counterfeit goods. Approximately $70 \%$ of counterfeit goods seized globally over the 2008-2010 period came from China” (p. 910). And "some large and successful companies in China have infringed foreign IP and used that as a basis for their success... These companies and consumers know that they benefit from China's failure to enforce property rights. Many of them have significant political influence” (p. 912). Summarizing, China systematically violates laws of intellectual property by copying information, using concrete technical thought to produce imitation goods, and being guided in abstract technical thought by knowledge discovered by others. And this flagrant violation is supported by the Chinese government.

At first glance, this combination appears to be cognitively natural. China is recognizing that knowledge is non-rival and non-excludable. China has no laws that prevent individuals from gaining mental ownership. And China is focusing upon mass-producing consumer items at the cheapest price. This combination has resulted in extensive mental ownership within technical thought. This mental ownership can be seen in the development of manufacturing hubs. "For example, Shenzhen, a city bordering Hong Kong in the southeast, has evolved as a hub for the electronics industry. It has cultivated an ecosystem to support the manufacturing supply chain, including component manufacturers, low-cost workers, a technical workforce, assembly suppliers, and customers” (Bajpai, 2021). Notice that mental ownership spanning the entire 'manufacturing supply chain' has been acquired by an entire 'technical workforce'. More generally, “The Chinese economy thrives as a manufacturing powerhouse and the nation’s products seem to be everywhere” (Bajpai, 2021).

Mental ownership is required when turning words and ideas into real products (or when using technical products). But we have seen that laws of intellectual property are incompatible with mental ownership. American firms have addressed this problem by physically separating intellectual property from mental ownership. This has expressed itself as a symbiotic relationship between the United States, with its laws of intellectual property that suppress mental ownership, and China, with its focus upon mental ownership that ignores laws of intellectual property. Thus, many products are designed in the United States and then manufactured in China. One US government briefing summarizes that "China is the single biggest offshore in destination for U.S.-based firms. Of the nearly 14 million workers employed by U.S. multinationals' affiliates in 2014 , more workers (1.7 million, or $12 \%$ of the total) were employed in China than any other country. Moreover, about half of these workers (753,000 or 45\%) were employed within China’s robust manufacturing sector” (Hammer, 2017).

In the short term, this symbiotic relationship has increased profits for firms as well as decreasing prices for consumers, because it has permitted the American economy to experience the benefits of having laws of intellectual property while at the same time experiencing the benefits of not having laws of intellectual property.

But there are major longer-term costs. One significant result has been the loss of middle-class jobs in the United States. One report summarizes that "In the past half century, the United States labor market has experienced an economic restructuring that has fundamentally changed the occupational profile of the American middle class. Technological improvements in assembly line automation and the 
offshoring of factories have reduced the demand for middle-skill production jobs and have displaced workers into low-skill service jobs. At the same time, as demand for high-skill positions has increased, these positions remain out of reach for most individuals who lack a four-year college degree" (Seltzer, 2018, p. 1). Notice how many 'middle-skill production jobs' have been exported to countries such as China, and these have been replaced by 'low-skill service jobs'.

One can interpret this economically as a loss of earning power, but there is also the accompanying mental cost. A 'low-skill' job requires less mental ownership than a 'middle skill' job. But mental ownership extends beyond the workplace. Instead, mental ownership affects a person's ability to grasp all forms of technical knowledge. And "A report conducted by the OECD... has found that a staggering 36 million adults in the U.S. are 'low-skilled.' That is, they lack the most basic skills in literacy, numeracy and problem-solving deemed minimally necessary for meaningful employment in a hightech global economy” (Crotty, 2015). This lack of basic technical skills became apparent during the recent Trump administration and covid pandemic, because it became obvious that a significant proportion of Americans lack the ability to analyze technical information in a competent manner.

Another significant long-term cost has been the extensive intellectual 'borrowing' by China. This applies obviously to the production of goods, and it was mentioned a few paragraphs earlier that 'China is the world's primary source of counterfeit goods'. However, this is starting to change-at a local level. An article in Wired describes this change. "Most of the time, the electronics were assembled in China; almost never were they invented in China. This image is still deeply ingrained in the western imagination - that of the industrious 'copycat' nation. But a few years ago, China's leaders decided they wanted the country to be known for a new kind of electronics- not only 'Made in China', but 'Designed in China'... For now, these worlds co-exist: China past and China future” (Larson, 2018).

Looking at this cognitively, in the same way that many Americans have not gained mental ownership as a result of working at low-skill jobs instead of middle-skill jobs, so many Chinese have acquired mental ownership as a result of working at middle-skill manufacturing jobs. As a result, the 'China past' of 'made in China' is starting to be replaced by a 'China future' of 'designed in China'.

Lending was interpreted earlier as retaining Perceiver ownership of money while temporarily transferring Server ownership; the borrower can use money that belongs to the lender. Applying this to the intellectual 'borrowing' of China, the modern 'made in China' began when Western firms outsourced manufacturing to Chinese factories. The Western firms maintained Perceiver ownership of the items while the Chinese manufacturers gained Server ownership by practicing the skills that were needed to produce the items. Intellectually speaking, this was borrowed knowledge, because the Server skills were not accompanied by Perceiver knowledge. Using Server thought without Perceiver thought leads to copying, and the Server person excels at copying the actions of others. This expressed itself as ‘the industrious copycat nation’ of China.

Going further, using technical skills will gradually 'pay back' the 'loan' of borrowed knowledge, because Perceiver thought will start to acquire facts resulting in partial understanding. This leads to the next stage of 'counterfeited in China', which combines the skills of Server ownership with partial ownership of knowledge in Perceiver thought. Initially, these counterfeits will be of low quality, 
reflecting a low level of Perceiver ownership. But as more of the mental debt of borrowed knowledge is paid off, the quality of the counterfeit will increase. The following quote describes the transition from borrowed knowledge to quality counterfeit. "There are thousands of counterfeit manufactures in Guangdong, many of which also produce legitimate products. 'Genuine items on the day shift, counterfeit on night and weekend'... Wengang specialized in counterfeiting pens; Taizhou for auto parts; and Chaozhou for cosmetics. Being responsible for nearly $80 \%$ of the counterfeit production in the world trade, the market has been offering job opportunities for countless people who work on counterfeit activities” (Jiang, 2014, p. 74). Notice how different Chinese cities have acquired technical expertise in counterfeiting various items. Eventually, sufficient abstract technical knowledge will be acquired to go beyond 'counterfeited by China' to 'designed in China'.

But that still leaves the problem of 'borrowed knowledge' at the social and national level. Absolute truth was described earlier as borrowed knowledge. And the Chinese social and educational system emphasizes absolute truth. Looking at this historically "Rather to be considered as a moral offense, copying or imitation was considered to be ‘a noble art,' a 'time-honored learning process' which people manifested respect for their ancestors in Chinese history. Reproduction of masterworks was a normal learning method for Chinese people” (Jiang, 2014, p. 74). Notice that copying is regarded as showing 'respect for ancestors'. Cognitively speaking, absolute truth is ultimately based in Mercy feelings of respect for some source of information. And reproduction provided the 'time-honored learning process' for turning emotional ‘truth’ into absolute truth.

Going further, a basic premise of communism is that only Server ownership exists. This can be seen in the opening paragraph of the Encyclopaedia Britannica article on communism. Communism is a "political and economic doctrine that aims to replace private property and a profit-based economy with public ownership and communal control of at least the major means of production (e.g., mines, mills, and factories) and the natural resources of a society” (Ball, 2019). 'Private property' refers to Perceiver ownership, which communism attempts to replace. Communism focuses instead upon controlling 'the major means of production', which refers to Server ownership. Thus, Chinese communism reinforced the traditional Chinese de-emphasis of Perceiver ownership, as well as laying the groundwork for the Server ownership of Chinese 'borrowing'. Thus, one could say that China has succeeded in gaining control over the 'major means of production' for the world partially through replacing intellectual property with public ownership.

Moving to the present, a mindset of absolute truth "is reinforced by the traditional master-student relationship within schools and universities where, all too often, copying is the default position. Students at university will regularly copy out essays from the internet and present them, uncited, in all innocence. In their view, there is nothing wrong with plagiarising the 'correct answer' from a respected expert, instead of spending time trying to give their interpretation of the answer that could be wrong. Seen through Chinese eyes, copying is not only sensible, but it is a symbol of respect for authority” (Williams, 2020). 'Respect for authority' lies at the heart of absolute truth. Absolute truth thinks in terms of right and wrong, defining the 'correct answer' as one which quotes from 'a respected expert'. Going further, belief in absolute truth will only remain as long as it is felt that the source of truth has much greater emotional status than personal identity. Thus, using personal thought to 'try to give an 
interpretation of the answer' will be viewed instinctively as corrupting the 'correct answer' of the established expert. Similar traits can be seen in the attitude of a fundamentalist religion to a holy book.

And this same mindset of absolute truth characterizes the attitude of China as a nation towards Western countries. This can be seen explicitly in the following quote from a Central People's Government advisor. "If you want to promote a market economy you need the rule of law. This is at least what Westerners keep telling us for the last 30-40 years. [...] It is pure dogmatism. In previous times, the Communist Party has dogmatically followed the Soviet Union. Today, we follow the neo-liberal ideas of the West without questioning them. We believe that whatever works in the West will also be effective in China” (Rühlig, 2018, p. 6). Notice how China used to regard the Soviet Union as the legitimate source of absolute truth, but now blindly follows the West. Perceiver facts are being regarded as 'pure dogmatism' based in Mercy feelings of respect for some source of absolute truth. Thus, Perceiver truth is being 'borrowed'. But there is Server ownership, because 'what works' is being 'followed'.

However, a belief in absolute truth will only remain as long as it is felt that the source of truth has much greater status in Mercy thought than personal identity. In contrast, belief in absolute truth will naturally fade as personal identity gains in emotional status relative to the source of truth. This means that China will only respect Western rule of law to the extent that China feels that it is inferior to the West. This is no longer the case. In terms of nominal GDP, China is now the second largest economy in the world, behind only the United States. If one adjusts for cost of living, then China now has the world's largest economy (Silver, 2020). And China has increasingly been acting in ways that show a disregard for international law. This can be seen, for instance, in Chinese island-building in the South China Sea (Mollman, 2016) or Chinese suppression of Hong Kong democracy (Soo, 2021).

China achieved this dominance by focusing upon the concrete technical thinking of manufacturing. And a similar focus can be seen in the way that China is attempting to assert its new international status. This Chinese focus upon concrete technical thought is shown by the Belt and Road Initiative, which "consists of several economic and some non-economic elements. Perhaps the most frequently mentioned economic element is a Chinese commitment to invest heavily in a wide variety of infrastructure projects in order to strengthen the economic capacity and 'connectivity' among the nations within the One Belt, One Road area and with China’s western regions” (Swaine, 2015). Infrastructure is an example of Teacher order-within-complexity. But it is a physical example that involves manufacturing the physical items of concrete technical thought.

Summarizing, intellectual property can be defined either by extending from physical ownership to the intellectual and then enforcing this artificial extension through extensive government laws, or by extending from the intellectual to personal ownership through the concept of mental ownership. The Western economy has attempted to follow both of these alternatives simultaneously by domestically maintaining laws of intellectual property while exporting manufacturing to a country such as China that respects mental ownership but does not enforce laws of intellectual property. This juxtaposition has worked in the short-term but has led to several long-term complications. 


\section{Teacher-driven Growth}

It was mentioned a few paragraphs earlier that America has lost many middle-skill jobs.

"Technological improvements in assembly line automation and the offshoring of factories have reduced the demand for middle-skill production jobs and have displaced workers into low-skill service jobs” (Seltzer, 2018, p. 1). The previous section looked at the offshoring of factories. This section will examine assembly-line automation and other forms of technology-driven production.

The Great Depression was accompanied by considerable economic deflation. We saw earlier that the path to economic recovery included using government to deliberately create a positive motivation for economic activity at the level of Teacher thought. Modern society is currently experiencing a strongly deflationary force. But this is not leading to a depression because it too is being counterbalanced by emotional support from Teacher thought. This current deflationary pressure is recognized by technologists, but they are complaining that it is being ignored by economists (Foremski, 2020).

In simple terms, the price of computers keeps going down. This long-term deflationary trend is obvious to anyone who has shopped for computers. This is not just a minor drop in prices. For instance, it was mentioned earlier that a desktop computer from the 1980s can now be placed on a single chip. A 1980s Z80 computer cost several thousand dollars, while a single chip ez80 can be purchased today for about $\$ 10$. And simpler 8-bit single chip computers can be purchased that cost a fraction of a dollar apiece. This explains why most gadgets now contain embedded computers. It is cheaper to program a singlechip computer to carry out some function than it is to build a normal machine to perform this function.

Deflation was interpreted earlier as a tightening of technical definitions. The greatest single factor driving the continual drop in the prices of computer chips could be described as a physical tightening of technical definitions. This is known as feature size or process node and typically refers to the size of the smallest element on a chip. In 1989, the feature size was 1000 nanometers (nm), in 1999 it was $180 \mathrm{~nm}$, in 2010 it was $32 \mathrm{~nm}$, and in 2021 the latest process node is $5 \mathrm{~nm}$ ("Process technology”, 2021). Deflation refers to an overall drop in prices, or a general tightening of technical definitions. Similarly, when feature size shrinks, then every part of a computer (or other) chip shrinks proportionally. Feature size does not shrink automatically. Instead, each shrink requires the development of new fabrication machines that are capable of functioning at this new level of technical precision.

Economic theory predicts that such severe deflation would lead to an economic depression in which sales dropped precipitously. That is because classic microeconomics states that the demand for some item will go down if people think that the price of this item will fall. And there is a tendency to postpone computer purchases until some future time when the price will be less. However, this Mercy disincentive against purchasing computers is accompanied by a strong Teacher incentive to buy computers. That is because computers contain ever-increasing Teacher order-within-complexity. This was pointed out earlier when observing that today's smartphone is capable of carrying out half of the functions of the devices that were being marketed in a 1980s RadioShack catalog. Demand for desktop computers may have fallen, but consumers are still buying computers in the form of tablets or smartphones, and the demand for embedded computers continues unabated. 
This is another example of Teacher emotion overcoming personal reluctance. The personal reluctance of the Great Depression was overcome by having government intervene at the level of Teacher thought. Similarly, the personal reluctance of 'buying a computer that will be cheaper tomorrow' is being overcome by positive Teacher feelings generated by the growing order-within-complexity of computers. Going further, the increasing Teacher order of computers combined with the decreasing Mercy cost means that many devices can be made more cheaply by replacing most of their parts with a computer.

Looking at the bigger picture, current society is experiencing both significant inflation and significant deflation. At the social level, postmodern questioning is leading to the inflation of technical language. However, at the technical level, the development and spread of computers is causing significant deflation. Saying this another way, postmodern humans have become less capable of using technical thought, while computer-driven machines have become more capable of exhibiting technical thought. Added to this is the additional factor that most middle-skill jobs involving technical expertise have been outsourced from the West to China. These three factors have totally altered the balance between humans and machines - between human capital and physical capital. Saying this bluntly, the average Western human has become technically dumber because of postmodern questioning and because of the exporting of middle-skill jobs. Meanwhile, machines keep getting technically smarter.

The contrast between dumb humans and smart machines has reached the point of creating a general theory of hopelessness within the mind of many consumers. This theory could be summarized as 'I will never be able to understand modern technology'. Any attempt to explain some aspect of technology to such a person will be viewed by Teacher thought as an emotional threat to their general theory of technological hopelessness, and the response will be a dismissive waving of the hand combined with some comment such as 'That stuff is far too complicated for me.' I do not know how pervasive this theory is, but I have encountered it quite often, especially in North America, and it provides an emotional drive that exacerbates what will be described in the next paragraphs.

The juxtaposition of technical computers and non-technical humans has led to technical computers being made for non-technical people. This can be seen in the development of the GUI, or graphical user interface. The original personal computers of the 1970s were controlled at the level of Teacher words by typing technical commands into the computer. This characterized early operating systems such as DOS or CP/M. This was necessary because early computers were slow and interpreting typed commands does not require a fast computer. But this also meant that significant human capital was required to use the physical capital of computers. Humans had to have technical skills because computers lacked in technical ability.

The GUI replaced the CLI (command line interface) with a visual desktop that mimics the physical objects of concrete thought, and the 'objects' on a screen can be moved and controlled by using a mouse or a finger, mimicking the Server actions of concrete thought. This makes using a computer easier but also requires a more powerful computer. A 2013 article in ZDNet observed that "Simplification is now the latest trend in UX [user experience] design changes, across all of the major platforms... After 40 years of personal computing, the end user has become a simpleton, no longer requiring specialized knowledge to operate the system. In effect, he's been transformed into a cranky 
idiot who becomes angry when even the smallest change requiring learning new habits is introduced" (Perlow, 2013). Summarizing, technical knowledge is no longer required to use a computer. Instead, the extensive simplification of the 'user experience' makes it possible for computers users to be 'cranky idiots' driven by mental networks of culture. And this article was written in a technical magazine aimed at a technical audience. The average user is not even aware of being a 'cranky idiot' but considers this form of culturally-driven concrete thought to be normal when using a computer.

A similar simplification has happened in the working environment. On the one hand, some highly trained — and highly paid—workers are still needed to design, build, and maintain the complicated machines. A Brookings research article summarizes that "As forces like globalization and automation reshape the labor market, it is clear that some people and places are positioned to do well while others risk becoming collateral damage. The well-educated and technically savvy find ample employment opportunities, while those with lower levels of education face a labor market that is decidedly less welcoming, with lower wages and less potential for career growth” (Ross, 2019).

But for many low-skill workers, the imbalance between physical capital and human capital has led to a situation where technical machines rule while non-technical humans are the slaves. Quoting from a Verge article mentioned earlier, “The robots are here, they're working in management, and they're grinding workers into the ground. The robots are watching over hotel housekeepers, telling them which room to clean and tracking how quickly they do it. They're managing software developers, monitoring their clicks and scrolls and docking their pay if they work too slowly. They're listening to call center workers, telling them what to say, how to say it, and keeping them constantly, maximally busy” (Dzieza, 2020).

Turning now to the subjective realm of mental networks, complicated computers with intuitive interfaces are being used for social media. However, when computers are used at the level of MMNs to facilitate the social interaction of MMNs, then the use of computers will naturally become dominated by MMNs. For instance, in March 2021, three of the top ten websites in the United States were social media (Facebook, Reddit, and Twitter), while two appealed directly to MMNs of visual experience (Youtube and Pornhub) (“Top 100”, 2021).

One primary cognitive result of emphasizing social MMNs is that Perceiver thought will become overwhelmed by these MMNs, causing computer-enabled social interaction to turn into echo chambers that emphasize emotions, downplay facts, and remain disconnected from other echo chambers. A recent paper that examined 100 million pieces of content on social media concluded that "Social media platforms provide direct access to an unprecedented amount of content. Platforms originally designed for user entertainment changed the way information spread... Such a paradigm shift affected the construction of social perceptions and the framing of narratives; it may influence policy making, political communication, and the evolution of public debate, especially on polarizing topics. Indeed, users online tend to prefer information adhering to their worldviews, ignore dissenting information, and form polarized groups around shared narratives” (Cinelli, 2021).

Translating this into cognitive language, social media was 'originally designed for user entertainment'; it was meant to appeal to the MMNs of consumers. But it has 'changed the way information spread'; it 
has altered the way that Perceiver thought gathers information. This has 'influenced policymaking' and 'public debate'; Perceiver information from social media has spilled over into the social and political realms. Social media users 'prefer information adhering to their worldviews'; Perceiver facts have become determined by emotional MMNs. Users have 'ignored dissenting information'; Perceiver facts that are inconsistent with MMNs are ignored. And users have formed 'polarized groups around shared narratives'; people have become separated into tribal groups based upon shared MMNs. Ironically, this triumph of MMNs over factual connections is being carried out on highly technical computer networks that require ultra-stable factual connections to function.

Finally, using MMNs to overwhelm Perceiver thought is becoming an active strategy in which unwelcome facts and people are 'cancelled' through emotional pressure on social media. The struggle between social MMNs and Perceiver thought can be seen in a Vox article entitled Why we can't stop

fighting about cancel culture (Romano, 2020). The article was originally written in 2019, but was last updated in August 2020. This update must have been insufficient, because there is now an additional explanatory article written in 2021. The explanatory article opens by describing how factual dialogue has become overshadowed by emotional posturing. “'Cancel culture,' as a concept, feels inescapable... It sometimes seems all-encompassing, as if all forms of contemporary discourse must now lead, exhaustingly and endlessly, either to an attempt to 'cancel' anyone whose opinions cause controversy or to accusations of cancel culture in action, however unwarranted” (Romano, 2021). This describes emotional 'truth', in which MMNs are being used to try to overwhelm Perceiver thought. Absolute truth has stability. Emotional 'truth' is determined by the latest emotional outburst.

And 'cancelling' now has an economic impact. A 2018 Edelman survey found that "Nearly two-thirds (64 percent) of consumers around the world will buy or boycott a brand solely because of its position on a social or political issue... a staggering increase of 13 points from last year. Belief-driven buyers are now the majority across markets... age groups... and income levels” (“Two-thirds”, 2018).

Summarizing, when physical capital exceeds human capital, then there are short-term benefits, because machines do all the work and humans only have to push the buttons. But the long-term result is that humans become the slaves of machines, both mentally and physically. Whatever the solution is, it will not involve some instant fix that can be achieved by pushing some button, because that kind of 'solution' will only make the problem worse. Instead, all the solutions appear to involve some version of increasing human capital.

\section{The Exchange of Currency and Knowledge}

Money has been treated so far as a single entity. But the world contains over 150 different currencies. Similarly, this paper has treated the economy as a single entity. The relationship between China and the West was discussed, but that was interpreted as a single hybrid economy composed of two parts in a symbiotic relationship. This section will look more generally at international trade.

International trade is like normal trade but includes the additional step of having to convert from one currency to another. The amount of money being exchanged is massive. “A 2013 Bank of International 
Settlements survey found that \$5.3 trillion per day was traded on foreign exchange markets... In contrast, 2013 U.S. real GDP was \$15.8 trillion per year” (macro, p. 383).

From the viewpoint of concrete technical thought, money is a form of generic cause-and-effect: Person A receives money for using technical thought to produce some good or perform some service. This money is then given to person B in exchange for some technical good or service. Exchange adds an additional step to this cause-and-effect: Person A receives the money. This money is then exchanged for some foreign currency. Person B then receives the foreign currency.

Each intermediate step has uncertainty. Inflation weakens the Perceiver connection between cause-andeffect, which means that what person A receives may be less that what person A performed. Exchange adds another level of Perceiver uncertainty. If the exchange rate changes, then what person A receives may be quite different in value than what person A initially performed. This extra uncertainty can be eliminated through a hedge. For instance, "Let's say you want to know for sure what the contract will be worth, and not take a risk that the euro will be worth less in U.S. dollars than it currently is. You can hedge, which means using a financial transaction to protect yourself against a risk from one of your investments (in this case, currency risk from the contract). Specifically, you can sign a financial contract and pay a fee that guarantees you a certain exchange rate one year from now" (macro, p. 385).

Going further, exchanging currencies can itself be viewed as a kind of market governed by supply and demand. "In reality, the exchange rate is a price-the price of one currency expressed in terms of units of another currency. The key framework for analyzing prices... is the operation of supply and demand in markets" (macro, p. 383). In other words, a currency will appreciate, or go up in value, when the demand for this currency goes up and depreciate when the demand goes down. However, foreign exchange is not a normal market because Teacher generality is being traded and not Mercy specifics.

For instance, suppose that eggs become more expensive. This will affect the price of items that use eggs or egg substitutes, but only a few items will become more expensive. However, when some currency appreciates, then all goods and services which use that currency become more expensive. When everything within some area is impacted in a similar manner, then one is dealing with a general Teacher theory. This implies that exchange needs to be analyzed from the Teacher perspective of abstract technical thought and general Teacher theories.

Abstract technical thought deals with precise definitions. Inflation was interpreted in a previous section as words losing their precise meanings. The assumption was that only one language is being used. However, the world actually uses many languages, each with its own set of precise definitions. Different languages add the additional step of translation to the task of communication. Translation involves Perceiver thought. Saying this more carefully, a word or sentence acquires a meaning when some sequence of verbal sounds or letters in Server thought becomes connected with some fact or collection of facts in Perceiver thought. All humans inhabit similar bodies and live in the same physical world. This experiential commonality will lead to a substantial overlap in the Perceiver facts that people acquire. For instance, everyone has encountered objects such as stones, trees, clouds, or houses, and most people know about eggs, fish, cars, or phones. However, each language associates these Perceiver facts with different Server sequences of words and symbols. Translation uses Perceiver 
thought to connect Server sequences in different languages that have the same Perceiver meaning. For instance, 'stone', 'pierre', and 'אֶבֶ ' are different Server sequences of verbal symbols that all have the same Perceiver meaning.

Like exchange, translation adds an extra level of Perceiver uncertainty. Verbal 'inflation' leads to Perceiver uncertainty because one is no longer certain exactly what a word or sentence means. Translation increases this Perceiver uncertainty because one is not certain if a word or sentence has been translated precisely.

So far we have been looking at actual languages, and there is a partial relationship between currencies and languages. That is because many countries have their own currencies and speak their own languages. International trade often combines the uncertainties of converting between one currency and another and translating from one language to another.

However, the nature of technical thought ensures that additional problems of translation will naturally arise within a market economy. On the concrete side, a market economy allows people to specialize, which means using concrete technical thought to perform some limited activity faster and better. But on the abstract side, each specialization will also use abstract technical thought to describe the various technical elements of that specialization using words with precise meanings. In order to interact with some specialization, one must learn the precise meanings of the technical terms that are used by that specialization. For instance, physics assigns precise meanings to words such as work, energy, and power.

Therefore, any commercial activity that crosses specializations will involve some form of translation, because the technical language of one specialization will have to be translated into the technical language of another. For instance, consider the task of purchasing medical equipment. The equipment has to perform in a manner that meets the technical requirements of medicine and display its results in a manner that reflects the technical language of medicine. But this equipment has to be designed and constructed using the technical language of electronics. Purchasing this equipment may not involve any exchange at the level of currency, but it definitely will involve a 'currency exchange' at the level of specialization. The result will be two levels of Perceiver uncertainty: First, can the facts that are being portrayed by the machine be trusted as being sufficiently precise? Second, can the translation between medical requirements and electronic circuits be trusted as being sufficiently precise? The first uncertainty arises whenever some medical specialist provides some diagnosis. The second uncertainty arises because an electronic machine is being used to provide the medical diagnosis. ${ }^{33}$

It was mentioned earlier that the exchange market deals with Teacher generality, because a change in some currency will universally affect every good and service which uses that currency. Similarly, the change in status of some language will have an indirect impact upon everything that is said using this language. This applies to some extent to normal language but more extensively to the various languages of technical specializations.

33 There is also the additional question of whether this diagnosis accurately describes reality, but that problem goes beyond the problem of exchange and translation being discussed here. 
Going further, every economic trade is carried out in some currency. Purchasing some item requires purchasing first the currency in which that item is sold. The relative value of a currency goes up when people purchase this currency and it goes down when this currency is being sold. This is also a matter of Teacher generality, because the generality of some item increases when it is used in more specific situations. A currency that is used for many transactions has more Teacher generality than one that is only used for a few.

Currencies that have the greatest Teacher generality will acquire the general Teacher function of acting as an international currency. For instance, the American dollar is currently the primary international currency. Notice the convergence of several related Teacher generalities. English, which is the language of the United States, was the most common language in 2021, spoken as either a first or second language by about 1.35 billion people. Mandarin Chinese comes in second with 1.12 billion speakers (Szmigiera, 2021). Turning to academic language, a 2012 study found that about $80 \%$ of academic papers are written entirely in English (van Weijen, 2012). Going further, "In many countries, collegelevel science education is now conducted in English—partially because studying science in English is good preparation for a future scientific career, and partially because the necessary words often don't exist in any other language" (Huttner-Koros, 2015). Notice how the universality of English increases when dealing with the precise terminology required by abstract technical thought, because in many languages the required precise terms do not exist.

Turning now to economics, the United States also has the world's largest economy, with a nominal GDP of 21 trillion dollars, followed by China at 14 trillion dollars (“GDP”, 2021). That is around 16\% of the world's economy. But in 2016, 88\% of currency exchanges involved the American dollar (macro, p. 383). Since every currency exchange involves two currencies, this means that $44 \%$ of currency exchanges involved either selling or buying American dollars. And all of the references being quoted here presented these statistics in English using American dollars. Again, one sees the generality of an international currency being greater when dealing with this currency at the level of abstract technical thought.

In each case, Teacher feelings of generality are causing an existing dominance to be exaggerated. The American dollar moved from being the currency of the economy of the country with the greatest status in Mercy thought to being used as an international currency that brings Teacher order to the structure of the world economy. The English language moved from being the language spoken by the countries with the greatest Mercy status to being used as an international language to bring Teacher order to the international systems of trade and academia. Finally, a cognitive movement towards Teacher thought was described previously when looking at Platonic forms, and this can also be seen with the American economy, because the American economy turned into the Platonic form of 'The American Dream'.

This Teacher dominance of America is now being threatened by the rise of China. When viewed from the perspective of concrete technical thought, then China can claim to be the new leader of the world, because concrete technical thought thinks in terms of cause-and-effect, and Chinese factories carry out a significant portion of the world's technical cause-and-effect of manufacturing physical goods. The Chinese focus upon concrete technical thought can also be seen in the Belt and Road Initiative 
mentioned earlier. Infrastructure is an example of Teacher order-within-complexity. But it is a physical example that involves the physical items of concrete technical thought.

However, an international economy functions at the level of Teacher thought and requires the precise definitions of abstract technical thought. And here China does not provide an adequate replacement for Western technical thought. In the words of one author, "Time and again, European and Chinese policymakers disagree over issues related to China's approach to the law: Both the Chinese domestic rule of law and the country's compliance record with international law remain subject of contentious discussions. Many Europeans interpret China's reference to the rule of law as pure rhetoric” (Rühlig, 2018, p. 1). In other words, at the abstract level of words with precise meanings, the 'currency' of Chinese language is considered by the West to be worthless-vague words that lack any precise meaning. Saying this more carefully, "China has a less coherent approach to law depending on concrete contexts and the respective cost-benefit calculations: When legal certainty is beneficial for China, it is improved. In other cases, China prefers vague legal norms that are open to interpretation not constraining the exercise of political power” (p. 2). In other words, China keeps technical language vague in order to allow Perceiver facts of the rule of law to be determined by MMNs of Chinese culture and status. Turning from general to specific, an example was given near the beginning of this paper of Chinese no-name rechargeable batteries being described using terms that did not match reality. That is also a case of words lacking precise meanings.

Notice that China exhibits inadequate Perceiver thought in two ways: The first way involves cause-andeffect. China copied others and borrowed knowledge because of emphasizing Server ownership and lacking Perceiver ownership. This Perceiver deficit has been partially overcome as a result of growing Chinese expertise, and 'made in China' now coexists with 'designed in China'. The second way involves precise meanings. China views the rule of law as a form of absolute truth imposed by the West, and precise meanings are assigned to words only when it is to China's advantage. The behavior of China suggests that this second form of Perceiver deficit is not being addressed. Instead, when other nations focus upon the facts of Perceiver thought, the standard Chinese government response seems to be to try to overwhelm Perceiver thought through some sort of personal attack on Mercy thought. A Canadian example can be found in in the 'hostage diplomacy' of the 'two Michaels', in which two Canadians in China were charged with spying in retaliation for the Canadian arrest of the CFO of Huawei (Ivison, 2020).

Summarizing, if one thinks purely in economic terms, then it makes sense that China might replace the United States as the new global superpower. But if one goes beyond macroeconomics to include abstract technical thought, then one concludes that China is lacking the fundamental elements that are required to function adequately at an international level—let alone set the standards for international behavior within Teacher thought. But this conclusion must also be accompanied by a related question. To what extent does the United States still live up to the Teacher standards of universality that it helped to establish? China may be unqualified to take the crown of setting the international standard, but is the United States qualified to continue holding this crown?

Looking further, does the Teacher universality of international behavior require the backing of an economic and/or military superpower, or is this a form of commodity-backed currency? Commodity- 
backed currency has been replaced by fiat currency which is backed up by the abstract technical thinking of various institutions. Similarly, is it possible for the 'commodity-backed currency' of a world superpower to be replaced by some form of 'fiat currency' that does not require the domination of some single country?

At the level of the English language, these questions are expressed in the three terms world English, international English, and global English. "The first has been used to mean both standard English and all English; the second refers to the multinational use of English (notably in language teaching); and the third both implies vast use and links the language (often negatively) with socio-economic globalization” (McArthur, 2004). Translating this into cognitive language, 'world English' recognizes that English goes beyond being the language of some specific country or group in Mercy thought, and this spread of English is typically divided into an 'inner circle', an 'outer circle', and an 'expanding circle' (Bolton, 2006). 'International English', in contrast, views English from a Teacher perspective as a form of 'international currency' of communication. 'Global English' then adds the other elements of Teacher universality that have just been discussed, recognizing that the international use of English is only part of the larger phenomena of globalization.

\section{The Demand for Currency}

Returning to the topic of currency exchange, the demand for a currency can be subdivided into four groups: "(1) firms that are involved in international trade of goods and services; (2) tourists visiting other countries; (3) international investors buying ownership (or part ownership) of a foreign firm; (4) international investors making financial investments” (macro, p. 383).

In each of these cases, one currency is being exchanged for another, giving the impression that these are all equivalent. A more complete picture emerges if one thinks in terms of translation.

In the first group, the translation happens to specific goods after they are produced by some firm. This may include the translation of actual words, such as translating the instructions on how to use some product. But the product itself will need to be 'translated', because it is being taken out of the paradigm in which it was made in order to be used in some foreign paradigm. A good or service often has to be modified in order to fit within a foreign market. This applies when exporting goods to other countries, but it also applies when 'exporting' goods or services across technical specializations. For instance, consider the example of medical equipment. The electronic device will have to be translated into a form that 'makes sense' within a medical environment. This goes beyond merely placing medical labels on the buttons and using medical terms on the menus to providing results that are medically meaningful. The need for adequate translation becomes more apparent when both countries and specializations are being crossed, such as ordering medical equipment from other countries.

In summary, the cost of international trade goes beyond the cost of exchanging one currency for another. There is the additional cost of translating both language and technical requirements. For instance, this additional cost can be seen in international call centers, where technical support for some product is being provided from another country. 
In the second group of tourism, the experiences of some region are being 'translated' into the language of visitors. A foreign tourist who is visiting some location is converting foreign money into the local currency. But the experiences of the local region are being translated into the language and mindset of the foreign tourist. This often includes translating from one language to another but also involves the translation of concepts and expectations; the experiences of the local region have to be translated into a form that is comprehensible to the foreign tourist.

In the third group of buying ownership, the translation involves the firm itself. When some foreign entity purchases a firm, then that foreign entity will attempt to impose its way of thinking upon that firm. This involves extensive translation because an entire system is being converted to a new way of thinking and not just some individual product. This extensive translation is apparent even at an economic level. "With foreign direct investment the investor... typically assumes some managerial responsibility. Thus, foreign direct investment tends to have a more long-run focus... [A] U.S. firm that wants to buy or sell a company, such as one that manufactures automobile parts in the United Kingdom, will find that planning and carrying out the transaction takes a few weeks, even months” (macro, p. 385). The extensive translation required when purchasing a company illustrates the distinction between using money to buy something and having cognitive ownership of an item. Buying a foreign firm is fairly straightforward. Obtaining cognitive ownership of that firm is much more difficult.

The fourth group of international investment involves only the exchange of currency. This makes the exchange quite simple. For instance, "A U.S. portfolio investor who wants to buy or sell U.K. government bonds can do so with a phone call or a few computer keyboard clicks" (macro, p. 385). But adequate translation is being assumed. The investor is assuming an adequate understanding of both the foreign investment and the foreign economy.

In each of these cases, the bulk of the translation is happening in the opposite direction as the currency exchange. In the first case, money is being converted from the currency of some market into the currency of the firm, while the product is being translated from the language of the firm into the language of the market. In the second case, a tourist is spending money in some foreign country, while merchants and guides in this foreign country are translating local experiences into the language and culture of the tourist. In the third case, foreign investors are converting their currency into local currency in order to buy some local firm, while the technical thinking and culture of the local firm are being converted into the thinking and culture of the foreign investors.

The final case of financial investment illustrates what happens when there is only economic exchange and no translation. Abstract technical thought requires precise definitions. But if abstract technical thought is to interact with reality, then a precise definition must ultimately be a definition of some fact, connection, or object within Perceiver thought. A financial investment simplifies an exchange at the cost of reducing the correspondence with reality. This applies both to investment in foreign currencies and countries as well as investment in 'foreign' technical fields. In both cases, an investor is assuming the meanings of words, and when the meanings of words are being assumed, then there is no guarantee that these words have any meaning, and it becomes possible to pretend that words have meanings. 
In all these cases, the cost can be minimized by using Perceiver and Server thought to translate before the exchange is made. We saw earlier when looking at supply and demand that an effective market requires an infrastructure of the normal thinking of Perceiver facts and Server sequences to bridge the technical thinking of supply with the mental networks of demand. A similar principle applies to currency exchange. Selling a product abroad will be more successful if Perceiver thought learns facts about the foreign market and Server thought learns how things are done in that environment. This need to acquire facts and learn sequences is even more significant when attempting to purchase some foreign firm. This is known in economics as due diligence. Similarly, a tourist can make a trip more successful by learning facts about the region being visited and how things are done there. And financial investments are often accompanied by a prospectus that provides information about some potential investment—but clicking a button is usually simpler than reading a long technical document.

However, translation is only useful to the extent that the mental networks and technical thinking exist. Technical knowledge will not help an investor who does not know how to use technical thought. Similarly, a knowledge of local culture will not make any different to a tourist who lacks an appreciation for culture.

Exchange rate will be affected by various factors. "If a country experiences a relatively high inflation rate compared with other economies, then the buying power of its currency is eroding, which will tend to discourage anyone from wanting to acquire or to hold the currency" (macro, p. 393). Notice that this is happening at the level of a currency and not with specific products. Inflation was interpreted previously as words losing their precise meanings. If the words of some technical specialization lose their precise meanings, then this will cause all the concepts of this specialization to be treated as suspect, causing all the facts of this field to be avoided.

For instance, consider the following statement in the forward to a book on the cognitive science of religion. "Theology has a long and sometimes distinguished intellectual history. But the institutionalized forms that provide the playground for the manipulation and development of such abstractions never succeed in playing the decisive role that the theologians constantly hope for... Sometimes theology seems to do little more than provide soothing background noise. Even if this is an unnecessarily harsh characterization of theology's place in religious systems, at least it must be said that such notions are not the motor that drives religious ideas and the practices these ideas inform, nor does it play any significant role in the growth and decline of religious traditions” (Tremlin, 2010, p. xvi). Looking at this statement cognitively, theology used to be regarded as a valid currency of abstract technical thought. But it has now become devalued to the point of being regarded merely as 'soothing background noise'. Notice that specific theological points are not being discussed. Instead the entire currency of theological discussion is being regarded as meaningless, and thus worthless. ${ }^{34}$

An even greater devaluing of currency can be seen in postmodern thought. This was discussed previously in the context of hyperinflation, but it also applies to the context of 'currency exchange'. Postmodern questioning does not examine specific facts - or question the 'currency' of some academic specialization. Instead it calls into question the very concept of academic currency. Quoting from the

34 I suggest elsewhere (Friesen, 2012, 2015) that theology is cognitively meaningful, but this is not the position taken by the cognitive science of religion. 
Encyclopaedia Britannica, postmodernism does not believe that "The descriptive and explanatory statements of scientists and historians can, in principle, be objectively true or false” (Duignan, 2020). Cognitively speaking, this denies any relationship between Perceiver meanings and Perceiver facts about reality. But Perceiver thought uses facts about reality to translate between Perceiver meanings within one specialization and another.

Saying this more explicitly, postmodernism does not believe that "Reason and logic are universally valid-i.e., their laws are the same for, or apply equally to, any thinker and any domain of knowledge. For postmodernists, reason and logic too are merely conceptual constructs and are therefore valid only within the established intellectual traditions in which they are used” (Duignan, 2020). Reason and logic refer to abstract technical thought. If abstract technical thought is 'valid only within its intellectual tradition', then this means that it is not possible to convert from one academic 'currency' to another.

Applying this to economics, postmodernism denies that "Through the use of reason and logic, and with the more specialized tools provided by science and technology, human beings are likely to change themselves and their societies for the better” (Duignan, 2020). This questions a fundamental premise of economics, which is that technical thought can improve the ability of a market economy to generate better subjective experiences for society.

Returning to the topic of currency exchange, "If rates of return in a country look relatively high, then that country will tend to attract funds from abroad. Conversely, if rates of return in a country look relatively low, then funds will tend to flee to other economies. Changes in the expected rate of return will shift demand and supply for a currency” (macro, p. 392). Interest was defined cognitively as the mental cost of using the 'borrowed' knowledge of absolute truth. A high interest rate implies that working within some field requires significant technical thought. Notice that the emphasis is upon appearance, because potential investors are being attracted to countries where the interest rate looks high. A similar emphasis upon appearance can be seen in education, because "a good academic reputation was the most important factor influencing prospective decisions when shortlisting universities" ("Why Reputation”, 2018). And "the prestige, or reputation for quality of an institution is often more important than its actual quality, because it represents the perceived excellence of the institution which guides the decisions of prospective students to enrol with the institution” (Munisamy, 2013). What is being described here is not the content being taught at some academic institution, but rather the academic reputation of an institution as viewed by outsiders. Here too, the emphasis is upon appearance.

A country that is too small to establish its own currency may dollarize. "Sometimes small economies use an economically larger neighbor's currency. For example, Ecuador, El Salvador, and Panama have decided to dollarize - that is, to use the U.S. dollar as their currency” (macro, p. 382). Similarly, an academic discipline or industry has to reach a certain size before it can develop its own currency of technical vocabulary and technical thought. Thomas Kuhn describes this transition into some 'currency' of technical language. "When the individual scientist can take a paradigm for granted, he need no longer, in his major works, attempt to build his field anew, starting from first principles and justifying the use of each concept introduced. That can be left to the writer of textbooks... No longer will his researches usually be embodied in books addressed... to anyone who might be interested in the subject 
matter of the field. Instead they will usually appear as brief articles addressed only to professional colleagues, the men whose knowledge of a shared paradigm can be assumed and who prove to be the only ones able to read the papers addressed to them” (Kuhn, 1970, pp. 19 - 20). Mental symmetry has not reached this level. Therefore, this paper began with an introduction to the theory of mental symmetry and attempts to describe concepts using language that is precise but not too technical. In fact, if mental symmetry is to be used as a meta-theory that is capable of tying together technical specializations, then it is important for mental symmetry not to be treated as a technical discipline with its own specialized vocabulary and journals that can only be understood by a select group of technical insiders.

We are looking here at the positive side of dollarization, the replacement currency that is being adopted. A country that dollarizes is adopting the US dollar because it is currently the international currency, as reflected in the term dollar-ize. A system or theory 'dollarizes' by adopting the technical language of academia. For instance, academic dollarization can be seen in the frequent direct quotes in this essay. The underlying assumption is that the technical language of mental symmetry has no 'internationally accepted' meaning.

Kuhn's statements also explain why this paper is quoting extensively from introductory textbooks on economics and not just from academic papers. The goal of this paper is to show that the theory of mental symmetry can be used to explain the fundamental concepts of economics. But, as Kuhn stated, fundamental concepts are taught in textbooks while being assumed by academic papers.

Dollarization was discussed previously in the context of hyperinflation. The focus there was upon the failure of the local currency. That happened, for instance, with Zimbabwe. "By late 2008, the money was nearly worthless, which led Zimbabwe to adopt the U.S. dollar, immediately halting their hyperinflation” (macro, p. 465). Similarly, if the language of some academic discipline loses sufficient meaning, then the technical language and thinking of a more widely respected discipline may have to be adopted. For example, it was mentioned earlier that theology has lost much of its academic reputation. The cognitive science of religion illustrates one possible response to this academic 'hyperinflation', which is to adopt the academic ‘currency' of cognitive experiments and evolutionary theory.

Looking at the larger picture, the value of a currency is determined by two different factors. Currency is subject to a market of supply and demand, guided primarily by Teacher feelings of generality: A currency that is used more will be worth more. But at the same time, a currency also has intrinsic value, because it can be used to purchase goods and services within some market economy. In the long-term, the value of a currency will be determined by its purchasing power. "Over long periods of many years, exchange rates tend to adjust toward the purchasing power parity (PPP) rate, which is the exchange rate such that the prices of internationally tradable goods in different countries, when converted at the PPP exchange rate to a common currency, are similar in all economies” (macro, p. 405). In other words, an item that is purchased with one currency will cost the same if the money is converted into another currency and the same item bought with that other currency. Academically speaking, this means that explaining power eventually trumps popularity. The value of some academic currency is ultimately 
determined not by the popularity of that technical paradigm but rather by how well it describes and explains reality.

However, popularity does affect the value of a currency in the short-term. "In the extreme short run, ranging from a few minutes to a few weeks, speculators who are trying to invest in currencies that will grow stronger, and to sell currencies that will grow weaker influence exchange rates. Such speculation can create a self-fulfilling prophecy, at least for a time, where an expected appreciation leads to a stronger currency and vice versa” (macro, p. 405). Similarly, academic disciplines are also subject to fads. In the words of one paper, “Academics are generally committed to truth, and they are drawn to ideas that can be shown to be good ones. Hence the most optimistic answer to these questions is that ideas survive because and to the extent that they are true or good... these claims contain some truth, but they are far too optimistic. Academics, like everyone else, are subject to cascade effects. They start, join, and accelerate bandwagons. More particularly, they are subject to the informational signals sent by the acts and statements of others. They participate in creating the very signals to which they respond" (Sunstein, 2001, pp. 1 - 2).

Interest rates tend to affect currencies in the medium-term. "In the relatively short run, differences in rates of return influence exchange rate markets. Countries with relatively high real rates of return (for example, high interest rates) will tend to experience stronger currencies as they attract money from abroad" (macro, p. 405). The academic analog is that academic reputation dominates in the mediumterm. Reputation has a longer-lasting impact than academic fads but is ultimately overruled by purchasing power.

For instance, the theory of mental symmetry is relatively unknown. Therefore, from the viewpoint of the currency market, it is relatively worthless. However, mental symmetry has been growing in academic reputation as papers are presented at conferences and posted in academic circles. Going further, mental symmetry appears to have great purchasing power because it can be used to explain a wide range of topics in a reasonably rigorous manner. When a theory is capable of explaining a lot but is not popular, then it is possible to get academically rich. The explaining power makes the acquisition of academic wealth possible, while the lack of popularity means that there is little competition. This is known economically as getting in on the ground floor. Such a combination does not guarantee wealth but rather makes the acquisition of wealth possible. One still has to 'pay the price' of acquiring the mental confidence that is required to 'own' knowledge.

The exchange of currency has been compared to the translation of technical knowledge from one 'currency' of precise definitions to another. This translation may involve the verbal sequences of language, which uses Perceiver thought to equate one meaning with another. But it may also involve translating technical sequences, which is done by explaining that one thing functions like another. This is known as an analogy, and analogies play a major role in technical education. For instance, "Stephen Hawking used at least 74 everyday analogies in A brief history of time to explain astrophysics and quantum ideas” (Harrison, 2006, p. 15).

One author refers to an analogy that describes function as an enriched analogy. "Enriching the analogy does more than tell the student under what conditions the analogy holds; it tells the student that the 
analogy is about processes, about dynamic functions and not limited to superficial structures. Indeed, the difference between a simple structural analogy and an enriched functional analogy is the addition of some form of causation” (Harrison, 2006, p. 17). Looking at this cognitively, a simple analogy deals with Perceiver facts, while an enriched analogy uses the Perceiver-Server cause-and-effect elements of concrete technical thought. But these elements are not being used by concrete technical thought to reach some Mercy goal. Instead, abstract technical thought is being used to compare one structure of cause-and-effect elements with another.

For instance, an electric circuit is often explained using the analogy of water traveling through pipes. Technical analogies make it possible to 'convert' the 'currency' of one technical specialization into another. Instead of having to learn some technical concept from scratch, existing technical knowledge in one field can be extended into another through the use of analogy. For example, if a student knows how water moves through a pipe, then this existing technical understanding can be extended into a knowledge of electric circuits. The appropriate use of analogy is discussed in another paper (Friesen, 2020).

Applying this to our discussion of macroeconomics, we have been mapping the cause-and-effect of concrete technical thought onto the precise definitions of abstract technical thought. Such a mapping does not eliminate the need for cause-and-effect but rather expands its applicability. For instance, we have seen that there are extensive cognitive parallels between the banking system and academia. These are 'enriched functional analogies' because the banking system and academia function in a similar manner.

Translation is never perfect. Terms from one language or technical specialization seldom translate exactly into the terms of another. Similarly, analogy is never perfect. And analogies between technical specializations seldom reach the level of rigor that is used by technical definitions within a technical specialization. But an analogy can be made semi-rigorous by including both generalities and details. I describe this as mapping hands onto hands and fingers onto fingers.

Looking at this in more detail, a semi-rigorous analogy maintains Teacher generality by mapping the general concepts of one area onto the general concepts of another. This makes it possible to view the paradigm of one technical specialization as a variation of the paradigm of another. This is what is meant by 'mapping hands onto hands'. For instance, economics states that personal decisions are motivated by feelings of utility. Similarly, mental symmetry states that personal behavior is motivated by emotional experiences within Mercy thought, the cognitive module that is used to represent people. In both cases, subjective feelings are recognized as a significant motivating force.

A semi-rigorous analogy also preserves technical thought by mapping the details of one area onto the details of another. This is what is meant by 'mapping fingers onto fingers'. A detailed mapping makes it possible to retain technical thought while moving from one specialization to another. For instance, the analogy between the banking system and academic thought was not just presented in this paper as a sweeping generality. Instead, considerable details were added to this analogy, turning the general analogy into a semi-rigorous mapping. 
Analogies can be viewed as an abstract version of infrastructure. Infrastructure describes the network of Server roads and Perceiver connections that makes it possible to connect supply with demand through trade. Similarly, analogies provide a mental grid of Server sequences and Perceiver facts that make it possible to mentally translate between technical specializations. Saying this in terms of supply and demand, technical specializations provide a 'supply' of precise definitions, while Teacher thought generates an emotional ‘demand' of general understanding. Analogies make it possible to connect supply with demand.

It was mentioned when looking at infrastructure that technical thought needs to be emphasized when constructing an infrastructure, but only a modicum of technical thought is required to use an infrastructure. Similarly, technical thought should to be used when coming up with adequate analogies, but using analogies involves the less technical thinking of normal thought. For instance, the theory of mental symmetry uses cognitive analogies to connect various subjects. However, constructing these analogies meant becoming proficient in a number of unrelated technical fields. Applying this to education, analogies play a major role in effective teaching. An instructor will use technical thought to come up with analogies that are appropriate, while a student will probably comprehend this analogy using the less rigorous thinking of normal thought.

Demonstrating that analogical reasoning respects technical thought requires writing extended papers, such as this excessively long paper on economics. That is because sufficient fingers of one hand have to be compared with sufficient fingers of another hand in order to make it clear that one is not just presenting a 'handwaving' argument. This problem does not arise when using technical thought within some specialization, because technical thought works with specific 'bricks' of information while assuming the existence of the 'house' of some paradigm. Therefore, it is sufficient to present a few 'bricks' of new information to colleagues who accept the same paradigm — as described a few pages earlier in a quote by Kuhn. Demonstrating adequate analogical reasoning, in contrast, requires presenting several 'houses' to an audience that is probably only familiar with the 'house' of one paradigm, and then taking the time to compare a number of 'bricks' from these various houses, which means continually jumping from one paradigm to another in a way that will feel scattered to technical thought.

\section{Teacher versus Mercy}

This paper began by examining microeconomics and its utility of emotional experiences and mental networks within Mercy thought. When examining macroeconomics, the focus then shifted to Teacher emotions of order-within-complexity. This paper will conclude by looking briefly at the relationship between Mercy thought and Teacher thought.

It was suggested at the beginning of this paper that the childish mind acquires an inadequate set of MMNs during Piaget's first sensorimotor cognitive stage and becomes mentally driven by these inadequate MMNs in Piaget's second preoperational cognitive stage. Piaget's four stages give the impression that the ultimate goal is to be driven by the abstract Teacher-based thinking of Piaget's fourth formal operational stage. Stated briefly, one may conclude that the goal of cognitive 
development is to replace Mercy thought with Teacher thought. However, I suggest that this is a mistaken conclusion.

Instead, I suggest that a distinction needs to be made between process and goal. Teacher and Server thought think in terms of time, sequence, and actions. Therefore, abstract technical thought can come up with new and better processes. Perceiver and Mercy thought, in contrast, think in terms of objects and experiences. Therefore, concrete technical thought needs to be used when determining goals.

Looking at an obvious example, the Manhattan Project of World War II was guided by the laws of physics within Teacher thought to discover the powerful new processes of atomic energy. But it soon became clear that this process could be used for radically different goals. Atomic energy can be used to build nuclear bombs which have the goal of destroying society, or atomic energy can be used to build power plants which have the goal of enabling society. Since World War II, nations that possess the nuclear bomb have had to choose not to pursue the goal of destroying society. Saying this more simply, morality has to be added explicitly to science and technology. If this morality is not added, then people will be driven by Teacher emotions to do something just because it can be done. But some of the things that can be done, such as blowing up the world, should not be done.

That brings us back to the distinction between positive statements and normative statements discussed near the beginning of this paper. We saw there that economics claims to come up with normative conclusions while only making positive statements. I suggest that this combination can be clarified by examining the distinction between intrinsic and extrinsic value. The Stanford Encyclopedia of Philosophy explains that "Intrinsic value has traditionally been thought to lie at the heart of ethics. Philosophers use a number of terms to refer to such value. The intrinsic value of something is said to be the value that that thing has 'in itself,' or 'for its own sake,' or 'as such,' or 'in its own right.' Extrinsic value is value that is not intrinsic. Many philosophers take intrinsic value to be crucial to a variety of moral judgments” (Zimmerman, 2019).

Absolute truth leads naturally to extrinsic value. That is because some source of truth is using emotional status to impose statements of value upon personal identity. This will lead to the feeling that morality is being imposed upon personal identity by some external force, such as society, government, or God. Saying this another way, absolute truth will naturally express itself through normative statements, such as 'God tells you to do this!' or 'Society forbids you from doing that!' Universal truth, in contrast, leads naturally to intrinsic value. That is because universal truth uses Perceiver thought to look for connections of cause-and-effect that are repeated. Such a repeated connection is intrinsic because it describes how things work.

For instance, stating that one should not use atomic bombs to blow up the world is based in intrinsic value, because some extrinsic entity is not stepping in to blow up the world as a punishment for using nuclear weapons. ${ }^{35}$ Instead, the connection between 'using atomic bombs' and 'destroying life on earth' is an intrinsic one based in how the natural world works. This may seem like a contrived example, but

35 This distinction was initially clarified by Socrates in the Euthyphro dilemma (Plato, 1954). A cognitive approach rephrases this question. Instead of asking 'Is an action right because it is commanded by the gods, or do the gods command it because it is right?', it asks what kind of cognitive mechanism will cause a person to think that 'An action is right because it is commanded by the gods'? 
the Christian fundamentalist doctrine of the Rapture and Great Tribulation explicitly teaches that God will step in as an extrinsic entity to rain massive destruction upon the physical earth as a punishment for rejecting the absolute truth of the Bible.

Applying this to the relationship between Teacher thought and Mercy thought, mental symmetry suggests that the existence of humanity depends upon making normative statements (or moral judgments). Looking at an obvious example, if physical life is to continue on earth, then humans have to submit to the moral statement that 'It is wrong to blow up the world'. Mental symmetry suggests that it is possible to construct an intrinsic system of morality based in an understanding of how the mind works. Stated simply, if mental and social well-being are to be achieved, then mental wholeness has to be respected and pursued. This relates to economics, because economics claims that the market economy improves social well-being.

This also explains why this paper has examined the relationship between absolute truth and religion. Religion makes moral statements. But absolute truth causes these moral statements to be viewed as extrinsic. As a result, the average person equates moral statements with absolute truth and extrinsic value. These implicit assumptions need to be analyzed if one is to construct an intrinsic system of morality. And it is suggested elsewhere (Friesen, 2015, 2020) that it is possible to build a system of religion upon the intrinsic value of how the mind works.

The relationship between the processes of Teacher thought and the goals of Mercy thought can be illustrated using economic examples. One common assumption is that Teacher thought makes Mercy thought obsolete. For instance, the Industrial Revolution introduced new Teacher-driven methods of industrial production that rendered obsolete the existing Mercy mental networks of the cottage industry. But the introduction of new processes during the Industrial Revolution was followed, especially in Britain, by vigorous debate over the goals of society. Among other things, a series of Factory Acts was passed that limited hours of employment, improved work safety, and restricted the use of child labor (Cooke-Taylor, 1894). In other words, people were driven by Mercy emotions to decide that some things that could be done using the new machines and factories should not be done. Quoting one brief passage from this book, "In some large factories from one-fourth to one-fifth of the children were cripples or otherwise deformed, or permanently injured by excessive toil, sometimes by brutal abuse. The younger children seldom lasted out more than three or four years without severe illness, often ending in death” (p. 40).

It has been mentioned several times that the mind represents people as mental networks within Mercy thought. This is not just a theoretical statement. It means that if Teacher feelings of efficiency and order are followed without including Mercy feelings, then the result will eventually become inhuman, because the part of the mind that represents humanity is being excluded. That happened, for instance, during the Industrial Revolution. Eventually, Mercy thought became so distressed by the inhumanity that steps had to be taken to preserve humanity. ${ }^{36}$

36 Preserving humanity was discussed previously in the context of following technical thought at the expense of MMNs of personal identity. In both cases, preserving humanity means giving MMNs the right to exist. 
Looking at this from a positive economic perspective, the generality introduced by Teacher thought does not eliminate the role of Mercy thought. This can be seen in the discussion on trade. The basic premise of economics is that specialization can improve the well-being of a society. However, when people use technical thinking to specialize, then supply must be connected with demand through trade. Trade functions at the microeconomics level of the market economy. But trade also functions at the macroeconomics level of international trade. "The evidence that international trade confers overall benefits on economies is pretty strong. Trade has accompanied economic growth in the United States and around the world... There is no modern example of a country that has shut itself off from world trade and yet prospered” (macro, p. 476).

The cognitive reason why trade functions in a similar manner at both a local and an international level can be explained by examining the nature of a machine. It was mentioned earlier that the same machine can be viewed either by concrete technical thought as a tool to reach some goal in Mercy thought, or by abstract technical thought as many parts functioning together in a way that expresses Teacher orderwithin-complexity. For instance, a gasoline engine contains many precisely-defined parts that operate together. Designing and optimizing these parts to function together efficiently requires abstract technical thought. But a gasoline engine as a whole can also be viewed by concrete technical thought as a tool of cause-and-effect that transforms gasoline into rotational movement. Going further, a gasoline engine is one part of the machine of a car, which was designed and optimized using abstract technical thought. And a car can itself be viewed as a tool of cause-and-effect that takes people from one location to another.

Whenever some system is being viewed as a tool of cause-and-effect, then one has to ask questions about goals in Mercy thought. These Mercy questions may have to be asked at different levels of Teacher generality. But the basic Mercy question still remains: What promotes and preserves humanity within Mercy thought?

Going further, even when dealing at the macroeconomic level of international trade, the microeconomic trade in individual products still remains. For instance, "International trade often does not involve nations trading whole finished products like automobiles or refrigerators. Instead, it involves shipping more specialized goods like, say, automobile dashboards or the shelving that fits inside refrigerators. Intra-industry trade between similar countries produces economic gains because it allows workers and firms to learn and innovate on particular products - and often to focus on very particular parts of the value chain” (macro, p. 488).

Thus, I suggest that the Teacher-driven thinking of abstract technical thought needs to be viewed as a multiplier of the Mercy-driven thinking of concrete technical thought, rather than as a replacement. Notice how the market economy is being multiplied by the global economy in the following description. "We live in a global marketplace. The food on your table might include fresh fruit from Chile, cheese from France, and bottled water from Scotland. Your wireless phone might have been made in Taiwan or Korea. The clothes you wear might be designed in Italy and manufactured in China. The toys you give to a child might have come from India” (macro, p. 476). 
Looking at another example of Teacher-driven multiplication, the supply generated by concrete technical thought is ultimately driven by the facts of reality. This is the basis for absolute advantage. "Absolute advantage can be the result of a country's natural endowment. For example, extracting oil in Saudi Arabia is pretty much just a matter of 'drilling a hole.' Producing oil in other countries can require considerable exploration and costly technologies for drilling and extraction-if they have any oil at all” (macro, pp. 476 - 7). Stated simply, a country can only export oil if oil exists to be exported.

It is possible for absolute advantage to be extensively modified by the use of Teacher-driven abstract technical thought. "The underlying reason why a country like the United States, Japan, or Germany produces one kind of machinery rather than another is usually not related to U.S., German, or Japanese firms and workers having generally higher or lower skills. It is just that, in working on very specific and particular products, firms in certain countries develop unique and different skills” (macro, p. 487). This is no longer describing an advantage based in physical differences, such as the presence or absence of oil in some country. Instead, the difference here is one of technical training. The workers in one country have developed technical knowledge and skills in different areas than the workers of another country.

However, while abstract technical thought can multiply and modify the Mercy-driven trade of the market economy, it must never replace it. A classic example of this principle can be seen in the environmental destruction of the Aral Sea, caused by the Soviet over-production of cotton in the region. In the words of one paper, "There were over 1100 islands in the Aral Sea, with countless lagoons and shallow straits... Stalin's five-year plans demanded that the Soviet Union become self sufficient in cotton and that increasing quotas and targets be met. This led to massive irrigation projects in the Aral Sea Basin commencing in the 1950s, accompanied by large-scale monocropping of cotton... To improve crop yields, more water, fertiliser, and pesticides were applied. The exposed former seabed consists of lifeless, salt encrusted sands contaminated by pesticides. Large dust storms, which can occur ten times annually, scour the seabed and transport tens of millions of tons of dust per year to be dumped on the surrounding land and its inhabitants” (Whish-Wilson, 2002, pp. 29 - 30).

Looking at this cognitively, the Soviet Union came up with a central plan guided by Teacher feelings of order-within-complexity. Part of this central plan involved bringing all of the Aral Sea Basin within the simple Teacher theory of 'growing cotton', which is an example of using abstract technical thought to cause all the parts of some system to work together in harmony to carry out some simple function. But this central plan treated Teacher-driven abstract technical thought as a substitute for the Mercy-driven market economy. In typical communist fashion, this meant having no capitalist market economy, but it also meant ignoring Perceiver facts and Mercy experiences about the impact that growing cotton was happening upon the Aral region. When natural cause-and-effect is ignored, then unpleasant natural consequences will grow until they can no longer be ignored. In the case of the Aral region, a sea with 'countless lagoons and shallow straits' turned into a dustbowl of 'lifeless, salt encrusted sands contaminated by pesticides'.

We saw at the beginning of this paper that childish MMNs will drive the mind to think magically in Piaget's preoperational stage. Magical thinking is primarily an error of process and not an error of goal. "Magical thinking is the tendency to think the two events that go together - either in time, distance, or 
similarity of features - are causally linked. The key difference between magical thinking and the confusion of correlation and causation is that magical thinking does not require that there be any actual statistical connection between the two events" (Risen, 2007, p. 121). Process describes the way in which one moves from one Mercy experience to another, the method by which one reaches from the current Mercy situation to the goal in Mercy thought. Confusion of causation happens when Perceiver thought notices that Mercy experiences are repeatably connected but no Server action actually leads from to one Mercy experience to the other. Magical thinking emerges when the mind treats Mercy experiences as related, but no repeated connection exists between these Mercy experiences. ${ }^{37}$

Thus, moving beyond the magical thinking of childish MMNs does not mean letting go of goals and dreams in Mercy experiences. Instead, it means using Teacher understanding and technical thought to come up with processes that are capable of reaching these goals and realizing these dreams. This has happened to a large extent thanks to science and technology, because it is now possible to use technology to perform many actions and reach many goals that were previously considered to be within the realm of magic.

Going the other way, Clarke's statement that 'Any sufficiently advanced technology is indistinguishable from magic' can also be viewed as a warning that physical capital should not replace human capital. Advanced technology is an example of physical capital. Magical thinking is an example of inadequate human capital, because a person who thinks magically lacks the technical knowledge to understand the processes by which Mercy goals are realized. When that happens, then machines become the masters and humans become the slaves, and that is also inhuman. Western society is heading in this direction. "An automation crisis has already arrived. The robots are here, they're working in management, and they’re grinding workers into the ground” (Dzieza, 2020).

\section{Conclusion}

This paper has used the theory of mental symmetry to explain most of the basic elements of economics. On the one hand, this analysis shows that economic theory is cognitively natural. Economics is not just a random collection of theories involving money and the economy. Instead, economic theories actually form a coherent package that resonates with the structure of the mind. But on the other hand, economic theory is limited because it provides a narrow picture of human thought and behavior. Thus, the skeleton of economic theory needs to be expanded in order to demonstrate how it is consistent with the structure of the mind. Economists describe economic thought as rational. Economic thinking is rational compared to behavior motivated by childish MMNs, but it is only locally rational when compared to the thinking of the entire mind.

Money can be viewed as a generic form of cause-and-effect, and cause-and-effect is the basic element of concrete technical thought. The precise definition, in contrast, is the basic element of abstract technical thought. If money is viewed as a precise definition, then many core elements and institutions

37 This explains why sufficiently advanced technology is indistinguishable from magic. The person experiencing the technology accurately notices that one Mercy experience is being followed by another, but has no comprehension of the technological process by which these Mercy experiences are being connected. 
of macroeconomics make cognitive sense, and a deep cognitive parallel emerges between the banking system and academia.

The usefulness of a meta-theory such as mental symmetry has also been demonstrated. One might ask why a meta-theory is required if one theory is being compared with another. The answer is that a metatheory acts as a kind of skeletal framework within which other more specific theories can be placed, and this changes the emotional nature of theoretical interaction.

When the 'middleman' of a meta-theory is not present, then theories that interact will tend to be viewed as rivals. Teacher thought feels bad when there is an exception to the general rule, and rival theories will tend to be interpreted emotionally as exceptions to the rule. This kind of emotional rivalry will also tend to be present when using abstract technical thought, because each technical specialization is emotionally backed up by the Teacher theory of some paradigm. A meta-theory changes the emotional environment from rival to cooperative. That is because Teacher emotion comes from order-withincomplexity. Each specific theory that is placed within a meta-theory increases the overall order-withincomplexity of that meta-theory. A similar emotional cooperation can be seen in the modern global economy, because each national economy adds to the overall order-within-complexity of the global economy.

We have seen in this paper that economics tends to regard other theories as rivals that detract from the study of pure economics. This paper has treated economics as a kind of meta-theory, using economic concepts as a starting point for presenting a more general theory of cognition. The ultimate goal of a meta-theory is to produce an academic 'economy' that matches the international scope of the modern global economy.

\section{Acknowledgements}

I would like to thank Angelina Van Dyke for providing extensive feedback on this paper. 


\section{References}

Abadi, M. (2018). Taser, Xerox, Popsicle, and 31 more brands-turned-household names. In Business Insider. Retrieved from https://www.businessinsider.com/google-taser-xerox-brand-names-genericwords-2018-5

Aylesworth, G. (2015). Postmodernism. In The Stanford Encyclopedia of Philosophy (Spring 2015 Edition), Edward N. Zalta (ed.), Retrieved from https://plato.stanford.edu/archives/spr2015/entries/postmodernism/

Bajpai, P. (2021). Why China is 'the world's factory'. In Investopedia. Retrieved from https://www.investopedia.com/articles/investing/102214/why-china-worlds-factory.asp

Baker, L. \& Roumeliotis, G. (2018). IBM to acquire software company Red Hat for \$34 billion. Retrieved from https://www.reuters.com/article/us-red-hat-m-a-ibm/ibm-to-acquire-software-companyred-hat-for-34-billion-idUSKCN1N20N3

Ball, T. (2019). Communism. In Encyclopaedia Britannica. Retrieved from https://www.britannica.com/topic/communism

Ballor, J. (2020). Adam Smith in theological perspective. Retrieved from https://www.adamsmithworks.org/documents/adam-smith-in-theological-perspective

Baramov, L. (2011). U.S. Patent No. 7,987,145. Washington, DC: U.S. Patent and Trademark Office.

Barberis, N. (2013). Thirty Years of Prospect Theory in Economics: A Review and Assessment. Journal of Economic Perspectives, 27 (1), 173-196. doi: 10.1257/jep.27.1.173

Berridge, K. C. (1996). Food reward: brain substrates of wanting and liking. Neuroscience Biobehavior Review, 20(1), 1-25. doi: 0.1016/0149-7634(95)00033-b

Berridge, K. C. (2019). A liking versus wanting perspective on emotion and the brain. The Oxford Handbook of Positive Emotion and Psychopathology, 184-196.

Bertocco, G. \& Kalajzić A. (2019) Great Recession and Macroeconomic Theory: A Useless Crisis?, Review of Political Economy, 31(3), 382-406, doi: 10.1080/09538259.2020.1714202

Bolton, K. (2006). Varieties of world Englishes. In Kachru, B., Kachru, Y., \& Nelson, C. (eds), The handbook of world Englishes. Blackwell Publishing Ltd, Oxford, UK. 289-312. doi: 10.1002/9780470757598.ch17

Brander, J. A., Cui, V., \& Vertinsky, I. (2017). China and intellectual property rights: A challenge to the rule of law. Journal of International Business Studies, 48(7), 908-921. doi: 10.1057/s41267-017-0087-7

Bruhin, A., Fehr-Duda, H., \& Epper, T. (2010). Risk and rationality: Uncovering heterogeneity in probability distortion. Econometrica, 78(4), 1375-1412. doi: 10.3982/ECTA7139

"Cambridge Bitcoin Electricity Consumption Index." (2021). Cambridge Centre for Alternative Finance. Retrieved from https://cbeci.org/ 
"Causes of the decline.” (2021). In Encyclopaedia Britannica. Retrieved from https://www.britannica.com/event/Great-Depression/Causes-of-the-decline

"Cell Phones in Africa: Communication Lifeline." (2015). Pew Research Center, Washington, D.C. Retrieved from https://www.pewresearch.org/global/2015/04/15/cell-phones-in-africa-communicationlifeline/

"Christian fundamentalism.” (2021). In Wikipedia. Retrieved from https://en.wikipedia.org/w/index.php?title=Christian_fundamentalism\&oldid=1026127818

Cinelli, M., Morales, G. D. F., Galeazzi, A., Quattrociocchi, W., \& Starnini, M. (2021). The echo chamber effect on social media. Proceedings of the National Academy of Sciences, 118(9). doi: 10.1073/pnas.2023301118

Clarke, A. C. (1968). Clarke’s Third Law on UFO’s. Science. 159 (3812): 255. doi:10.1126/science.159.3812.255-b

Cooke-Taylor, R. W. (1894). The factory system and the factory acts (Vol. 12). London: Methuen. Cornell, B. (2021). Why every investor should remember visicalc. Retrieved from https://www.cornellcapital.com/blog/2019/07/why-every-investor-should-remember-visicalc.html\#

Crotty, M. (2015). 36 Million Americans Lack Basic Work Skills. In Forbes. Retrieved from https://www.forbes.com/sites/jamesmarshallcrotty/2015/02/28/a-staggering-36-million-americans-lackbasic-work-skills/

Curott, N. (2017). Adam Smith's theory of money and banking. Journal of the History of Economic Thought, 39(3), 323-347. doi: 10.1017/S1053837217000396

Cutting, J. (2012). Vague language in conference abstracts. Journal of English for academic purposes, 11(4), 283-293. doi: 10.1016/j.jeap.2012.05.004

David, L., Baum, M., Benkler, Y., Berinsky, A., Greenhill, K., Menczer, F., ... \& Zittrain, J. (2018). The Science of Fake News: Addressing Fake News Requires a Multidisciplinary Effort. Science, 359(8). doi: 10.1126/science.aao2998

De Bock, D., Van Dooren, W., Janssens, D., \& Verschaffel, L. (2007). The illusion of linearity: from analysis to improvement. New York: Springer.

Degli Esposti, S. (2014). When big data meets dataveillance: The hidden side of analytics. Surveillance \& Society, 12(2), 209-225. doi: 10.24908/ss.v12i2.5113

Di Domenico, S. I., \& Ryan, R. M. (2017). The emerging neuroscience of intrinsic motivation: A new frontier in self-determination research. Frontiers in human neuroscience, 11, 145. doi:

10.3389/fnhum.2017.00145

Dirac, P. A. (1940). XI.-The Relation between Mathematics and Physics. Proceedings of the Royal Society of Edinburgh, 59, 122-129. doi:10.1017/s0370164600012207 
Doctorow, C. (2011). The Coming War on General Computation. Retrieved from http://opentranscripts.org/transcript/coming-war-general-computation/

Dwyer, M. (2017). These Canadian universities have the most international students. In Maclean's. Retrieved from https://www.macleans.ca/education/which-canadian-universities-have-the-mostinternational-students/

Duignan, B. (2020). Postmodernism. In Encyclopaedia Britannica Online. Retrieved from https://www.britannica.com/topic/postmodernism-philosophy

Dzieza, J. (2020). How hard will the robots make us work? In The Verge. Retrieved from https://www.theverge.com/2020/2/27/21155254/automation-robots-unemployment-jobs-vs-humangoogle-amazon

Evans, J. S. B. (2010). Intuition and reasoning: A dual-process perspective. Psychological Inquiry, 21(4), 313-326. doi: 10.1080/1047840X.2010.521057

“eZ80190. Product Specification.” (2008). Retrieved from http://www.zilog.com/docs/ez80/ps0066.pdf

Floresco, S. B. (2015). The nucleus accumbens: an interface between cognition, emotion, and action. Annual review of psychology, 66, 25-52. doi: 10.1146/annurev-psych-010213-115159

Floyd, J. (2021). Topic 1: Indifference Curves. Retrieved from https://www.economics.utoronto.ca/jfloyd/modules/idfc.html

"FACT SHEET: President Biden Takes Executive Actions to Tackle the Climate Crisis at Home and Abroad, Create Jobs, and Restore Scientific Integrity Across Federal Government.” (2021). The White House. Retrieved from https://www.whitehouse.gov/briefing-room/statements-releases/2021/01/27/ fact-sheet-president-biden-takes-executive-actions-to-tackle-the-climate-crisis-at-home-and-abroadcreate-jobs-and-restore-scientific-integrity-across-federal-government/

Farris, P. W., Bendle, N., Pfeifer, P. E., \& Reibstein, D. (2010). Marketing metrics: The definitive guide to measuring marketing performance. Pearson Education.

Foremski, T. (2020). Unstoppable tech-driven deflation will be the next economic challenge. In Zdnet. Retrieved from https://www.zdnet.com/article/unstoppable-tech-driven-deflation-will-be-the-nexteconomic-challenge/

Frank M., O’Reilly R., Curran T. (2006). When Memory Fails, Intuition Reigns: Midazolam Enhances Implicit Inference in Humans. Psychological Science, 17(8),700-707. doi: 10.1111/j.14679280.2006.01769.x

Friedman, A., Homma, D., Bloem, B., Gibb, L. G., Amemori, K. I., Hu, D., ... \& Graybiel, A. M. (2017). Chronic stress alters striosome-circuit dynamics, leading to aberrant decision-making. Cell, 171(5), 1191-1205. doi: 10.1016/j.cell.2017.10.017

Friesen, Lane (1986). Cognitive Styles in History: Contributor and Server. Victoria, BC: Lane Friesen, Inc. 
Friesen, Lane (1986). Cognitive Styles in History: Perceiver and Mercy. Victoria, BC: Lane Friesen, Inc.

Friesen, Lorin (2012). God, Theology, and Cognitive Modules: A General Theory of Human Thought. Abbotsford, BC: Lorin Friesen.

Friesen, L., \& Van Dyke, A. (2013). A Cognitive Meta-Theory for TESOL. Retrieved from researchgate.net. doi: 10.13140/RG.2.1.3552.2721

Friesen, Lorin (2015). Natural Cognitive Theology. Abbotsford, BC: Lorin Friesen.

Friesen, Lorin (2019). Mapping a cognitive theory onto neurology. Retrieved from researchgate.net. doi: 10.13140/RG.2.2.28982.24641

Friesen, Lorin (2020). A cognitive model of science and theology. Retrieved from researchgate.net. doi: 10.13140/RG.2.2.27653.17122/1

“GDP (current US\$).” (2021). In The World Bank. Retrieved from https://data.worldbank.org/indicator/NY.GDP.MKTP.CD

Goodfriend, M. \& McDermott, J. (2021). The American System of economic growth. Journal of Economic Growth 26, 31-75. doi: 10.1007/s10887-021-09186-X

Goodson, S. (2012) If You're Not Paying For It, You Become The Product. In Forbes. Retrieved from https://www.forbes.com/sites/marketshare/2012/03/05/if-youre-not-paying-for-it-you-become-theproduct/

Grandey, A. A., Dickter, D. N., \& Sin, H. P. (2004). The customer is not always right: Customer aggression and emotion regulation of service employees. Journal of Organizational Behavior: The International Journal of Industrial, Occupational and Organizational Psychology and Behavior, 25(3), 397-418. doi: 10.1002/job.252

Greenlaw, S., \& Shapiro, D. (2017). Principles of Macroeconomics 2e. Retrieved from https://openstax.org/details/books/principles-macroeconomics-2e

Greenlaw, S., \& Shapiro, D. (2018). Principles of Microeconomics 2e. Retrieved from https://openstax.org/details/books/principles-microeconomics-2e

Grinvald, L. C., \& Tur-Sinai, O. (2019). Intellectual Property Law and the Right to Repair. Fordham L. Rev., 88, 63.

Haber S. N. (2016). Corticostriatal circuitry. Dialogues in clinical neuroscience, 18(1), 7-21. doi: 10.31887/DCNS.2016.18.1/shaber

Hall, M. (2020). Sony. In Encyclopaedia Britannica. Retrieved from https://www.britannica.com/topic/Sony

Hammer, A. B. (2017). The Size and Composition of US Manufacturing Offshoring in China. Executive Briefings on Trade (USITC). 
Harrison A.G., Treagust D.F. (2006) Teaching and Learning with Analogies. In: Aubusson P.J., Harrison A.G., Ritchie S.M. (eds) Metaphor and Analogy in Science Education. Science \& Technology Education Library, vol 30. Springer, Dordrecht. Doi: 10.1007/1-4020-3830-5_2

Haruvy, E., Mahajan, V., \& Prasad, A. (2004). The effect of piracy on the market penetration of subscription software. The Journal of Business, 77(S2), S81-S107. doi: 10.1086/381520

Harvey, F. (1976). Motivational Gifts. Vision Magazine, 18(6). pp. 5-9.

Healey, T. A., Rosson, R. S., \& Wilkes, K. W. (2010). U.S. Patent No. 7,853,392. Washington, DC: U.S. Patent and Trademark Office.

“History of banking.” (2021). In Wikipedia. Retrieved from https://en.wikipedia.org/w/index.php? title=History_of_banking\&oldid=1026625135

Hogan, P., Galaro, J., \& Chib, V. (2019). Roles of ventromedial prefrontal cortex and anterior cingulate in subjective valuation of prospective effort. Cerebral Cortex, 29(10), 4277-4290. doi:

1093/cercor/bhy310

Hollister, S. (2021). In 2021, we need to fix America’s internet. In The Verge. Retrieved from https://www.theverge.com/22177154/us-internet-speed-maps-competition-availability-fcc

Hsu, H., Rolls, E.T., Huang, C., Chong, S. T., Zac Lo, C., , Feng, J., \& Lin., C. (2020) Connections of the human orbitofrontal cortex and inferior frontal gyrus. Cerebral Cortex 30(11), 5830-5843. doi: 10.1093/cercor/bhaa160

Huang, R., \& Sarigöllü, E. (2014). How brand awareness relates to market outcome, brand equity, and the marketing mix. In Fashion branding and consumer behaviors (pp. 113-132). Springer, New York, NY. doi: 10.1007/978-1-4939-0277-4_8

Huitt, W. \& Hummel, J. Piaget's theory of cognitive development. Educational Psychology Interactive. Valdosta State University, Valdosta, GA, 2003.

Huttner-Koros, A. (2015). In The Atlantic. Retrieved from https://www.theatlantic.com/science/archive/2015/08/english-universal-language-science-research/ 400919/

Ivanova, A. (2013). Shopping in Beriozka. Consumer Society in the Soviet Union.

i Vidal, J. B., Draca, M., \& Fons-Rosen, C. (2012). Revolving door lobbyists. The American Economic Review, 102(7), 3731-3748. doi: 10.1257/aer.102.7.3731

Ivison, J. (2020). Canada leads multilateral move to fight China's 'hostage diplomacy’: foreign affairs minister. In National Post. Retrieved from https://nationalpost.com/news/canadas-multilateral-moveon-fighting-chinas-hostage-diplomacy

Jiang, L. (2014). Call for Copy-The culture of counterfeit in China. Journal of Chinese Economics, 2(2). 
Judge, T. A., \& Klinger, R. (2008). Job satisfaction: Subjective well-being at work. In M. Eid \& R. J. Larsen (Eds.), The science of subjective well-being (p. 393-413). Guilford Press.

Katznelson, I. (2017). What America Taught the Nazis. In The Atlantic. Retrieved from https://www.theatlantic.com/magazine/archive/2017/11/what-america-taught-the-nazis/540630/

Kline, D., Kappos, D. (2021). Introduction to Intellectual Property. Retrieved from https://openstax.org/details/books/introduction-intellectual-property

Konkel, F. (2013). CIA CTO sheds light on intelligence community's need for cloud. In The Business of Federal Technology. Retrieved from https:/fcw.com/articles/2013/03/22/gus-hunt-cia-amazon.aspx

Konovalov, A., \& Krajbich, I. (2019). Over a decade of neuroeconomics: what have we learned?.

Organizational Research Methods, 22(1), 148-173. doi: 10.1177/1094428116644502

Kovic, M., Rauchfleisch, A., Sele, M., \& Caspar, C. (2018). Digital astroturfing in politics: Definition, typology, and countermeasures. Studies in Communication Sciences, 18(1), 69-85. doi:

10.24434/j.scoms.2018.01.005

Kuhn, T. S. (1970). The Structure of Scientific Revolutions (2nd Ed.). Chicago: University of Chicago Press.

Lanford, S. D. (1982). A Gothic Epitome: Ralph Adams Cram as Princeton's Architect. The Princeton University Library Chronicle, 43(3), 184-220. doi: 10.2307/26402155

Larson, C. (2018). From imitation to innovation: How China became a tech superpower. In Wired. Retrieved from https://www.wired.co.uk/article/how-china-became-tech-superpower-took-over-thewest

Lee, J. W. (2007). Economic growth and human development in the Republic of Korea, 1945-1992. Reconstruction, 1945, 61.

Leprince-Ringuet, D. (2021). The global chip shortage is creating a new problem: More fake components. In ZDNet. Retrieved from https://www.zdnet.com/article/the-global-chip-shortage-iscreating-a-new-problem-more-fake-components-as-fraudsters-cash-in/

Liberto, D. (2021). Ceteris Paribus. In Investopedia. Retrieved from https://www.investopedia.com/terms/c/ceterisparibus.asp

Liu, R. T., Kleiman, E. M., Nestor, B. A., \& Cheek, S. M. (2015). The hopelessness theory of depression: A quarter-century in review. Clinical Psychology: Science and Practice, 22(4), 345-365. doi: $10.1111 /$ cpsp.12125

Loewenstein, G., \& Issacharoff, S. (1994). Source dependence in the valuation of objects. Journal of Behavioral Decision Making, 7(3), 157-168. doi: 10.1002/bdm.3960070302

Lowe, R. A., \& Knight, R. (1982). Building the ivory tower: The social functions of late nineteenth century collegiate architecture. Studies in Higher Education, 7(2), 81-91. doi:

10.1080/03075078212331379171 
Lüscher, C., Robbins, T. W., \& Everitt, B. J. (2020). The transition to compulsion in addiction. Nature Reviews Neuroscience, 21(5), 247-263. doi: 10.1038/s41583-020-0289-z

Malvaez, M. (2020). Neural substrates of habit. Journal of neuroscience research, 98(6), 986-997. doi: 10.1002/jnr.24552

Mann, M. (2004). Explaining the Rise of Interwar Authoritarianism and Fascism. In Fascists (pp. 3192). Cambridge: Cambridge University Press. doi:10.1017/CBO9780511806568.003

Marks, J. (1993). Historiography of eugenics. American Journal of Human Genetics, 52(3), 650-652.

Marsden, G. (1997). The Monkey Trial and the Rise of Fundamentalism: Christian History Interview Spurring on Secularism. In Christianity Today. Retrieved from

https://www.christianitytoday.com/history/issues/issue-55/55h042.html

Marshall, A. (2009). Principles of economics: unabridged eighth edition. Cosimo, Inc.

Masnick, M. (2014). What The Intelligence Community Doesn’t Get: Backdoor For 'The Good Guys' Is Always A Backdoor For The ‘Bad Guys’ As Well. In Techdirt. Retrieved from https://www.techdirt.com/articles/20140108/23073325816/what-intelligence-community-doesnt-getbackdoor-good-guys-is-always-backdoor-bad-guys-as-well.shtml

McArthur, T. (2004). Is it world or international or global English, and does it matter?. English Today, 20(3), 3-15. doi: 10.1017/S0266078404003025

Minter, A. (2019). Those Amazon Returns? They're Killing the Environment. In Bloomberg. Retrieved from https:/www.bloomberg.com/opinion/articles/2019-11-13/those-amazon-returns-they-re-killingthe-environment

Mollman. S. \& Timmons, H. (2016). China has no respect for international law, its neighbors, or marine life, a tribunal rules. In Quartz. Retrieved from https://qz.com/729524/chinas-activities-in-thesouth-china-sea-are-illegal-and-destroying-the-environment-an-international-court-finds/

Motoki, K., Sugiura, M., \& Kawashima, R. (2019). Common neural value representations of hedonic and utilitarian products in the ventral striatum: An fMRI study. Scientific reports, 9(1), 1-10. doi: 10.1038/s41598-019-52159-9

Munisamy, S., Jaafar, N. I. M., \& Nagaraj, S. (2014). Does reputation matter? Case study of undergraduate choice at a premier university. The Asia-Pacific Education Researcher, 23(3), 451-462. doi: 10.1007/s40299-013-0120-y

Neiberg, M. S. (2017). The Treaty of Versailles: A Concise History. Oxford University Press.

Parvizi, J., Rangarajan, V., Shirer, W. R., Desai, N., \& Greicius, M. D. (2013). The will to persevere induced by electrical stimulation of the human cingulate gyrus. Neuron, 80(6), 1359-1367. doi: 10.1016/j.neuron.2013.10.057 
Perlow, J. (2013). GUIs: The computing revolution that turned us into cranky idiots. In ZDNet. Retrieved from https://www.zdnet.com/article/guis-the-computing-revolution-that-turned-us-intocranky-idiots/

Pirzada, J. (2008). The patent problem. Retrieved from https://www.bcs.org/content-hub/the-patentproblem/

Plato. (1954). The last days of Socrates: Euthyphro. Tr. Tredennick H. London: Penguin.

“Postmodernism.” (2021, June 4). In Wikipedia. Retrieved from https://en.wikipedia.org/w/index.php? title=Postmodernism\&oldid=1025553309

“Process technology.” (2021). In PcMag. Retrieved from

https://www.pcmag.com/encyclopedia/term/process-technology

Quinn, G. (2018). Protecting an Idea: Can Ideas Be Patented or Protected? Retrieved from https://www.ipwatchdog.com/2018/11/17/protecting-idea-can-ideas-be-patented/

Rawat, S., \& Meena, S. (2014). Publish or perish: Where are we heading?. Journal of research in medical sciences: the official journal of Isfahan University of Medical Sciences, 19(2), 87-89.

Redish, A. (1993). Anchors Aweigh: The Transition from Commodity Money to Fiat Money in Western Economies. The Canadian Journal of Economics / Revue Canadienne D'Economique, 26(4), 777-795. doi: $10.2307 / 135820$

Regier, T., \& Kay, P. (2009). Language, thought, and color: Whorf was half right. Trends in cognitive sciences, 13(10), 439-446. doi: 10.1016/j.tics.2009.07.001

“Religion” (2020). In Encyclopaedia Britannica. Retrieved from https://www.britannica.com/topic/religion

Risen, J., \& Gilovich, T. (2007). Informal Logic Fallacies. In Critical thinking in psychology, Cambridge University Press.

Rolls, E. T. (2019). The cingulate cortex and limbic systems for emotion, action, and memory. Brain Structure and Function, 224(9), 3001-3018. doi: 10.1007/s00429-019-01945-2

Romano, A. (2020). Why we can’t stop fighting about cancel culture. In Vox. Retrieved from https://www.vox.com/culture/2019/12/30/20879720/what-is-cancel-culture-explained-history-debate Romano, A. (2021). The second wave of “cancel culture.” In Vox. Retrieved from https://www.vox.com/22384308/cancel-culture-free-speech-accountability-debate Romer, C. (2020). Great Depression. In Encyclopaedia Britannica Online. Retrieved from https://www.britannica.com/event/Great-Depression

Ross, M. \& Bateman, N. (2019). Meet the low-wage workforce. In Brookings. Retrieved from https://www.brookings.edu/research/meet-the-low-wage-workforce/ 
Rühlig, T. (2018). How China approaches international law: implications for Europe. European Institute for Asian Studies--EU-Asia at a Glance.

Rung, J. M., \& Madden, G. J. (2018). Experimental reductions of delay discounting and impulsive choice: A systematic review and meta-analysis. Journal of Experimental Psychology: General, 147(9), 1349-1381. doi: 10.1037/xge0000462.

Salamon, L. \& Newhouse, C. (2019). Nonprofit Economic Data Bulletin \#47. Baltimore: Johns Hopkins Center for Civil Society Studies. Available at ccss.jhu.edu.

Sartwell, C. (2017) Beauty. In The Stanford Encyclopedia of Philosophy (Winter 2017 Edition), Edward N. Zalta (ed.), Retrieved from https://plato.stanford.edu/archives/win2017/entries/beauty/

Segal, T. (2020). Conflict of Interest. Retrieved from https://www.investopedia.com/terms/c/conflictof-interest.asp

Seltzer, N. (2018, April). The Mortality Implications of Disappearing Middle Class Jobs in the United States. In PAA 2018 Annual Meeting. PAA.

Shenhav, A., Botvinick, M. M., \& Cohen, J. D. (2013). The expected value of control: an integrative theory of anterior cingulate cortex function. Neuron, 79(2), 217-240. doi:

10.1016/j.neuron.2013.07.007

Shenhav, A., Straccia, M. , Musslick, S., Cohen, J., \& Botvinick, M. (2018). Dissociable neural mechanisms track evidence accumulation for selection of attention versus action. Nature communications, 9(1), 2485. doi: 10.1038/s41467-018-04841-1

Shenhav, A., Dean Wolf, C. K., \& Karmarkar, U. R. (2018a). The evil of banality: When choosing between the mundane feels like choosing between the worst. Journal of Experimental Psychology: General, 147(12), 1892. doi: 10.1037/xge0000433

Shiller, R. J. (2007). 1. Why Do People Dislike Inflation? (pp. 13-70). University of Chicago Press. doi: 10.7208/9780226724836-005

Shumilov, K., Real, M. Á., Valderrama-Carvajal, A., \& Rivera, A. (2018). Selective ablation of striatal striosomes produces the deregulation of dopamine nigrostriatal pathway. PloS one, 13(8), e0203135. doi: 10.1371/journal.pone.0203135

Silver, C. (2020). The top 25 economies in the world. In Investopedia. Retrieved from https://www.investopedia.com/insights/worlds-top-economies/

Simoens, S., \& Dooms, M. (2011). How much is the life of a cancer patient worth? A pharmacoeconomic perspective. Journal of clinical pharmacy and therapeutics, 36(3), 249-256. doi: 10.1111/j.1365-2710.2010.01181.x

Smith, A. (1776). An Inquiry into the Nature and Causes of the Wealth of Nations, Book IV, Chap. 2. London: W. Stahan, \& T. Cadell. 
“Social Media Use in 2021.” (2021). Pew Research Center, Washington, D.C. Retrieved from https://www.pewresearch.org/internet/2021/04/07/social-media-use-in-2021/

Soo, Z. (2021). 7 Hong Kong democracy leaders convicted as China clamps down. In AP News. Retrieved from https://apnews.com/article/democracy-hong-kong-jimmy-lai-china-asia-pacificdd17218f4e242fcaf57db74d39450a3a

Sterling, G. (2019). Don’t call me: Nearly 90\% of customers won’t answer the phone anymore. Retrieved from https://martech.org/dont-call-me-nearly-90-of-customers-wont-answer-the-phoneanymore-study-2/

“Stock market crash of 1929.” (2021). In Encyclopaedia Britannica Online. Retrieved from https://www.britannica.com/event/stock-market-crash-of-1929

Suber, P. (2009). Knowledge as a public good. Sparc open access newsletter, 139.

Sumner, S. (2015). Are German schoolchildren taught about the 1929-32 deflation? In The Library of Economics and Liberty. Retrieved from https://www.econlib.org/archives/2015/01/are_german_scho.html

Sunstein, C. R. (2001). Foreword: On academic fads and fashions. Michigan Law Review, 99(6), 12511264.

Sunstein, C. R. (2018). Nudging: a very short guide. In The Handbook of Privacy Studies (pp. 173180). Amsterdam University Press. Doi: 10.1515/9789048540136-007

Swaine, M. D. (2015). Chinese views and commentary on the 'One Belt, One Road' initiative. China Leadership Monitor, 47(2), 3.

Szmigiera, M. (2021). In Statista. Retrieved from https://www.statista.com/statistics/266808/the-mostspoken-languages-worldwide/

“Top 100: The Most Visited Websites in the US.” (2021). Retrieved from https://www.semrush.com/blog/most-visited-websites/

Tremlin, T. (2010). Minds and gods: The cognitive foundations of religion. Oxford University Press.

Turley, J., Krcmar, H., \& Bilandzic, M. (2009). Embedded Systems-Connecting Everyone to Everything. Technology Radar Feature Paper. doi: 10.1.1.494.2414

Tversky, A. \& Kahneman, D. (1992). Advances in prospect theory: Cumulative representation of uncertainty. J Risk Uncertainty 5, 297-323. doi: 10.1007/BF00122574

“Two-thirds of consumers worldwide now buy on beliefs.” (2018). In Edelman. Retrieved from https://www.edelman.com/news-awards/two-thirds-consumers-worldwide-now-buy-beliefs

“University of Bologna.” (2021). In Wikipedia. https://en.wikipedia.org/w/index.php? title=University_of_Bologna\&oldid=1026450643 
Van den Bos, W. \& McClure, S. (2013). Towards a general model of temporal discounting. Journal of Experimental Analysis of Behavior, 99(1), 58-73. doi: 10.1002/jeab.6

Van Weijen, D. (2012). The language of (future) scientific communication. Research trends, 31(11), 2012.

"Victorian era.” (2021, May 26). In Wikipedia. https://en.wikipedia.org/w/index.php? title=Victorian_era\&oldid=1025186746

Westbrook, A., Lamichhane, B., \& Braver, T. (2019). The subjective value of cognitive effort is encoded by a domain-general valuation network. Journal of Neuroscience, 39(20), 3934-3947. doi: 10.1523/JNEUROSCI.3071-18.2019

Whish-Wilson, P. (2002). The Aral Sea environmental health crisis. Journal of Rural and Remote Environmental Health, 1(2), 29-34.

"Why Reputation is Critically Important for Universities." (2018). In QS. Retrieved from https://www.qs.com/what-makes-reputation-important-in-higher-education/

Williams, A. (2020). The origins of China's copycat culture. Retrieved from https://www.globalbriefing.org/2014/01/the-origins-of-chinas-copycat-culture/

Williams, C. C., Martinez-Perez, A., \& Kedir, A. M. (2017). Informal entrepreneurship in developing economies: The impacts of starting up unregistered on firm performance. Entrepreneurship Theory and Practice, 41(5), 773-799. doi: 10.1111/etap.12238

Yee, D. M., Crawford, J. L., Lamichhane, B., \& Braver, T. S. (2021). Dorsal Anterior Cingulate Cortex Encodes the Integrated Incentive Motivational Value of Cognitive Task Performance. Journal of Neuroscience 41(16), 3707-3720. doi: 10.1523/JNEUROSCI.2550-20.2021

Zeki, S., Romaya, J. P., Benincasa, D. M., \& Atiyah, M. F. (2014). The experience of mathematical beauty and its neural correlates. Frontiers in human neuroscience, 8 , 68. doi:

10.3389/fnhum.2014.00068

Zeki, S., Chén, O. Y., \& Romaya, J. P. (2018). The biological basis of mathematical beauty. Frontiers in human neuroscience, 12, 467. doi: 10.3389/fnhum.2018.00467

Zimmerman, M. J. and Bradley, B. Intrinsic vs. Extrinsic Value. (Spring 2019 Edition). In The Stanford Encyclopedia of Philosophy (Spring 2019 Edition), Edward N. Zalta (ed.), Retrieved from https://plato.stanford.edu/archives/spr2019/entries/value-intrinsic-extrinsic/ 